Grégoire Jean-François Demets

Contribuição à Química das Cucurbit[n]urilas

Ribeirão Preto

2014 
Grégoire Jean-François Demets

\title{
Contribuição à Química das Cucurbit[n]urilas
}

Tese apresentada para a obtenção do título de Livre Docente

\author{
Universidade de São Paulo \\ Faculdade de Filosofia Ciências e Letras de Ribeirão Preto
}

Ribeirão Preto

2014 
Grégoire Jean-François Demets

Contribuição à Química das Cucurbit[n]urilas/ Grégoire Jean-François Demets. - Ribeirão Preto, 2014-

190 p. : il. (algumas color.) ; $30 \mathrm{~cm}$.

Tese (Livre Docência) - Universidade de São Paulo

Faculdade de Filosofia Ciências e Letras de Ribeirão Preto, 2014.

1. Cucurbiturilas. 2. Química das. I. Grégoire Jean-François Demets. II. Universidade de São Paulo. III. Faculdade de Filosofia Ciências e Letras de Ribeirão Preto. IV. Contribuição à Química das Cucurbit[n]urilas 
Grégoire Jean-François Demets

\section{Contribuição à Química das Cucurbit[n]urilas}

Tese apresentada para a obtenção do título de Livre Docente

Trabalho aprovado. Ribeirão Preto, aos de de 2014:

Prof. Dr. Hermi Felinto de Brito

Universidade de São Paulo

Profa. Dra. Vera Regina Leopoldo

Constantino

Universidade de São Paulo

Prof. Dr. Sidney José Lima Ribeiro

Universidade Estadual Paulista Júlio de

Mesquita Filho

Prof. Dr. Antonio Eduardo Mauro

Universidade Estadual Paulista Júlio de

Mesquita Filho

Prof. Dr. Herenilton Paulino Oliveira

Universidade de São Paulo

Ribeirão Preto

2014 
Dedico esta tese aos meus filhos e minha esposa, que iluminam minha vida. Aos meus pais. 


\section{Agradecimentos}

Meus sinceros agradecimentos a todos que tornaram de certa forma este trabalho possível, pela ajuda e convivência. Um agradecimento especial aos:

- Meus mestres e amigos do IQ-USP pelos ensinamentos e por estarem sempre dispostos a ajudar: Koiti Araki, Mário J. Politi, Lúcio Angnes, Mauro Bertotti, Vera R. L. Constantino, Ana Maria da C. Ferreira, Gianlucca C. Azzellini, Henrique E. Toma, Hermi F. de Brito, Antonio C. Borin, Dalva L. A. de Faria, Márcia L. A. Temperini, Paulo T. Sumodjo, Roberto de Torresi, Susana I. C. de Torresi, Josef W. Baader, Massuo J. Kato, Cassius V. Stevani, Oswaldo Sala, José M. Riveros, Yoshio Kawano, Luiz F. da Silva Jr., Frank H. Quina, Ernesto Giesbrecht(in memorian).

- Aos amigos e colegas do DQ-FFCLRP: Adalgisa R. de Andrade, Antonio C. Tedesco, Arthur H. C. de Oliveira, Ana P. Ramos, Anderson R. M. Oliveira, Antônio E. M. Crotti, Bruno S. de Martinis, Carmen L. Cardoso, Celso T. Mendes Jr., Elia Tfouni, Fábio G. Doro, Francisco A. Leone, Fritz C. Huguenin, Gil V. J. da Silva, Glaico Chiericato Júnior, Gláucia M. S. Degrève, Herenilton P. Oliveira, Joana J. de Andrade, João B. Valim, José F. de Andrade, José M. Caiut, José C. Toledo Jr., José M. Rosolen, José R. Romero, Laura T. Okano, Léo Degrève, Luis G. Dias, Marcelo F. de Oliveira, Marcia A. M. S. da Veiga, Maria E. D. Zaniquelli, Maria E. Q. Nassur, Maria L. A. M. Campos, Marilda D. Assis, Miguel J. Dabdoub Paz, Osvaldo A. Serra, Paulo M. Donate, Paulo Olivi, Pietro Ciancaglini, Richard J. Ward, Rogéria R. Gonçalves, Rosa P. M. F. Inocentes, Sérgio E. Galembeck, Wagner F. De Giovani, Valéria R. Spiller,Yassuko Iamamoto. Mauricio G. Constantino, Luiz A. B. de Moraes, Sofia Nikolaou e Hamilton Varela pela valiosa ajuda durante este anos. A todos os funcionários do Departamento, em especial a: Lourivaldo S. Pereira, Rodrigo F. Silva, Ivana A. Borin, e Mércia V. Carlos que trabalham com afinco e dedicação, dando o melhor de si.

- À minha tia Martine Demets (in memorian), por me enviar uma cópia do artigo de Behrend, ponto inicial da química dos cucurbitandos.

- Principalmente aos meus alunos e ex-alunos sem os quais não seria possível este trabalho: Érick M. S. dos Santos, Rodrigo Francelin, Beatriz V. S. Schneider, Greice S. Vertuan, Henrique D. Correia, Tiago M. B. Teodósio, Silvânia M. de Lima, Thiago S. Cavallini, Evandro Castaldelli, Luis F. S. da Silva, Lucas V. Jardim, Renato S. Cicolani, Francisco A. Silva, Felipe C. S. Silva, Ayla R. B. S. Galaço, Hélio S. Rocha, Raphael F. Moral, Ulisses A. Fiorin, Guilherme Silva Dias, Victor C. Costacurta, Giuliano Simocelli Jr. Diego Baptista, Fabiano Silvério.

- Aos nossos colaboradores externos: Eduardo Triboni, Jorge Antonio Gómez, Sérgio Dovidauskas, Koiti Araki, Claudio Antonio Tedesco, Marcelo Oliveira, Maria E. D. Zaniquelli, Roberto Santana, Luis Gustavo Dias, Fritz Huguenin, Fabio Pichierri, Severino Alves Jr., Ravi Silva, Lynn Rozanski, Claudio Habert.

- Àqueles que possa ter esquecido...

- Ao CNPq, à Pró-reitoria de pesquisa da USP e à FAPESP pelo aporte financeiro. 
"O Justo é Atlas.

Sobre ele repousa o peso dos fracos e dos oportunistas.

A resistência, sua virtude... 


\section{Resumo}

São apresentados nesta tese diversas frentes de pesquisa envolvendo a família de macrociclos orgânicos do tipo cucurbit[n]urila, desenvolvidas pelo grupo de pesquisa do autor. São apresentadas as características destes compostos e, na forma de um retrospecto, os recentes progressos realizados pelo grupo em diversas áreas do conhecimento como a química de interfaces químicas e filmes, química supramolecular e catálise, além de síntese de materiais nanoestruturados suportada por cucurbiturilas. Os trabalhos aqui expostos são pioneiros, e representam uma contribuição significativa à química das cucurbit[n]urilas. 


\section{Abstract}

Herein are presented several research themes, develloped by the author's research group, involving the cucurbit[n] uril-type family of organic macrocycles. The main characteristics of these compounds are reported, as well as a retrospective of the recent progresses achieved by the group in several areas of knowledge such as chemical interfaces chemistry and films, supramolecular chemistry and catalysis, and cucurbit[n]uril-supported synthesis of nanostructured materials. The works presented here are pioneer and they represent a significative contribution to cucurbit[n] urils chemistry.

Key-words: Cucurbiturils. Chemistry of. 


\section{Lista de ilustrações}

Figura 1 - Estrutura da $\beta$-CB $[6] \ldots \ldots \ldots \ldots . \ldots \ldots$

Figura 2 - Representação da $\alpha-\mathbf{C B}[5], \gamma-\mathbf{C B}[7]$ e $\delta$-CB $[8] \ldots \ldots . . . . . .22$

Figura 3 - Representação da transferência de um soluto da cavidade da esfera de solvatação para a cavidade de um hospedeiro de inclusão. . . . . . . . . 28

Figura 4 - Representação de uma interação solvofóbica. . . . . . . . . . . . . . . . 29

Figura 5 - Coordenaçãode cátions metálicos aos portais da $\beta$-CB $[6]$. . . . . . . 34

Figura 6 - Estrutura colunar de um aduto de $\beta$-CB[6] com Ho. . . . . . . . . . . 34

Figura 7 - Evolução do número de (azul) artigos de revisão, (verde) patentes, (vermelho) artigos tratando de calixarenos (a); de resorcinarenos (b); e de cucurbiturilas (c). Numero de documentos por ano (d) para calixarenos em preto, resorcinarenos em azul e cucurbituirlas em vermelho. . . . . 37

Figura 8 - Esquema de restrição de acesso de substratos ao centro metálico coordenado a uma molécula de $\beta-\mathrm{CB}[6] \ldots$. . . . . . . . . . . . . . 40

Figura 9 - Anatomia de um sensor . . . . . . . . . . . . . . . 44

Figura 10 -Imobilização de cavitandos sobre ouro . . . . . . . . . . . . . . . . . 44

Figura 11 -Representação esquemática de imobilização axial de cucurbiturilas em superfícies. . . . . . . . . . . . . . . . . . 45

Figura 12 - Processo de obtenção de monocamadas de $\beta-\mathbf{C B}[6]$ pelo método do hidróxido de amônio. . . . . . . . . . . . . . . . . . . . . 46

Figura 13 -Espectro vibracional de reflectância total atenuada (ATR) de um dos filmes sobre FTO - linha cheia- comparado ao espectro vibracional convencional da $\beta$-CB $[6]$ em pastilha de KBr. . . . . . . . . . . . . . 48

Figura 14 - Absorção dos cromófors do monômero e do dímero de azul de metileno (AM) adsorvidos na superfície de um filme de $\beta$-CB[6] . . . . . . . .

Figura 15 -Estrutura do aduto superficial de azul de metileno (AM) com os opérculos de $\beta$-CB $[\mathbf{6}]$ facilitando a formação de dímeros do corante.Estrutura obtida por métodos semi-empírico PM3. . . . . . . . . . . . 50

Figura 16 -Dispersão dos valores de $C_{\text {total }}$ em função do número de camadas de deposição de $\beta$-CB $[6]$. . . . . . . . . . . . . . . . . 50 50

Figura 17 - Análise de seção transversal por MFA da região de borda de um filme de $\beta$-CB $[6]$ obtido pelo método da amônia. . . . . . . . . . . . . . 51

Figura 18 -Micrografia por MFA da região de borda do filme de $\beta$-CB[6] da figura anterior. . . . . . . . . . . . . . . . . 5 51

Figura 19 -Representação esquemática da permeação de um íons por uma membrana do tipo Cubion. . . . . . . . . . . . . . . . 52 
Figura 20 -Etapas de montagem: a- eletrodo limpo, b- deposição do material eletroativo, c-recobrimento com a suspensão . . . . . . . . . . . . . . . 53

Figura 21 -EQM de Cubion vs EQM de pasta de carbono . . . . . . . . . . . . 55

Figura 22 - Voltamogramas do EQM de Ferroceno (Fc)/Cubion em diversas velocidades de varredura. . . . . . . . . . . . . . . . . . . . 55

Figura 23 -Voltamogramas cíclicos de EQM de ferroceno sobre carbono vítreo em diversos eletrólitos de suporte onde podemos observar o efeito dos ânions e dos cátions na resposta eletroquímica do sistema. . . . . . . . . . 56

Figura 24 - Variação de $\Delta \mathrm{E}_{p}$ e $\operatorname{Ip}_{c}$ em função do tamanho do ânion no eletrólito suporte para EQM de ferroceno sobre carbono vítreo. . . . . . . . . . 57

Figura 25 -Fotomicrografias de membrana PVC/ $\beta$-CB[6] a $4 \%$ a 1000x de aumento, mostrando as vesículas deixadas pela evaporação do solvente.

Figura 26 -Preparação de membranas por projeção de aerosol. . . . . . . . . . . . 61

Figura 27 - Corte de uma membrana de PVDF/ $\beta$-CB[6] 46 \% preparada por aerosol. . . . . . . . . . . . . . . . . . . . 6 61

Figura 28 - Classificação das membranas de acordo com o tamanho de poro, adaptado da $\operatorname{ref}^{191} \ldots \ldots \ldots$. . . . . . . . . . . . . . . . 6 62

Figura 29 -Visão esquemática da célula de difusão utilizada nos experimentos. . 62

Figura 30 -Valores de condutividade do meio hipotônico em tempo pré-determinado, em função do teor de $\beta$-CB[6] nas membranas utilizadas. . . . . . . . 63

Figura 31 -Dependência do fluxo de prótons com o gradiente de concentração trans-membrana . . . . . . . . . . . . . . . 6 63

Figura 32 -Fluxo de $H^{+}, \mathrm{Li}^{+}$e $\mathrm{K}^{+}$por membranas de Cubion a $9 \%$. . . . . . . . 64

Figura 33 -Correlação entre fluxo e raios iônicos hidratados. . . . . . . . . . . 64

Figura 34 - Permeação gasosa por membrana de Cubion $\left(\mathrm{He}=\right.$ preto, $\mathrm{CO}_{2}=$ vermelho, propano=verde.) . . . . . . . . . . . 6 66

Figura 35 -Separação de misturas água/glicerol utilizando membranas de Cubion. 67

Figura 36 -Absorção de petróleo por Cubion . . . . . . . . . . . . . . 68

Figura 37 -Efeito da $\beta$-CB[6] nos absorventes. . . . . . . . . . . . . . . 69

Figura 38 -Absorção de óleo de soja por esponjas de Cubion. . . . . . . . . . . . . 70

Figura 39 -Recuperação do óleo absorvido pelas esponjas . . . . . . . . . . . . . 70

Figura 40 -Um esponja após absorção de petróleo em água salgada. . . . . . . . . 71

Figura 41 -Estruturas calculadas para os complexos mono e binucleares de $\beta$ CB[6] com o íon vanadila. . . . . . . . . . . . . . . . 73

Figura 42 -Tga do complexo de CBVO . . . . . . . . . . . . . 74

Figura 43 -FTIR do complexo de CB6VO . . . . . . . . . . . . 75

Figura 44 -Espectros eletrônicos do $(\mathrm{VO}(\beta-\mathbf{C B}[6])) \mathrm{SO}_{4} .9 \mathrm{H}_{2} \mathrm{O}$ e do $\mathrm{VOSO}_{4}$. . . 76

Figura 45 -Diedros do íon $\mathrm{VO}^{2+} \ldots \ldots \ldots \ldots \ldots$ 


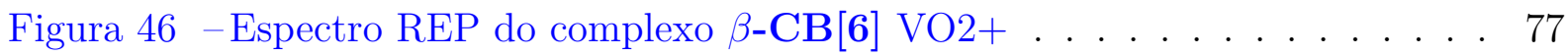

Figura 47 -Estrutura proposta para o $(\mathrm{VO}(\beta-\mathrm{CB}[6])) \mathrm{SO}_{4} \cdot 9 \mathrm{H}_{2} \mathrm{O} \ldots \ldots \ldots$

Figura 48 -Voltamogramas cíclicos de $(\mathrm{VO}(\beta-\mathrm{CB}[6]))(\mathrm{SO})_{4} .9 \mathrm{H}_{2} \mathrm{O} \ldots \ldots . \ldots 79$

Figura 49 -Esquema do catalisador confinado . . . . . . . . . . . . . 83

Figura 50 -Regulação de íons no solo. . . . . . . . . . . . . . . . . 85

Figura 51 -Testes de germinação com feijão comum em bandejas. . . . . . . . . . . 86

Figura 52 -Tamanho da raiz. . . . . . . . . . . . . . 87

Figura 53 -Tamanho do caule. . . . . . . . . . . . . . 88

Figura 54 -Testes de germinação com sementes de agrião. . . . . . . . . . . . . . . 89

Figura 55 -Testes de germinação com sementes de rúcula. . . . . . . . . . . . . . 90

Figura 56 -Testes de germinação com sementes de alface. . . . . . . . . . . . . 91

Figura 57 -Condutividade do efluente. . . . . . . . . . . . . . . . . 93

Figura 58 -Soluções de nanopartículas de prata $/ \gamma$-CB $[7] \ldots$. . . . . . . . . 96

Figura 59 -Efeito do $\gamma$-CB[7] no espectro uvvis das NP de Ag. . . . . . . . . . . 96

Figura 60 -Espectros eletrônicos das nanopartículas de prata sintetizadas com razões $\mathrm{Ag} / \gamma$-CB[7] igual ou menores que $1 . \ldots 97$

Figura 61 -Espectros eletrônicos das NP de prata preparadas com razões de $\mathrm{Ag} / \gamma$ -

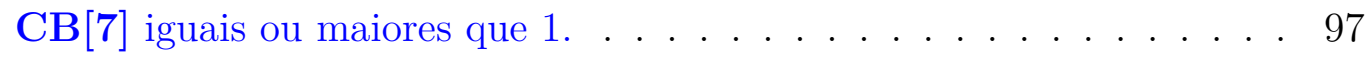

Figura 62 - Correlação entre tamanho de partícula e máximo de absorção da banda de plasmon. . . . . . . . . . . . . . . . . . . 98

Figura 63 -Correlação entre tamanho de partícula e largura de meia banda de plasmon. . . . . . . . . . . . . . . . . . . . . 98

Figura 64 -Fotomicrografia de transmissão eletrônica de nanopartículas Ag/ $\gamma$-CB[7] $(1: 1)$ a 800 k vezes. . . . . . . . . . . . . . . . . . . . 999

Figura 65 -Dispersidade das NP de Ag/ $\gamma-\mathbf{C B}[7] 1: 1 \ldots$. . . . . . . . . . 100

Figura 66 -Fotomicrografia de transmissão eletrônica de um cluster de 4 nanopartículas $\mathrm{Ag} / \gamma-\mathrm{CB}[7](1: 1)$ a 800k vezes. . . . . . . . . . . . . . 101

Figura 67 -Representação equemática da estrutura do efeito de grampo da $\gamma$ CB[7] em nanopartículas de prata. . . . . . . . . . . . . . . . . . 101

Figura 68 -Representação equemática da estrutura do $\mathrm{PbI}_{2}$. . . . . . . . . . . 102

Figura 69 -Fotografias do $\mathrm{PbI}_{2}$ puro (esquerda) e preparado com $\gamma$-CB $[7]$. . . . 102

Figura 70 -Espectros de reflectância difusa do $\mathrm{PbI}_{2}$ puro (azul) e preparado com

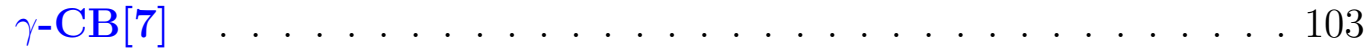

Figura 71 -Arranjo tipo castelo de cartas. . . . . . . . . . . . . . . . . 104

Figura 72 -DRX dos nanodiscos de iodeto de chumbo . . . . . . . . . . . 105

Figura 73 -Mecanismo de esfoliação do $\mathrm{PbI}_{2}$ com $\gamma$-CB[7] . . . . . . . . . . . . 106

Figura 74 -Fotomicrografias HRTEM dos nanodiscos de $\mathrm{PbI}_{2}$. . . . . . . . . 107

Figura 75 -Fotografias de iodeto de mercúrio, e do mesmo obtido na presença de $\gamma-\mathbf{C B}[7] \ldots \ldots \ldots \ldots$. . . . . . . . . . . . . . . . . . . . . . . . . . . 
Figura 76 - Padrões de difração no pó dos sólidos obtidos na ausência (a) e na presença (b) de $\mathbf{C B}[7]$. As linhas em vermelho indicam a posição e a intensidade do difratograma padrão da zincita. . . . . . . . . . . . . . . 109

Figura 77 -Fotomicrografias eletrônicas de varredura das máculas micrométricas de zincita produzidas na ausência de $\mathbf{C B}[7]$ (a) e dos glóbulos de nanopartículas obtidos em sua presença (b) . . . . . . . . . . . . . . . 110

Figura 78 -Fotomicrografias de força atômica dos agregados de nano-esferas de $\mathrm{CB}[7] /$ ZnO . . . . . . . . . . . . . . . . . . 111

Figura 79 -Espectros de absorção e emissão das maclas de ZnO (linhas cheias) e das nanoesferas $\mathrm{CB}[7] / \mathrm{ZnO}$ (linhas pontilhadas) $\lambda_{\text {exc }}=250 \mathrm{~nm} . \quad$. . . 111

Figura 80 . . . . . . . . . . . . . . . . . . . . . 112

Figura 81 -Distrubuição de densidades eletrônicas aos longo do eixo cristalográfico

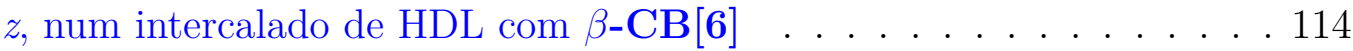

Figura 82 -Remoção de íons dodecilsulfato dos intercalados de CB/HDL . . . . . . 114

Figura 83 -Extração de CBs do intercalado de CB/HDL com hexanodiamina. . . . 115

Figura 84 - Variação de carga durante os 50 primeiros ciclos de voltametria, em função do primeiro $\left(Q_{n} / Q_{1}\right)$, com $i=0,2 \mathrm{~mA} \ldots \ldots . . \ldots 117$

Figura 85 - Cargas anódica e catódica para o VXG, VXG.CB6 1\%, e o VXG.CB6VO $1 \%$ normalizadas pela massa do óxido, obtidas pela integração das ondas voltamétricas ( de 1,5 a -1,5 V a $20 \mathrm{mV} / \mathrm{s} ; 40$ ciclos). c) Diferenças (resíduos) entre a carga anódica e catódica para as mesmas amostras. . 118

Figura 86 - Capacidade de armazenamento de $\mathrm{Li}^{+}$(xLi) e carga específica em função da densidade de corrente catódica (descarga) obtidos por cronopotenciometria (pot. $+1,5$ a $-1,5 \mathrm{~V})$. . . . . . . . . . . . 119

Figura 87 -Mapas de potencial eletrostático da hemi-cucurbit[6]urila e sua cavidade.122

Figura 88 -Diversas curvas de titulação e seus pontos de equivalência (setas vermelhas) da ref $^{348}$. a) Só o titulado absorve, b) só o titulante, c) só o produto absorve, d) o titulado e o titulante absorvem, e) o produto e o titulante absorvem f) um indicador externo absorve . . . . . . . . . . 154

Figura 89 -Desenho da célula de difusão com as dimensões. No quadro, detalhe do grampo de inox, que prende as semi-células no ponto de inserção da membrana em teste. . . . . . . . . . . . . . . . . . 155 


\section{Lista de tabelas}

Tabela 1 - Dimensões dos cucurbitandos . . . . . . . . . . . . . . . 22

Tabela 2 - Constantes de formação de caviplexos de $\beta$-CB[6] com alcanodiaminas em meio ácido ${ }^{95} \ldots \ldots \ldots \ldots$. . . . . . . . . . . . . . 24

Tabela 3 - Parâmetros termodinâmicos para a dissolução de metano em água e ciclohexano ............................ 30

Tabela 4 - Log das constantes de formação de complexos com cátions duros e

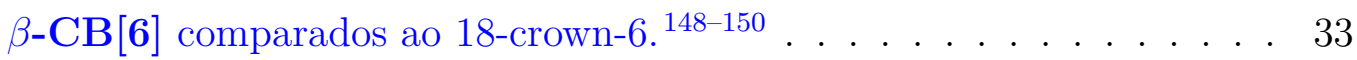

Tabela 5 - Dados para cáclulo de recobrimento de superfície de ouro por microgravimetria de quartzo . . . . . . . . . . . . . . . . . . . . 47

Tabela 6 - Dados espectroscópicos para o $[\mathrm{VO}(\beta-\mathrm{CB}[6])] \mathrm{SO}_{4} \cdot 9 \mathrm{H}_{2} \mathrm{O}$ e o $\mathrm{VOSO}_{4}$ e sua atribuição. . . . . . . . . . . . . . . . . . . . . 77

Tabela 7 - Ensaios catalíticos ("CBVO t.t." =CBVO tratado termicamente). . . . 80

Tabela 8 - Resultados dos ensaios catalíticos utilizando $[\mathrm{VO}(\beta-\mathrm{CB}[\mathbf{6}])](\mathrm{SO})_{4} .9$ $\mathrm{H}_{2} \mathrm{O}$ e o $\beta$-CB $[6]$ puro como controle. . . . . . . . . . . . . . 81

Tabela 9 - Constantes de estabilidade $(\log \mathrm{K}, \mathrm{K}$ em l/mol) para a complexação de CBn com íons alcalinos e alcalino-terrosos, da ref. ${ }^{148}$. ${ }^{*}$ decametil- $\alpha$ $\mathrm{CB}[5] \ldots \ldots \ldots \ldots \ldots \ldots$

Tabela 10 - Testes de germinação de Phaseolus Vulgaris ssp. na presença de diversos aditivos. . . . . . . . . . . . . . . . . 86

Tabela 11 - Testes de germinação hidropônica de Lactuca Sativa, Eruca Sativa e Spilanthes Acmella na presença de aditivos. . . . . . . . . . . . . . . 88

Tabela 12 - Taxas de germinação por espécie e meio e tamanho médio dos brotos. . 89 Tabela 13 - Concentrações médias de P e K na água eluvial das amostras (Desv. Pad. em itálico); <:abaixo do lim. de detecção . . . . . . . . . . . . . . 92

Tabela 14 -Estimativa do tamanho das NP de prata a partir dos dados espectrais. 98

Tabela 15 - Dados de solubilidade de CBs em diversos solventes, em mmol.dm ${ }^{-3}$. 150 Tabela 16 -Dados de RMN para as diversas cucurbiturilas. Das refs. ${ }^{87,349,350}$. . . . 157 Tabela 17 -Identificação das CBs por espectrometria de massas . . . . . . . . . . . 159 


\section{Lista de abreviaturas e siglas}

ATD Análise térmica diferencial

ATR Attenuated total reflection, ou reflexão total atenuada

AM Azul de Metileno

CB(n) Cucurbit[n]urila

CTAB Brometo de cetil trimetilamônio

DMSO dimetil sulfóxido; solvente orgânico

DS Dodecilsulfato

EQM Eletrodo Quimicamente Modificado

EIS Electrochemical Impedance Spectroscopy, ou Espectroscopia de Impedância Eletroquímica

$E_{p a} \quad$ Potencial de pico anódico

$E_{p c} \quad$ Potencial de pico catódico

EpH $\quad$ Eletrodo padrão de hidrogênio

F cste. de Faraday:96485, $3399^{24} C \cdot \mathrm{mol}^{-1}$

fc Ferroceno

FIR Far Infrared, infravermelho distante: região de $\lambda=15 \mu \mathrm{m}$ a $1 \mathrm{~mm}$

FTIR Fourier Transform Infrared Spectroscopy, ou Espectroscopia vibracional por transformada de Fourier

FTO Eletrodo condutor de vidro recoberto com óxido de estanho dopado com flúor

HBA/HBD Hydrogen-bond Acceptor/Donor

HDL hidróxido duplo lamelar

$\operatorname{hmCB}(\mathrm{n}) \quad$ Hemicucurbit[n]urila

HRTEM High Resolution Transmission Electron Microscopy, Microscopia eletrônica de transmissão de alta resolução 


\begin{tabular}{|c|c|}
\hline$I_{p a}$ & corrente de pico anódico \\
\hline$I_{p c}$ & corrente de pico catódico \\
\hline LED & Light emitting diode, Diodo emissor de Luz. \\
\hline $\mathrm{MeCN}$ & Acetonitrila \\
\hline $\mathrm{MEV}$ & Microscopia eletrônica de varredura \\
\hline MET & Microscopia eletrônica de transmissão \\
\hline MFA & Microscopia de força atômica \\
\hline MSPS & Membrana semi-permeável sólida \\
\hline NIR & Near infrared, infravermelho próximo: região de $\lambda=0,7 \mu \mathrm{m}$ a $5 \mu \mathrm{m}$ \\
\hline NP & Nanopartícula \\
\hline $\mathrm{PhIO}$ & Iodosilbenzeno \\
\hline PU & Poli(uretana) \\
\hline $\mathrm{PVC}$ & Poli(cloreto de vinila) \\
\hline PVDF & Poli(difluoreto de vinilideno) \\
\hline QSPR & $\begin{array}{l}\text { Relação quantitativa entre estrutura e propriedade; Quantitative Structure- } \\
\text { Property Relationship }\end{array}$ \\
\hline REP & Ressonância de Elétrons Paramagnéticos \\
\hline $\mathrm{RMN}$ & Ressonância magnética nuclear \\
\hline RPS & Ressonância plasmônica de superfície \\
\hline TG & Termogravimetria \\
\hline $\mathrm{XPV}$ & Xerogel de pentóxido de vanádio \\
\hline$\lambda$ & comprimento de onda (nm) \\
\hline$\Gamma$ & Concentração superficial $\left(\mathrm{mol} / \mathrm{cm}^{2}\right):\left(\Gamma=\frac{Q}{n F A}\right)$ \\
\hline$\tilde{\nu}$ & número de onda $\left(\mathrm{cm}^{-1}\right)$ \\
\hline$\Delta H p p$ & separação de picos em Gauss \\
\hline
\end{tabular}




\section{Sumário}

I Apresentação 19

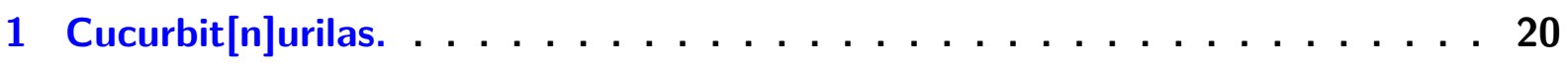

2 Os Cucurbitandos . . . . . . . . . . . . . . . 21

2.1 Histórico e considerações gerais . . . . . . . . . . . . . . . 21

2.2 Química em Meio Confinado e Caviplexos de cucurbiturilas . . . . . . . . 25

2.2.1 Analogias Entre a Solvatação e a Caviplexação . . . . . . . . . . . 27

2.2 .2 Interações solvofóbicas . . . . . . . . . . . . . . . . 28

2.2.2.1 Parametrização de solventes . . . . . . . . . . . . . . 31

2.2 .3 Mecanismos de formação de caviplexos . . . . . . . . . . . . . 32

2.3 Adutos e Complexos metálicos de Coordenação . . . . . . . . . . . . 33

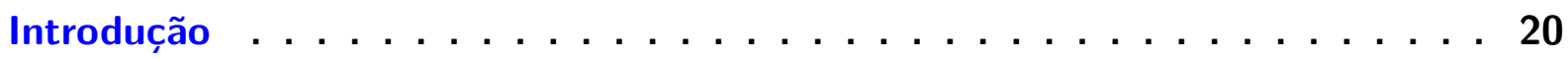

II Proposta e Estratégia de Investigação 36

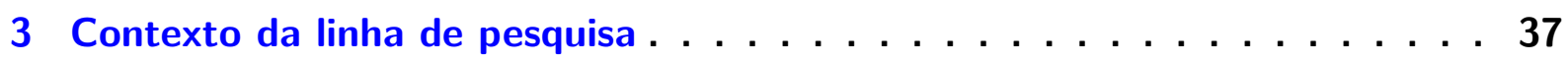

3.0.1 Revestimentos e Filmes Finos para Sensores . . . . . . . . . . 38

3.0 .2 Compostos de Coordenação com Ácidos Duros . . . . . . . . . . . 39

3.0 .3 Nanoestruturas e Nanomateriais . . . . . . . . . . . . . . . . . 40

3.0.4 Métodos de separação e meios sequestrantes . . . . . . . . . . . . 40

III Resultados $\quad 42$

4 Interfaces Químicas Baseadas em Cucurbiturilas . . . . . . . . . . . 43

4.1 Filmes Finos . . . . . . . . . . . . . . . . . . . . . 43

4.2 Materiais eletródicos . . . . . . . . . . . . . . . 52

4.3 Membranas Poliméricas Semipermeáveis _. . . . . . . . . . . . 57

4.3 .1 As Membranas de Cubion . . . . . . . . . . . . . . . . . 60

4.3 .2 Outras Aplicações . . . . . . . . . . . . . . . . . . . . 65

4.3.2.1 Purificação de Gases . . . . . . . . . . . . . . . . . . 65

4.3.2.2 Purificação de Biodiesel . . . . . . . . . . . . . . . . 65

4.3.2.3 Esponjas de Cubion . . . . . . . . . . . . . . 66

5 Cucurbiturilas Frente a Espécies em Solução e complexos … . . . . 72

5.1 O Sistema $\mathrm{CB}[6] / \mathrm{VO}^{2+} \ldots \ldots \ldots \ldots \ldots \ldots . \ldots \ldots . \ldots \ldots$ 
5.1 .1 Catálise Seletiva . . . . . . . . . . . . . . . 78

5.2 Reguladores de fertilizantes NPK . . . . . . . . . . . . . 83

5.2 .1 Testes de germinação em solo . . . . . . . . . . . . . . . 85

5.2 .2 Testes de germinação hidropônica . . . . . . . . . . . . . . . . 86

6 Nanocompósitos e nanomateriais . . . . . . . . . . . . . . . 94

6.1 Moldes para nanopartículas . . . . . . . . . . . . . . . 95

6.1.1 Nanopartículas de prata . . . . . . . . . . . . . 95

6.1.2 Nanopartículas de iodetos de $\mathrm{PbI}_{2}$. . . . . . . . . . . . . . 100

6.1.3 Nanopartículas de óxido de Zinco . . . . . . . . . . . . . . . . . 106

6.2 Cucurbiturilas como hóspedes em compostos de intercalação . . . . . . . . 112

6.2.1 Matrizes de hidróxidos duplos lamelares . . . . . . . . . . . . . . 113

6.2.2 Matrizes de pentóxido de vanádio . . . . . . . . . . . . . . . . 115

$\begin{array}{ll}\text { IV Conclusão e Perspectivas } & 120\end{array}$

7 Conclusão e Perspectivas $\ldots \ldots \ldots \ldots \ldots \ldots \ldots \ldots \ldots \ldots$

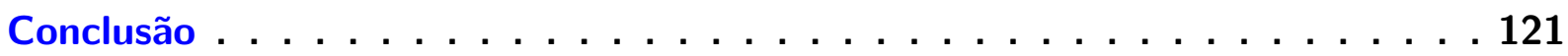

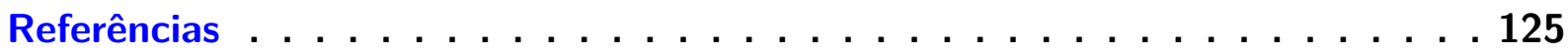

$\begin{array}{ll}\text { Apêndices } & 145\end{array}$

APÊNDICE A Procedimentos Experimentais Gerais e de Rotina . . . . . 146

A.1 Sínteses . . . . . . . . . . . . . . . . . . . . . . . 146

A.1.1 Síntese das cucurbit $[n]$ urilas . . . . . . . . . . . . . . . 146

A.1.1.1 Rota 1................... . . 146

A.1.1.2 Rota 2 . . . . . . . . . . . . . . . . 147

A.1.1.3 Rota 2- R2V1 . . . . . . . . . . . . . . . . 147

A.1.1.4 Rota 2 variação 2- R2V2 . . . . . . . . . . . . . . . . . . 147

A.1.1.5 Rota 2 variação 3- R2V3 . . . . . . . . . . . . . . 148

A.1.2 Síntese de hemi $[6]$ cucurbiturila . . . . . . . . . . . . . . . . . . . 148

A.1.3 Separação e purificação das cucurbiturilas . . . . . . . . . . . . . . 148

A.1.4 Síntese do pentóxido de vanádio em gel . . . . . . . . . . . . . 149

A.1.5 Síntese de nanopartículas de zincita . . . . . . . . . . . . . . . . . 149

A.1.6 Síntese de nanopartículas de iodeto de chumbo . . . . . . . . . . . . 149

A.1.7 Síntese de nanopartículas de prata . . . . . . . . . . . . . . . . . 151

A.2 Caracterização de compostos de inclusão . . . . . . . . . . . . . . . . . . 151

A.2.1 Métodos espectroscópicos . . . . . . . . . . . . . . . 151 
A.2.1.1 Método da variação contínua . . . . . . . . . . . . . . 151

A.2.1.2 Método de Benesi-Hildebrand . . . . . . . . . . . . . . . . 152

A.2.1.3 Titulações espectrofotométricas . . . . . . . . . . . . . . . 153

A.3 Ensaios de permeação em membranas . . . . . . . . . . . . . . . . . . 154

A.4 Ensaios de catálise . . . . . . . . . . . . . . . . . . . 155

A.5 Preparo e eletrodos modificados com membranas semipermeáveis . . . . . . 156

A.6 Instrumentação . . . . . . . . . . . . . . . . . . . . 156

A.6.1 Espectroscopia . . . . . . . . . . . . . . . 156

A.6.1.1 Espectroscopia eletrônica de absorção . . . . . . . . . . . 156

A.6.1.2 Espectroscopia eletrônica de emissão . . . . . . . . . . . . 156

A.6.1.3 Espectroscopia vibracional . . . . . . . . . . . . . 157

A.6.1.4 Espectroscopia de fluorescência de raios-X . . . . . . . . . 157

A.6.1.5 Ressonância magnética nuclear . . . . . . . . . . . . . 157

A.6.1.6 Ressonância de elétrons paramagnéticos-R.E.P. . . . . . . 157

A.6.2 Espectrometria de massas-M.S. . . . . . . . . . . . . . . . . . . . 158

A.6.3 Análise térmica . . . . . . . . . . . . . . . . . . . . . . 158

A.6.4 Microscopia . . . . . . . . . . . . . . . . . 158

A.6.4.1 Microscopia eletrônica de varredura (MEV) . . . . . . . . 158

A.6.4.2 Microscopia eletrônica de transmissão de alta resolução (METAR) . . . . . . . . . . . . . . . 158

A.6.4.3 Microscopia de força atômica . . . . . . . . . . . 158

A.6.5 Difratometria de raios-X . . . . . . . . . . . . . . . . . . . . 158

A.6.6 Métodos Teóricos . . . . . . . . . . . . . . . . . . . . 160

A.6.7 Eletroquímica . . . . . . . . . . . . . . . . . . . . 160

A.6.7.1 Cronocondutimetria . . . . . . . . . . . . 160

Anexos

ANEXO A Artigos de Referência por Ano de Publicação. . . . . . . . . . 162

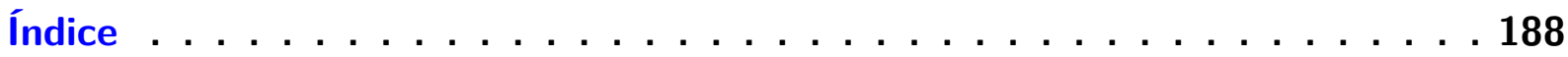


Parte I

Apresentação 
1 Cucurbit[n]urilas. 


\section{Os Cucurbitandos}

\subsection{Histórico e considerações gerais}

A descoberta dos cucurbitandos remonta a 1905 quando Behrend, Meyer e Rusche publicaram um extenso artigo intitulado "Ueber Condensationsproducte aus Glycoluril und Formaldehyd" ${ }^{1}$, onde reportaram diversos produtos de condensação destes precursores. Em condições fortemente ácidas, obtiveram um sólido branco, insolúvel nos solventes usuais, que não puderam caracterizar estruturalmente. Na ocasião acreditavase na existência de um polímero, pelas suas características químicas, que passou a ser chamado de polímero de Behrend. 76 anos mais tarde, Mock e Freeman decidiriam caracterizar o polímero de Behrend por RMN, que já era disponível nos grandes centros de pesquisa. Observaram assim que se tratava de uma estrutura cíclica composta por meros glicolurílicos ligados pelos átomos de nitrogênio por pontes metilênicas. Pela forma de abóbora que adotava a molécula, recebeu o nome de cucurbit[6]uril já que o fruto pertence à família das cucurbitacea. Por ser um cavitando, pertence ao grupo dos cucurbitandos.

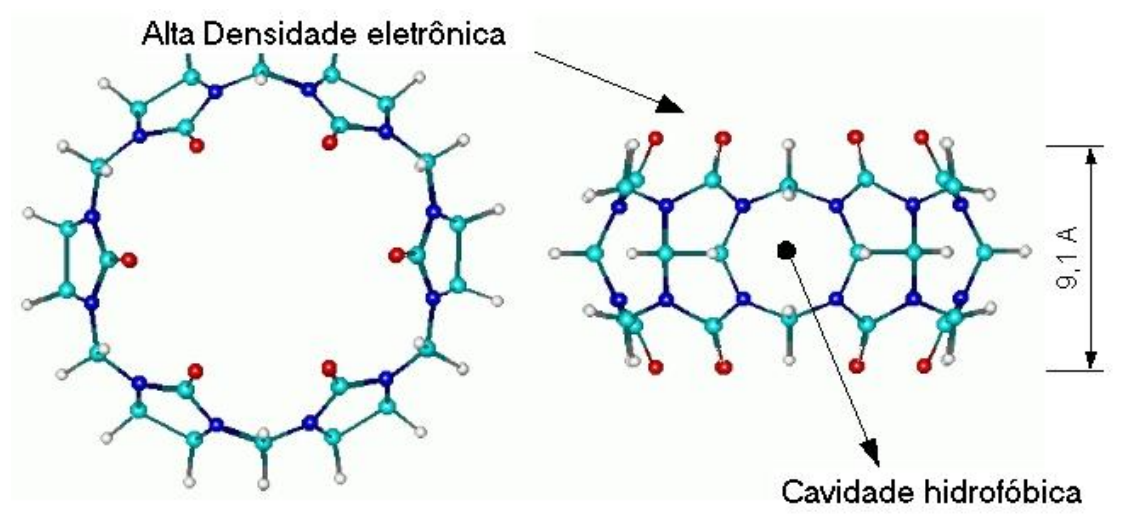

Figura 1: Estrutura da $\beta$-CB $[6]$, carbono em azul claro, oxigênios em vermelho, nitrogênio em azul escuro.

Esta estrutura de simetria $D_{6 h}$, possui uma cavidade central hidrofóbica relativamente grande, que é capaz de acomodar espécies químicas variadas para a formação de compostos de inclusão, também chamados de caviplexos, como o fazem outras famílias de cavitandos como as ciclodextrinas ou calixarenos. Na cucurbit[6]urila, existem 12 carbonilas orientadas para fora das cavidades, 6 de cada lado, formando assim dois portais para as cavidades, e conferindo à molécula um caráter básico de Lewis. Esta estrutura também permite, portanto, que se coordenem a íons metálicos duros como os alcalinos, alcalino-terrosos e lantanídeos. Alguns anos mais tarde, $\mathrm{Kim}^{2}$ e seus colaboradores assim como o grupo de Day ${ }^{3}$ descobriram a existência de outros homólogos que continham 5, 7,8 , e 10 unidades glicolurílicas e que a família era mais numerosa do que se imaginava 
(fig. 2). Da mesma forma, alterando alguns parâmetros de síntese era possível alterar a distribuição destes homólogos, mas sempre o $\beta$-CB[6] era o produto principal. Day identificou e isolou o $\zeta-\mathbf{C B}[10]$ na forma de $\alpha @ \zeta-\mathbf{C B}[5] @ \mathbf{C B}[10]$ em quantidades que representavam apenas $65 \mathrm{~g}$ por kilo de glicolurila ${ }^{4}$. A partir deste momento houve uma explosão no campo da pesquisa da química das cucurbiturilas por serem sérios candidatos a substituirem as tão difundidas ciclodextrinas e calixarenos em todo o tipo de aplicação.
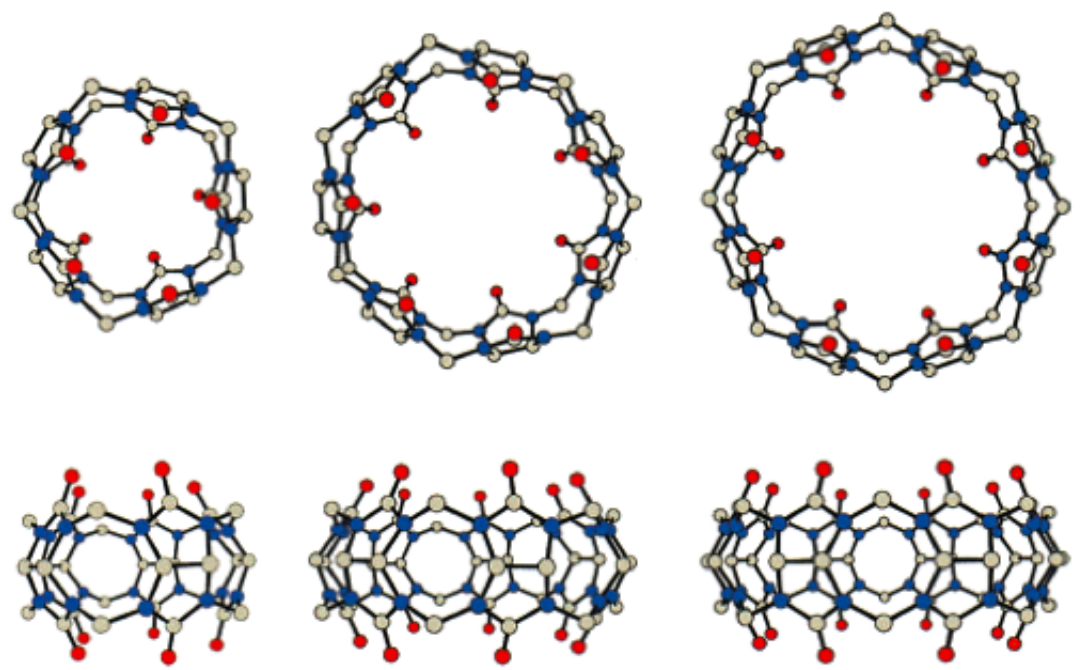

CB[5]
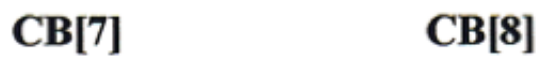

Figura 2: Representação da $\alpha-\mathrm{CB}[5], \gamma-\mathrm{CB}[7]$ e $\delta$-CB[8] da ref. ${ }^{2}$

Além destes novos homólogos, foram reportados por diversos autores CBs invertidos (i-CB $)^{5}$, nor-sec-CBs ${ }^{6}$ e congêneros cíclos dos mais variados ${ }^{7-12}$. As dimensões e propriedades das cucurbiturilas são bem diferentes quando se passa de um homólogo para outro (tabela 1).

Tabela 1: Dimensões dos cucurbitandos

\begin{tabular}{ccccccc}
\hline Homólogo & Altura $(\AA)$ & $\varnothing$ opérculo $(\AA)$ & $\varnothing$ int. $(\AA)$ & $\varnothing$ ext. $(\AA)$ & M.M. $(\mathrm{g} / \mathrm{mol})$ & ref. \\
\hline $\mathrm{CB}[5]$ & 9,1 & 2,4 & 4,4 & 13,1 & 830 & 13 \\
$\mathrm{CB}[6]$ & 9,1 & 3,9 & 5,8 & 14,4 & 996 & 4,13 \\
$\mathrm{CB}[7]$ & 9,1 & 5,4 & 7,3 & 16,0 & 1163 & \\
$\mathrm{CB}[8]$ & 9,1 & 6,9 & 8,8 & 17,5 & 1329 \\
$\mathrm{CB}[10]$ & 9,1 & $\sim 10$ & $\sim 11$ & - & 1661 \\
$\mathrm{CB}[11]$ & 9,1 & - & - & - & 1828 \\
glicolurila & & - & - & - & 142 \\
\hline
\end{tabular}

Por terem uma estrutura em forma de barril, serem simétricos além de possuirem cavidades hidrofóbicas, os cucurbitandos constituem um importante e versátil bloco de 
montagem para estruturas supramoleculares. Muitos exemplos de utilização dos cucurbitandos e derivados em supramoléculas podem ser encontrados na literatura, na forma de rotaxanos e pseudo-rotaxanos ${ }^{7,9,14,15}$, chaveadores moleculares ${ }^{16}$, carreadores de fármacos ${ }^{17-72}$, modificadores de colunas cromatográficas ${ }^{11,73-75}$, "rolamentos moleculares" 76 , complexos de inclusão ${ }^{77-85}$, adutos e outras estruturas que têm sido obtidas em diversos grupos de pesquisa do mundo, com enfoque em química supramolecular e nanotecnologia. Existem alguns reviews que tratam de quase todas as aplicações da cucurbiturilas em diversos campos de pesquisa e podemos destacar três deles: um deles por ser escrito em português, do nosso grupo ${ }^{86}$, outro pelo grupo de Isaacs ${ }^{13}$ bastante consistente e o mais completo e recente até agora pelo grupo de Masson ${ }^{4}$.

A preparação das CBs é muito simples, sendo basicamente uma reação de condensação em meio ácido de formaldeído e glicolurila. A separação dos homólogos no entanto ainda é extrememante complicada e demorada. Todos estes procedimentos estão descritos em detalhes no apêndice desta tese. A solubilidade destes compostos é baixa em todos os solventes conhecidos, principalmente em água, onde somente o $\alpha$-CB[5] e o $\gamma$-CB[7] apresentam solubilidades moderadas. A tabela 15 do apêndice traz valores de solubilidades para as diversas CBs.

A inércia química é um dos fatores limitantes para a expansão da química das cucurbiturilas, por fornecer poucos derivados. Recentemente foi descoberta uma rota sintética que levaria ao derivado radial peridroxilado, $\beta$ - $\mathbf{C B}[\mathbf{6}](\mathrm{OH})_{12}$, pela reação de $\beta$ - $\mathbf{C B}[\mathbf{6}]$ com $\mathrm{K}_{2} \mathrm{~S}_{2} \mathrm{O}_{8}$, que seria um ponto de partida para novos compostos contendo aminas, tióis, grupos aromáticos, ou fosfinas por exemplo. Outros derivados podem ser obtidos partindo de glicolurilas modificadas como é o caso da $\left(\mathrm{CH}_{3}\right)_{10} \alpha-\mathbf{C B}[5]$. Alguns trabalhos recentes tem trazido novas idéias para a funcionalização das cucurbiturilas, criando uma série de compostos análogos ${ }^{9-11,87-93}$.

Os fatores mais importantes que governam a inclusão de compostos químicos em cucurbiturilas são essencialmente cinco ${ }^{71,94-97}$ :

- O primeiro deles é o tamanho óbviamente. Moléculas muito grandes, que simplesemente não caibam na cavidade das CBs não poderão formar compostos de inclusão. Anéis aromáticos por exemplo são grandes demais para entrarem na cavidade da $\alpha-\mathrm{CB}[5]$ ou na $\beta-\mathrm{CB}[6]$.

- O segundo são as interações solvofóbicas, descritas em detalhe mais adiante, mas que podem ser resumidas em termos de afinidade por polaridade. Uma vez que as cavidades das CBs são hidrofóbicas, dificilmente incluirão moléculas hidrofílicas, por falta de interações solvofóbicas.

- O terceiro são a carga da molécula hóspede. Por possuirem uma alta densidade eletrônica nos oxigênios das carbonilas, os portais tendem a interagir por interações 
Tabela 2: Constantes de formação de caviplexos de $\beta$-CB[6] com alcanodiaminas em meio ácido ${ }^{95}$.

\begin{tabular}{|c|c|}
\hline Diamina & Cste. de formação relativa $\left(K_{f}^{a}\right)$ \\
\hline $\mathrm{NH}_{2}\left(\mathrm{CH}_{2}\right)_{3} \mathrm{NH}_{2}$ & 2,8 \\
\hline $\mathrm{NH}_{2}\left(\mathrm{CH}_{2}\right)_{4} \mathrm{NH}_{2}$ & 480 \\
\hline $\mathrm{NH}_{2}\left(\mathrm{CH}_{2}\right)_{5} \mathrm{NH}_{2}$ & 7600 \\
\hline $\mathrm{NH}_{2}\left(\mathrm{CH}_{2}\right)_{6} \mathrm{NH}_{2}$ & 8600 \\
\hline $\mathrm{NH}_{2}\left(\mathrm{CH}_{2}\right)_{7} \mathrm{NH}_{2}$ & 135 \\
\hline $\mathrm{NH}_{2}\left(\mathrm{CH}_{2}\right)_{8} \mathrm{NH}_{2}$ & 28 \\
\hline $\mathrm{NH}_{2}\left(\mathrm{CH}_{2}\right)_{9} \mathrm{NH}_{2}$ & 1,5 \\
\hline $\mathrm{NH}_{2}\left(\mathrm{CH}_{2}\right)_{1} 0 \mathrm{NH}_{2}$ & 0,3 \\
\hline
\end{tabular}

íon-dipolo, com cátions ou fragmentos com baixa densidade eletrônica.

- O quarto é o fator de pré-organização, comum a todos os sistemas de inclusão. Basicamente deve haver algum momento em que hóspede e hospedeiro estejam em uma orientação que permita a entrada de um no outro.

- O quinto, menos relevante mas que aumenta muito as constantes de formação de compostos de inclusão, é o fator de forma ou de topotaticidade. Alcanodiaminas protonadas formam complexos com $\beta$-CB[6] . As constantes de formação relativas no entanto com a pentano e a hexano diamina, são mais de 20 vezes superiores às da heptano e da butano diamina (ver tab. 2). Isto porquê elas têm o tamanho ideal para intergirem ao máximo com a cavidade (maximizando a interação solvofóbica) e com os dois portais ao mesmo tempo (interações íon-dipolo). Este é o conceito utilizado para descrever enzimas e seus substratos do "Schloss und Schlussel", explicado adiante.

Estes fatores, chamados também de atratores em discussões sobre auto-organização estática são tratados pela química supramolecular, que é um conjunto de conceitos desenvolvidos por Lehn, Cram, Pedersen e Balzani, principalmente.

A química supramolecular não trata essencialmente dos mesmos assuntos do que a química sintética, também chamada de química molecular. A última, trata basicamente de se obter meios de quebrar e formar ligações químicas com o objetivo de se construir moléculas, que existam na natureza ou não. A química supramolecular estuda o que ocorre quando duas ou mais moléculas interagem e associam-se em um sistema mais complexo. Alguns autores a chamam também de sociologia molecular, que procura descobrir porquê moléculas se associam e o que acontece quando estas o fazem. Geralmente a associação de mais de uma molécula gera um agregado com propriedades que transcendem as propriedades de seus componentes isolados, dando origem assim a propriedades que vão além (supra) das propriedades moleculares componentes. Esta é a origem do termo "supramolecular" 98-102. 
Mas as moléculas não se associam de qualquer maneira. Existem algumas condições para que tais agregados possam se formar. Para que duas ou mais moléculas possam interagir de forma específica, são necessárias algumas condições:

- Interação: Alguma força deve atrair ambas as moléculas de forma que se aproximem e possam ligar-se ou interagirem por aproximação. Estas podem ser do tipo:

Eletrostáticas, ligações de hidrogênio, coordenação (interações doador-aceptor de carga), Van der Waals, ou consequência dos meios como interações solvofóbicas.

- Informação: Conjunto de fatores que discrimine moléculas tornando as interações específicas para um tipo de combinações específicas. Este é o conceito proposto por Emil Fischer "Schloss und Schlüssel" em 1894.

Neste ponto é necessário haver complementariedade geométrica (topologia ou topotaticidade adequada).

Neste ponto é necessário haver complementariedade de interações (sinergismo dinâmico).

- Pré-organização: é necessário que as moléculas estejam disponíveis umas para as outras para que estas interações possam ocorrer.

Quando estas condições são atendidas ocorre o processo de reconhecimento molecular que é o processo que forma agregados supramoleculares. Existem diversos tipo de agregados, que apresentam diferentes graus de reconhecimento molecular, que são classificados de acordo com sua complexidade e especificidade e que vão por exemplo da formação uma monocamada de lipídeos na interface água/ar até as interações entre antígenos e anticorpos. No primeiro caso nos referimos geralmente a processos de auto-organização (self organization) e no úlitmo a auto-ligação (self-assembly). Os processos biológicos são os exemplos mais evidentes de sistemas supramoleculares e do que decorre de sua criação. A informação genética, as membranas celulares, os processos enzimáticos, e centenas de outros exemplos são regidos e mantidos por processos supramoleculares. A consequência mais perturbadora da química supramolecular é a própria Vida, que consiste basicamente em sistemas autoorganizados capazes de se replicarem. Por incrível que pareça, a replicação também é consequência de princípios supramolecuares de topicidade (topologia adequada ou moldes) catálise supramolecular e sinergismo dinâmico.

\subsection{Química em Meio Confinado e Caviplexos de cucurbiturilas}

Mas por quê a química dos compostos de inclusão é tão interessante? A restrição de espaço é um fator limitante ou determinante quando se pensa na reatividade de espécies químicas e na distribuição de produtos de reação. A diminuição de graus de liberdade, 
de um determinado reagente pode favorecer estados de transição bem definidos, estabilizar intermediários de reação ou simplesmente produtos em detrimento de outros. Da forma oposta, o confinamento pode simplesmente inviabilizar uma reação qualquer por desestabilização de estados de transição e intermediários. Processos catalíticos, positivos ou negativos são muito comuns em ambientes confinados. Estas propriedades são particularmente interessantes quando pensamos em reações paralelas, que gerem dois ou mais produtos em solução ou em fase gasosa, pois cavidades podem alterar seu percurso ou mecanismo e alterar totalmente a distribuição de produtos, e mesmo gerar novos produtos que não são obtidos em solução.

A química em meio confinado representa uma oportunidade singular em química sintética, uma vez que possibilita a obtenção de determinadas substâncias em quantidades muito maiores do que as obtidas em solução, ou evitar que se formem determinados produtos. A restrição de movimento pode ser acompanhado de outros fatores como alteração da pressão interna, deslocamentos de equilíbrios, e criação de reações suportadas, como no caso de vesículas, micelas, nanotubos, zeólitas, e redes de coordenação ${ }^{103-107}$. Por conta da restrição de espaço em vesículas, por exemplo, o número de colisões entre subtratos reativos é muito maior do que em solução, o que afeta também a cinética das reações ${ }^{105}$. A natureza da cavidade também exerce um papel fundamental uma vez, que pode criar campos elétricos localizados que induzam variações de momento de dipolo em espécies confinadas, alterando assim a dinâmica de processos envolvendo transferência eletrônica inclusive e processos de transferência de energia envolvendo luz também. Cavidades podem também interagir fracamente com algum reagente em posição específica, direcionando a reação como um todo, o que é conhecido como reação topotática. Cavidades abertas apresentam algumas vezes um comportamento similar ao de enzimas, uma vez que podem apresentar menor afinidade com os produtos de reação do que com seus reagentes. Desta forma, os produtos tendem a ser expulsos da cavidade e os reagentes tendem a entrar na mesma. Neste caso, a solvofobicidade das cavidades em questão também é um fator determinante além de interações pontuais: A cavidade acaba atuando como uma esfera de solvatação rígida. Alguns trabalhos tem sido publicados nestes sentido, descrevendo processos catalíticos em cavidades como ciclodextrinas e cucurbiturilas entre outras cavidades orgânicas sintéticas ${ }^{15,108-128}$.

Caviplexo, ou complexo de inclusão, é o nome que recebem os conjuntos discretos constituídos por uma molécula hospedeira (cavidade) e outra ou outras moléculas hóspedes (existem vários casos de $\delta$-CB[8] com mais de um hóspede). Entende-se por discreta, uma cavidade que não seja considerada como ponto de inclusão em alguma estrutura periódica como é o caso por exemplo das zeólitas, uréias ou fenóis sólidos etc... que usalmente formam clatratos dos mais diversos ${ }^{129-131}$. Caviplexos constituem agregados moleculares independentes de retículo, e possuem propriedades químicas distintas de seus componentes isolados. São entidades supramoleculares associativas e reversíveis do 
tipo hóspede-hospedeiro (doravante Host-Guest), onde a molécula que delimita a cavidade é a chamada hospedeira (Host) e aquela que troca de meio durante a formação do caviplexo é chamada de hóspede (Guest). A priori as moléculas hóspedes são menores e exibem afinidade com as cavidades que podem ser encaradas como meios contínuos de certa forma, comparáveis a solventes . Cram definiu um Host como sendo a molécula onde os sítios de ligação convergem, enquanto que o Guest é aquela onde os sítios divergem. ${ }^{132}$

Como já mencionamos anteriormente, as condições gerais para que haja a formação de um caviplexo são primeiramente a compatibilidade de tamanhos entre o hóspede e hospedeiro. Geralmente caviplexos deixam de se formar por impedimento estérico. En segundo lugar, é necessário que exista um ou mais tipos de interação intermolecular que possa estabilizar um caviplexo a se formar. Encontramos na literatura caviplexos mantidos por atração eletrostática, interação íon-dipolo, interações solvofóbicas, ligações de hidrogênio e, frequentemente, por mais de um tipo de interação. Além da compatibilidade de tamanho fatores estruturais podem favorecer ou não a entrada de um hóspede em alguma cavidade. Dois isômeros de posição por exemplo, podem apresentar constantes de formação de caviplexo distintas com uma determinada cavidade se um deles tiver uma estrutura que facilite de alguma forma alguma interação intermolecular. Em terceiro lugar, que a transferência da molécula hóspede do seio do solvente para o interior da cavidade seja termodinamicamente favorável. Espécies solvatadas, tendem geralmente a perderem seu solvente antes de adentrar qualquer tipo de cavidade, como se esta última fosse meramente um novo solvente com o qual o hóspede tam maior afinidade.

Não é raro encontrar na literatura exemplos de caviplexos envolvendo íons orgânicos e inorgânicos que são tratados como compostos de coordenação, o que é conceitualmente errado, uma vez que compostos de coordenação geram campos ligantes, o que quase nunca ocorre em compostos de inclusão, sendo mais parecidos com esferas de solvatação rígidas e contínuas. É importante salientar porém que grande parte dos procedimentos de análise de formação, estabilidade e características de caviplexos são muito similares às utilizadas para complexos metálicos inorgânicos ou ainda agregados supramoleculares orgânicos, já que em todos os casos trata-se de processos associativos, onde há diminuição da molecularidade ao longo da reação de caviplexação.

\subsubsection{Analogias Entre a Solvatação e a Caviplexação}

A cavidade de um macrociclo pode ser interpretada como a cavidade criada por um solvente qualquer, estruturada no entorno de um soluto qualquer. A esfera de solvatação primária é a conformação mais estável que adotam as moléculas do solvente em torno deste soluto, de modo a aumentar ao máximo as interações fracas com ele. Estas interações podem ser do tipo ion-dipolo (40-600 kJ/mol), ligações de hidrogênio (10-40 kJ/mol) ou forças de Van der Waals $(1-40 \mathrm{~kJ} / \mathrm{mol})$, que incluem as interações do tipo dipolo 
permanente-dipolo permanente (forças de Keesom), dipolo permanente-dipolo induzido (forças de Debye) e dipolo instantâneo-dipolo induzido (forças dispersivas de London). Espécies carregadas e dipolos permanentes dispersos entre moléculas de algum solvente tendem a criar pontos de interação com outros íons, e com outros dipolos permanentes. É de se esperar portanto que solventes polares interajam melhor com este tipo de soluto do que aqueles incapazes de criar tais interações. De maneira oposta, espera-se que solventes apolares não sejam capazes de interagir de maneira satisfatória com tais solutos (veja seção 2.2.2). Os cavitandos se comportam da mesma forma que os solventes, porém agindo como cavidades mais rígidas do que as de um solvente. Uma vez superadas as limitações estéricas, uma espécie hóspede (soluto) pode se alojar na cavidade hospedeira (solvente) na conformação que aumente ao máximo as interações fracas que descrevemos acima, formando um agregado estável (espécie solvatada). Podemos fazer analogias entre a reação de caviplexação e uma transferência de fase (fig. 3).

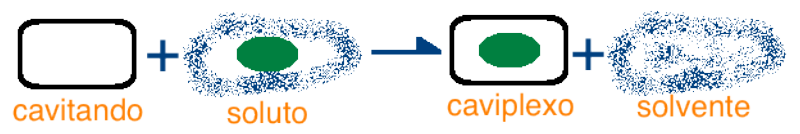

Figura 3: Representação da transferência de um soluto da cavidade da esfera de solvatação para a cavidade de um hospedeiro de inclusão.

\subsubsection{Interações solvofóbicas}

Um dos fatores importantes que governam a formação de caviplexos são as interações solvofóbicas que possam existir entre as espécies envolvidas, que mencionamos acima. A falta de afinidade de solutos por determinados solventes é uma propriedade conhecida por solvofobicidade, contrária portanto à solvofilicidade. Em termos práticos isto explica uma velha máxima empírica de que "semelhante dissolve semelhante". Mas em termos moleculares o que vem a ser a solvofobicidade? Ela só pode ser explicada em termos de interações soluto-solvente, ou à falta delas, que possam levar ou não à solvatação de determinada molécula. De acordo com a IUPAC, o parâmetro de solvofobicidade $\left(S_{P}\right)$ para determinado solvente pode ser definido como:

$$
S_{P}=1-\frac{M_{\text {solvente }}}{M_{\text {hexadecano }}}
$$

e deriva das energias molar padrão de Gibbs de transferência $\left(\Delta \mathbf{G}_{t}^{o}\right)$ de uma série de solutos $(\mathrm{X})$ da água para várias misturas aquosas de solventes e solventes puros $(\mathrm{S})$ :

$$
\Delta \mathbf{G}_{t}^{o}(X, \text { agua } \rightarrow S)=M \times R_{T}+D
$$

onde $R_{T}$ é um parâmetro do soluto, dependente de seu tamanho, e M e D caracterizam o solvente. Os valores de M são usados para definir o efeito solvofóbico de determinado 
solvente, $S_{P}$ cujo valor vai de 1 para a água até 0 para o hexadecano. Para entender estas relações é conveniente utilizar um exemplo bem simples envolvendo hidrocarbonetos e água. Os hidrocarbonetos são praticamente insolúveis em água, o que indica que este processo deve envolver variações positivas de energia de Gibbs $(\Delta \mathbf{G}=\Delta \mathbf{H}-T \Delta \mathbf{S})$. A dissolução de um hidrocarboneto em água é geralmente exotérmica o que implica em valores negativos de $\Delta \mathbf{H}_{\text {solv }}^{\ominus}$. indicando que o processo implica em uma diminuição de entropia do sistema. Só podemos entender esta diminuição de entropia se considerarmos que as moléculas de água só poderiam solvatar um hidrocarboneto, se conseguissem se organizar em torno do soluto de maneira mais ordenada do que estariam no seio do solvente em si, fenômeno conhecido como incremento estrutural. Se duas moléculas de soluto, no caso de hidrocarboneto, viessem a se aproximar em solução poderiam juntarse num agregado, permitindo assim que parte das moléculas de solvente, voltassem à estrutura da água pura, diminuindo a ordem do sistema e tornando a variação entrópica positiva (fig 4).

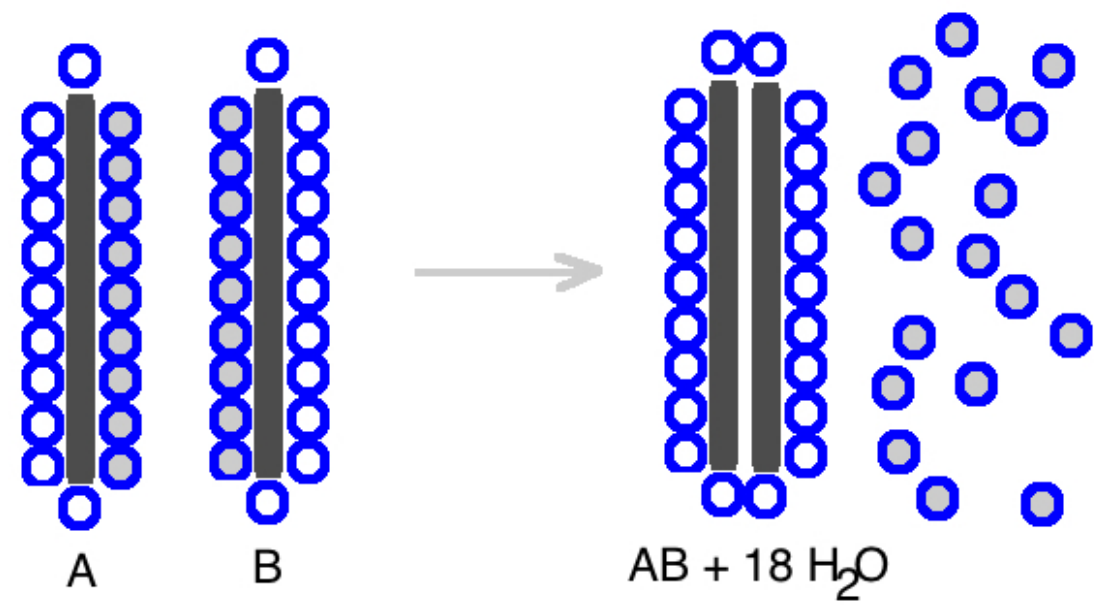

Figura 4: Representação esquemática de uma interação solvofóbica, onde vemos duas moléculas de soluto A e B interagindo de forma a liberar moléculas de solvente.

A saída de água de solvatação torna a formação do agregado vantajosa do ponto de vista energético e a energia livre diminui desta forma. Este é um exemplo do que se chama de interação solvofóbica (neste caso hidrofóbica, pois envolve água), que é um fator que pode governar processos de auto-montagem. A tabela 3 mostra os parâmetros termodinâmicos para a dissolução de metano gasos em água e ciclohexano, a $273 \mathrm{~K}$. Observamos claramente que os processos são altamente desfavoráveis pelos valores de $\Delta \mathbf{G}_{s}^{o}$ e $\Delta \mathbf{S}_{s}^{o}$, o que sugere que as interações solvofóbicas são entropicamente dirigidas na sua maioria. Apesar desta enorme contribuição entrópica, sabe-se também que a própria associação de moléculas polares com grupos tipicamente apolares como metilenos é desfavorável entalpicamente também ${ }^{133-142}$. Este tipo de efeito também é importante para a formação dos caviplexos. Considerando a formação de um caviplexo em solução, poderíamos descrever 
Tabela 3: Parâmetros termodinâmicos para a dissolução de metano em água e ciclohexano

\begin{tabular}{cccc} 
Solvente & $\Delta \mathbf{G}_{s}^{o}\left(\mathrm{~kJ} . \mathrm{mol}^{-1}\right)$ & $\Delta \mathbf{H}_{s}^{o}\left(\mathrm{~kJ} . \mathrm{mol}^{-1}\right)$ & $\Delta \mathbf{S}_{s}^{o}\left(\mathrm{~kJ} . \mathrm{mol}^{-1} \cdot \mathrm{K}^{-1}\right)$ \\
\hline Água & 26,4 & $-13,8$ & -134 \\
Ciclohexano & 14,2 & $-2,5$ & -54
\end{tabular}

o processo com uma equação simples:

$$
H_{s}+G_{s} \rightleftharpoons G @ H_{s}+S
$$

onde S representa as moléculas de solvente em excesso após a inclusão do hóspede no hospedeiro, antes em solução. Na formação de caviplexos 1:1 devemos entender que existem duas cavidades no solvente, cada uma contendo um componente do futuro caviplexo, que se fundem em uma só contendo o composto de inclusão. Isto implica em uma mudança de área superficial das cavidades de solvente, em dessolvatação parcial tanto do $\mathrm{H}$ como do G para que haja contato entre as espécies e ressolvaltação do caviplexo recém formado. A energia livre envolvida no processo pode ser descrita utilizando um ciclo termodinâmico que envolvesse energia de formação do caviplexo em fase gasosa, de dessolvatação dos componentes e energia livre de solvatação do caviplexo como este:

$$
\Delta \mathbf{G}(G+H)_{s}=\Delta \mathbf{G}(H+G)_{g}-\Delta \mathbf{G}\left(H_{s}\right)-\Delta \mathbf{G}(G)_{s}+\Delta \mathbf{G}(G @ H)_{s}
$$

A constante de formação de caviplexos é dada pela equação:

$$
k=\frac{\left[G_{n} @ H_{m}\right]}{[G]^{n} \cdot[H]^{m}}
$$

A constante termodinâmica de equilíbrio varia com a temperatura de acordo com a equação de Van’t Hoff como descrito abaixo:

$$
\frac{d \ln K}{d T}=\frac{\Delta \mathbf{H}^{0}}{R T^{2}}
$$

Assumindo que o calor de reação seja constante com a temperatura obtemos:

$$
\ln \left(\frac{K_{2}}{K_{1}}\right)=\frac{\Delta \mathbf{H}^{0}}{R}\left[\frac{1}{T_{1}}-\frac{1}{T_{2}}\right]
$$

Das relações termodinâmicas clássicas temos que :

$$
\Delta \mathbf{G}^{0}=\Delta \mathbf{H}^{0}-T \Delta \mathbf{S}^{0}
$$

Aliado a estes fatores é necessário também que tanto $\mathrm{H}$ quanto $\mathrm{G}$ tenham geometrias e posições relativas favoráveis à caviplexação para que o encontro entre as entidades seja efetivo, o que não é sempre o caso. Cram definiu tal parâmtero como fator de pré-organização. Não é raro observar enormes variações nas constantes de formação de caviplexos em diferentes solventes, e frequentemente estão intimamente relacionadas à energia de dessolvatação dos hóspedes. Quanto maior esta energia, menos o equilíbrio tende a se deslocar para a formação do caviplexo ${ }^{139}$. 


\subsubsection{Parametrização de solventes}

Os solventes são vistos muitas vezes como espécies espectadoras no meio reacional, mesmo quando sabemos que eles são as principais componentes do meio e que na verdade eles são o meio reacional. A maioria dos livros-texto não aborda bem a questão da influência que os solventes exercem nos mecanismos e na cinética das reações químicas, sempre enfocando os centros aceptores e doadores dos reagentes em si. Este pode ser um equívoco uma vez que desde Berthelot, que estudou com Péan de St.-Gilles seguidos por Menshutkin reações de esterificação em diferentes solventes, sabemos que reações químicas não progridem da mesma forma em solventes distintos ${ }^{137,138}$. Alguns exemplos como as reações do iodeto de etila com a trimetilamina, equilíbrios ceto-enólicos, reações competitivas de dediazoniação de sais de arenodiazônio, para citar apenas algumas, são extremamente sensíveis ao solvente, tanto mecanistica quanto cineticamente. De maneira geral podemos generalizar alguns aspectos de reações orgânicas que também podem ser extrapolados para reações inorgânicas e de caviplexação ${ }^{143}$.

- Reações com estados de transição assimétricos ou dipolares apresentam grande efeito de solvente (tanto $\mathrm{S}_{N} 1$ quanto $\mathrm{S}_{N} 2$ ).

$$
\begin{aligned}
& R-X \rightleftharpoons\left[R^{\delta \oplus} \cdots X^{\delta \ominus}\right]^{\ddagger} \\
& Y:+R X \rightleftharpoons\left[Y^{\delta \oplus} \cdots R \cdot X^{\delta \ominus}\right]^{\ddagger}
\end{aligned}
$$

- Estados de transição isopolares e reações radicalares apresentam pouco efeito de solvente.

A explicação para os efeitos de solvente é muito simples: dependem da habilidade dos solventes de interagir de forma específica com os reagentes, estados de transição e produtos. Solventes apresentam ou não momento de dipolo, são próticos ou não, ácidos ou bases de Lewis, são polarizáveis ou não, são polarizantes ou não entre outras propriedades, que são chamados de descritores moleculares. Não é raro também observar efeitos de solvente em propriedades espectroscópicas, quando um composto passa a absorver em regiões de maior ou menor energia, dependendo exclusivamente do solvente. Isto porquê alguns estados excitados podem ser estabilizados em determinados tipos de solvente e desestabilizados em outros. Na falta de modelos completos, que levassem em conta o maior número possível de descritores de solventes, foram criadas diversas escalas empíricas que tentavam associar alguns dos descritores principais com os efeitos que exercem em reações e propriedades espectroscópicas principalmente. São exemplos muito comuns a escala de Reichardt $\left(\mathrm{E}_{T}(30)\right)^{143}$, de Kamlet-Taft ${ }^{144}$, e de Catalán ${ }^{134}$. A partir do calor de vaporização de um determinado solvente, em J.cm ${ }^{-3}$ é possível delinear uma grandeza que está relacionada à intensidade das forças que mantêm as moléculas daquele solvente unidas, ou a energia coesiva o que também é importante quando pensamos em sovatação 
e dessolvatação, pois estes processos envolvem destruição e criação de interações entre as próprias moléculas do solvente. A chamada densidade de energia coesiva (c) é dada por:

$$
c=\frac{\Delta H-R T}{V_{m}}
$$

Onde: $\Delta H$ é a entalpia de vaporização

$V_{m}$ o volume molar do solvente

$R T$ tem seus significados usuais. Por conta dos diversos mecanismos envolvidos em reações de caviplexação, de susbstituições de hóspedes e de catálise em caviplexos, estas propriedades dos solventes também devem ser levadas em conta, já que a formação e a destruição de um caviplexo pode ser interpretada como sendo uma reação competitiva de dois solventes pelo mesmo soluto.

\subsubsection{Mecanismos de formação de caviplexos}

Como em qualquer reação de substituição, a troca de hóspedes no interior das cavidades das $\mathrm{CB}[\mathrm{n}]$ pode ser interpretada como sendo uma reação associativa ou dissociativa. No primeiro caso o hóspede substituinte $\left(\mathrm{H}_{s}\right.$ representado por $\bullet$, eq. 2.10), desloca o hóspede residente $\left(\mathrm{H}_{r}\right.$ representado por $\left.*\right)$, empurrando-o para fora da cavidade em uma única etapa. No segundo caso, o $\mathrm{H}_{s}$ só pode entrar na cavidade após a saída do $\mathrm{H}_{r}$, que ocorrer por conta do equilíbrio dinâmico de formação dos caviplexos (eq. 2.11) ${ }^{145,146}$.

$$
\begin{gathered}
\bullet+\circledast \rightarrow[\bullet-\bigcirc-*]^{\ddagger} \rightarrow \bigodot+* \\
\bullet+\circledast \rightarrow \bullet+\bigcirc+* \rightarrow \bigodot+*
\end{gathered}
$$

A expressão geral para a formação de um caviplexo em função do tempo pode ser dada pela equação onde o parâmetro $r$ depende das condições iniciais em $t=0$.

$$
[\odot]=[\bigodot]_{\infty}+\frac{\left([\odot]_{0}-[\odot]_{\infty}\right) r e^{-r t}}{r+k_{\text {entrada }}\left([\odot]_{0}-[\odot]_{\infty}\right)\left(r e^{-r t}-1\right)}
$$

onde

$$
r=\sqrt{k_{\text {saida }}^{2}+4 k_{\text {saida }} \cdot k_{\text {entrada }} \cdot[\bigodot]_{0}} \text { quando } \quad[\bigcirc]_{0}=[\bullet]_{0}
$$

e onde

$$
r=k_{\text {saida }}+2 k_{\text {entrada }}[\bullet] \text { para }[\bigcirc]_{0}=[\bullet]_{0} \quad \text { e } \quad[\odot]_{0}=0
$$

e onde

$$
r=\sqrt{\left(k_{\text {saida }}+k_{\text {entrada }}\left([\bigcirc]_{0}-[\bullet]_{0}\right)\right)^{2}+4 k_{\text {saida }} k_{\text {entrada }}[\bigcirc]_{0}} \quad \text { quando } \quad[\bigcirc]_{0} \neq[\bullet]_{0} \quad \text { e } \quad[\odot]_{0}=0
$$

No caso das cucurbiturilas, a substituição de Guest sempre ocorre de forma dissociativa como demonstrou Marquez ${ }^{71}$. Por razões ainda obscuras, as cavidades das CBs sempre 
armazenam moléculas de água, mesmo quando secas a vácuo, o que é a princípio incompatível com a natureza de suas cavidades. Portanto, moléculas de água devem ser levadas em conta na formação de qualquer caviplexo, sendo consideradas Guests de partida.

\subsection{Adutos e Complexos metálicos de Coordenação}

As cucurbiturilas, por conta dos átomos de oxigênio que contém, comportam-se como ligantes duros na formação de complexos. Podemos fazer uma analogia com os éteres de coroa desenvolvidos por Pedersen ${ }^{147}$, sendo que cada opérculo do macrociclo se comporta como uma coroa independente. Por conta disto, observamos a formação de complexos metálicos com diversos cátions alcalinos, alcalino-terrosos, lantanídeos e amônio com constantes de formação consideráveis (tabela 4).

Tabela 4: Log das constantes de formação de complexos com cátions duros e $\beta$-CB[6] comparados ao 18-crown-6. ${ }^{148-150}$

\begin{tabular}{|c|c|c|c|}
\hline Cátion & $\mathrm{r} / \AA$ & $\beta$-CB $[\mathbf{6}]$ & 18 -crown-6 \\
\hline $\mathrm{Na}^{+}$ & 1,02 & 3,69 & 0,8 \\
\hline $\mathrm{K}^{+}$ & 1,38 & 3,96 & 2,03 \\
\hline $\mathrm{Rb}^{+}$ & 1,49 & 4,41 & 1,56 \\
\hline $\mathrm{Cs}^{+}$ & 1,7 & 4,82 & 0,99 \\
\hline $\mathrm{Ca}^{2+}$ & 1,0 & 4,57 & 0,48 \\
\hline $\mathrm{NH}_{4}^{3+}$ & 1,7 & 3,97 & 1,23 \\
\hline $\mathrm{H}^{+}$ & 1,38 & 3,02 & 1,28 \\
\hline $\mathrm{Ln}^{3+}$ & $0,86-1,03$ & 3 & $1,32-8,75$ \\
\hline
\end{tabular}

Percebemos aqui que as constantes de formação com o $\beta$-CB[6] são maiores para todos os cátions, com exceção dos lantanídeos. Isto pode ser entendido como consequência do efeito quelato, já que os pontos de coordenação estão mais próximos uns dos outros, diminuindo a energia necessária para rearranjos estruturais do ligante para a coordenação ao centro metálico. Cálculos teóricos por DFT no vácuo mostram bem este efeito, principalmente para os cátions mais volumosos como o $\mathrm{Rb}^{+}$e o $\mathrm{Cs}^{+}$(fig. 5). Os cátions amônio podem inclusive ligar-se por mais de um ponto às carbonilas formando uma espécie de tampa, principalmente com $\alpha$-CB[5] . Foi descrito um complexo de $\left(\mathrm{CH}_{3}\right)_{10} \alpha$-CB[5] com chumbo $^{151}$.

O que observamos mais frequentemente nos compostos de cucurbiturilas com metais são os adutos. Adutos são compostos de adição, formados principalmente mas não exclusivamente de moléculas, íons ou átomos ligados entre si por moléculas de água. Nos adutos estas moléculas de água agem como conectores mantendo a estrutura supramolecular coesa, por meio de ligações de hidrogênio. A totalidade destes compostos descritos na literatura são frutos de co-cristalização, sem qualquer planejamento. São descritas apenas 

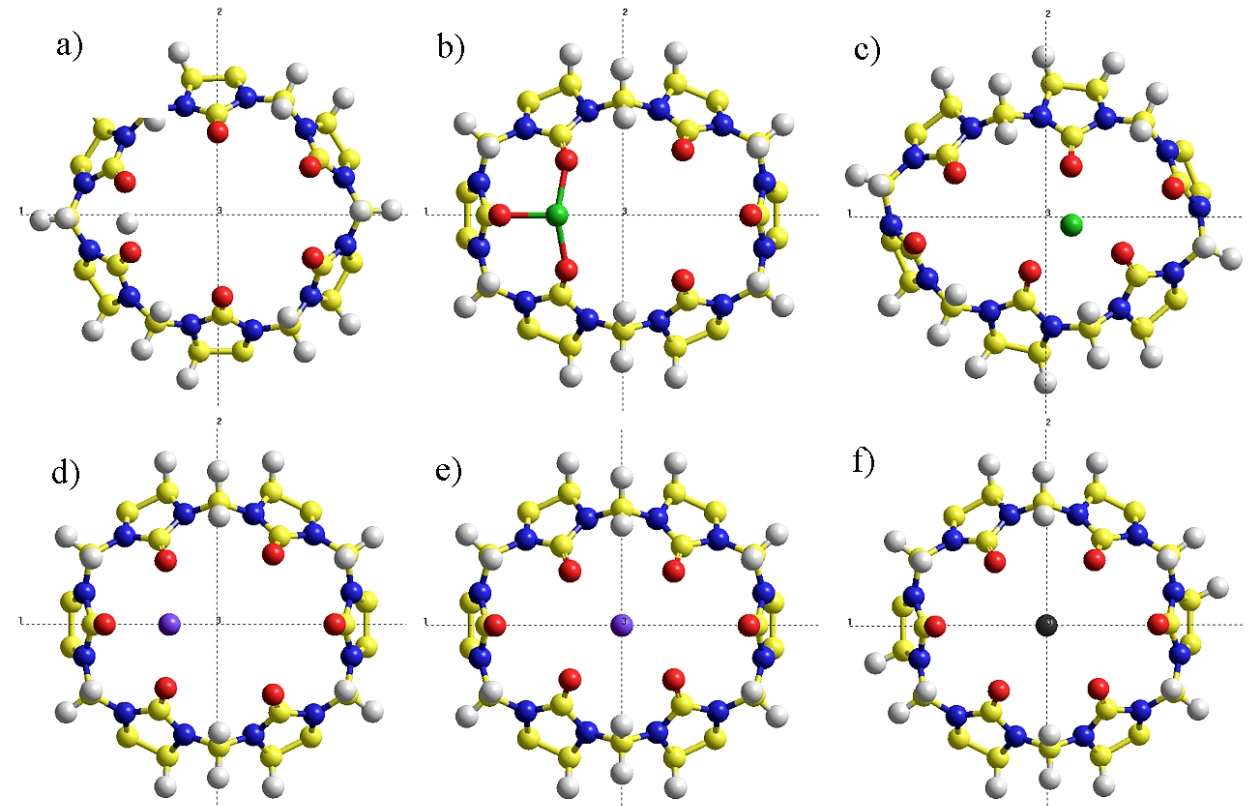

Figura 5: Estruturas minimizadas por DFT no vácuo para de a) a f) $\mathbf{H}^{+}, \mathbf{L i}^{+}, \mathbf{N a}^{+}, \mathbf{K}^{+}, \mathrm{Cs}^{+}$, $\mathbf{R b}^{+}$

suas estruturas cristalinas, sem nenhuma aplicação em vista. Todavia formam estruturas estendidas muito elegantes (fig. 6).

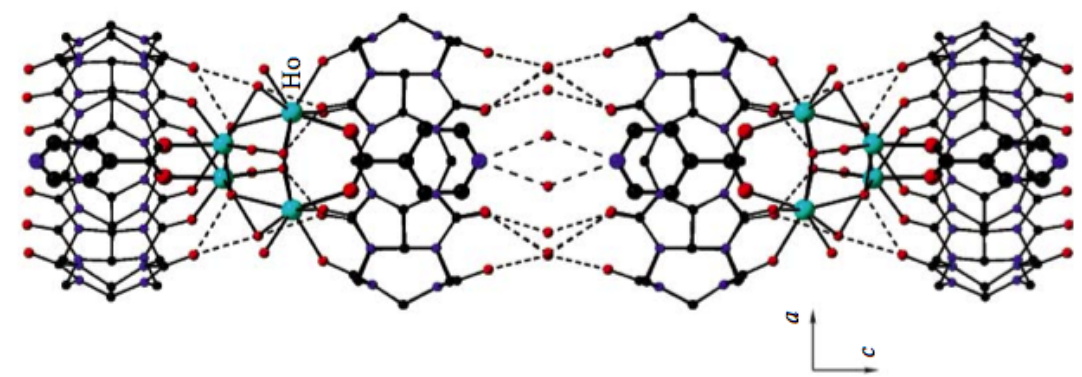

Figura 6: Estrutura do aduto $\left[\mathrm{Ho}_{4}\left(\mu_{3}-\mathrm{OH}\right)_{4}\left(\mu_{2}-\mathbf{O H}\right)_{2}\left(\mathrm{C}_{5} \mathrm{NH}_{4} \mathbf{C O O}\right)_{2}\left(\mathbf{H}_{2} \mathbf{O}\right)_{4}(\mathrm{CB}[\mathbf{6}])_{2}\right]^{4+}\left(\mathrm{H}_{2} \mathbf{O}\right)_{7 \infty}$, da ref. ${ }^{152}$

Aparecem nos trabalhos complexos com estrôncio e $\beta$-CB $[6]$ de fórmula $\left[\mathrm{M}_{4}\left(\mathrm{NO}_{3}\right) @ \mathrm{~L}\right]^{7+153}$ e complexos poliméricos com rubídio colunares ${ }^{154}$ do tipo $\left[\mathrm{M}_{2}(\mathrm{~m}-\mathrm{OH})_{2}\left(\mathrm{H}_{2} \mathrm{O}\right)_{2} \mathrm{~L}\right]^{2+}$ onde $\mathrm{L}=\mathrm{CB}[6]$, bastante diferentes dos complexos com os outros metais alcalinos do tipo $\left[\mathrm{M}_{2} \mathrm{~L}\right]^{2+}$, como é o caso do $\mathrm{Cs}^{+}$com $\mathrm{CB}[8]^{155}$. Ions mais complexos também foram utilizados para a formação destes adutos poliméricos como é o caso por exemplo dos sulfeto e seleneto de $\mathrm{W}^{156}$, do $\mathrm{In}^{157}$ e $\mathrm{W}^{158,159}$, do cloreto de uranila ${ }^{160}$, de molibdatos ${ }^{161-164}$, Sm e $\mathrm{Th}^{165,166}$, Zr (IV) e Hf (IV) ${ }^{167}$, Cr (III) e Ni (II) ${ }^{161,164,168}$ entre muitos outros outros.

Esta tese foi dividida em 3 partes. Na primeira delas, está contextualizada o tema de pesquisa do nosso grupo, e os nossos principais objetivos quando da sua implantação. A seguir foram escolhidos alguns tópicos de nossas pesquisas nessa linha, e alguns dos 
nossos resultados mais significativos, na forma de uma discussão em três partes: Interfaces e filmes finos, complexos e espécies em solução e nanomateriais. Cada uma destas partes contém um texto introdutório de contextualização dos propósitos específicos das pesquisas desenvolvidas. Ao final apresentamos nossas conclusões e nossos novos objetivos em 2014 . Por fim há um apêndice onde descrevemos a metodologia das sínteses e caracterizações que mais foram utilizadas a título de material consulta. Estão anexados ao fim do documento os artigos que nortearam a discussão, quando se tratar de material publicado. 


\section{Parte II}

Proposta e Estratégia de Investigação 


\section{Contexto da linha de pesquisa}

A linha de pesquisa com cucurbiturilas foi proposta em 2004, e implantada de fato a partir de 2006 no Departamento de Química da FFCLRP, quando o Laboratórios de Materiais e Interfaces Moleculares recebeu espaço físico no bloco 5 inferior do Departamento de Química da FFCLRP. A pesquisa sobre o assunto era ainda muito incipiente no mundo todo como pode ser visto na figura 7, e nosso grupo foi pioneiro no Brasil em tratar da química destes compostos. Sabia-se ainda muito pouco sobre o potencial deste tipo de molécula, não se conheciam muitos derivados, não eram empregadas em materiais, não existiam filmes filnos, membranas ou qualquer tipo de nanocompósito com elas. Do ponto de vista da química inorgânica, pouco se sabia sobre a formação de compostos de coordenação com cucurbiturilas e metais de transição $d$. O que existia até então eram diversas descrições de estruturas cristalinas que eram na verdade adutos, onde a água fazia o papel de ligar os íons metálicos aos macrociclos.
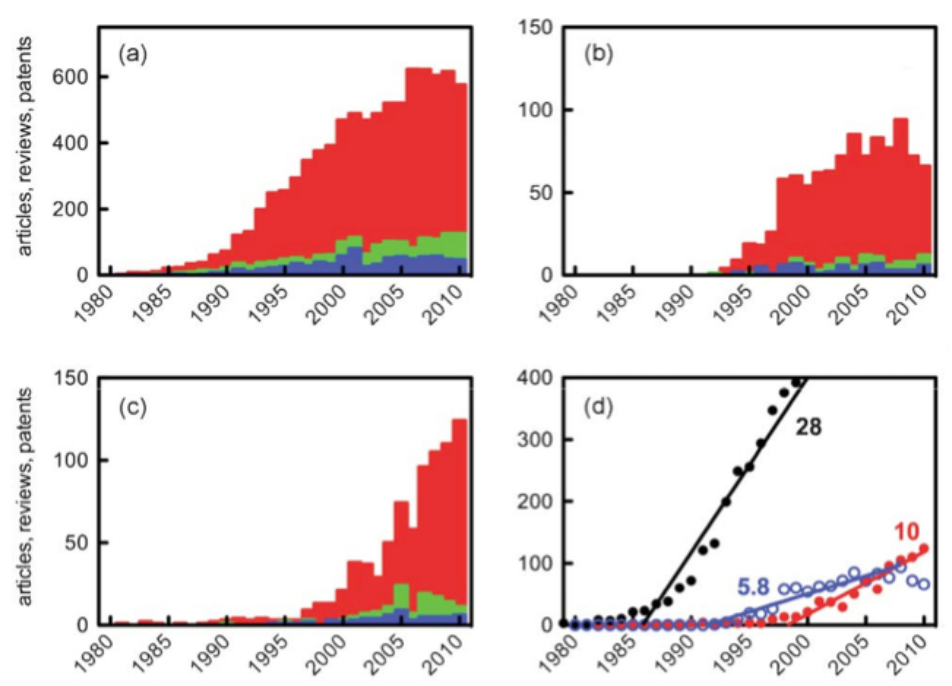

Figura 7: Evolução do número de (azul) artigos de revisão, (verde) patentes ${ }^{169-176}$, (vermelho) artigos tratando de calixarenos (a); de resorcinarenos (b); e de cucurbiturilas (c). Numero de documentos por ano (d) para calixarenos em preto, resorcinarenos em azul e cucurbituirlas em vermelho.- da ref. ${ }^{4}$

Neste cenário foram vislumbradas oportunidades de pesquisa que viessem a contribuir e avançar nestas áreas, ainda pouco exploradas. Os pontos que balizaram nossos objetivos podem ser separados em 4 tópicos, procurando desenvolver principalmente a confecção de materiais e revestimentos especiais para sensores, a química de coordenação destes compostos visando propriedades catalíticas e processos de separação em fase líquida e gasosa. 


\subsubsection{Revestimentos e Filmes Finos para Sensores}

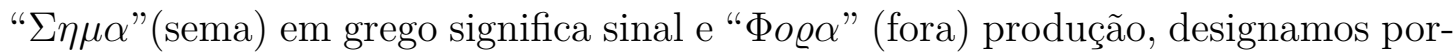
tanto por semióforo, todo material que seja capaz de gerar sinais em determinadas circunstâncias. Estes sistemas químicos comportam-se como chaveadores moleculares, que são capazes de gerar dois ou mais estados lógicos discerníveis por alguma propriedade físicoquímica, de acordo com seu estado de agregação. Neste contexto trata-se de sistemas supramoleculares capazes de formar estruturas organizadas em substratos sólidos, que possam atestar a presença de alguma espécie química ou condição física num gás ou líquido para a montagem de sensores ópticos, elétricos, piezelétricos ou híbridos. Os semióforos devem ser imobilizados em superfícies para que seja possível aproveitar suas propriedades em algum tipo de dispositivo. A imobilização em interfaces moleculares permite dar coerência aos sinais gerados, de maneira que se torne possível utilizá-los e amplificá-los para a nossa escala. A base da maioria dos semióforos que escolhemos são cavitandos; moléculas que, por parte de sua estrutura, delimitam algum tipo de cavidade. Existe uma infinidade de tipos de cavitandos distintos, cada um com suas características próprias, como descrevem com excelência Cram e Lehn ${ }^{100,177,178}$. Uma cavidade implica em um vão, e isto significa imediatamente, a possibilidade de formação de compostos de inclusão, cuja formação é governada essencialmente por fatores estéricos e interações moleculares específicas, que já descrevemos na introdução. Pensando no caso das cucurbiturilas, deveriamos encontrar métodos de imobilização que gerassem filmes que mantivessem as cavidades disponíveis para a inclusão/complexação de diversos analitos de interesse como por exemplo:

- Íons simples e complexos de metais e outros elementos (como o Ba, Zn, As, U, V, $\mathrm{Sn}, \mathrm{Se}, \mathrm{Ni}, \mathrm{Pb}, \mathrm{Mn}, \mathrm{Hg}, \mathrm{Cu}, \mathrm{Cr}, \mathrm{Cd}, \mathrm{Bi}, \mathrm{Be})$.

- Gases como o $\mathrm{I}_{2}, \mathrm{Br}_{2}, \mathrm{Cl}_{2}, \mathrm{O}_{3}, \mathrm{NO}, \mathrm{NO}_{2}, \mathrm{SO}_{2}, \mathrm{CO}, \mathrm{CO}_{2}, \mathrm{NH}_{3}$ e $\mathrm{H}_{2}$ entre outros

- Moléculas orgânicas como 1,1 e 1,2-dicloroetano, 1,1,2-tricloretano, 2-metilfenol, acetona, ascarel, benzeno, BHC ou hexaclorocicloexano ou Lindano, DDT ou dicloro Difenil Tricloroetano, Dioxinas, heptacloro e drins (Aldrin, Endrin, Isodrin, Dieldrin), hexaclorobenzeno, MTBE ou metil tert-Butil Éter, PCB ou Bifenis Policlorados, Pentaclorofenol (ou Pó da China), Tolueno além de drogas ilícitas.

Para se obter revestimentos adequados tanto para eletrodos quanto para materiais ópticos ou piezzelétricos deveríamos atender a alguns pré-requisitos essenciais. O primeiro ponto é que deveríamos ser capazes de obter filmes finos e extremamanete regulares. Em outras palavras, ser capazes de recobrir a totalidade de uma superfície sem deixar espaços não recobertos, e com a mesma quantidade de material em qualquer ponto da superfície. O ideal na maioria dos casos é obter monocamadas. Outro ponto importante é desenvolver métodos com alta reprodutibilidade, como em qualquer processo. Da mesma forma, esta 
reprodutibilidade é desejável com métodos simples. Existem inúmeras formas de se produzir filmes, sejam por deposição de vapor, a partir de solução ou ainda por reações químicas de superfícies, ancoragem, filmes de Langmuir-Blodgett entre muitas outras. Os métodos mais simples no entanto, são geralmente aqueles que utilizam soluções depositadas em superfícies por dip-coating (método de imersão) ou spin-coating (espalhamento por força centrífuga). Estes métodos são rápidos, simples, baratos e confiáveis para produção em larga escala por exemplo.

Para que fossem viáveis sensores com cucurbiturilas seria necessário imobilizá-las na superfície dos transdutores. Para isto poderíamos criar derivados com algum ponto de ancoragem em superfícies, criar filmes fisiossorvidos, ou ainda utilizar alguma matriz inerte como suporte. O primeiro caso se mostrava pouco viável uma vez que seriam necessárias funcionalizações axiais das cucurbiturilas, o que era sabidamente muito complicado, às vezes até inviável. Os dois outros métodos seriam possíveis. Este é um dos pontos que desenvolvemos nos últimos anos que apresentaremos nesta tese.

\subsubsection{Compostos de Coordenação com Ácidos Duros}

Durante estes últimos dez anos procuramos preparar compostos de coordenação, e não simples adutos como existiam na época, utilizando íons como $\mathrm{V}^{4+}, \mathrm{V}^{5+}$ e $\mathrm{Cr}^{5+}$ além de compostos com $\mathrm{Fe}^{3+}$. A escolha destes cátions é estratégica. Precisavamos de cátions de metais de transição $d$, que tivessem propriedades eletrônicas e catalíticas interessantes, e que fossem ácidos duros de Pearson ${ }^{179}$, já que a coordenação se daria por átomos de oxigênio, conhecidas bases duras. A tarefa ainda é mais restritiva quando pensamos em termos de geometria do ligante, uma vez que seus pontos de coordenação estão situados no mesmo plano, em simetria $D_{6 h}$ para a $\beta$-CB $[\mathbf{6}]$. A idéia de formar compostos de coordenação com as cavidades repousa no fato da própria cavidade ser um seletor molecular, permitindo que apenas alguns tipos de molécula se aproximem do centro metálico para interagir com o mesmo e eventualmente sofrer reação catalítica (fig. 8). Não se sabia ao início de nossos estudos se este modelo era viável nem tampouco como preparar este tipo de composto.

É sabido que alguns compostos de vanádio são catalisadores para diversas reações de oxidação e que outros atuam de maneira similar à insulina no organismo, o que tem aumentado o interesse pelos complexos do metal. Muito controverso no entanto é o mecanismo de certas reações catalíticas, envolvendo o íon $\mathrm{VO}^{2+}$ em particular. Não se sabe ao certo de o oxigênio do íon participa diretamente ou não das reações de oxidação de alcanos a alcoóis por exemplo. A geometria de coordenação deste íon é tipicamente $\mathrm{C}_{4 v}$, formando assim pirâmides de base quadrada com número de coordenação do metal igual a 5. Limitando o acesso de reagentes na base da pirâmide, poderíamos dizer se o oxigênio 


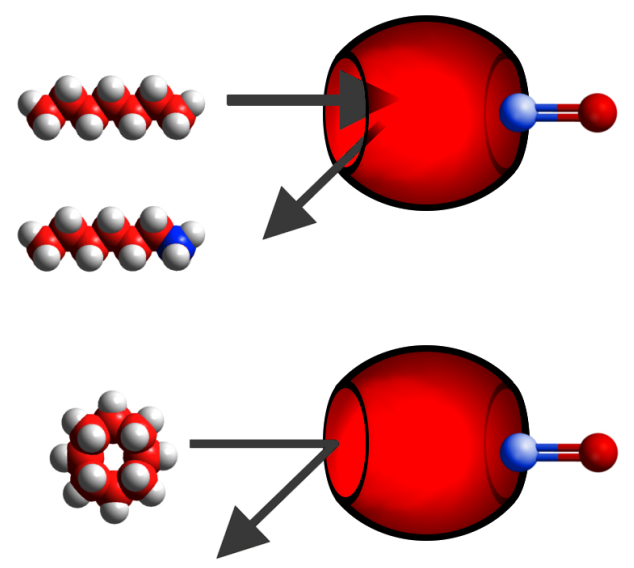

Figura 8: Esquema de restrição de acesso de substratos ao centro metálico coordenado a uma molécula de $\mathrm{CB}[6]$.

está ou não envolvido nestas reações de oxidação.

\subsubsection{Nanoestruturas e Nanomateriais}

Outro ponto de interesse era utilizar as cavidades de CB[n] para a preparação de nanopartículas e pontos quânticos, de maneira similar ao que fez Corma e seu grupo, que conseguiu preparar nanopartículas dentro de suas cavidades ${ }^{180}$. A idéia no entanto era utilizar componentes binários, em especial iodetos e óxidos metálicos na tentativa de criarmos pontos quânticos, já que estes apresentam propriedades físicas bastante interessantes para a eletrônica, medicina e óptica. Da mesma forma, pensamos nas cucurbiturilas como elementos estruturais de compostos de intercalação híbridos, chamados também de nanocompósitos, pois além de possibilitarem a preparação de matrizes lamelares pilarizadas, também poderiam atuar como matrizes de inclusão dentro destes materiais, sendo assim matrizes de inclusão dentro de matrizes de intercalação. Raros são os materiais deste tipo na literatura, e não existiam até então com cucurbiturilas. Apresentaremos aqui alguns resultados obtidos por nosso grupo de pesquisa.

\subsubsection{Métodos de separação e meios sequestrantes}

Uma vertente essencial de nosso plano de pesquisa repousa no desenvolvimento de processos e tecnologias que utilizem a seletividade por tamanho e afinidade das cucurbiturilas para o tratamento de misturas gasosas e líquidas. Em princípio poderíamos pensar em diversas possibilidades para utilizar as características das cucurbiturilas para separar espécies em misturas. Procuramos empregar as cucurbiturilas como canais moleculares por onde algumas espécies químicas pudessem passar, outras lá ficariam retidas, e outras nem sequer viriam a interagir. Isto seria particularmente interessante quando pensamos em matrizes complexas, soluções líquidas ou gasosas contendo diversos componentes. Pre- 
parando fases estacionárias ou interfaces químicas apropriadas, poderíamos tratar uma série de problemas e criar interfaces que fossem:

1. Barreiras semipermeáveis sólidas, que constituiriam receptáculos para gases pelos quais espécies químicas de tamanho adequado pudessem permear e espécies maiores continuassem confinadas.

2. Barreiras semipermeáveis sólidas separando meios líquidos distintos, pelas quais determinados solutos e/ou solventes pudessem permear retendo outros.

3. Revestimentos eletródicos separando meios líquidos de condutores eletrônicos (no caso eletrodos) mediando processos de migração e transferência eletrônica de forma seletiva.

4. Revestimentos para materiais ópticos, separando meios gasosos e líquidos, e que permitam que apenas algumas espécies atinjam e se liguem reversivelmente à interface sólida.

5. Meios sequestrantes, que são na verdade meios que capturam determinadas espécies de um determinado meio transferindo-os de uma fase líquida ou gasosa para outra fase, de preferência sólida. Misturas gasosas onde diversas espécies coexistem podem ser enriquecidas em determinados componentes por remoção seletiva de outras do mesmo meio.

Esperavamos portanto que seria possível criar barreiras semipermeáveis a diversas espécies, vislumbrando diversas aplicações como purificação de água, separadores eletrolíticos e purificação de gases de interesse industrial.

Esta foi a principal motivação de nossa linha de pesquisa principal, que obteve êxito em muitas destas propostas. Nesta tese serão apresentados alguns exemplos mais importantes, infelizmente não todos, que pudemos desenvolver por quase dez anos até agora. 
Parte III

Resultados 


\section{Interfaces Químicas Baseadas em Cucurbi- turilas}

\subsection{Filmes Finos}

Moléculas ocas em forma de barris rígidos são muito úteis quando se pensa na criação de sensores químicos e filmes com propriedades ópticas interessantes. No caso de sensores, sejam eles ópticos, piezelétricos ou eletroquímicos elas podem atuar como receptores de analitos na interface de transdutores diversos como prismas de Otto-Kretschmann, cristais piezelétricos ou eletrodos de diversos tipo, desde que haja algum modo de imobilizá-los a estas superfícies. A inclusão total ou parcial de espécies químicas nas cavidades imobilizadas, altera uma série de propriedades das interfaces, como por exemplo índice de refração (importante para RPS), coloração (caso o analito tenha cromóforos ou seja solvatocrômico), a massa adsorvida (piezelétricos), os potenciais redox da interface, a capacitância ou condutividade, enfim: quase todas as propriedades da superfície são alteradas. Estas variações podem ser entendidas como sinais, que podem ser analisados por transdutores que os convertam geralmente para sinais elétricos e depois amplificados e percebidos pelo ser humano.

Os sensores químicos têm quase sempre a mesma anatomia. A primeira "camada"do sensor é aquela onde ocorre o evento molecular, por qualquer tipo de interação específica com uma classe de moléculas especial: os semióforos. Um semióforo, tem a função de traduzir este evento molecular em algum tipo de sinal por variação ou criação de alguma propriedade físico-química. São geralmente sistemas complexos, que podem ir desde enzimas até polímeros. Falamos de semioquímica, reconhecimento molecular e química supramolecular. Este sinal raramente é transformado diretamente em algo legível ou mensurável, precisa ser amplificado e freqüêntemente transformado em outro tipo de sinal. Utilizamos então interfaces físicas que fazem este trabalho, e que condicionam o sinal para a última etapa da realização do sensor. Este nível é análise fisico-química, e geralmente é realizado com auxílio da eletroquímica ou da espectroscopia. Por fim existe um aparato que converte o sinal da interface física em algo inteligível para o homem. Pode ser um registrador, computador ou outro meio qualquer. Estamos falando aqui de instrumentação.(Figura 9)

Como já dissemos anteriormente, "Sema"em grego significa sinal e "fora"produção, designamos portanto por semióforo, todo material que seja capaz de gerar sinais em determinadas circunstâncias. A imobilização em interfaces moleculares permite dar coerência 


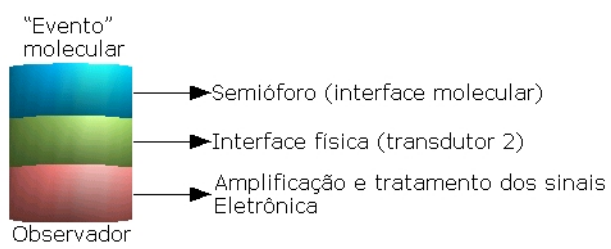

Figura 9: Diagrama que descreve a estrutura funcional dos sensores químicos.

aos sinais gerados, de maneira que se torne possível utilizá-los e amplificá-los para a nossa escala. Para utilizar cucurbitandos com esta finalidade temos de encontrar meios de imobilizá-los. Existem basicamente 3 métodos de simples para realizar esta tarefa. A primeira seria imobilização por ligações covalentes, ligando ao macrociclo algum grupo âncora. Estes podem ser dos mais variados, como tióis, aminas, carboxilatos, silanóis etc...(figura 10) Deveríamos para isto funcionalizar os CBs, pois são totalmente inertes. Pensando nisto alguns autores descreveram um maneira de criar derivados partindo de seu derivado peridroxilado - $(\mathrm{OH})_{2 n} \mathrm{CB}[\mathrm{n}]$ - obtido a partir do macrociclo e persulfato de potássio. Seria ótimo se fosse possível prepará-lo conforme a descrição na literatura. Por mais de 15 vezes tentamos reproduzir a síntese que simplesmente não funciona ${ }^{9,11}$. Os autores se esquivam em dar explicações mais detalhadas.

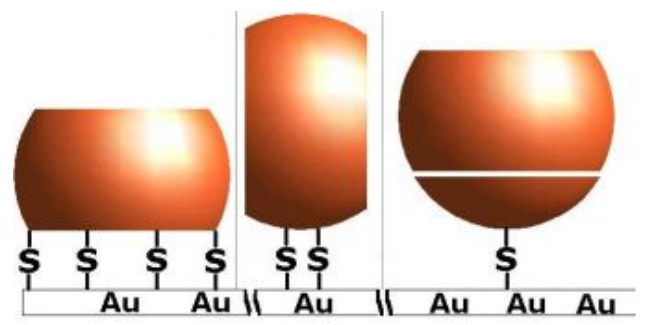

Figura 10: Imobilização de cucurbitandos em superfícies de ouro, utilizando grupos âncora. O terceiro caso utiliza "tampas"modificadas com âncoras, no caso aqui grupo tiol.

A segunda maneira, seria imobilização indireta, onde utilizaríamos uma matriz, que pode ser um polímero, um sólido ou gel, insolúvel no qual os macrocilcos estariam dispersos, sem orientação específica. A terceira maneira seria por adsorção simples na superfície, o que não garante ligações fortes, mas garante uma orientação bem determinada (fig. 11). Durante nossas pesquisas exploramos estes dois métodos de imobilização. Obtivemos filmes finos por adsorção e polímeros especiais com estes macrociclos.

A preparação de filmes finos de cucurbit[n]urilas é uma tarefa extremamente complicada uma vez que são praticamente insoluveis em quaisquer solventes, tornando sua deposição sobre qualquer substrato impossível por técnicas convencionais em solução. A preparação de filmes no entanto deve ser controlada a ponto de se obter uma morfologia desejada, e técnicas mais acessíveis como o spin-coating ou dip-coating não permitem muito controle sobre a morfologia destes filmes. O maior interesse na preparação de filmes 


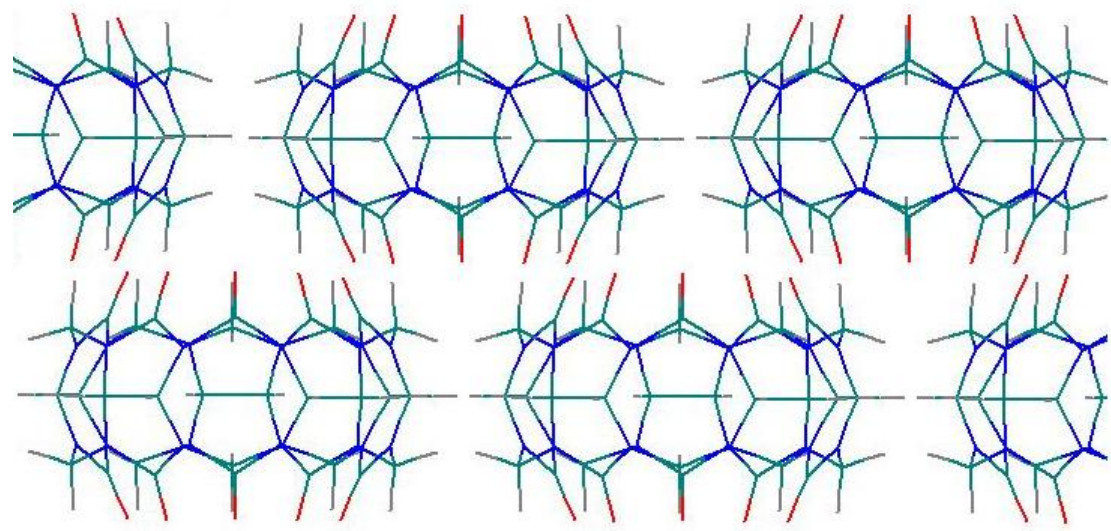

SUBSTRATE

Figura 11: Representação esquemática de imobilização axial de cucurbiturilas em superfícies.

de $\beta$-CB $[6]$, é o fato de tornarem possível a formação de estruturas parecidas com favos de colméia sobre superfícies planas. Isto significa que o macrociclo pode ficar deitado sobre a superfície com um de seus opérculos voltados para cima. Desta forma, seria capaz de interagir com espécies químicas diversas nesta nova interface molecular. Este é o ponto de partida para sua utilização na qualidade de receptores sintéticos para sensores químicos, como sensores potenciométricos por exemplo. As primeiras tentativas de se recobrir lâminas de vidro com CB[6] de maneira uniforme, partindo de suspensões aquosas ou ainda de soluções em ácido fórmico deram origem a filmes irregulares e opacos. Ficou evidente que o macrociclo estava fracamente adsorvido à superfície do substrato e que seria difícil um controle de morfologia destes filmes. É sabido no entanto que os íons $\mathrm{NH}_{4}^{+}$

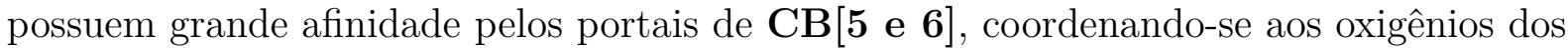
grupos carbonila presentes nestes portais ${ }^{96,148,181}$. Não é raro observar, decorrente disto, aumentos consideráveis de solubilidade dos cucurbitandos em meios salinos. Desta forma, preparamos soluções saturadas de $\beta$ - $\mathbf{C B}[6]$ em $\mathrm{NH}_{4} \mathrm{OH}(35 \% \mathrm{~m} / \mathrm{m})$ sob agitação por 48 horas. Com isto esperamos obter os complexos $\left[\left(\mathrm{NH}_{4}\right)_{1-2}(\beta-\mathbf{C B}[\mathbf{6}])\right]^{1-2+}$, bastante solúveis em água. Optamos então por utilizar ao invés de suspensões am água, soluções do complexo de $\mathbf{C B}[\mathbf{6}]$ com íons amônio afim de conseguir obter filmes regulares e transparentes. Esta escolha se justifica uma vez que o macrociclo possui uma alta afinidade por metais alcalinos, alcalino-terrosos e íons amônio formando complexos muito estáveis com estes íons. Desta forma é possível colocá-los em solução devido à sua carga e produzir soluções concentradas o bastante para a produção de filmes por "dip coating". Para o preparo destas soluções foram misturados sob agitação 1,0 g de CB[6] em $100 \mathrm{~mL}$ de $\mathrm{NH}_{4} \mathrm{OH}$ aquoso (a $35 \%$, Synth) por 48 horas. A partir deste ponto, o excesso de CB[6] é removido por filtração e ar comprimido é borbulhado no filtrado por 6 horas em um erlenmeyer, afim de remover o excesso de $\mathrm{NH}_{4} \mathrm{OH}$ na forma de $\mathrm{NH}_{3}$. Após este período a solução começa a ficar turva e é filtrada uma vez mais dando origem a um filtrado que 
contém aproximadamente $1.09 \mathrm{~g} / \mathrm{L}$ de $\mathrm{CB}[6]$, que pode ser armazenado à temperatura ambiente desde que em frasco fechado. Preparamos diversos filmes sobre eletrodos de 1 $\mathrm{cm}^{2}$ de vidro condutor de FTO (fluorine dopped tin oxides galss electrodes) utilizando a técnica de dip-coating em diversas velocidades que iam de 1 a $300 \mathrm{~mm} . \mathrm{s}^{-1}$. Procurando as condições ideais de produção destes filmes, utilizamos a solução amoniacal em diversas diluições também $(1 / 4,1 / 3$ e $1 / 2)$.

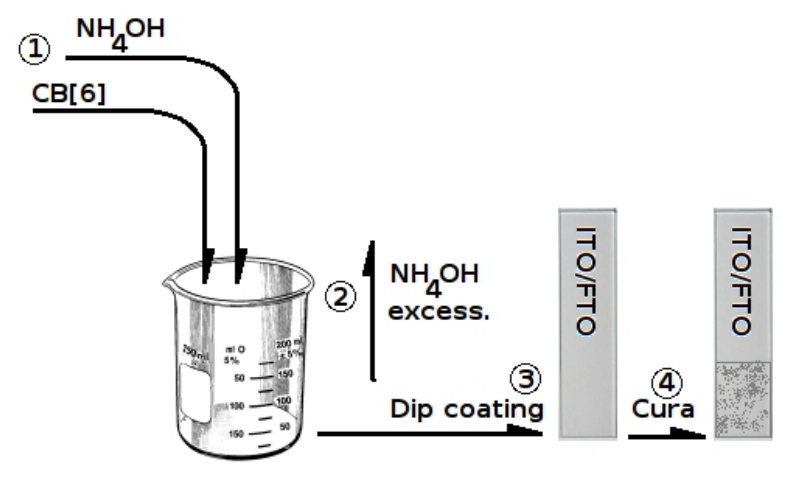

Figura 12: Processo de obtenção de monocamadas de $\beta$-CB[6] pelo método do hidróxido de amônio.

Dentre todas as tentativas, os melhores resultados foram obtidos utilizando o licor mãe puro e puxando filmes a $5 \mathrm{~mm} \cdot \mathrm{seg}^{-1}$ ou menos. Desta forma observamos que é possível depositar camadas sucessivas de $\beta$ - $\mathbf{C B}[6]$, desde que os ions $\mathrm{NH}_{4}^{+}$fossem removidos dos opérculos dos macrociclos entre cada deposição, prevenindo desta forma que retornem à solução por lixiviação, em banhos sucessivos. A maneira mais simples de remover estes íons dos opérculos é por aquecimento simples dos filmes a $100^{\circ}$ por 10 minutos. Desta forma, decompomos o hidróxido de amônio em $\mathrm{H}_{2} \mathrm{O}$ e $\mathrm{NH}_{3}$, que pelo fato de ser neutro, apresenta menos afinidade com os portais, deixando os rapidamente. Depois deste tratamento térmico obtivemos filmes de $\beta$ - $\mathbf{C B}[6]$ totalmente transparentes com sítios livres para ligarem-se a analitos em sensores por exemplo. O mesmo processo realizado utilizando ouro como substrato ao invés de vidro FTO. Neste caso, não conseguimos recobrir mais do que $25 \%$ da superfície do metal na melhor das hipóteses como nos revelaram os resultados de microgravimetria de cristal de quartzo. Com auxílio desta técnica procuramos correlacionar as variações de massa que medimos por unidade de área dos cristais piezelétricos, com todas as possibilidades em termos de conformação da $\beta$-CB[6] e seus sais de amônio, sejam elas a 90 graus ou deitadas, com os opérculos para cima (tabela 5).

Espectros de reflexão total atenuada na região do infravermelho (ATR), fig. 13, mostram a presença de vários modos vibracionais típicos do $\beta$ - $\mathbf{C B}[\mathbf{6}]$ por exemplo as bandas das carbonilas em $1732 \mathrm{~cm}^{-1}(\nu \mathrm{C}=\mathrm{O})$, uma em 1639, e outras mais em 1477 ( $\nu$ $C-N), 1417,1376$ e $1322 \mathrm{~cm}^{-1}$ ) o que demonstra a presença dos macrociclos na superfície analisada. 


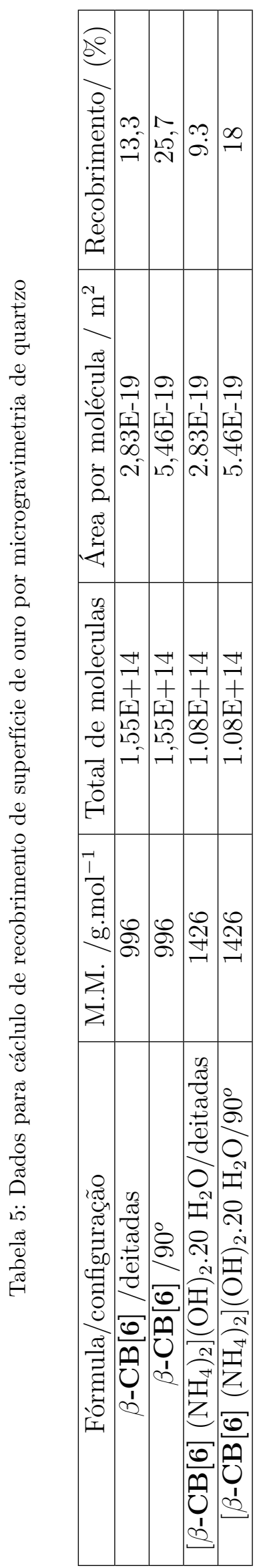




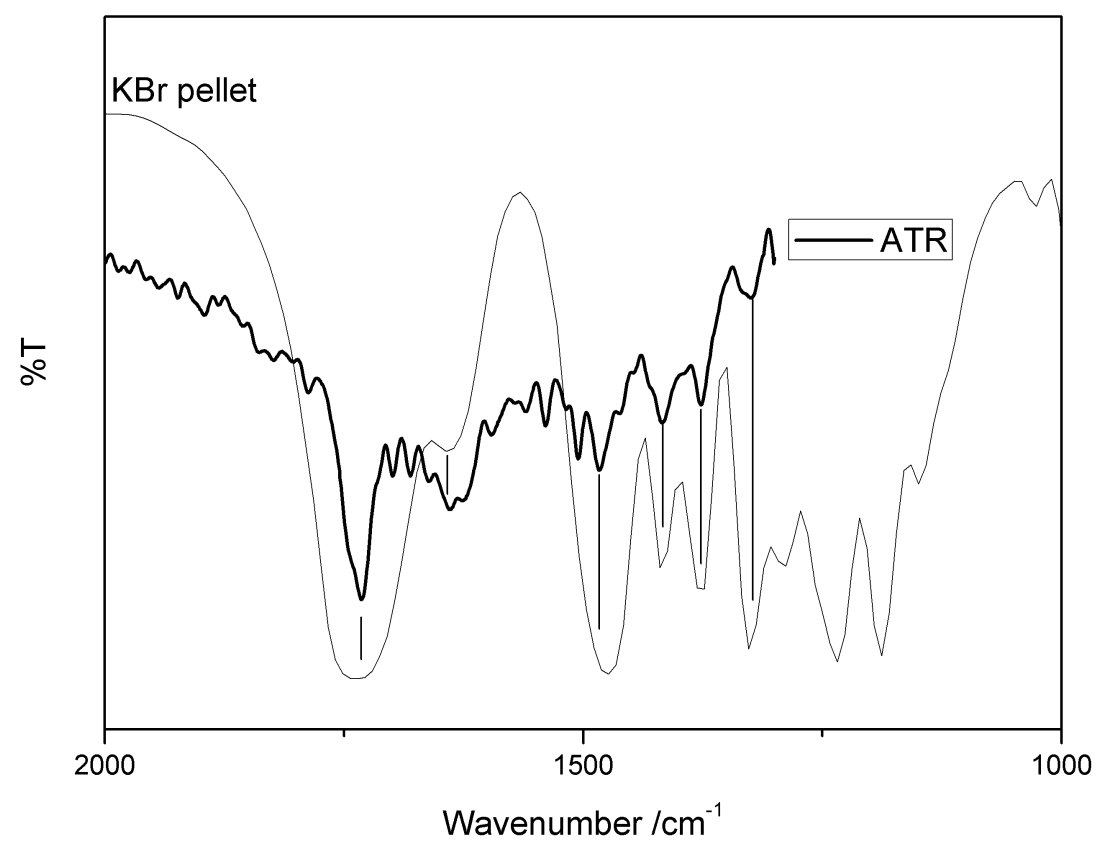

Figura 13: Espectro vibracional de reflectância total atenuada (ATR) de um dos filmes sobre FTO - linha cheia- comparado ao espectro vibracional convencional da $\beta$-CB $[6]$ em pastilha de $\mathrm{KBr}$.

Medidas de ângulo de contato demonstram que a superfície modificada com o macrociclo se torna mais hidrofóbica passando de ângulos de 29,5 para o vidro limpo a $44^{\circ}$ sobre um filme de 3 camadas de $\beta$-CB $[6]$. Apesar da presença de átomos de hidrogênio que tenderiam a favorecer as ligações com moléculas de água, devemos lembrar que existem vãos na estrutura, que podemos considerar como "vãos hidrofóbicos", já que neles não há possibilidade de se formarem ligações de hidrogênio, o que poderia explicar este aumento de hidrofobicidade da superfície de alguma forma. A $\beta$ - $\mathbf{C B}[6]$ não possui cromóforos na região do UV-visível convencional e esta é a razão pela qual não podemos utilizar a espectroscopia eletrônica sem algum corante para estimar sua quantidade sobre os slides de vidro. Decidimos utilizar para isto o azul de metileno (AM), que é capaz de interagir com os opérculos e oferecer um meio de quantificação indireto, utilizando espectrofotometria UV-visível (figura 14).

Afim de corar os filmes imergimos uma placa de vidro sem modificador e outra recoberta com 3 camadas de $\beta$ - $\mathbf{C B}[\mathbf{6}]$ em uma solução aquosa de $\mathbf{A M}$ a $9,35.10^{-5}$ mol.dm ${ }^{-3}$, à temperatura ambiente por 30 minutos. Os filmes continuaram imersos por mais tempo e medidas de absorção foram realizadas e 1, 10 e 960 minutos. Observa-se visualmente em um primeiro momento, que o vidro modificado retém mais AM do que o vidro limpo, e que a adsorção do corante em ambos os substratos é muito rápida, bastando apenas 10 minutos para que se atinja o equilíbrio. No caso do filme de $\beta$-CB[6] nota-se uma quantidade de dímeros de AM adsorvida bem maior do que no caso do vidro sem modificador. Isto é verificado por espectrsocopia UV-vis, onde distinguimos claramente as 


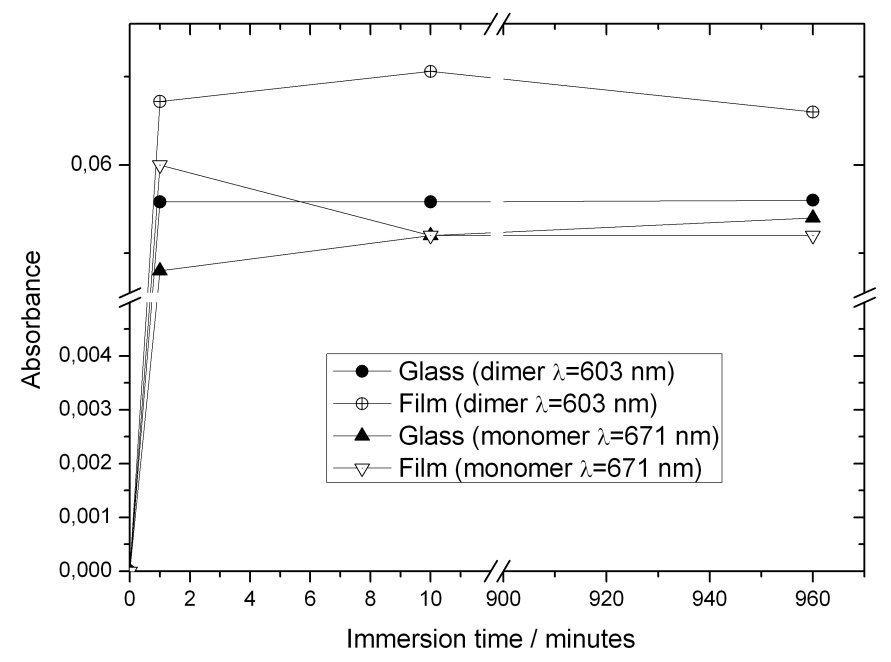

Figura 14: Absorção dos cromófors do monômero e do dímero de azul de metileno (AM) adsorvidos na superfície de um filme de $\beta-\mathrm{CB}[6]$.

bandas de monômero (em $671 \mathrm{~nm}$ ) e dímero (em $603 \mathrm{~nm})^{182-184}$. Podemos inferir portanto que a orientação relativa das moléculas de $\mathbf{A M}$ na superfície do vidro é diferente daquela adotada no substrato modificado. Tudo indica que a espécie monomérica de azul de metileno se reorienta sobre o substrato modificado para formar dímeros, explicando assim o aumento de dímeros que é proporcional à diminuição de monômeros adsorvidos (fig.14). Este fenômeno pode ser explicado com base em diferenças de morfologia da interface, que no caso do $\beta$-CB[6] direciona e favorece topotaticamente a formação destes dímeros.

Por um cálculo simples utilizando o método semi-empírico PM3 no vácuo, é possível demonstrar que o tamanho dos dímeros, mais específicamente, a distância entre os dois radicais iônicos distais $=\mathrm{NH}^{2+}$, corresponde exatamente à distância entre os centros de dois opérculos de $\mathrm{CB}[6]$ adjacentes num arranjo do tipo colméia de abelhas. Este fato explica porquê a adsorção de AM sobre a superfície modificada ocorre em duas etapas: Numa primeira etapa são adsorvidos monômeros que tendem a se associar posteriormente a outras moléculas de AM afim de formarem dímeros. Nesta condição conseguem maximizar a interação das aminas catiônicas com os opérculos dos macrocilcos. Uma representação destas interações consta na figura 15.

Dados de impedância eletroquímica destes filmes mostram um comportamento típico de um circuito equivalente do tipo RC (resistor e capacitor), mas não é possível estabelecer uma relação entre a capacitância total do filmes $\left(C_{\text {total }}\right)$ com a espessura dos filmes o que indica que a superfície não é totalmente bloqueante como se esperaria de um dielétrico perfeito, ou ainda que o filme apresenta imperfeições. Esta falta de correlção, pode ser explicada de várias formas. Podemos entender que os filmes não são perfeitamente regulares, podendo apresentar falhas, ou trincas o que é comum durante o processo 


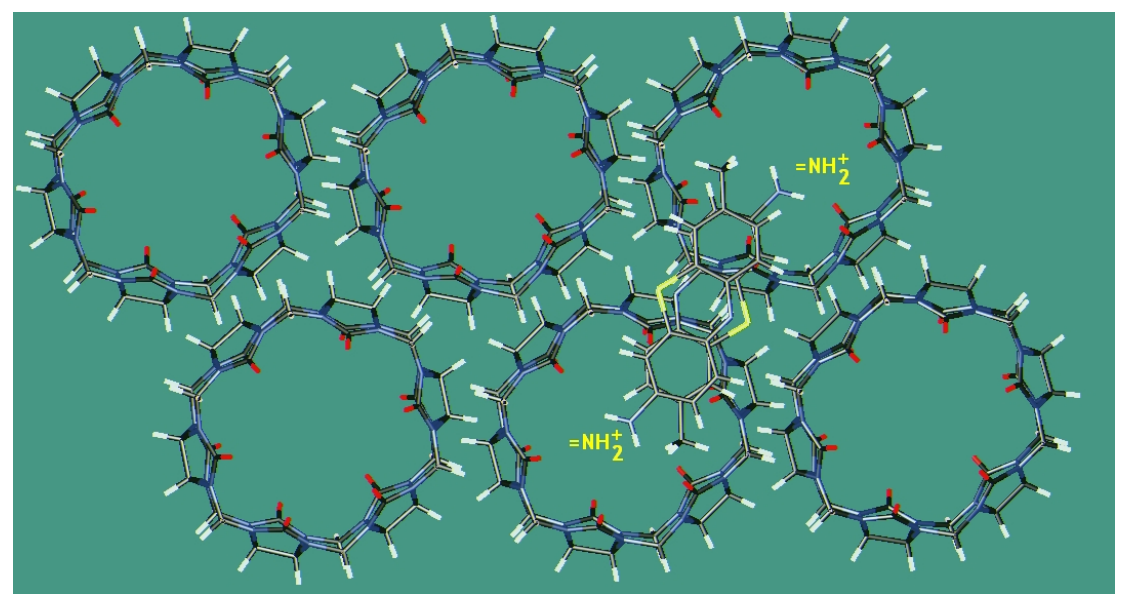

Figura 15: Estrutura do aduto superficial de azul de metileno (AM) com os opérculos de CB[6] facilitando a formação de dímeros do corante.Estrutura obtida por métodos semi-empírico PM3.

de secagem de solventes. Outra razão que explicaria seria uma certa permeabilidade dos filmes a íons, proveniente do eletrólito de suporte, o que também comprometeria o comportamento da barreira como dielétrico puro, introduzido um termo resistivo no circuito em paralelo com o capacitor. Seria o análogo a um capacitor com fuga. Finalmente, devemos levar em conta a regularidade da interface externa dos filmes, isto é, se a superfície é lisa ou rugosa, o que leva a aumentos significativos da área das interfaces. Todos estes fatores podem ter comprometido as tentativas de se correlacionar $C_{\text {total }}$ com a espessura dos filmes (figura 16).

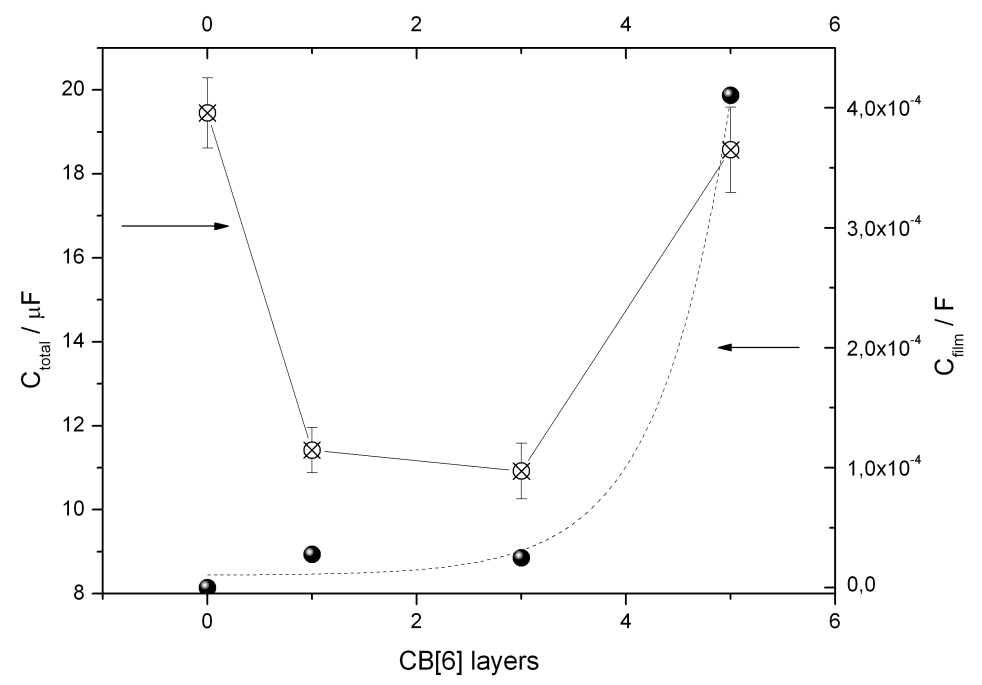

Figura 16: Dispersão dos valores de $C_{\text {total }}$ em função do número de camadas de deposição de $\beta-\mathbf{C B}[6]$.

O método mais indicado para se estudar o problema é a microscopia de força atômica (MFA), utilizada para analizar a região de borda dos filmes. Desta forma podemos 
medir sua espessura. Isto foi feito com um filme de 5 camadas de CB[6], já que uma só poderia ser muito fina para a medida, do qual varremos a borda com a sonda de prova. Analisando o perfil de corrida da sonda, foram observadas espessuras entre 3,6 e 4,6 nm e todas as regiões regulares do filme, tinham espessuras múltiplas de 9 Å. O último nível, quase rente ao eletrodo tinha espessuras de de $\sim 9 \AA$, o que corresponde exatamente à distância entre os portais de oxigênio da $\beta-\mathbf{C B}[6]$.

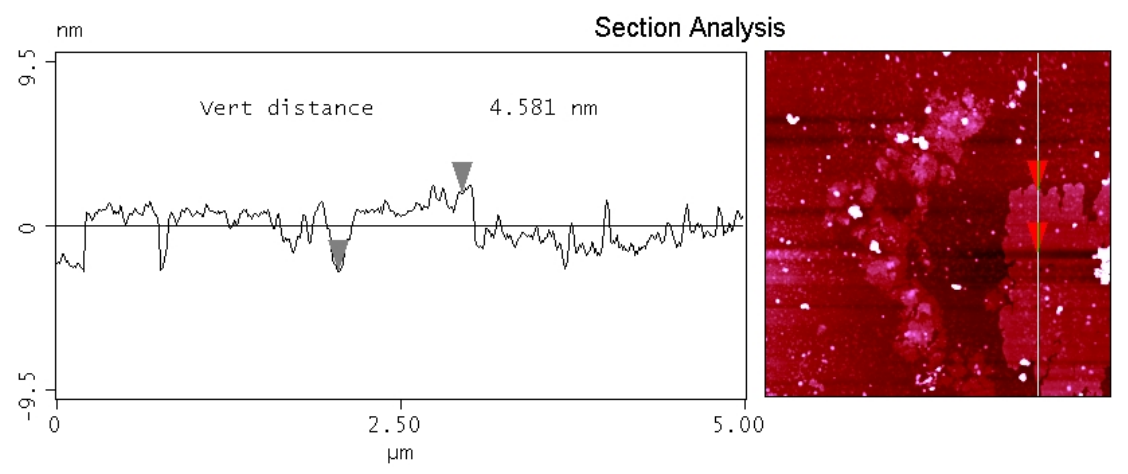

Figura 17: Análise de seção transversal por MFA da região de borda de um filme de $\beta$-CB[6] obtido pelo método da amônia.

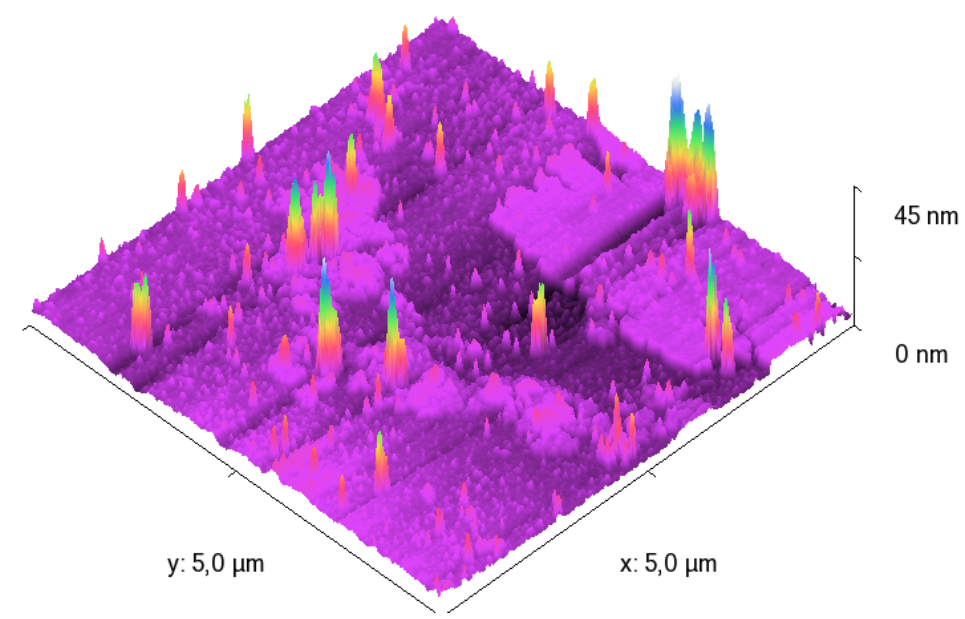

Figura 18: Micrografia por MFA da região de borda do filme de $\beta$-CB[6] da figura anterior.

Mostramos desta forma que formamos filmes bastante homogêneos sobre substratos não metálicos, em sucessivas monocamadas e que estas camadas possuem uma estrutura do tipo favo de colméia, como desejávamos no início. Este sem dúvida foi o primeiro trabalho em que se demonstrou que é possível obter monocamadas de $\beta$-CB[6] sobre diversos substratos, sobre os quais repousam as moléculas do macrociclo na posição vertical, com seus opérculos orientados em paralelo ao plano, sendo que esta conformação é essencial para aplicações nas quais os macrociclos ajam como receptores moleculares. Desta maneira desenvolvemos uma maneira prática, rápida e barata para preparar filmes da ordem de monocamada para os mais diversos fins, como sensores por exemplo. 
Esta técnica funciona muito bem em substratos como o vidro e o FTO. Funciona também, mas gerando filmes menos regulares, sobre ouro. Este procedimento resolve um dos maiores problemas em se imobilizar $\beta$-CB[6] e outras cucurbiturilas sobre superfícies. É possível estender este tipo de procedimento para outros veículos, desde que sejam sais que possam ser decompostos pelo calor como o $\mathrm{NH}_{4} \mathrm{HCO}_{3}$, por exemplo. Alguns meses depois de nossa publicação ${ }^{185}$, um grupo chinês conseguiu criar monocamadas sobre ouro por adsorção simples, deixando o metal imerso em soluções do macrociclo por tempos prolongados $^{186}$.

\subsection{Materiais eletródicos}

Por conta dos resultados de impedância que obtivemos no trabalho descrito acima, chegamos à conclusão que íons teriam tendência a taravessar uma barreira constituída por $\beta$-CB[6] , seja pelos alvéolos, seja pelos interstícios de uma estrutura alveolar que geramos. Alguns anos antes, num artigo extremamente importante de Kim e seu grupo ${ }^{187}$, foi que íons alcalinos permeavam seletivamente pelo lúmen do $\beta-\mathbf{C B}[\mathbf{6}]$ e do $\alpha-\mathbf{C B}[5]$ na seguinte ordem $\mathrm{Li}>\mathrm{Cs}=\mathrm{Rb}>\mathrm{K}>\mathrm{Na}$ para o $\beta-\mathrm{CB}[\mathbf{6}]$ e $\mathrm{Li}>\mathrm{Na}=\mathrm{K}=\mathrm{Cs}=\mathrm{Rb}$ para o $\alpha-\mathrm{CB}[5]$ quando há contra-fluxo de prótons. Este resultado é interessante, uma vez que percebemos que estes íons formam complexos lábeis com as CBs e que esta ordem é quase sempre inversamente proporcional à constante de formação dos complexos ${ }^{151}$.

Considerando agora a segunda alternativa de imobilização de CBs, aquela em que seriam imobilizados em uma matriz rígida, optamos por dispersá-las em soluções de polímeros como o PVC, PU, e o PVDF, que depois de sêcas daria origem a condutores iônicos. Em analogia ao Nafion, batizamos este tipo de polímero de Cubion. Distribuidas alaetoriamente na matriz sólida, esperavamos que de alguma forma, e a partir de alguma concentração, houvesse a criação de canais de permeação para íons e espécies químicas pequenas como gases por exemplo como representado na figura 19. Para demonstrar este

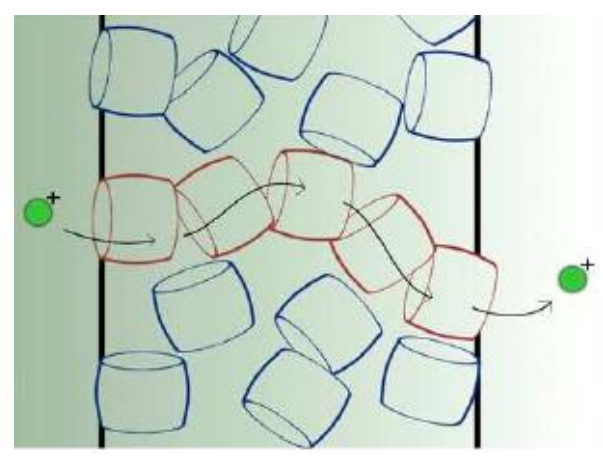

Figura 19: Representação esquemática da permeação de um íons por uma membrana do tipo Cubion. 
conceito, poderíamos forçar a migração destes íons com auxílio de eletrodos. Afim de registrarmos a migração de íons por estes materiais utilizamos uma sonda redox, como é o caso do ferroceno, bem conhecido por seu par redox reversível na voltametria cíclica. Para isto utilizamos uma suspensão a $47 \%$ (massa) de $\beta$-CB[6] e PVC em THF com a qual montamos eletrodos modificados para analisar o comportamento redox desta sonda em água, meio no qual é insolúvel, na presença de eletrólitos de suporte de tamanhos variados. A montagem deste tipo de eletrodo consiste em 3 etapas: Na primeira depositamos uma quantidade pequena e conhecida do analito sobre a superfície do eletrodo. Em seguida depositamos uma pasta composta de polímero (tipicamente PVC) e cucurbit[n]urila (tipicamente $\mathrm{n}=6$ ) em THF. O solvente é removido em seguida por aquecimento a $35^{\circ} \mathrm{C}$ por 15 minutos $^{188}$. Obtemos assim eletrodos modificados, onde as espécies eletroquimicamente ativas são mantidas em contato com o eletrodo e estão recobertas por uma fina camada de material inerte e permeável a íons, o que garante a eletro-neutralidade do sistema no decorrer das medidas (Figura 20).

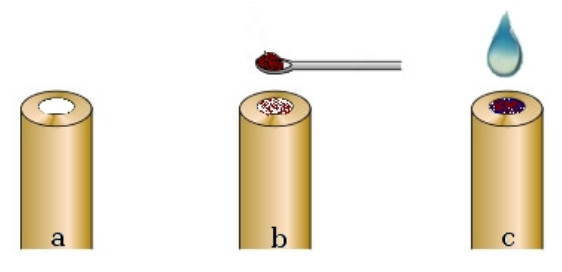

Figura 20: Etapas de montagem: a- eletrodo limpo, b- deposição do material eletroativo, c-recobrimento com a suspensão de Cubion

O fato de mantermos espécies imobilizadas na superfície do eletrodo e não em solução altera alguns parâmetros importantes da análise eletroquímica ${ }^{189}$. As espécies em contato com o eletrodo de trabalho não precisam mais difundir pelo eletrólito para lá transferirem elétrons, portanto o controle difusional da reação eletroquímica é eliminado. Por outro lado, podem existir limitações cinéticas à esta transferência ou ainda uma grande dificuldade de se manter a eletro-neutralidade do sistema imobilizado, quando a permeação de contra-íons do eletrólito é prejudicada pela morfologia do filme. Caso os íons conseguissem migrar pelo filme, observaríamos na voltametria cíclica, perfis bem definidos, que se traduziriam por ondas intensas ( $I_{p a}$ e $I_{p c}$ altos) e pequenos $\Delta E_{p}$. Utilizamos para isto ácidos clorídrico, nítrico e tricloroacético para verificar o efeito do ânion, além de $\mathrm{KCl}$, e $\mathrm{KNO}_{3}$ para estimar o efeito do cátion. A título de comparação fizemos as mesmas medidas utilizando eletrodo de pasta de carbono, muito utilizados para a análise de substratos insolúveis.

A caracterização eletroquímica de compostos químicos insolúveis no eletrólito suporte nem sempre é trivial. Quando são necessários dados desta natureza, recorre-se à montagem de eletrodos quimicamente modificados (EQM), onde as espécies em análises são imobilizadas sobre a superfície do eletrodo de trabalho de alguma forma. A montagem 
destes eletrodos pode recorrer a várias estratégias de imobilização sobre estas superfícies: Pode ser por intermédio de ligações covalentes, onde a superfície do eletrodo é tratada de modo a apresentar grupos funcionais reativos. Estes irão permitir a criação posterior de ligações covalentes com o analito utilizando alguma reação química apropriada, fixando-o à superfície. Também recorre-se à simples adsorção destas espécies (quimiossorção) sobre o substrato condutor onde interações fracas se encarregam de mantê-los presos à superfície condutora. A diferença de solubilidade do analito em diversos solventes pode ser utilizada para este propósito, quando se deposita uma pequena alíquota de solução de analito sobre a superfície do eletrodo em um solvente diferente daquele utilizado para as medidas, onde o analito é insolúvel após a secagem do solvente de preparação. Estes são os comumente chamados de "filmes". É possível combinar estas técnicas como é o caso dos filmes automontados, onde a primeira camada de material é depositada por alguma destes métodos e sobre ela depositam-se outras camadas que possam interagir com a primeira por forças de qualquer natureza. A técnica talvez mais antiga e conhecida, porém menos precisa, consiste na utilização de eletrodos de pasta de carbono, onde o analito é misturado a grafita em pó, o que garante a condutividade do conjunto e onde adiciona-se um agente aglutinante, eletroquimicamente inerte e que garante a coesão dos grãos na forma de uma pasta. Esta pasta é ligada a um contato elétrico formando assim um eletrodo.

A quantidade de material depositada sobre o eletrodo pode ser obtida da integração das ondas voltamétricas de acordo com a equação:

$$
\Gamma=\frac{Q}{n F A}
$$

Onde $\Gamma$ é a concentração superficial em mol.cm ${ }^{-2}$, Q a carga total (integral da onda) n é o número de elétrons envolvidos, F a cste. de Faraday, e A a área do eletrodo.

Num primeiro momento realizamos uma comparação entre eletrodos modificados com ferroceno pelo método da pasta de carbono, e outros também modificados, mas com membrana de Cubion. A respotas em $\mathrm{KCl}$ aquoso $10^{-3}$ molar é bastante interessante, uma vez que pudemos observar as ondas do par ferroceno/ferrocínio para os dois casos (fig. 21). A separação de potenciais de pico , $\Delta E_{p}$, é consideravelmente menor com Cubion (140 $\mathrm{mV})$ do que com pasta de carbono $(220 \mathrm{mV})$. Este é o maior indício de que a migração de contra-íons pelo Cubion é bem mais eficiente do que na pasta de carbono. Variando a velocidade de varredura para este eletrodo, é possível notar que a intensidade dos picos, $I_{p a}$ e $I_{p c}$, é proporcional à velocidade de varredura, o que indica que o ferroceno continua adsorvido à superfície durante os ciclos de voltametria (fig 22).

Foram realizadas diversas medidas para estes eletrodos, variando a composição do eletrólito de suporte. Utilizamos em dois experimentos, $\mathrm{KCl}$ e $\mathrm{HCl}$ a $10^{-3}$ mol.dm ${ }^{-3}$ , onde mantivemos o mesmo ânion cloreto, que é pequeno, e dois cátions pequenos mas de tamanhos distintos. No segundo experimento mantivemos o cátion $\mathrm{H}^{+}$, utilizando áci- 


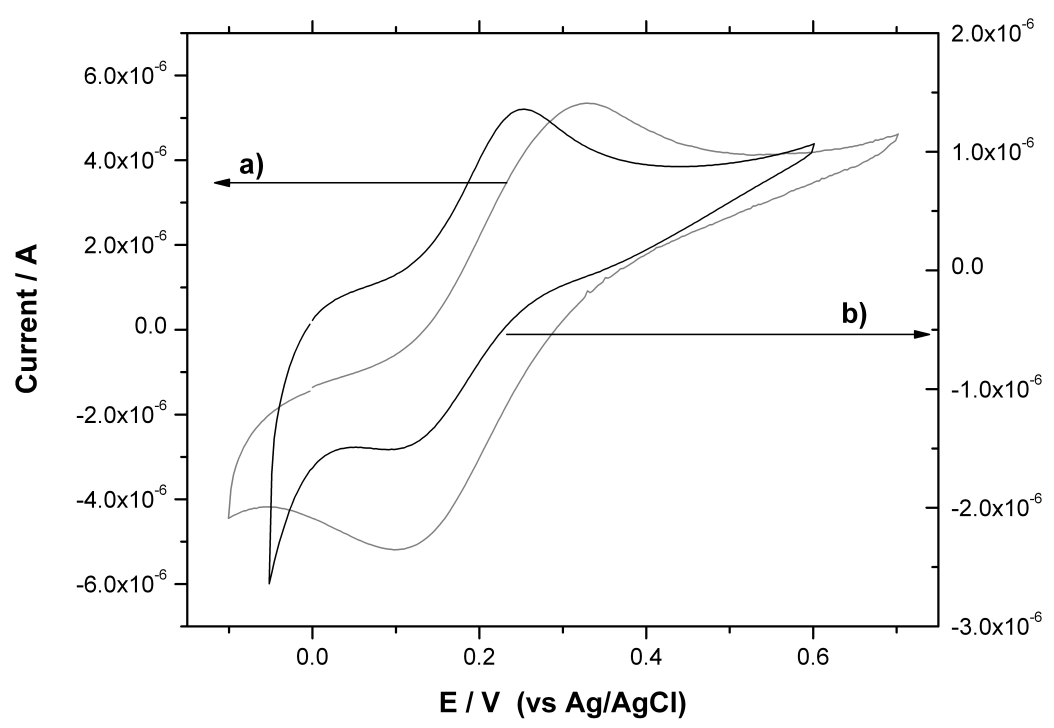

Figura 21: Voltamogramas cíclicos $\left(50 \mathrm{mV} / \mathrm{s}, 10^{\circ}\right.$ ciclo $)$ de eletrodos modificados com ferroceno em a) eletrodo de pasta de carbono $(\Delta E p=220 \mathrm{mV}$ e ferroceno $=0,0107 \mathrm{~g})$, (b) utilizando Cubion de CB[6]/PVC a $47 \%(\Delta E p=140 \mathrm{mV}$ e ferroceno $=0,0024 \mathrm{~g}) \mathrm{em} \mathrm{KCl}$ $10^{-3}$ mol.dm ${ }^{-3}$

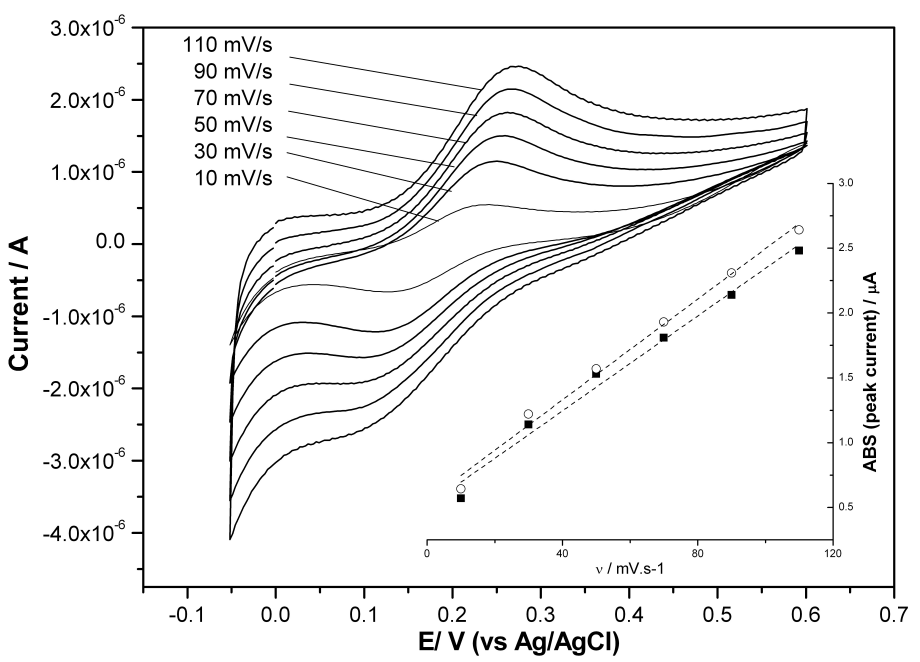

Figura 22: Voltamogramas do EQM de Ferroceno/Cubion em diversas velocidades de varredura em KCl $10^{-3}$ mol.dm ${ }^{-3}$. 
dos e ânions de tamanho diferentes, nas mesmas concentrações. Os resultados mostram diferenças significativas no comportamento dos eletrodos (fig. 23).

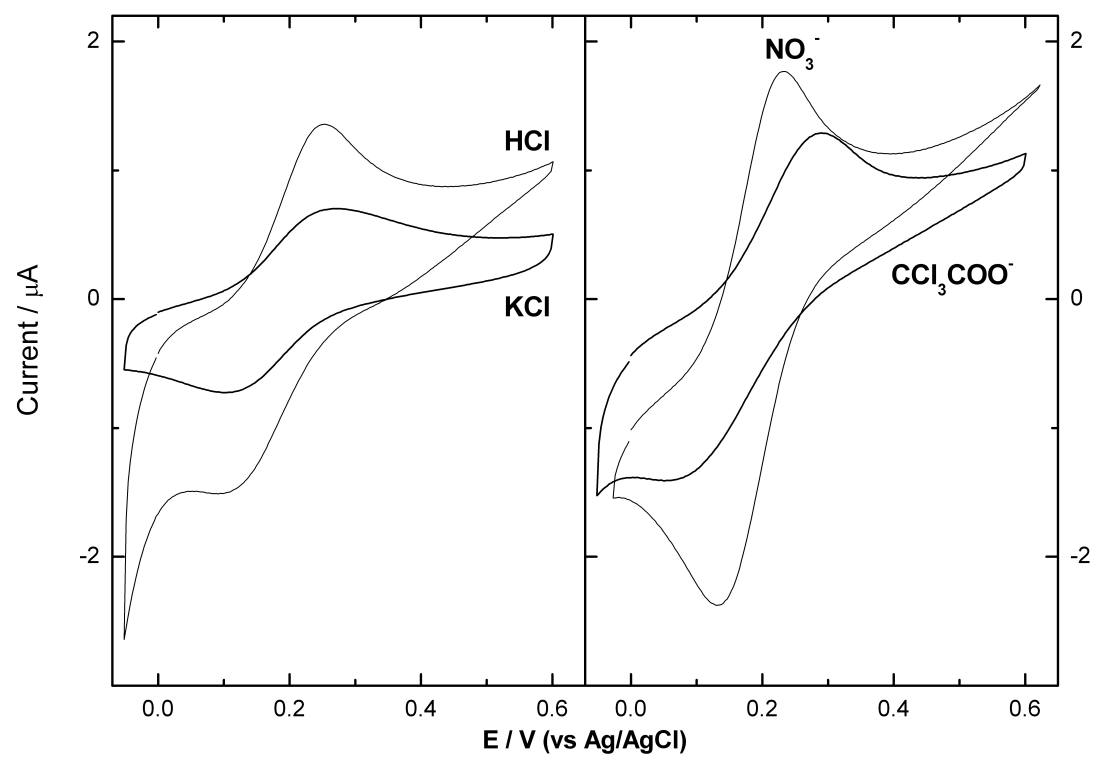

Figura 23: Voltamogramas cíclicos de EQM de ferroceno sobre carbono vítreo em diversos eletrólitos de suporte onde podemos observar o efeito dos ânions e dos cátions na resposta eletroquímica do sistema.

O próton dá origem a sinais bem mais intensos como era de se esperar, uma vez que possui dimensões extremamente diminutas. A posição dos picos no entanto não parece sofrer alterações significativas, mostrando que não há variações no sobrepotencial devido à natureza do cátion, mas que as diferenças entre as intensidades de corrente estão sim relacionadas com o diâmetro do cátion. O menor migra mais facilmente e compensa cargas com mais eficiência na superfície do eletrodo. A reação eletroquímica no entanto envolve a entrada de ânions para compensar carga já que formamos um cátion sobre o eletrodo de acordo com a equação 4.2 .

$$
F c \leftrightarrows F c^{+}+e^{-}
$$

Quando alteramos o tamanho do ânion, aumentamos a separação entre os potenciais de oxidação e redução como íons maiores, enquanto que a corrente catódica diminui na mesma proporção indo de $90 \mathrm{mV}$ e 1,8 mA para o íon nitrato a 0,230 mV e 1,29 mA para o tricloroacetato. O fato de serem ácidos garante que a limitação não se dê pelo fluxo de cátions, uma vez que prótons permeiam muito bem pelas membranas. O raio dos ânions $\mathrm{NO}_{3}^{-}(1,65 \mathrm{pm}), \mathrm{Cl}^{-}(1,81 \mathrm{pm})$ e $\mathrm{Cl}_{3} \mathrm{CCOO}^{-}(2,68 \mathrm{pm})$ afeta diretamente a posição dos máximos de corrente dos voltamogramas $\Delta \mathrm{E}_{p}$. Quanto maior o ânion, maior a energia 
necessária para garantir a compensação de cargas, e portanto maior o sobrepotencial. Esta limitação também resulta em menores correntes de pico como pode ser visto na figura 24 .

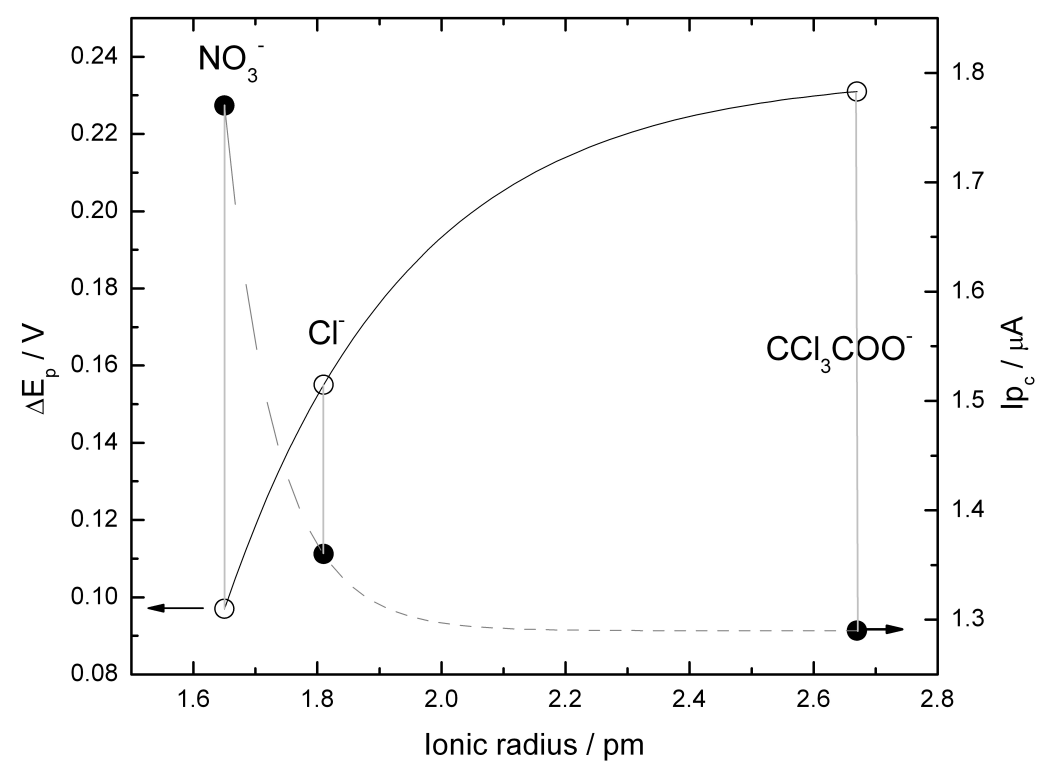

Figura 24: Variação de $\Delta \mathbf{E}_{p}$ e $\mathbf{I p}_{c}$ em função do tamanho do ânion no eletrólito suporte para EQM de ferroceno sobre carbono vítreo.

Esta foi uma maneira simples de demonstrarmos que as cucurbiturilas, mesmo imobilizadas em uma matriz polimérica, garantem o transporte de íons pelo material todo, podendo inclusive ser utilizadas para a montagem de eletrodos quimicamente modificados, garantindo resultados precisos, facilidade de preparação e proteção de espécies quimicamente instáveis na superfície dos eletrodos. Isto porquê são semipermeáveis a íons pequenos como $\mathrm{H}^{+}, \mathrm{Na}^{+}$e $\mathrm{K}^{+}$, sendo que a eficiência de permeação depende basicamente do tamanho dos cátions e ânions da solução além do tamanho dos opérculos das cucurbiturilas que contém.

\subsection{Membranas Poliméricas Semipermeáveis}

Membranas semipermeáveis são barreiras físicas que separam dois meios, permitindo o trânsito de determinadas espécies químicas entres eles. A permeação de espécies químicas pelas mebranas é governada por uma série fatores, como tamanho, gradientes de concentração entre as fases, cinética de permeação, carga, relações solvofóbicas e pela estrutura das membranas entre outros. Membranas semi-permeáveis podem se apresentar de diversas formas, mas as mais versáteis em termos de aplicações industriais são sem dúvida as membranas sólidas (MSPS). Boa parte das MSPS é capaz de segregar espécies 
e impedir a sua passagem de um meio a outro por exclusão de tamanho, uma vez que podem conter minúsculos canais ou poros de tamanho controlado, que impedem simplesmente a passagem das moléculas ou partículas maiores. Outros tipos de membrana fazem este trabalho por conta da presença de algum composto ativo em sua composição que é capaz de ligar-se com esta ou aquela espécie de um meio A, trazendo-as para o seio da membrana. Por difusão dentro da própria membrana e por conta do gradiente de concentrações entre os meios, além do equilíbrio de associação/dissociação com o composto ativo (carreador), as espécies conseguem migrar para o meio B. Diferenças de solubilidade das espécies migradoras no material da MSPS também podem ser as responsáveis pela migração de uma espécie e não de outra de um meio pra outro, além de diferenças de potencial elétrico entre as interfaces interna e externa das membranas. No caso das MSPS porosas o diâmetro dos poros é quem define sua classificação. Recebem o nome, por exemplo, de "membranas de osmose inversa" quando exibem poros de 2 a $5 \AA$, "membranas de nanofiltração" quando há poros de 5 a $10 \AA$ A, "membranas de ultrafiltração" entre 10 e $100 \AA$, e "membranas de microfiltração" entre 100 e $1000 \AA$ A. As MSPS sólidas podem ser isotrópicas, quando apresentam uma composição e morfologia regular em toda sua estrutura, ou ainda anisotrópicas quando apresenta mais de uma camada, ou um lado mais denso ou de composição distinta do outro ${ }^{190,191}$. A capacidade de separar espécies químicas é o maior atrativo desta classe de materiais, uma vez que esta propriedade viabiliza uma infinidade de processos industriais como processos de separação, como na osmose inversa usada na indústria para purificar de água, como sistema de permeação de prótons em células a combustível de hidrogênio, para purificar macromoléculas, para separar gases entre muitos outros. Entende-se por fluxo $(\mathrm{J})$ de massa, a quantidade de moléculas a atravessar uma seção de área (A) por um período de tempo (t) como mostra a eq. 4.3 .

$$
J=\frac{m}{A t}
$$

Por conta disto a unidade de fluxo é dada em mol.cm ${ }^{-2} \cdot \mathrm{min}^{-1}$ usualmente. Desde que haja gadrientes de concentração, temperatura ou campos elétricos entr dois pontos observaremos o aparecimento de fluxos em meios contínuos. Este transporte de massa recebe o nome de difusão, convecção e migração dependendo da força externa que o gera ("driving force"). A velocidade de difusão, que tem origem em gradientes de concentração, é chamado de coeficiente de difusão D, que pode ser definido pela equação de Stokes-Einstein, (eq. 4.4), onde entram parâmetros como o raio de giração do soluto $\left(r_{A}\right)$, a viscosidade do meio $(\eta)$ o número de Avogadro, e demais constantes usuais.

$$
D=\frac{R T}{6 \pi \eta N_{o} r_{A}}
$$

É de se esperar portanto que D aumente com a temperatura e diminua com a viscosidade e o tamanho do soluto. O fluxo (J) é associado ao coeficiente de difusão (D) pela primeira lei de Fick representada na eq. 4.5. Nela figura o gradiente de concentração em função de 
tempo para uma espécie x qualquer.

$$
J(x, t)=-D \frac{\partial C(x, t)}{\partial(x)}
$$

Inúmeros processos industriais de extrema importância, utilizam membranas sintéticas e movimentam um mercado enorme. O fato de constatarmos, por medidas eletroquímicas que descrevemos anteriormente, que os polímeros carregados com CBs eram condutores de íons, e que eram permeáveis somente aos menores, decidimos desde 2008 desenvolver membranas. Uma propriedade inexplorada até então das cucurbiturilas era simplesmente a sua forma: a de um tubo. O lúmen que delimitam é totalmente simétrico, permitindo desta maneira que espécies incluídas ou não entrem e saiam livremente na/da estrutura desde que tenham um tamanho adequado, que não apresentem altas afinidades com os cavitandos por solvofobicidade, interações eletrostáticas ou quaisquer outras, e nem enfrentem uma barreira energética para isto.

Partindo deste princípio é simples concluir que se houver um gradiente de potencial qualquer entre uma ponta e outra do cavitando, espécies pequenas podem atravessá-los de ponta a outra, e que as espécies maiores seria retidas por exclusão de tamanho. Gases simples como $\mathrm{CO}_{2}, \mathrm{CO}, \mathrm{H}_{2}, \mathrm{He}, \mathrm{CH}_{4}, \mathrm{SO}_{2}$, moléculas pequenas como $\mathrm{H}_{2} \mathrm{O}, \mathrm{H}_{2} \mathrm{~S}$, e íons pequenos como $\mathrm{H}^{+}, \mathrm{Li}^{+}, \mathrm{Na}^{+}$, e $\mathrm{K}^{+}$teriam em tese grandes chances de transpassar o lúmen das cucurbiturilas de acordo com esta tese.

Para isto utilizamos as suspensões de Cubion para produzir membranas sólidas, para as quais depositamos um pedido de patente junto ao INPI pelo CNPq em conjunto com a USP (pedido de patente "MATERIAIS SEMI-PERMEÁVEIS PARA NANOFILTRAÇÃO E USO DOS MESMOS", nº. P. I. 1.002.556-1./RPI Nº 2099 pág. 134).

Estas membranas (http://www.youtube.com/watch?v=H_4Whoeud4o, veja vídeo), além de terem um custo de produção irrisório, quando comparado a outros materiais como Nafion, apresentam inúmeras vantagens sobre os produtos atualmente disponíveis no mercado, como resistência térmica, mecânica, química e ao biofouling entre outras (fig.19). São permeáveis à água e a íons menores que o potássio quando elaboradas com $\beta$-CB[6] , além de apresentarem fatores de discriminação altos para o propano com relação ao $\mathrm{H}_{2}$, He ou $\mathrm{CO}_{2}$ (veja fig.34). Podem ser utilizadas, como já verificamos, para a separação de macromoléculas, purificação de água, de glicerol, de etanol, de emulsões, na recuperação de tintas e pigmentos, separação, purificação ou enriquecimento de gases e líquidos, dessalinização de água, osmose inversa, células de combustível, pilhas e super-capacitores, eletródica, ou outras aplicações baseadas na discriminação das espécies por tamanho de poros. Também poderiam ser empregadas teóricamente em filtros de ar do tipo EPA, hemodiálise, filtros para aparelho de ar condicionado, filtros de ar de hospitais e salas limpas, proporcionando uma assepsia do ar e barreiras físicas para micro-organismos em 
geral tais como: bactérias, fungos, leveduras, protozoários, viri, esporos, ácaros, entre outras aplicações.

Estas aplicações representam mercados que totalizam algumas centenas de milhões de dólares anuais (mais precisamente em torno de 1,5 bi, veja em http://www.bccresearch.com/ report/MST028D.html. O principal interesse das empresas nacionais está em reúso de águas, dessalinização de águas, supercapacitores e remoção eficiente de $\mathrm{CO}_{2}$ de gás natural de petróleo. Apresentaremos a seguir as principais características destes materiais e também alguma aplicações pontuais. Apresentaremos a seguir as principais características destes materiais e também alguma aplicações pontuais.

\subsubsection{As Membranas de Cubion}

Partindo de suspensões de $\beta$-CB[6] em soluções de PU, PVC e PVDF em tetrahidrofurano, com teores de macrociclo variando de 1 a $50 \%$ em massa, podemos preparar membranas sólidas por dois métodos principais: O casting, e a projeção de aerosol. No primeiro método estas suspensões são colocadas em moldes e o solvente simplesmente evapora. A elevada pressão de vapor do tetrahidrofurano, faz com que a secagem destas membranas seja muito rápida, mas deixa marcas na superfície do materials. Uma série de alvéolos se forma, por conta de bolhas que se formaram durante a saída do solvente fig. 25. A presença destas vesículas é ruim, pois diminuem a reprodutibilidade do processo de

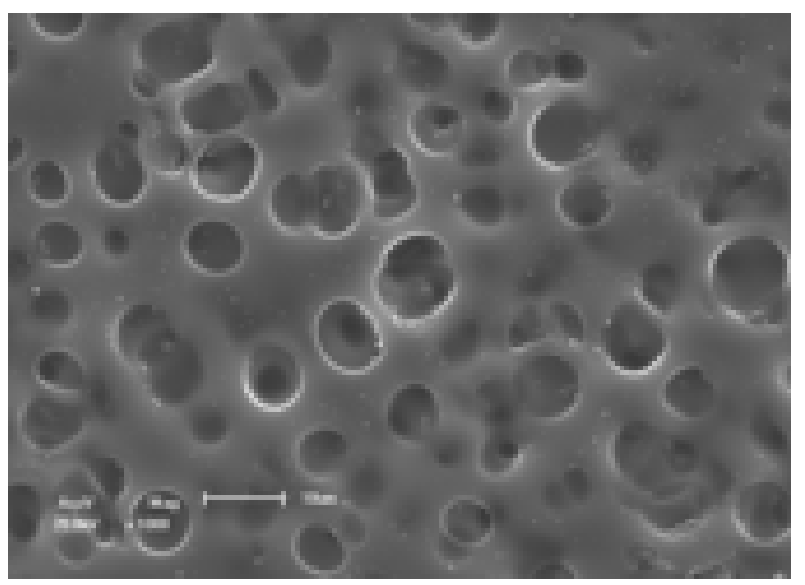

Figura 25: Fotomicrografias de membrana PVC/ $\beta$-CB[6] a $4 \%$ a $1000 x$ de aumento, mostrando as vesículas deixadas pela evaporação do solvente.

fabricação das membranas e acarretam frequentemente em furos, o que não é admissível para nossas finalidades. O segundo método gera materiais bem mais regulares, pois consiste em projetar a suspensão polimérica na forma de um aerosol, como se faz com pintura automotiva, sobre um anteparo giratório (fig. 26). As gotículas que atingem o anteparo secam imediatamente e os filmes resultantes adquirem uma textura regular e uniforme, além de uma estrutura em camadas, como massa folhada (fig. 27). 


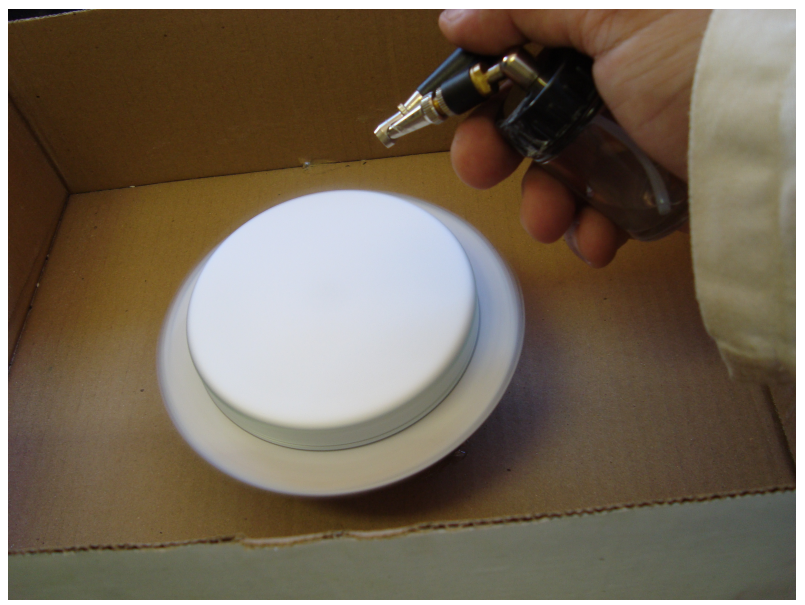

Figura 26: Preparação de membranas por projeção de aerosol.

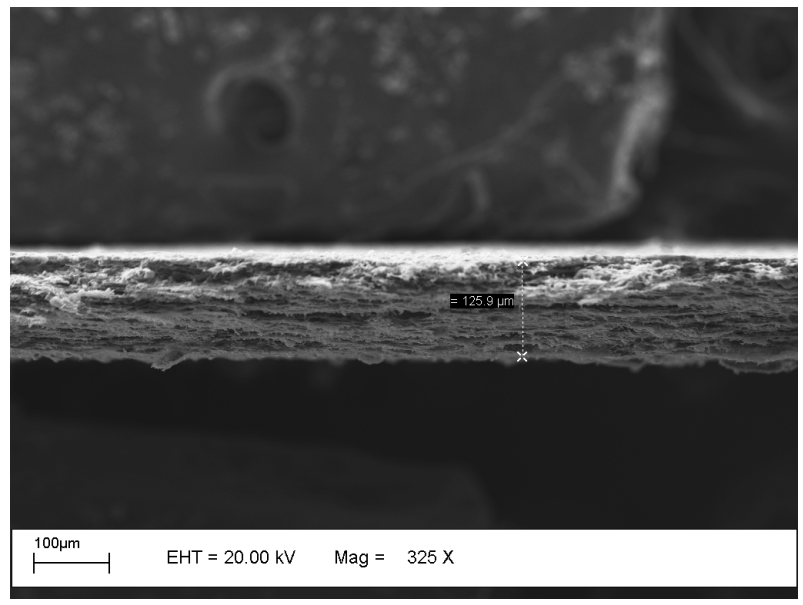

Figura 27: Corte de uma membrana de PVDF/ $\beta-\mathrm{CB}[6] 46 \%$ preparada por aerosol.

Pelo tamanhos (6-7 $\AA$ ) dos poros destas membranas, estamos falando de membranas de nanofiltração ou ainda de osmose inversa, já que são batizadas as membranas de acordo com o tamanho de poro ${ }^{191}$, fig. 28.

Foram realizados centenas de testes de transporte de massa passivo por estas membranas com diversas composições tanto de polímero de suporte quanto com teores variados de $\beta$-CB $[\mathbf{6}]$. Estes testes são realizados em uma célula de difusão universal que projetamos para esta finalidade ${ }^{192}$, descrita em detalhes no apêndice, que consiste em dois compartimentos separados pela membrana em teste. Num compartimento colocamos água deionizada e noutro um meio hipertônico, contendo sais, ácidos ou qualquer espécie que se deseja medir a permeabilidade ${ }^{193}$ (fig. 29).

O primeiro dado importante diz respeito à permeação de prótons, já que é importante para a montagem de separadores em baterias e membranas para células de combustível. O prótons por serem muito pequenos, permeiam bem pelo Cubion mas não se sabia se o faziam efetivamente pelos macrociclos ou pela rede polimérica. Para isto foram realizados experimentos com membranas de PVC contendo 1, 3, 5 e $10 \%$ de $\beta$-CB[6] , 


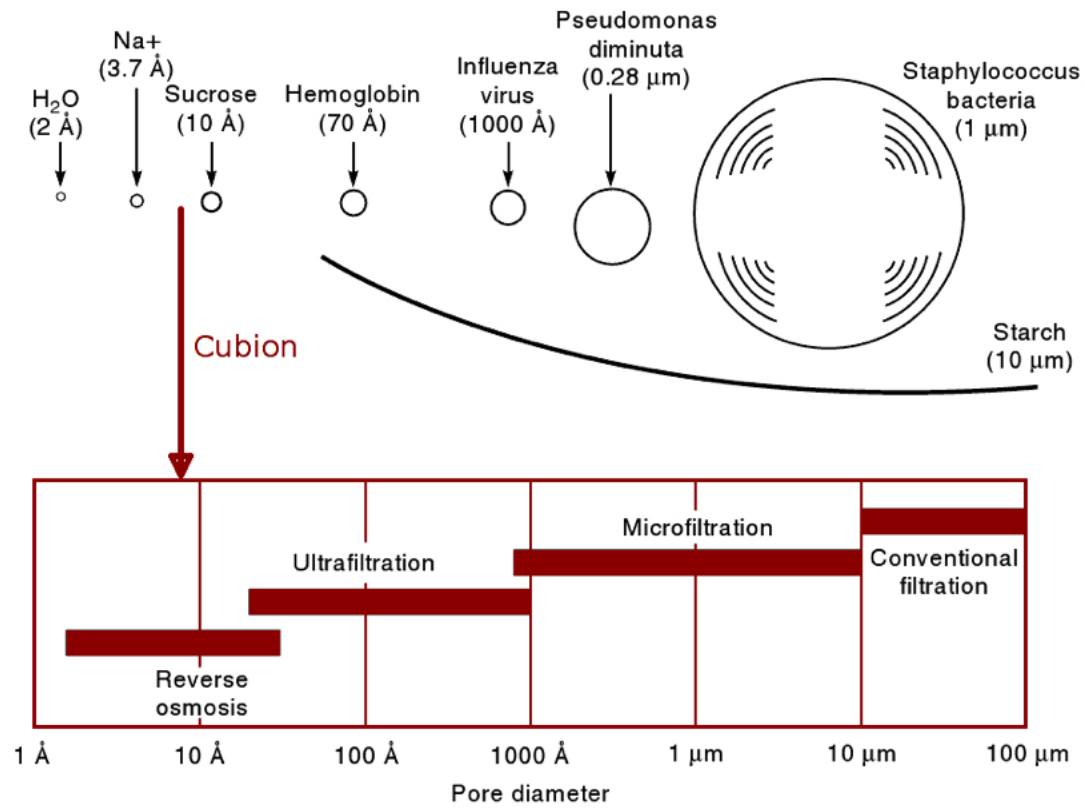

Figura 28: Classificação das membranas de acordo com o tamanho de poro, adaptado da ref $^{191}$

com espessuras da ordem de $120 \mu \mathrm{m}$. O meio hipertônico continha $\mathrm{HCl}$ a 0,5 mol.dm ${ }^{-3}$ e a quantidade de íons no meio hipotônico foi monitorado por condutimetria por 3 dias. O gráfico da figura 30 apresenta os valores de condutividade após 20 horas de experimento, e nele podemos perceber claramente a relação linear que existe entre a quantidade de íons que permeou e o teor de $\beta$-CB[6] nas membranas. Esta é a prova de que os íons se utilizam efetivamente dos lúmens da CB para permearem. Um teste com uma membrana de PVC puro, não apresentou variações de condutividade durante o mesmo período.

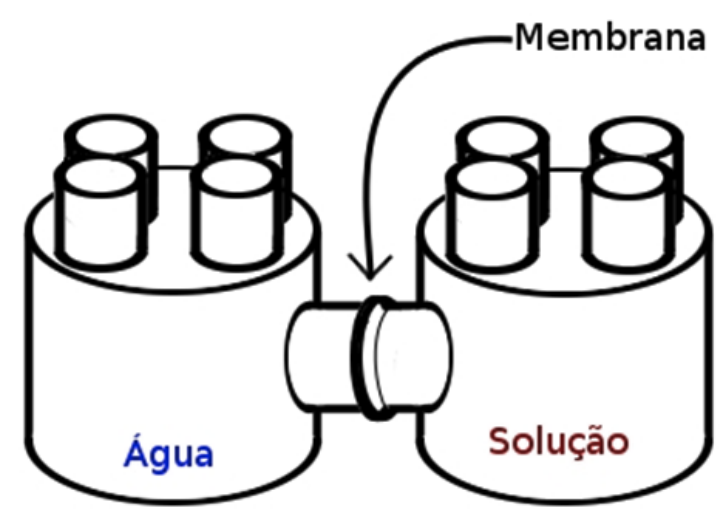

Figura 29: Visão esquemática da célula de difusão utilizada nos experimentos.

Uma outra série de testes foi relaizada variando agora o gradiente de concentração utilizando sempre membranas de PVC com $9 \%$ de $\beta$-CB[6] . A figura 31 deixa claro que é um processo governado predominantemente por gradientes de concentração, e que contra-fluxos têm uma contribuição minoritária no transporte de massa. 


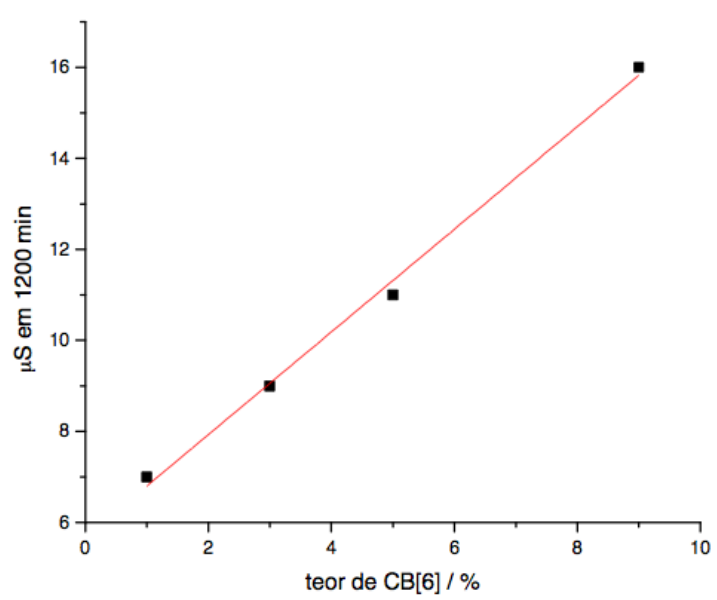

Figura 30: Valores de condutividade do meio hipotônico em tempo pré-determinado, em função do teor de $\beta$-CB[6] nas membranas utilizadas.

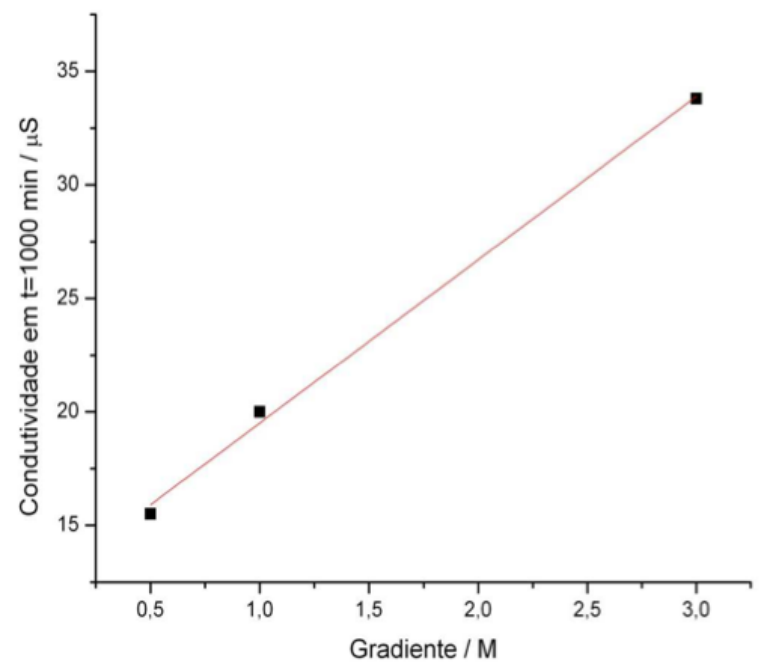

Figura 31: Dependência do fluxo de prótons com o gradiente de concentração trans-membrana

Observando a permeabilidade relativa dos íons $\mathrm{H}^{+}, \mathrm{Li}^{+}$e $\mathrm{K}^{+}$, todos a 1 mol.dm ${ }^{-3}$ , (figuras 32 e 33) por membranas de PVC a $47 \%$, surge um resultado surpreendente. A ordem de permabilidades é $\mathrm{H}^{+} \gg \mathrm{K}^{+} \gg \mathrm{Li}^{+}$, o que não condiz com seus raios iônicos. É sabido que o íon $\mathrm{Li}^{+}$é menor do que o $\mathrm{K}^{+}$, e portanto, por ter a mesma carga, deveria permear mais pelas membranas. Este fato não é observado no entanto quando pensamos nos cátions hidratados, que estes sim, tem valores de raios exatamente na ordem das permeabilidades, explicando este comportamento. Surge aqui um grande paradoxo: Se as cavidades dos polímeros são hidrofóbicas, como explicar que os cátions as atravessam hidratados? Ainda não há resposta para isto, e não sabemos ao certo se os íons se dessolvatam ao entrarem e se ressolvatam ao sairem das cavidades, e isto está sendo investigado atualmente pelo nosso grupo.

Outro ponto que precisa ser esclarecido é a intensidade dos efeitos da pressão os- 


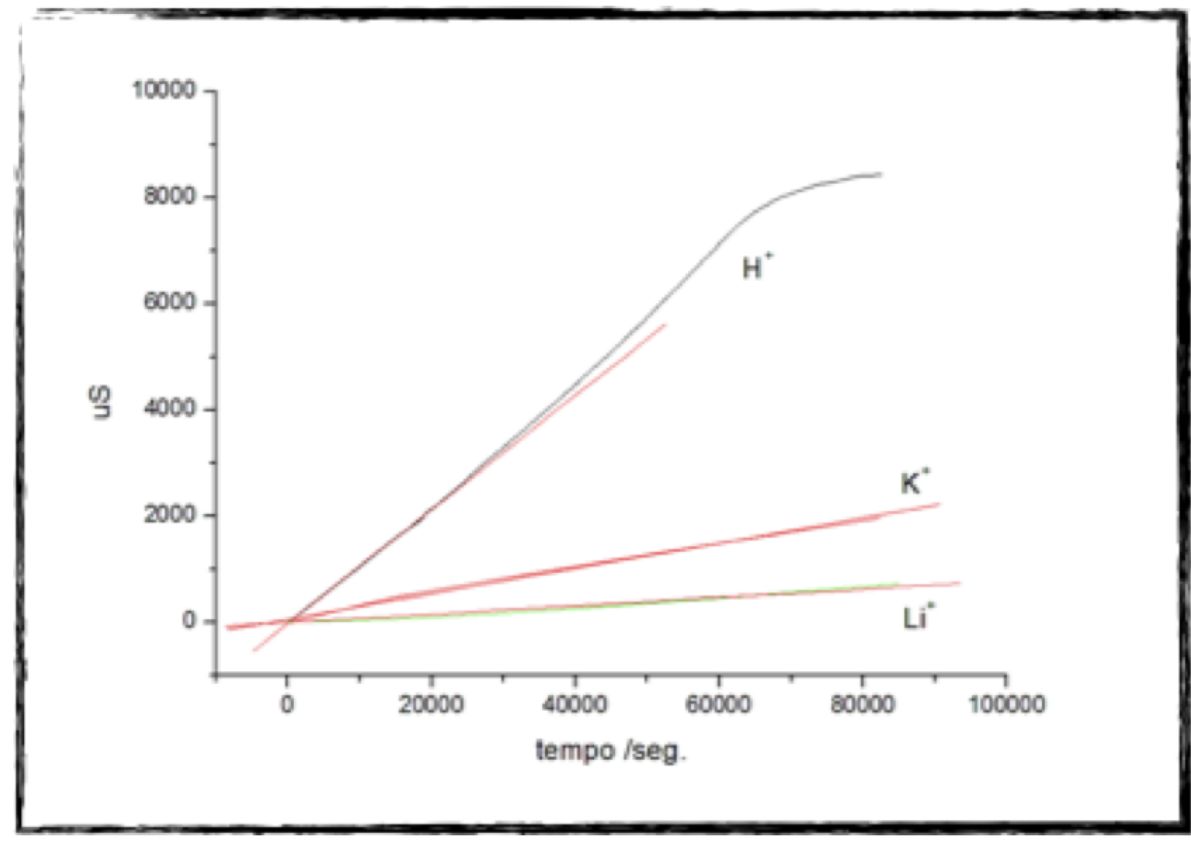

Figura 32: Fluxo de $H^{+}, \mathbf{L i}^{+}$e $\mathbf{K}^{+}$por membranas de Cubion a $\mathbf{9 \%}$

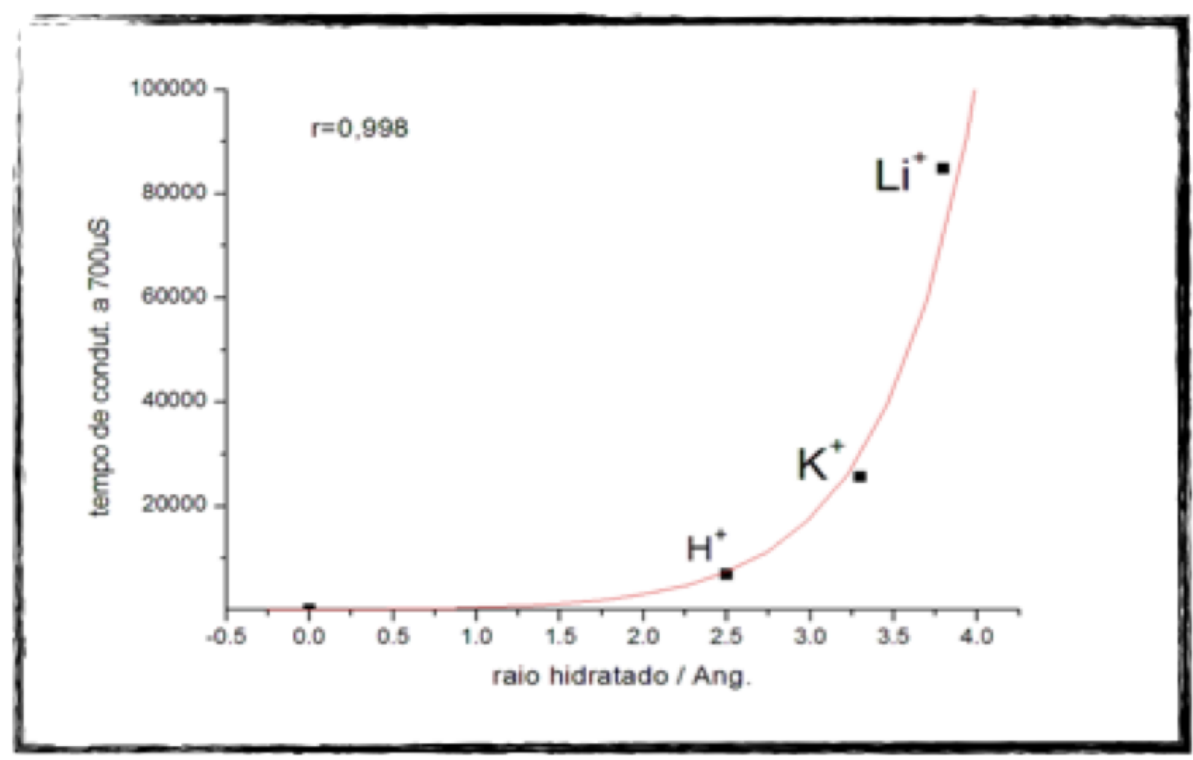

Figura 33: Correlação entre fluxo e raios iônicos hidratados. 
mótica em contra-fluxo ao dos íons assim como os efeitos de polarização das membranas. Devido à alta densidade de carga negativa nas entradas de seus opérculos, as cucurbiturilas apresentam grande afinidade por cátions, mas não ânions. Na prática isto significa que para serem capazes de atravessar o lúmen do ionóforo, os ânions devem vencer uma enorme barreira energética de natureza eletrostática, por menores que sejam. Portanto numa situação em que íons devem permear pelas membranas, seja por gradiente de potencial químico ou elétrico, pode haver uma assimetria de fluxo entre cátions e ânions. Assim sendo, é esperado que se observem fenômenos de polarização eletrostática junto à superfície das membranas que tendem a compensar quaisquer gradientes entre os meios, limitando a transferência de massa de um meio para o outro. Espera-se também que esta limitação seja cada vez maior à medida que aumentam carga e raio de giração destes ânions. Pretendemos portanto medir estes fenômenos pelas diferenças de potencial que vão gerar e um lado a outro das membranas. Foram realizados testes de dessalinização de água na COPPE da UFRJ no laboratório do Prof. Habert, num equipamento de testes de membranas para osmose inversa. Os reultados foram bastante animadores pois as membranas a $35 \%$ de $\beta$-CB[6] , sob 25 bar de pressão rejeitam 94,6 \% de $\mathrm{Na}_{2} \mathrm{SO}_{4}$ e 88,2 $\%$ do $\mathrm{NaCl}$ dissolvidos em água. Isto sem dúvida mostra que podem ser utilizadas para processos de dessalinização de água salobra e salgada, o que era nosso maior objetivo.

\subsubsection{Outras Aplicações}

\subsubsection{Purificação de Gases}

As membranas do tipo Cubion, são semi-permeáveis tanto para gases quanto líquidos e espécies em solução. Experimentos recentes, no laboratório do Prof. Habert da UFRJ, comprovaram por exemplo que membranas de PVC contendo $25 \%$ de CB[6] conseguem discriminar He de $\mathrm{CO}_{2}$ e de propano, sendo que todos são apolares, apresentando somente diferenças em seus raios de giração (fig.34). A 2 atm., o He permea 10 vezes mais rapidamente do que o $\mathrm{CO}_{2}$, onde o propano não permea. De acordo com estes dados é possível separar componentes de misturas gasosas em equipamentos multi-estágio, com fatores de discriminação extremamente elevados, o que é interessante em especial para a remoção de $\mathrm{CO}_{2}$, e $\mathrm{H}_{2} \mathrm{~S}$ em gás natural ou ainda para a purificação de GLP.

\subsubsection{Purificação de Biodiesel}

Ainda que incipiente, um trabalho está sendo desenvolvido com resultados animadores para as membranas de Cubion na purificação de combustíveis. Um dos maiores problemas da reação de transesterificação necessária para a produção de biodiesel é a grande quantidade de glicerol que gera. Este glicerol deve ser separado da matriz reacional, por um porcesso qualquer, que pode encarecer bastante a produção do combustível. A utilização de etanol na esterificação é problemática uma vez que forma emulsões ex- 


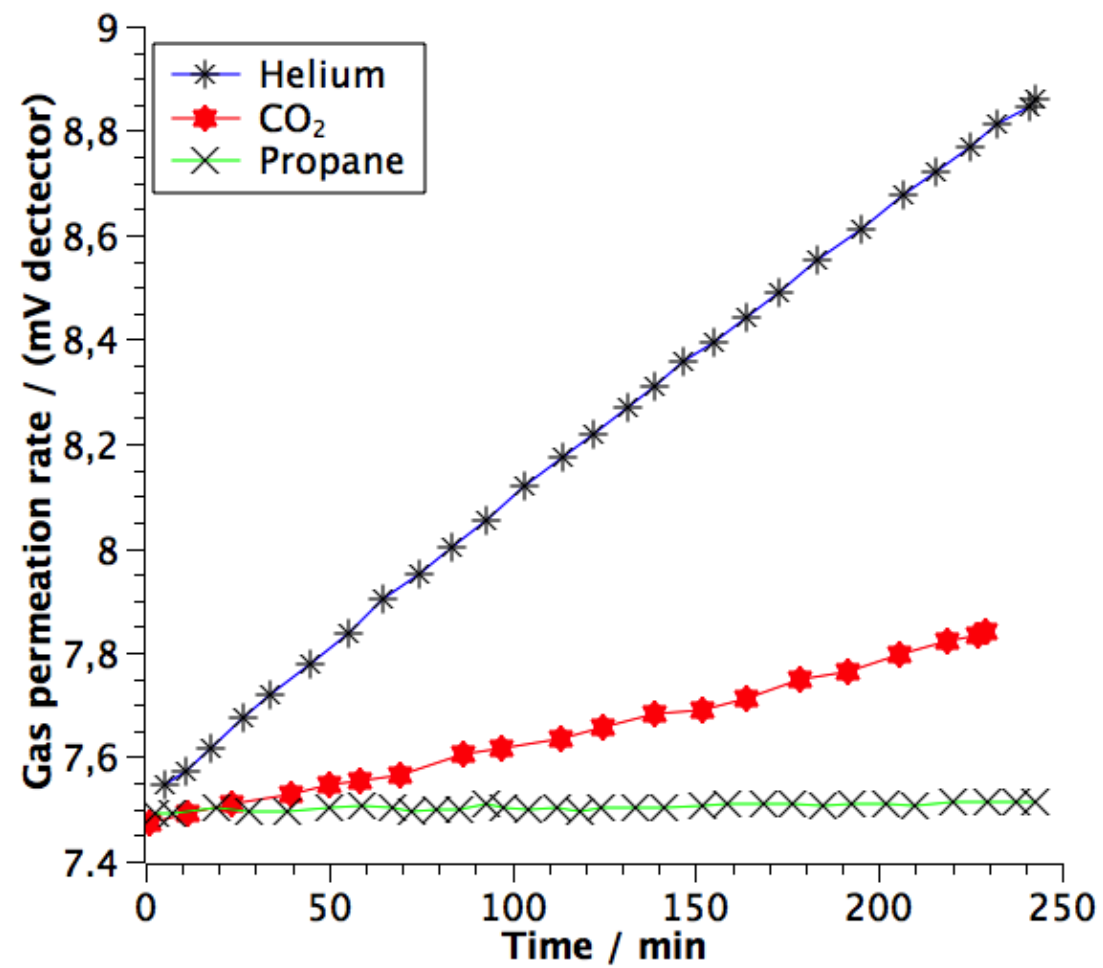

Figura 34: Permeação gasosa por membrana de Cubion $\left(\mathrm{He}=\right.$ preto, $\mathrm{CO}_{2}=$ vermelho, propano $=$ verde.)

tremamente estáveis no meio reacional, e deve estar presente em largo excesso para que a reação prossiga. A remoção de etanol e glicerol é um gargalo financeiro da produção de biodiesel a partir do etanol ${ }^{194}$. Em uma filtração simples, utilizamos uma membrana PVC/ $\beta$-CB [6] a $20 \%$ M.M e soluções de glicerol/ $\mathrm{H}_{2} \mathrm{O}$ 1:1 V/V (fig.35). Utilizando medidas de índice de refração pudemos observar que há um um fator de enriquecimento de $15 \%$ em glicerol na solução original após a filtrarmos metade dela.

Ainda não foram realizados testes de permeação por pressão com misturas contendo etanol, nem misturas ternárias, por falta de maquinário adequado, mas fica evidente que etapas sucessivas de filtração poderão alterar este fator de enriquecimento, separando a maior parte dos componentes da mistura. A utilização de CB[5] e hemi-CBs e o uso de outros métodos como o método de fibra oca, também devem melhorar estes fatores de enriquecimento, tornando possível a sua utilização industrial.

\subsubsection{Esponjas de Cubion}

A exploração do petróleo sempre trouxe graves consequências ao meio ambeinte, tanto na sua extração, processamento quanto na sua utilização propriamente dito. Durante a extração e transporte são comuns vazamentos, que afetam diretamente os corpos d'água, em especial o mar. A queima e seus resíduos contaminam também o ar e o solo. Em alto mar, o óleo recobre as penas das aves, sufoca os peixes, causa a morte do plâncton, 


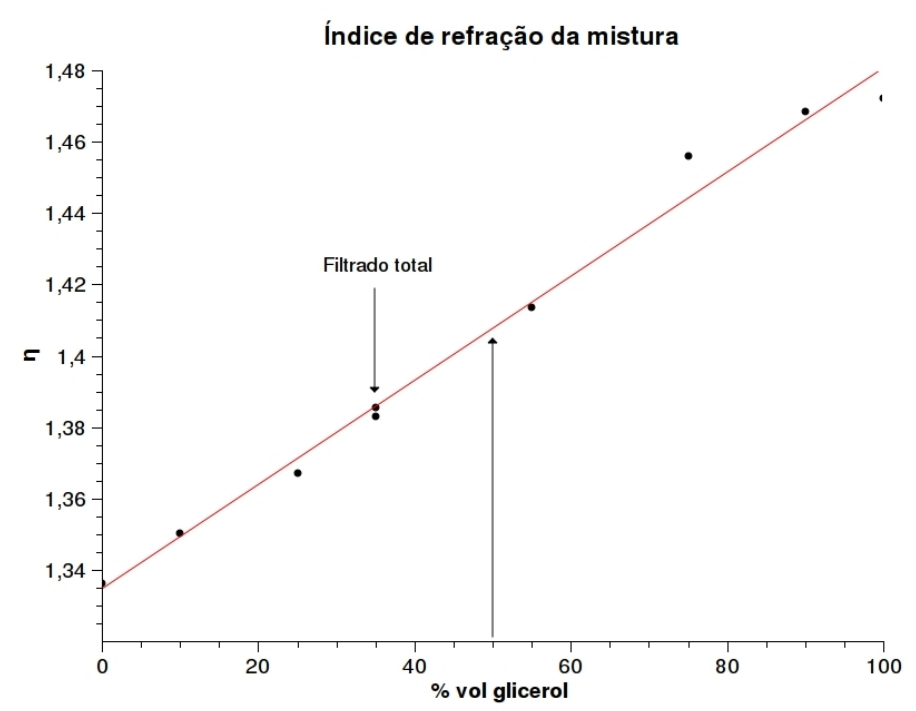

Figura 35: Separação de misturas água/glicerol utilizando membranas de Cubion.

pequenos crustáceos, algas e plantas na orla marítima ${ }^{195}$. Diversas alternativas para a remediação em água, no intuito de recolher o petróleo do mar, vem sendo utilizadas sendo a mais comum a técnica de contenção e remoção da mancha, onde se utilizam longas hastes sustentadas por bóias nas quais pende uma espécie de saia que impede o espalhamento da mancha que pode então ser bombeada. Outro processo mais radical é o de queima in situ, onde se atea fogo ao óleo derramado, porém esse processo é muito tóxico, pois gera fumaça e não pode ser utilizado próximo de habitações costeiras. Muitas vezes também se usam tensoativos para criar emulsões de petróleo de uma forma a dispersar o material de forma mais rápida do que a natureza é capaz. Biorremediação com micro-organismos também é possível, quando se utilizam fertilizantes e micro-organismos capazes de converter o petróleo em ácidos graxos e dióxido de carbono ou em outros compostos menos tóxicos. Seu benefício é a completa mineralização dos compostos, bem como a formação de biomassa. Porém a degradação do petróleo por biorremediação depende da presença de micro-organismos específicos e condições ambientais adequadas, além do que, a degradação do petróleo é lenta em vista das taxas inadequadas de nutrientes principalmente quando a concentração do óleo é alta ${ }^{196,197}$. Apesar de diversificadas, todas as alternativas oferecem obstáculos. Incapacidade de remover monocamadas residuais de óleo, alto custo, geração de gases tóxicos ou condições biológicas excepcionais mostram que ainda há espaço para novas propostas de materiais sorventes. Apesar dos esforços contínuos ainda não somos capazes de recuperar totalmente a flora, a fauna e os ecossistemas como um todo em curtos períodos de tempo. Após 18 anos do acidente com o navio Exxon Valdez, por exemplo, ainda existem áreas no estreito Prince Willian, no Alaska, poluídas com petróleo. Os métodos disponíveis hoje continuam relativamente caros e muitas vezes não são capazes de remover o óleo na sua totalidade, deixando ainda películas finas (praticamente monocomadas) do líquido na superfície da água. 
As cavidades hidrofóbicas das cavidades das CBs poderiam ser utilizadas como armadilhas para os componentes do petróleo, devido à grande afinidade, principalmente com os alifáticos de cadeia longa que compoem grande parte do líquido. Em um experimento preliminar muito simples, isto foi verificado em fragmentos de membranas de Cubion de 120 microns de espessura sobre uma fina camada de petróleo leve(36).

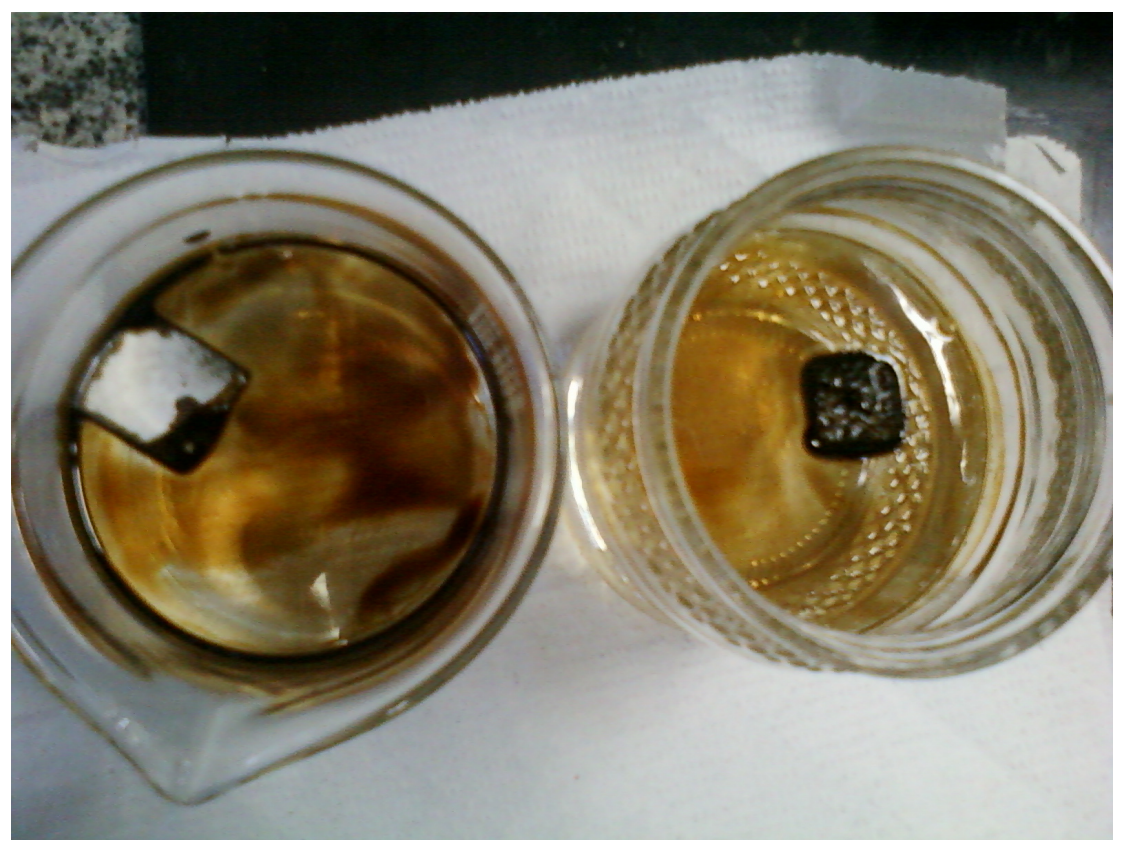

Figura 36: Absorção de petróleo em membranas de cubion sobre água: Início do processo (esquerda) e fim (direita).

Em menos de 20 min., a maior parte do petróleo havia sido absorvida. Apesar da enorme afinidade pelo óleo, o fator limitante para esta utilização é a superfície de contato destas membranas com a interface líquido-líquido. Uma possível solução para este problema seria criar uma esponja para realizar este trabalho. As esponjas são extremamente reticuladas, o que lhes confere áreas superficiais enormes quando comparadas a filmes finos. A inércia química das cucurbiturilas, aliada à sua estabilidade térmica, baixa toxicidade e sobretudo ao seu custo extremamente baixo as torna candidatas naturais para este tipo de aplicação. Na forma de esponjas conseguiríamos materiais extremamente eficientes, baratos, leves, e talvez recicláveis, uma vez que seria possível recuperar o óleo removido da água por pressão, e reutilizá-las no processo de remediação dos corpos d' água.

A preparação das esponjas é simples e consiste em adicionar algum carbonato à suspensão inicial de Cubion com PU, que por sua vez contém teores variáveis de $\beta$-CB[6] . Esta mistura é vertida em ácido aquoso, que causa a liberação de $\mathrm{CO}_{2}$ pelo carbonato, criando uma estrutura bastante reticulada, típica de esponjas. Utilizamos petróleo leve e óleo de soja para os testes de absorção em água. A quantidade inicial de óleo era medida, 
a massa da esponja incial e final eram obtidas.

Cobrindo $5 \%$ da área mancha de óleo as esponja com $\beta$-CB[6] a $60 \%$ consegue reter mais que o dobro de óleo do que uma esponja idêntica mas que não contém macrociclo. (figura 37)

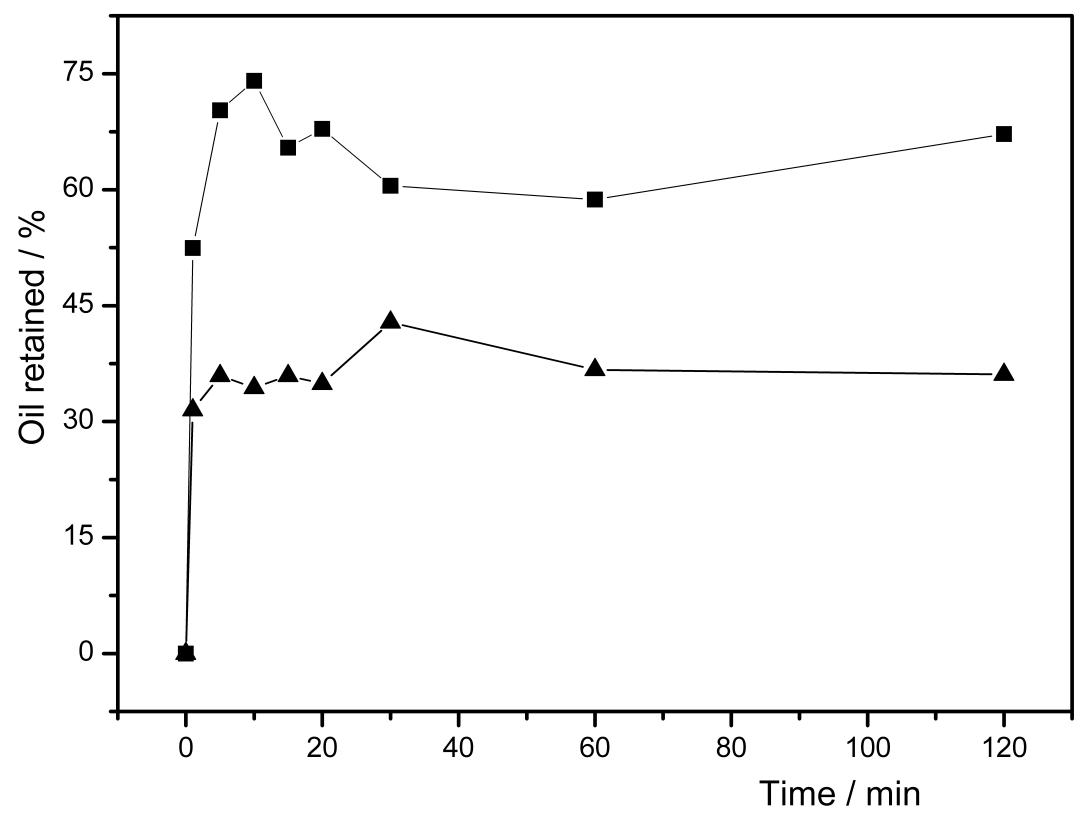

Figura 37: Efeito da presença de $\beta-\mathrm{CB}[6]$ na absorção de petróleo leve. $\square=60 \%$ de $\beta$-CB $[6]$ ; $\Delta=$ controle

O mesmo tipo de experimento foi realizado com óleo de soja, com esponjas de Cubion contendo 0, 1030 e $54 \%$ de $\beta$-CB[6], e novamente observamos um aumento de eficiência de absorção das esponjas consistente com o teor de macrociclo que contêm, como é visto na figura 38 .

O mais interessante destas esponjas, é que o material absorvido pode ser recuperado por prensagem, e as esponjas pode ser reutilizadas por pelo menos dez vezes, sem perda de eficiência. Um esponja cheia de petróleo, como vista na figura 40 é prensada e libera em média $98 \%$ do material que retirou da água, mesmo depois de 10 compressões e reusos consecutivos como mostra a figura 39.

As esponjas de cubion são eficientes, baratas, reutilizáveis e também recilcáveis, características estas que aumentam suas chances no mercado. Depositamos um pedido de patente junto ao INPI. (pat. verde PI 01814008260). 


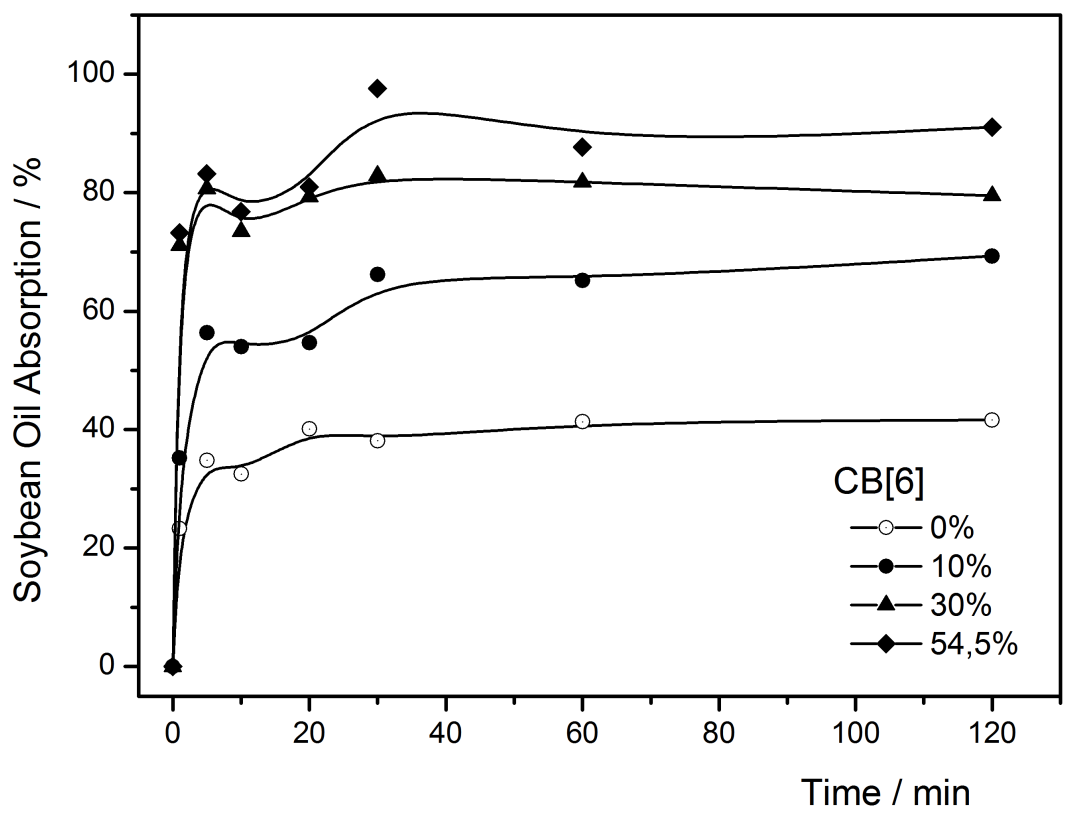

Figura 38: Absorção de óleo de soja em esponjas de cubion sobre água, mostrando que a eficiência está diretamente relacionada ao teor de $\beta$-CB[6] .

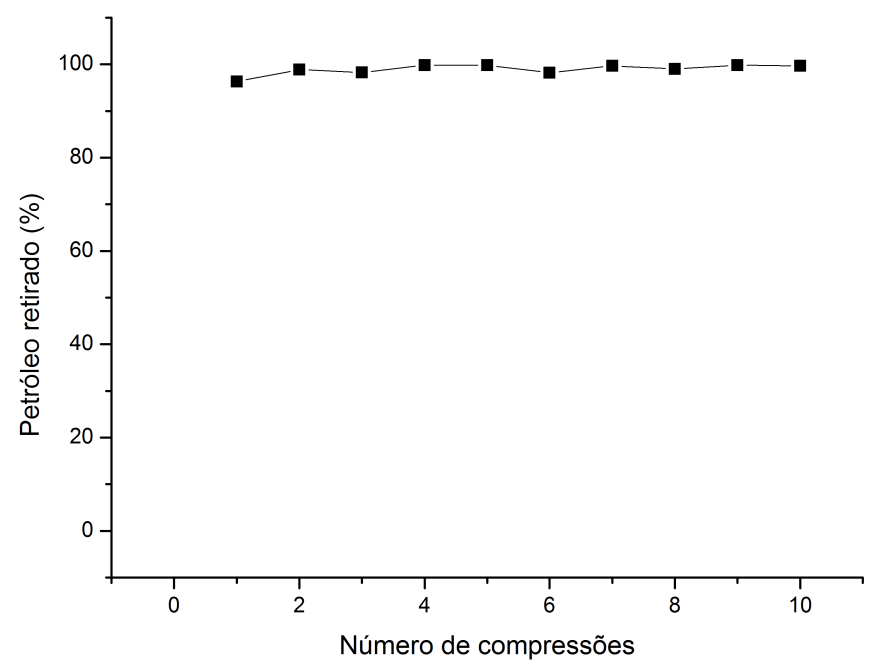

Figura 39: Recuperação do óleo absorvido pelas esponjas e seu reuso em ciclos consecutivos. 


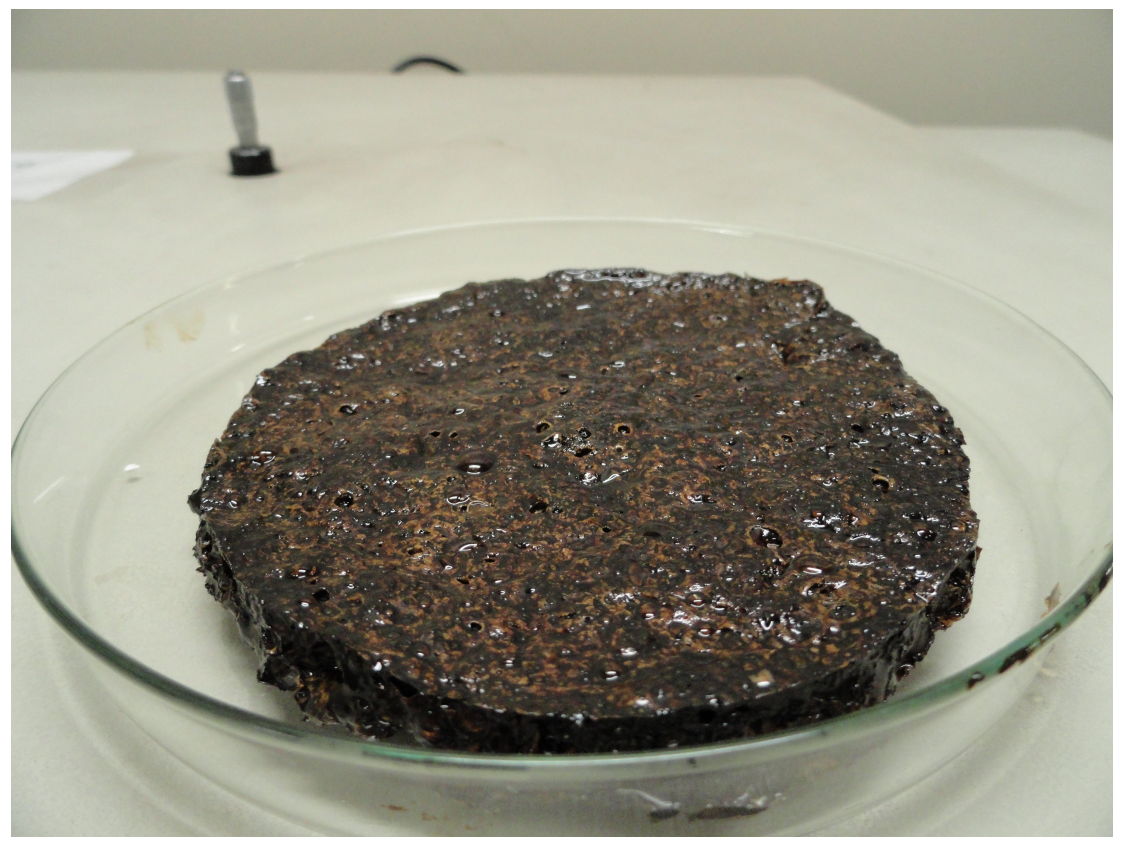

Figura 40: Fotografia de uma esponja de Cubion após absorção de petróleo em água salgada. 


\section{Cucurbiturilas Frente a Espécies em Solu- ção e complexos}

\subsection{O Sistema $\mathrm{CB}[6] / \mathrm{VO}^{2+}$}

A estrutura das cucurbiturilas permite vislumbrarmos uma série de possibilidade no tocante à preparação de novos compostos de coordenação ${ }^{198}$. Até meados de 2010 pouco havia sido feito com relação à coordenação de íons de transição atuando como ácidos duros aos opérculos das CBs. Varios trabalhos no entanto reportavam a caracterização estrutural de adutos poliméricos envolvendo alguns íons de transição, que eram obtidos ao acaso, por secagem de soluções contendo seus precursores ${ }^{153,156-164,166,168,199-218}$. Eram e são até hoje raros os trabalhos na literatura que se propoem a construir um complexo metálico com uma estrutura particular, visando uma aplicação em específico. É sabido que os complexos de vanádio apresentam propriedades únicas, no campo da catálise e compostos biomiméticos. É um metal essencial, presente em diversas enzimas ${ }^{219-221}$, e está envolvido em inúmeros processos biológicos. Muitas reações como oxidação de alcanos, alcenos, aromáticos, alcoóis são catalisadas por complexos de vanádio e em particular pelos complexos do íon $\mathrm{VO}^{2+}$. Estes íons são ácidos duros e podem formar complexos com espécies ricas em oxigênio como cetonas por exemplo, dando origem a compostos muito estáveis. Alguns complexos de vanádio apresentam propriedades similares à da insulina no organismo, que podem ser utilizadas para o estudo do metabolismo da glicose in vivo ${ }^{222-228}$.

Por conta disto é natural em se pensar em catalisadores seletivos por tamanho, aliando a cavidade das $\mathrm{CBs}$ com as propriedades catalíticas dos íons $\mathrm{VO}^{2+}$, formando um complexo metálico onde o íon estaria diretamente ligado aos átomos de oxigênio das carbonilas, sem a presença de água na forma de adutos, que seriam frágeis demais para serem utilizados em reações catalíticas. Três problemas surgem nesta proposta: o primeiro deles é a baixa solubilidade do $\beta-\mathbf{C B}[\mathbf{6}]$, que foi escolhido como ligante por possuir 4 pontos de coordenação acessíveis ao íon $\mathrm{VO}^{2+}$, que usualmente tem número de coordenação 5 , em uma pirâmide de base quadrada. O segundo obstáculo é a baixa mobilidade dos pontos de coordenação para formarem uma estrutura livre de tensões. $\mathrm{O}$ terceiro problema é que seria em tese, possível obter dois complexos, um mononuclear e outro binuclear, já que a $\beta$-CB[6] possui dois portais, potencialmente coordenantes. Estes compostos seria estabilizados basicamente pelo efeito quelato, mas a presença de dois núcleos talvez pudesse, pela proximidade, inviabilizar a estrutura por repulsão entre os cátions. Estruturas elaboradas por cálculo apontam para complexos onde o macrociclo 
deve assumir uma forma elipsoidal para garantir a coordenação dos íons $\mathrm{VO}^{2+}$, como mostra a figura 41.
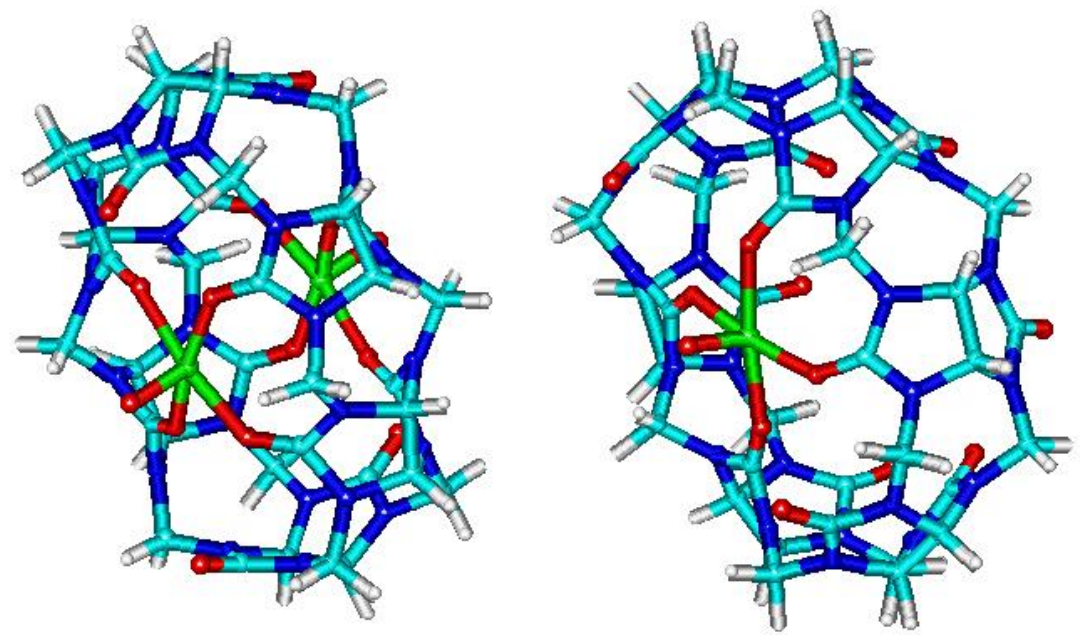

Figura 41: Estruturas claculadas para os complexos mono e binucleares de $\beta$-CB[6] com o íon vanadila. Vanádio em verde, oxigênios em vermelho, carbono em azul claro, nitrogênio em azul escuro.

Uma rota sintética foi otimizada para a preparação dos complexos $\left[\mathrm{CB}[6]_{n} \mathrm{VO}\right]\left(\mathrm{SO}_{4}\right)_{n}$ que consiste basicamente em dissolver $\mathrm{VOSO}_{4}$ e $\beta$-CB[6] em ácido sulfúrico aquoso a 10 $\%(\mathrm{v} / \mathrm{v})$ em manter um refluxo de aproximadamente $6 \mathrm{~h}$. Inicialmente todo o sólido passe para a solução que passa a adotar uma coloração azul celeste, límpida. Após este período o volume da solução é reduzido até um pouco menos da metade e resfriada à temp. ambiente. É então despejada em 5 vezes seu volume de etanol absoluto. O sólido azul precipita e é filtrado em membrana de $0,45 \mu \mathrm{m}$, lavado com etanol e sêco em dessecador (rendimento de aprox. $93 \%$ em massa). Uma vez precipitado o sólido não é mais solúvel em água, por razões que desconhecemos totalmente. O ácido fórmico $60 \%$ parece ser o único solvente capaz de dissolvê-lo, como ocorre com a $\beta$-CB[6]. Neste solvente o complexo é purificado em coluna de sílica. Maiores detalhes podem ser obtidos na referência ${ }^{111}$, en anexo. Quantidades maiores de $\mathrm{VO}^{2+}$ no meio reacional conduzem invariavelemente ao mesmo sólido, mostrando que a formação do complexo binuclear não é viável ou ainda que este tenha permanecido em solução em quantidade reduzidas.

A caracterização deste composto e a determinação de sua estrutura por difração de raios$\mathrm{X}$ se mostrou inviável uma vez que não se conseguiu cristais bons o suficiente. Toda a caracterização se deu por métodos espectroscópicos e de análise térmica. O vanádio (IV) é um metal de configuração $d^{1}$, e por conta disto deve dar origem a transições eletrônicas $d-d$ e ser ativo na ressonância de elétrons paramagnéticos (REP). A espectroscopia REP e UV-vis foram utilzadas aliadas à termogravimetria (TG) para propormos a estrutura do complexo.

Na figura 42 podemos ver 3 perdas de massa consecutivas (12,05\% entre 60 e 120 ${ }^{\circ} \mathrm{C}, 72 \%$ em torno de $340{ }^{\circ} \mathrm{C}$ e $9,06 \%$ a $445{ }^{\circ} \mathrm{C}$ ) e um resíduo que representa $6,89 \%$ da 


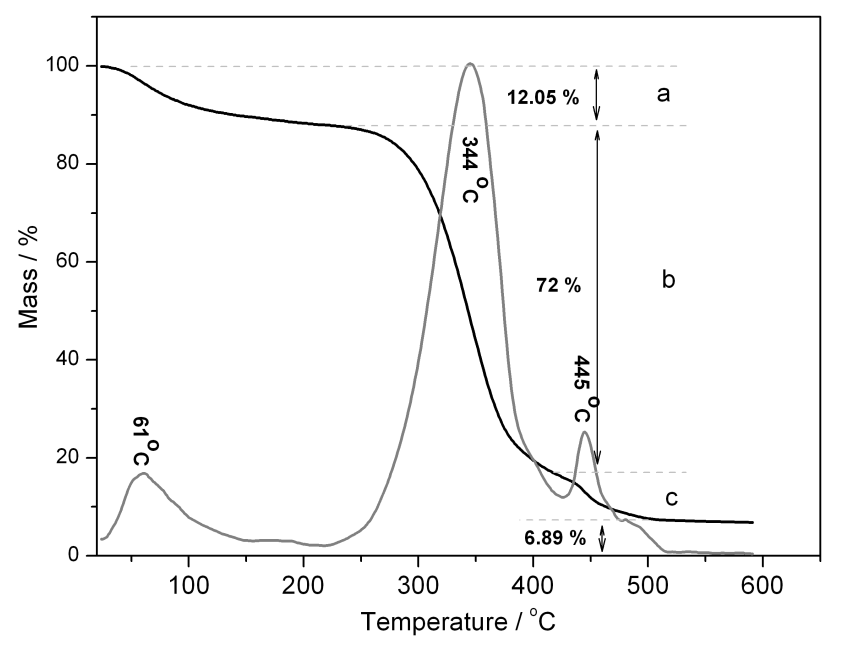

Figura 42: Curva termogravimétrica e sua derivada obtidas com o complexo $[\mathrm{VO}(\mathrm{CB}[6])] \mathrm{SO}_{4} \cdot 9 \mathrm{H}_{2} \mathrm{O}$ em atmosfera de oxigênio

massa inicial. Assumindo que a primeira perda seja referente à perda de água, inferimos que a segunda seja a decomposição do macrociclo como descrito por Germain na ref. ${ }^{229}$. As variações subsequentes correspondem à decomposição dos íons sulfato e à oxidação do cátion $\mathrm{VO}^{2+} \mathrm{a} \mathrm{V}_{2} \mathrm{O}_{5}$. Obtemos uma fórmula $[\mathrm{VO}(\mathrm{CB}[6])] \mathrm{SO}_{4} \cdot 9 \mathrm{H}_{2} \mathrm{O}, \mathrm{M}=1323 \mathrm{~g} \cdot \mathrm{mol}^{-1}$. A banda de estiramento $\mathrm{V}=\mathrm{O}^{230}$ aparece no espectro vibracional do composto em torno de $980 \mathrm{~cm}^{-1}$ sobreposta a diversas bandas do próprio macrociclo, o que dificulta sua visualização clara nos espectros como podemos observar na figura 43. Outras bandas também aparecem no espectro vibracional, e ainda não foram atribuidas. O fato de não termos verificado nenhuma banda em torno de $830 \mathrm{~cm}^{-1}$ elimina a possibilidade da presença de pontes $\mu$-oxo entre dois átomos de vanádio, eliminando assim a hipótese da formação de estruturas polinucleares em ponte.

No intuito de se descobrir como era o ambiente de coordenação do íon de transição, analisamos os espectros eletrônicos do complexo no estado sólido e em ácido fórmico 60 \% e o comparamos ao espectro de seu precursor, o $\mathrm{VOSO}_{4}$. Os espectros forma desconvoluidos em uma série de gaussianas, que nos permitiram obter a intensidade relativa e a posição das bandas de absorção com mais precisão para cada um dos casos (fig. 44).

Observando os modelos teóricos, podemos inferir que a cavidade, ou pelo menos os pontos de coordenação do opérculo da $\beta-\mathbf{C B}[\mathbf{6}]$ assumiriam uma simetria $\mathrm{C}_{2 v}$, mas com simetria local que se se aproxima de uma configuração $\mathrm{C}_{4 v}$ levemente distorcida, para poder acolher o íons vanadila. Em termos práticos isto corresponderia a uma coordenação do íon em uma geometria de pirâmide de base retangular, ao invés de quadrada, assumindo comprimentos de ligação V-L entre 2 e 2,5 Å, o que é totlamente compatível com o tamanho do opérculo. Por conta desta geometria de ligação espera-se que o íon vanadila 


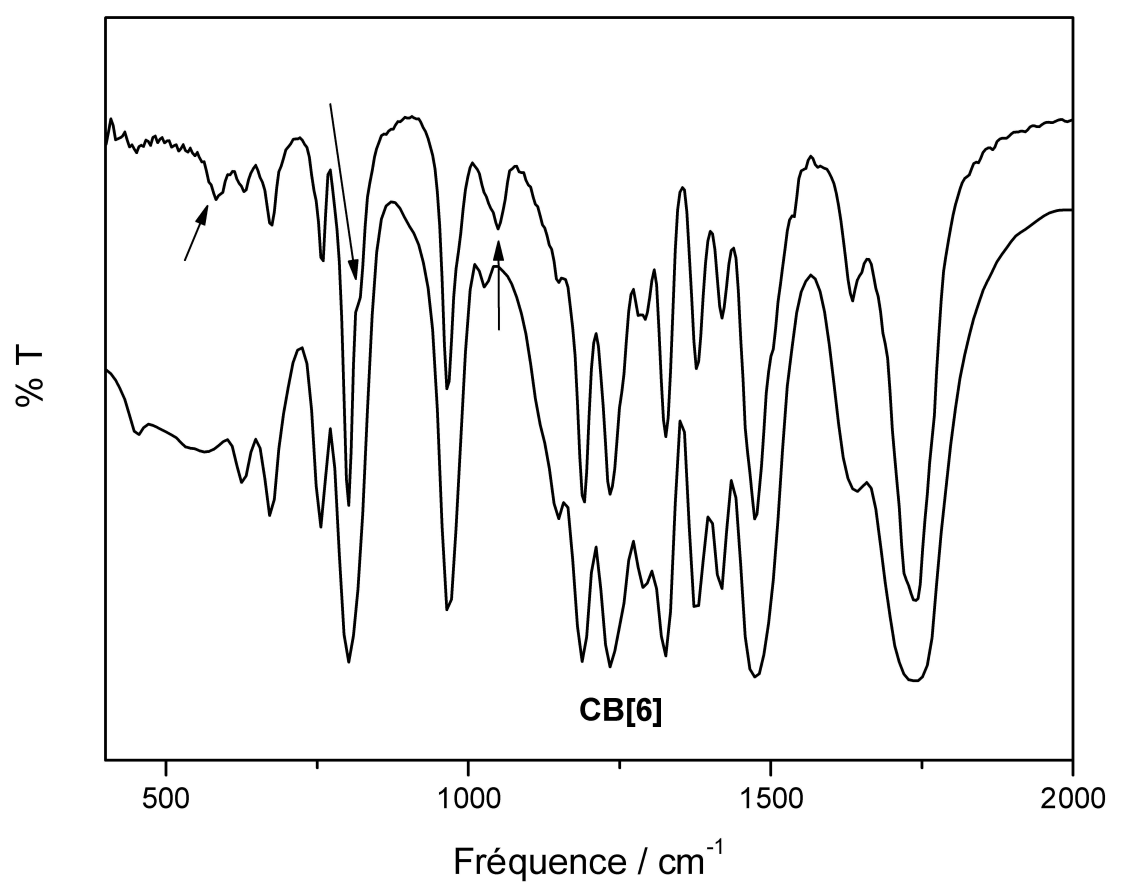

Figura 43: Espectros vibracionais da $\beta-\mathrm{CB}[6]$ e de seu complexo com $\mathrm{VO}^{2+}$

se encontre em um campo ligante característico do número de coordenação 5 levemente distorcido, o que deve gerar um desdobramento característico dos níveis $d$, pois sabemos que as características espectrais deste íon são bem particulares em ambiente $\mathrm{C}_{4 v}, \mathrm{C}_{2 v} \mathrm{e}$ $\mathrm{D}_{3 h}{ }^{231-235}$. Afim de estimar as distorções na base da pirâmide é conveniente identificar os diedros envolvidos, na figura 45.

Nesta figura podemos identificar os ângulos $\theta$ (entre $\mathrm{O}=\mathrm{V}-\mathrm{L}_{1}$ ), $\zeta$ (entre $\mathrm{L}_{1}-\mathrm{V}-\mathrm{L}_{2}$ ), e $\xi$ (entre $\left.\mathrm{L}_{2}-\mathrm{V}-\mathrm{L}_{3}\right)$. Fica evidente que qualquer distorção no ambiente de coordenação vai interferir nestes ângulos, e que $\zeta$ e $\xi$ deveriam ser iguais no caso de uma pirâmide de base quadrada. Outro parâmtero útil é o de pseudorotação de Berry dado por $\tau$, que varia de 1 a 0 de acordo com os diedros distais como dado na equação eq. (5.1).

$$
\tau=\frac{\left(L_{1} \widehat{-V}-L_{3}\right)-\left(L_{2} \widehat{-V}-L_{4}\right)}{60}
$$

De acordo com estes parâmetros o íon $d^{1}$ poderia dar origem a 2, 3 ou mesmo 4 transições, dependendo de seus valores. Apesar de ainda controversa a atirbuição espectral, a maioria dos autores concorda que simetrias $\mathrm{C}_{4} v$ dão origem a 3 bandas, chamadas de Bandas I, II e III que são atribuidas a transições $b_{2} \rightarrow e^{*} ; b_{2} \rightarrow b_{1}^{*}$ e $b_{2} \rightarrow a_{1}^{*}$. Um abaixamento de simetria para $\mathrm{C}_{2} V$ deveria quebrar totalmente a degenerescência dos níveis d separando os níveis $e$ em $b_{1}$ e $b_{2}$. Neste caso rebatizamos as Bandas em I, II, II', e III. A separação dos níveis e, depende essencialmente do ângulos $\zeta$ e $\xi$, consequentemente de $\tau$ também. A separação é frequentemente pequena demais para ser observada experimentalmente como ocorre no caso do $\left[\mathrm{VO}(\mathrm{acac})_{2}\right]^{232}$. Em solução, o espectro do $[\mathrm{VO}(\mathrm{CB}[6])] \mathrm{SO}_{4} \cdot 9 \mathrm{H}_{2} \mathrm{O}$ apresenta bandas fracas sobrepostas umas às outras compreendidas entre 400 e $1000 \mathrm{~nm}$ 


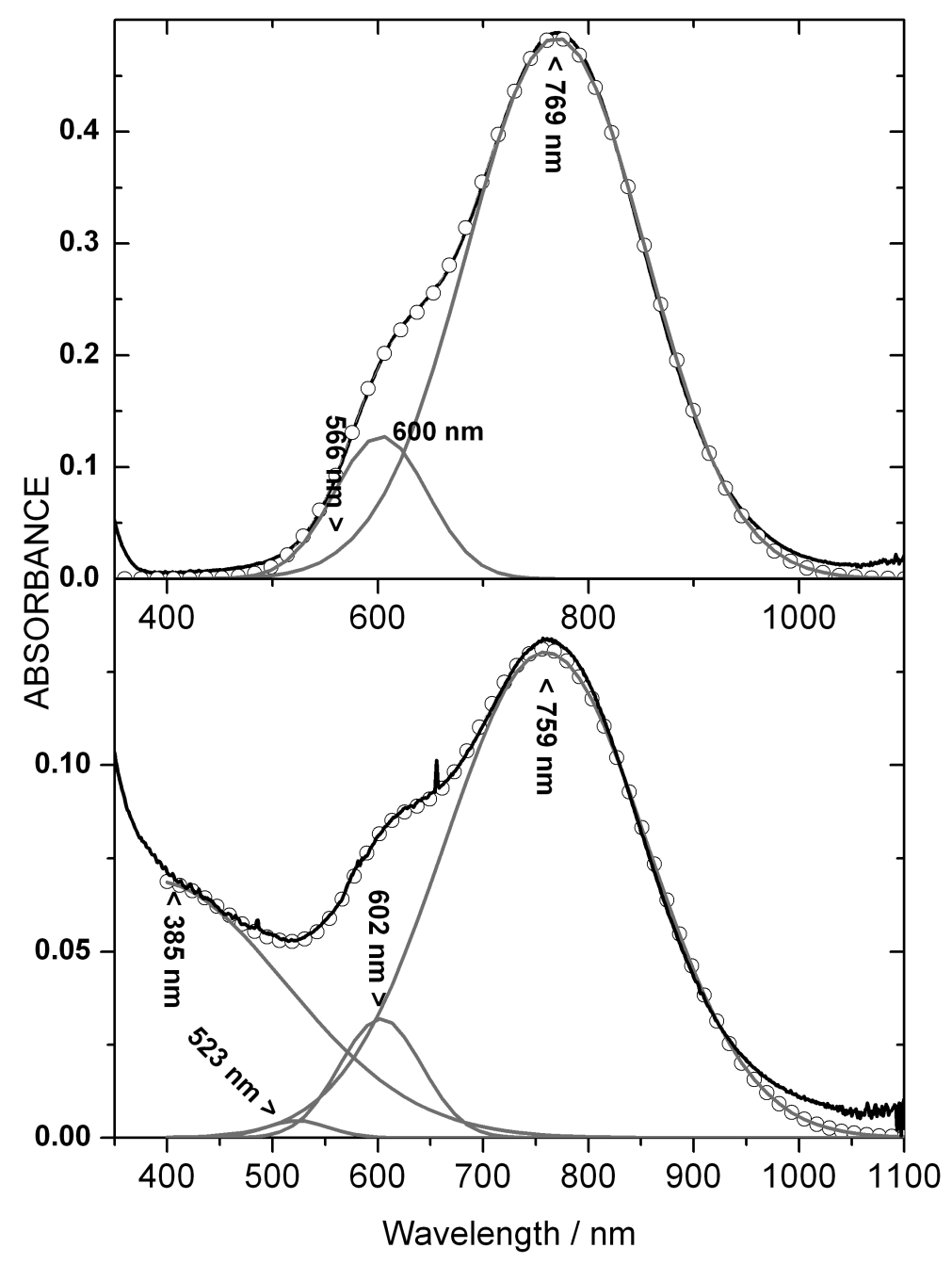

Figura 44: Espectros eletrônicos desconvoluídos em $\mathrm{H}_{2} \mathrm{O} / \mathrm{HCOOH} 60 \%$ do $[\mathrm{VO}(\beta-\mathrm{CB}[6]$

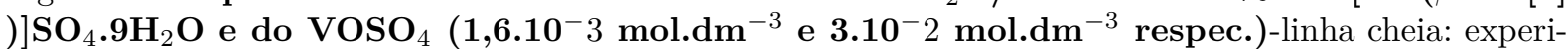
mental, cinza: desconvolução, bolinhas: espectros resultantes calculados.

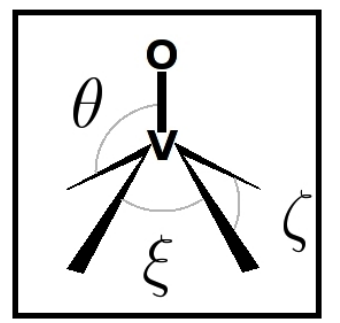

Figura 45: Diedros do íon $\mathrm{VO}^{2+}$ 
Tabela 6: Dados espectroscópicos para o $[\mathrm{VO}(\beta-\mathbf{C B}[\mathbf{6}])] \mathrm{SO}_{4} .9 \mathrm{H}_{2} \mathrm{O}$ e o $\mathrm{VOSO}_{4}$ e sua atribuição.

\begin{tabular}{|c|c|c|c|c|}
\hline Solvente & I $\left(\mathrm{cm}^{-1}\right)$ & II & II' & III \\
\hline $\mathrm{H}_{2} \mathrm{O} / \mathrm{HCOOH}$ & 13.175 & 16.610 & 19.120 & 25.974 \\
$\epsilon\left(\mathrm{cm}^{-1} . \mathrm{M}^{-1}\right)$ & 80 & 19 & 3 & 44 \\
VOSO $_{4}($ ac. fórmico $)$ & 13.000 & 16.666 & 17.667 & - \\
$\epsilon\left(\mathrm{cm}^{-1} . \mathrm{M}^{-1}\right)$ & 16 & 4 & 0,6 & - \\
Sólido & 12.804 & 15.045 & - & 30.233 \\
\hline
\end{tabular}

e a quarta banda não é visível no estado sólido. $\mathrm{O} \mathrm{VOSO}_{4}$ por sua vez apresenta 3 bandas apenas sendo uma delas muito fraca $(566 \mathrm{~nm})$. Os dados espectroscópicos estão relatados na tabela 6 .

Os resultados nos mostram uma série de transições proibidas por Laporte e em particular, transições compatíveis com a estrutura piramidal de base retangular onde $\xi<>\zeta$, previstas para uma simetria $\mathrm{C}_{2 v}$ Os dadoe de REP nos apresentam um padrão espectral típico do núcelo de ${ }^{51} \mathrm{~V}(\mathrm{IV})$ onde $\mathrm{I}=7 / 2$. O espectro fora simulado com uma precisão muito grande, considerando uma base quadrada levemente distorcida e utilizando os parâmetro e valores seguintes: $g_{\|}=1,921, g_{\perp}=1,97\left(g_{i s o}=1,954\right)$, and $A_{x x}=71,1 \times 10^{-4}$ $\mathrm{cm}^{-1}, A_{y y}=73,9 \times 10^{-4} \mathrm{~cm}^{-1}$, and $A_{z z}=182,4 \times 10^{-4} \mathrm{~cm}^{-1}\left(A_{i s o}=109,4 \times 10^{-4} \mathrm{~cm}^{-1}\right)$. Estes valores de $g_{i s o}$ e $A_{\text {iso }}$ são compatíveis aos da literatura ${ }^{236-242}$.É importante salientar, que foram feitas outras simulações, utilizando estes valores de $g_{\text {iso }}$ e $A_{\text {iso }}$ e assumindo uma simetria perfeitamente quadrada, para a base da pirâmide, e que em nehum caso foi obtida uma correspondência tão boa quanto a mencionada acima, principalmente na região maracda com um asterisco na figura 46.

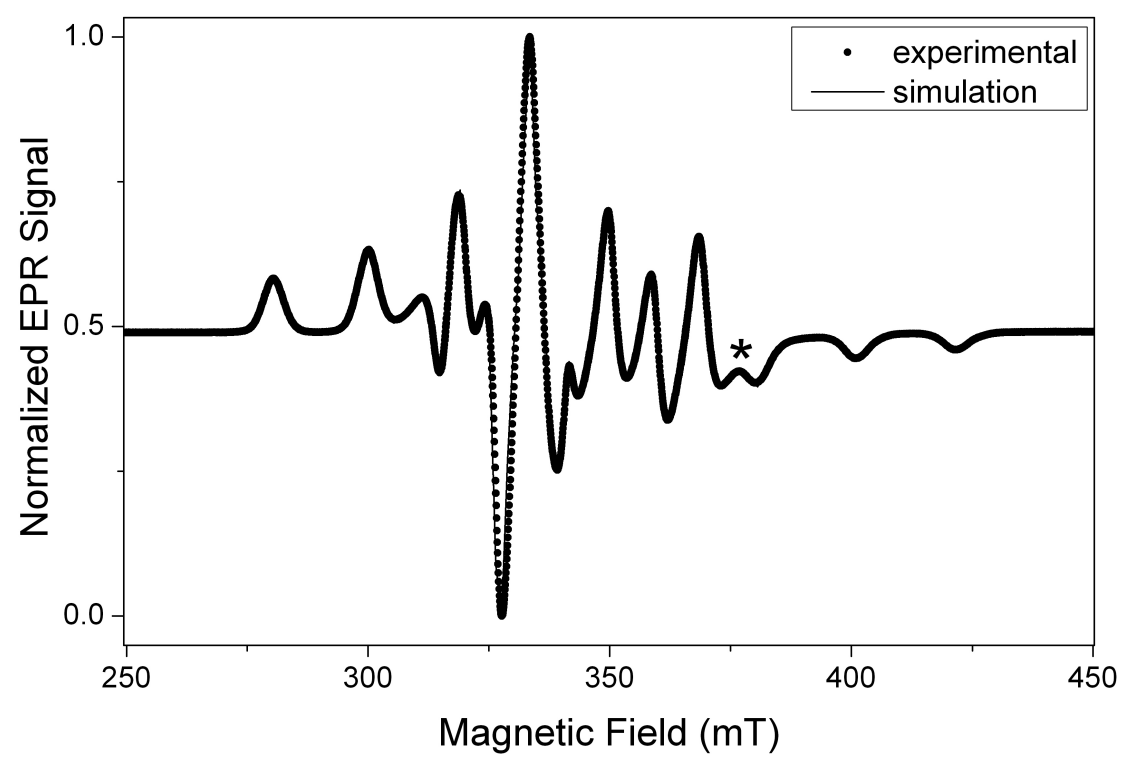

Figura 46: Espectro de ressonância de elétrons paramagnéticos do complexos de $\beta$-CB[6] com vanadila. 
Diversos autores tem estudado a geometria de coordenação do íon vanadila em ambientes similares por $\mathrm{REP}^{236}$ e comparando seus resultados a dados de difração de raios-X. Eles notaram que muitos destes complexos apresentam ambientes de coordenação mais parecidos com bipirâmides trigonais do que pirâmides de base quadrada. O valor de $\left|A_{x x}-A_{y y}\right|=2,8 \times 10^{-4} \mathrm{~cm}^{-1}$ reflete a intensidade de $\tau$, e mostra que a distorção de $\mathrm{C}_{4 v}-\mathrm{C}_{2 v}$ não é muito forte.

Com base nestes dados propusemos uma estrutura para o complexo parecida com a da figura 47.

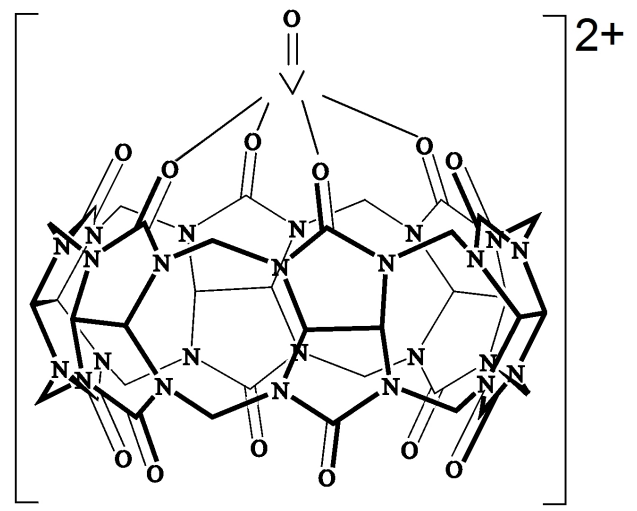

Figura 47: Estrutura proposta para o $[\mathrm{VO}(\beta-\mathrm{CB}[6])] \mathrm{SO}_{4} \cdot 9 \mathrm{H}_{2} \mathrm{O}$, baseada em dados espectroscópicos.

Pelos procedimentos descritos anteriormente não pudemos obter o análogo a esta estrutura binuclear, não sendo detectado em nenhuma etapa da preparação do mononuclear. Felizmente, o mononuclear é o compostos mais interessante pois é aquele que nos permite avaliar a atividade catalítica do íon vanadila em ambiente confinado. Nunca havia sido reportada uma estrutura similar na literatura, e podemos afirmar com toda a certeza se tratar do primeiro complexo metálico de $\beta$-CB[6] com um metal de transição.

\subsubsection{Catálise Seletiva}

Para reações de oxidação de alcanos, existem diversos mecanismos propostos na literatura, alguns dos quais mencionam que estas reações envolvem a ligação $\mathrm{V}=\mathrm{O}$ para a formação dos produtos ${ }^{243-245}$. Restringir o acesso dos substratos ao centro metálico é uma maneira importante de elucidar mecanismos de reações catalíticas. Foram realizadas uma série de reações catalíticas utilizando $[\mathrm{VO}(\mathrm{CB}[6])] \mathrm{SO}_{4} \cdot 9 \mathrm{H}_{2} \mathrm{O}$ para a oxidação de hidrocarbonetos como o n-pentano, o estireno, o ciclooctano e o ciclohexano. A escolha destes substratos foi proposital uma vez que o único a poder adentrar a cavidade do $\beta$ CB[6] é o n-pentano, tornando possível verificar se a entrada do substrato na cavidade é necessária à reação de oxidação. Utilizamos dois oxidantes: o peróxido de hidrogênio, por ser barato e gerar produtos simples, além do iodosil-benzeno, mais estável. Medidas eletroquímicas demonstararm que 3 estados de oxidação (3,4 e 5) do vanádio estão acessíveis, 
sem comprometer a estabilidade do complexo. Isto porquê os voltamogramas cíclicos do $[\mathrm{VO}(\mathrm{CB}[6])] \mathrm{SO}_{4} .9 \mathrm{H}_{2} \mathrm{O}$ apresentam dois pares de ondas aparentemente reversíveis (fig.48) correspondendo aos processos redox $\mathrm{V}^{3 / 4}$ (a-a') e $\mathrm{V}^{4 / 5}$ (b-b').

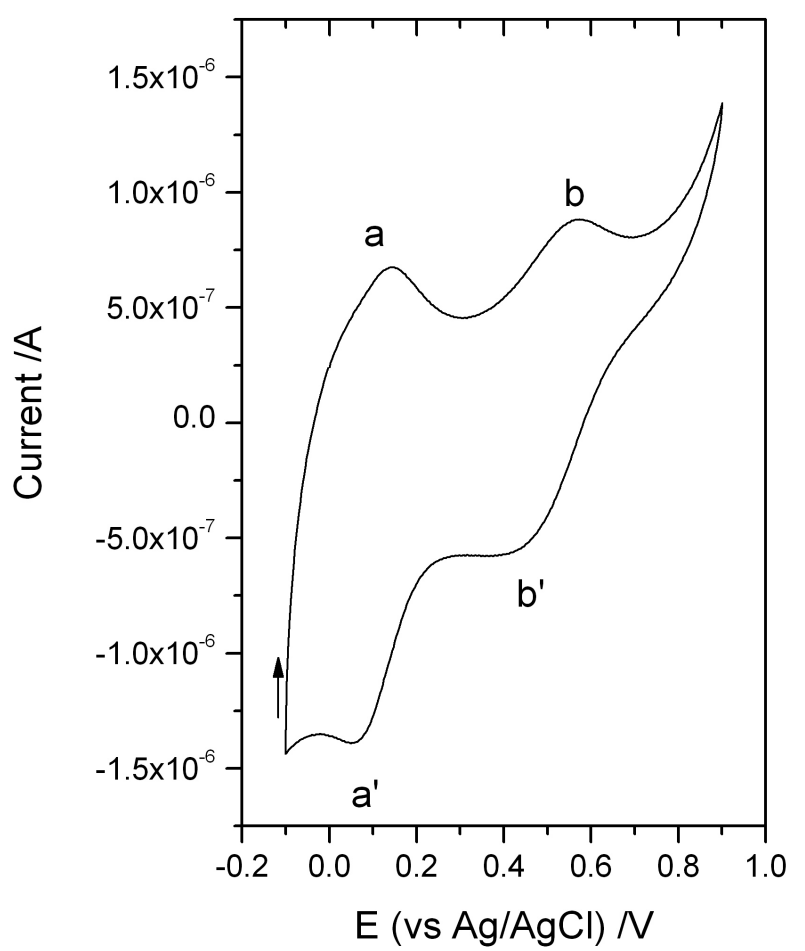

Figura 48: Voltamogramas cíclicos de $[\mathrm{VO}(\beta-\mathrm{CB}[6])](\mathrm{SO})_{4} .9 \mathrm{H}_{2} \mathrm{O}$ imobilizado sobre eletrodo de FTO $\left(10^{\circ}\right.$ ciclo, $\left.50 \mathrm{mV} \mathrm{s}^{-1}\right)$ em $\mathrm{HCl} 10^{-3}$ mol.dm $^{-3}$.

Os solventes empregados nestas reações foram a acetonitrila, a acetona, o benzeno e o diclorometano, para que pudessemos interpretar a influência do solvente nestas reações de oxidação à temperatura ambiente. Apesar de hidrofóbica, a cavidade do $\beta$-CB[6] pode acomodar moléculas de água em número elevado, por razões que ainda não são bem compreendidas. Para se eliminar a influência da água na cavidade secamos o catalisador de alguns testes catalíticos a $110^{\circ} \mathrm{C}$ por $8 \mathrm{~h}$, antes de ser utilizados (chamado de t.t.). Uma série de experimentos foi realizada como consta na tabela 7 e os detalhes dos experimentos de catálise encontram-se no apêndice deste documento.

A primeira coisa que salta aos olhos é que nem todos os substratos foram oxidados pelo $[\mathrm{VO}(\mathrm{CB}[6])](\mathrm{SO})_{4} \cdot 9 \mathrm{H}_{2} \mathrm{O}$, mesmo após períodos de $48 \mathrm{~h}$. Mesmo sabendo que substartos como o z-cicloocteno, o ciclohexano e o estireno são levados a formarem epóxidos em grandes quantidades ${ }^{243,244}$ na presença de complexos de $\mathrm{V}(\mathrm{IV})$, não foram detectados nos produtos das reações 1 a 3. No caso do n-pentano, foram detecados álcoóis e cetonas nos produtos de reação (essencialmente 2-pentanol, 2-pentanona e 3-pentanona), em 
Tabela 7: Ensaios catalíticos ("CBVO t.t." =CBVO tratado termicamente).

\begin{tabular}{ccccc}
\hline Ensaio & Substrato & Catalisador & Oxidante & Solvente \\
\hline 1 & z-Cicloocteno & CBVO & $\mathrm{H}_{2} \mathrm{O}_{2}(30 \%)$ & Acetonitrila \\
2 & Ciclohexano & CBVO & $\mathrm{H}_{2} \mathrm{O}_{2}(30 \%)$ & Acetonitrila \\
3 & Estireno & CBVO & $\mathrm{H}_{2} \mathrm{O}_{2}(30 \%)$ & Acetonitrila \\
4 & n-pentano & CBVO & $\mathrm{PhIO}$ & Acetonitrila \\
5 & n-pentano & CBVO & $\mathrm{H}_{2} \mathrm{O}_{2}(30 \%)$ & Acetonitrila \\
6 & n-pentano & CBVO t.t. & $\mathrm{PhIO}$ & Acetonitrila \\
7 & n-pentano & CBVO & $\mathrm{H}_{2} \mathrm{O}_{2}(30 \%)$ & Acetona \\
8 & n-pentano & CBVO & $\mathrm{H}_{2} \mathrm{O}_{2}(30 \%)$ & Diclorometano \\
9 & n-pentano & CBVO & $\mathrm{H}_{2} \mathrm{O}_{2}(30 \%)$ & benzeno \\
10 & n-pentano & CBVO & $\mathrm{PhIO}$ & Acetona \\
11 & n-pentano & CBVO t.t. & $\mathrm{PhIO}$ & Acetona \\
12 & n-pentano & CBVO t.t. & $\mathrm{H}_{2} \mathrm{O}_{2}(30 \%)$ & Acetona \\
13 & n-pentano & CB[6] puro & $\mathrm{PhIO}$ & Acetonitrila \\
\hline
\end{tabular}

proporções variáveis, além de subprodutos em quantidades diminutas. O fato de não encontrarmos 1-pentanol nos produtos de oxidação do pentano, é um forte indicativo de que a reação tenha se dado por intermediário de um radical de vida longa, que tivera tempo de migrar para carbonos secundários, gerando produtos 2 e 3-substituídos. A formação de alcoóis, poderia ser explicada por um mechanismo do tipo "oxygen rebound" mas deveria ocorrer no interior da cavidade (o que limita o processo pela alta molecularidade) ou ainda fora da cavidade, caso este radical formado fosse estável o bastante para sair dela e reagir, e sua saída seria uma etapa limitante do ponto de vista cinético para o processo catalítico como um todo. O oxidante também exerce um papel importante, já que são observados valores de turnover mais expressivos quando se utiliza $\mathrm{H}_{2} \mathrm{O}_{2}$ no lugar de iodosil-benzeno, que gera mais cetonas do que alcoóis. Quanto aos ciclos catalíticos, por serem observados em condições brandas, são relativamente altos, quando comparados a outros complexos ${ }^{228}$. Constatamos que a remoção das águas da cavidade afeta negativamente o desempenho do catalisador, quando comparamos os experimentos 4 e 6. Os solventes apróticos e polares como a acetonitrila facilitam a formação de cetonas, enquanto que os solventes menos polares facilitam a formação de alcoóis (tab. 8). 


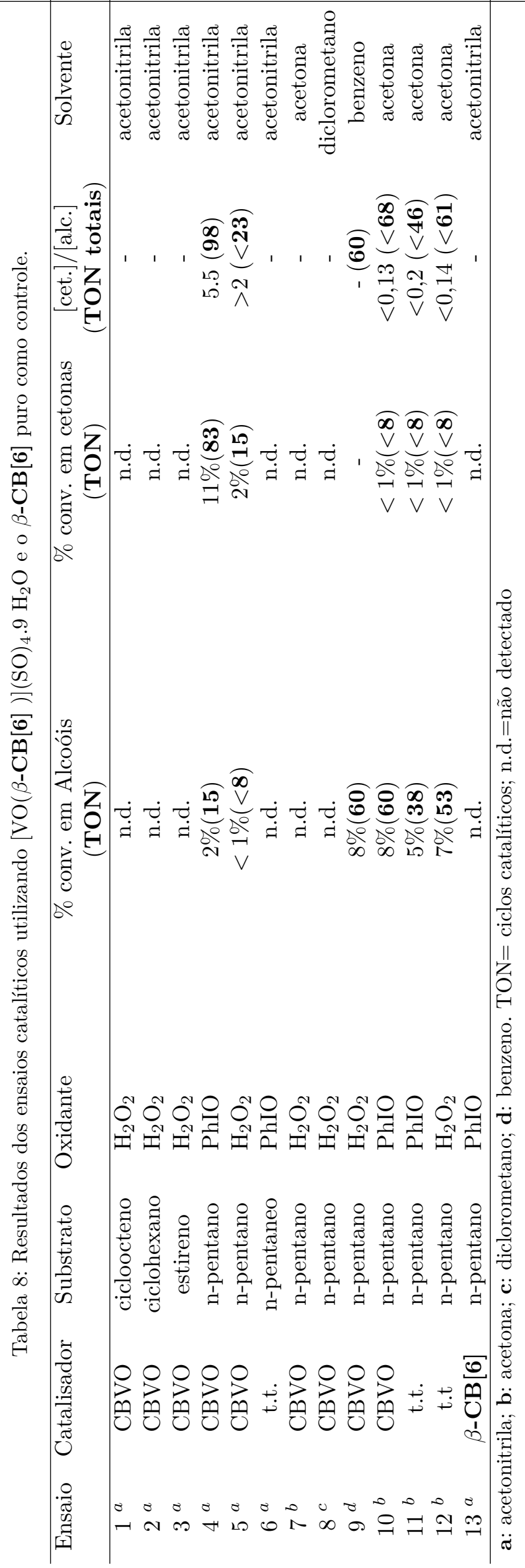


Estes resultados são bastante interessantes pois nos permitem deduzir uma série de coisas:

1. Descobrimos através deles que moléculas grandes não sofrem oxidação, indicando que esta se processa ao longo da orbital $d_{z^{2}}$.

2. A presença do oxidante, ativa os centros de vanádio, levando-os ao estado de oxidação $5^{+}$, o que explica a coloração amarela do catalisador esgotado.

3. O oxidante menor aumenta o número de ciclos catalíticos. Estaria ele dentro da cavidade também?

4. Estes centros criam espécies radicalares, que parecem ter vida longa o suficiente para sairem da cavidade, e se rearranjarem.

5. É importante que haja água para que as reações de oxidação ocorram.

6. Solventes pouco polares, mantêm as moléculas de água no interior da cavidade por interação solvofóbica. Talvez sejam elas a fonte de grupos $\mathrm{OH}$ na formação dos alcoóis.

7. Os rendimentos são baixos, indicando que há uma série de limitações mecanísticas, estéricas e cinéticas. É preciso haver tamanho adequado, molecularidade adequada, tempo de vida de radicais adequado e dissociação do caviplexo radicalar rápida o suficiente para que as reações ocorram.

A partir de um único composto de coordenação conseguimos demonstrar 7 relações existentes entre estrutura e atividade catalítica com muita simplicidade, o que é muito raro em artigos deste tipo. Para chegarem a este número de conclusões os autores em catálise geralmente precisam realizar estudos sistemáticos, envolvendo diversos compostos de coordenação diferentes, ou ainda disporem de técnicas de alto custo e complexidade. Aqui é um exemplo de como a presença de um macrociclo pode simplificar o estudo de mecanismos de reação por confinamento. Este trabalho foi o primeiro do gênero, a empregar complexos de cucurbiturilas com atividade catalítica para contribuir para a elucidação do mecanismo desta classe de reações, ainda bastante controverso na literatura. A figura 49 resume o que pudemos descobrir acerca deste sistema catalítico. Ainda não temos elementos suficientes para saber como se dá a aniquilação dos radicais livres formados para a formação de alcoóis e cetonas, que poderia ocorrer tanto dentro do cavitando quanto fora, nem tampouco como atua a água na formação de um intermediário de vanádio +5 . Para isto seriam necessários reagentes marcados, e uma análise mecanística mais detalhada, envolvendo cinética, espectrometria de massas e também REP e RMN. 


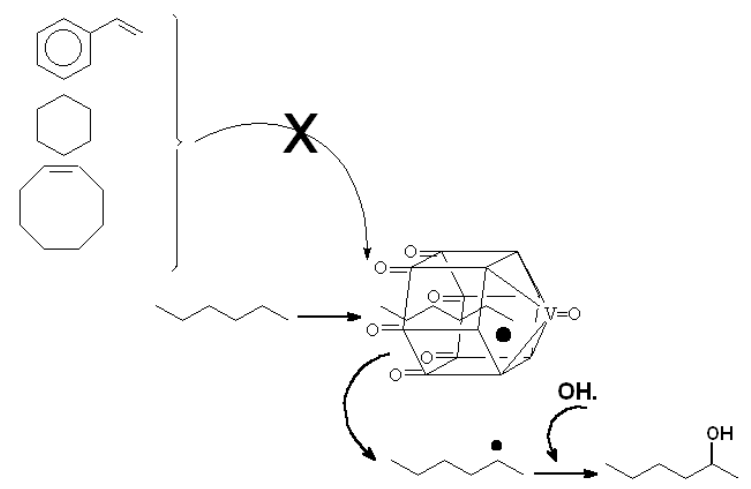

Figura 49: Esquema reacional envolvendo $[\mathrm{VO}(\mathrm{CB}[6])](\mathrm{SO})_{4} \cdot 9 \mathrm{H}_{2} \mathrm{O}$ na oxidação de hidrocarbonetos.

\subsection{Reguladores de fertilizantes NPK}

Até meados de 2006 não existia nenhum dado acerca da toxicidade dos cucurbitandos e seus derivados e homólogos. Por sua estrutura e atividade, esperava-se que agisse de maneira similar à valinomicina e éteres coroa ou outros antibióticos sequestrantes de íons. A baixa solubilidade destes compostos poderia limitar também sua atividade tóxica em organismos vivos. Este foi o primeiro impulso que nos levou a estudar a germinação e crescimento de plantas na presença destes compostos, já que seria o único tipo de experimento que seriamos capazes de desenvolver em nosso laboratório, sem envolver animais. Nosso trabalho demonstrou que não só as cucurbiturilas não parecem ser tóxicas, mas que também poderiam controlar o teor de íons no solo, atuando como reguladores iônicos. Alguns anos depois Nau e Day realizaram um estudo mais detalhado sobre toxicidade das $\gamma-\mathbf{C B}[7]$ e $\delta$-CB[8] in vitro e in vivo, chegando às mesmas conclusões que nós ${ }^{246}$. As cucurbiturilas são praticamente atóxicas e podem ser utilizadas como carreadores de fármacos ou materiais para aplicações biológicas.

A agricultura moderna pode alcançar marcas de produtividade impensáveis no passado graças aos progressos da ciência agronômica além das descobertas da genética. Muitos destes avanços foram alavancados pela descoberta e utilização dos fertilizantes químicos. O mais popular e conhecido deles talvez seja o "NPK" sigla que diz exatamente o que ele aporta: nitrogênio, na forma de nitratos ou amônio, fósforo, na forma de fosfatos e potássio na forma de óxido ou sal. Existe hoje uma enorme variedade de composições de NPK's além dos "super-fosfatos" e outros fertilizantes derivados. Para que possam ser aproveitados pelas plantas, precisam ser hidrossolúveis, e isto significa que boa parte deles será certamente lixiviada pelas chuvas após a sua aplicação na lavoura. Este fato , além de representar um grande desperdício de dinheiro, também é muito nocivo aos corpos aquíferos que recebem estes nutrientes lixiviados. Este excesso de nutrientes acaba promovendo a eutrofização destes corpos aquíferos compromentendo o equilíbrio entre as espécies locais. Sabe-se que as cucurbiturilas possuem grande afinidade po cátions duros especialmente 
Tabela 9: Constantes de estabilidade (log K, K em l/mol) para a complexação de CBn com íons alcalinos e alcalino-terrosos, da ref. ${ }^{148}$. ${ }^{*}$ decametil- $\alpha-\mathbf{C B}[5]$

\begin{tabular}{cccc}
\hline Ion & $\alpha$-CB[5] & $\mathrm{DM} \alpha-\mathbf{C B}[5] *$ & $\beta$-CB $[\mathbf{6}]$ \\
\hline $\mathrm{Na}^{+}$ & $1,85 \pm 0,05$ & - & $\sim 3,49 \pm 0,04$ \\
$\mathrm{~K}^{+}$ & $1,31 \pm 0,07$ & $1,11 \pm 0,05$ & $2,85 \pm 0,02$ \\
$\mathrm{Rb}^{+}$ & $1,01 \pm 0,32$ & $0,92 \pm 0,09$ & $2,98 \pm 0,03$ \\
$\mathrm{Cs}^{+}$ & $0,90 \pm 0,34$ & - & $2,52 \pm 0,04$ \\
$\mathrm{Ca}^{2+}$ & $1,73 \pm 0,07$ & $1,61 \pm 0,09$ & $3,61 \pm 0,03$ \\
$\mathrm{Sr}^{2+}$ & $1,50 \pm 0,13$ & $1,59 \pm 0,05$ & $2,90 \pm 0,03$ \\
$\mathrm{Ba}^{2+}$ & $1,32 \pm 0,16$ & $1,32 \pm 0,10$ & - \\
$\mathrm{NH}_{4}^{+}$ & $1,32 \pm 0,12$ & $1,10 \pm 0,28$ & $2,84 \pm 0,01$ \\
\hline
\end{tabular}

por alcalinos e alcalino-terrosos, formando diversos tipos de adutos e complexos. Por serem pouco solúveis, e sobretudo atóxicos, podemos pensar em imobilizar nutrientes em CBs por coordenação, na esperança que sejam liberados gradualmente conforme o aporte de água ao sistema, no equilíbrio que se estabelece entre a forma coordenada e os íons e ligantes livres conforme equação 5.2.

$$
[M(C B)]^{+}+H_{2} O \rightleftharpoons C B+M_{a q}^{+}
$$

A maioria dos fertilizantes NPK comerciais apresentam-se na forma de pellets duros, de solubilidade reduzida, justamente com o objetivo de reduzir perdas por lixiviação. Mesmo assim, estes se mantém nesta forma por curtos períodos de tempo. Observando a tabela 9 , notamos a grande afinidade das moléculas de $\beta$ - $\mathbf{C B}[6]$ por íons $\mathrm{K}^{+}$e $\mathrm{NH}_{4}^{+}$, que são os protagonistas principais deste estudo, sendo que os íons fosfato estão presentes na forma de contra-íons.

A figura 50 descreve bem a idéia desenvolvida aqui. Do lado esquerdo teríamos a situação em que se emprega NPK para a adubação, sendo que pouco é aproveitado efetivamente pela planta uma vez que a maior parte do aporte mineral é lixiviado e portanto perdido. No caso de NPKs estabilizados com cucurbiturilas, teríamos compostos iônicos muito menos solúveis, capazes de liberarem $\mathrm{K}^{+}, \mathrm{NH}_{4}^{+}$e consequentemente fosfato em quantidade pequenas porém constantes, de acordo com o equilíbrio de dissociação estabelecido na eq.5.2, aumentando a absorção efetiva da planta, estendendo o tempo de vida no solo do fertilizante e evitando sua lixiviação.

Preparamos então complexos de $\beta$-CB $[6]$ com $\mathrm{K}^{+}$e com $\mathrm{NH}_{4}^{+}$na forma de $\left(\mathrm{NH}_{4}\right) \mathrm{H}_{2} \mathrm{PO}_{4}$ e $\mathrm{KCl}$ (1:2 $\beta$-CB[6] / cátion), por refluxo em água e subsequente evaporação do solvente. Os complexos de $\mathrm{K}^{+}$e $\mathrm{NH}_{4}^{+}$foram misturados formando um pó branco na proporção 6:4, equivalente a de um NPK comercial 4-14-8 (Ultraverde). A esta mistura demos o nome de $\beta$-CB[6] NPK. Realizamos uma série de testes de germinação, tanto em substrato sólido quanto em condições hidropônicas, com diversos vegetais: o feijão comum (Phaseolus Vulgaris ssp., solo), alface (Lactuca Sativa,hidropônico), agrião (Spilanthes Acmella, hi- 


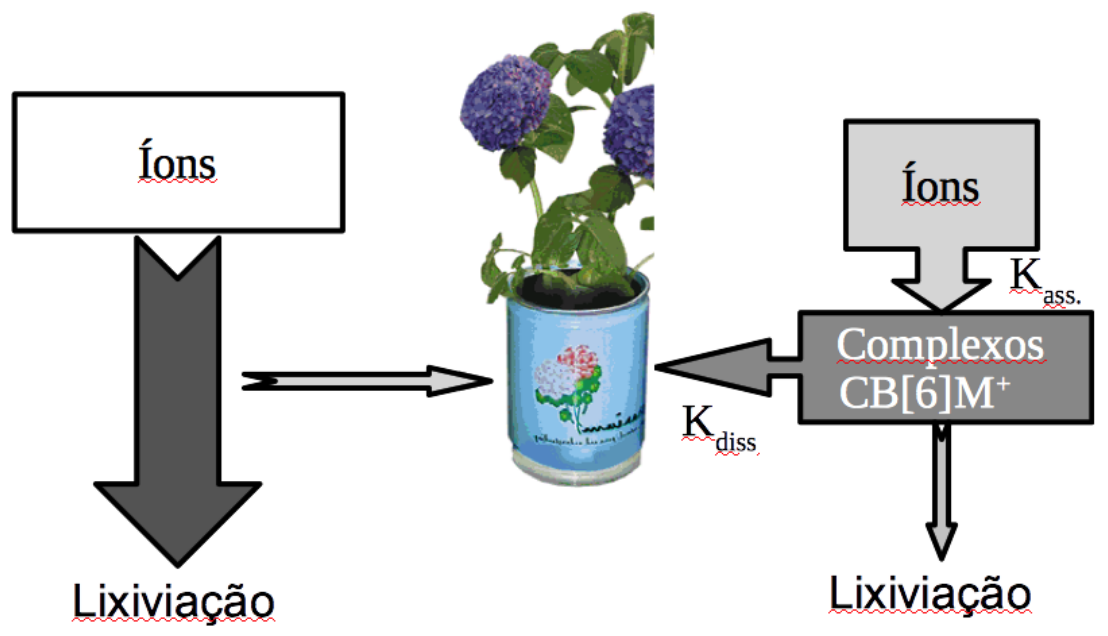

Figura 50: Esquema da regulação de íons no solo, mostrando o mecanismo de liberação sustentada governada pelos equilíbrios de formação e dissociação dos complexos de CB[6] com íons alcalinos.

dropônico ${ }^{1}$ ) e rúcula (Eruca Sativa, hidropônico), adicionando o $\beta$-CB[6] NPK, $\beta$-CB[6] sózinho, NPK comercial sózinho e comparamos os resultados a uma população de controle, em solo empobrecido ou água somente.

\subsubsection{Testes de germinação em solo}

Para avaliar melhor o efeito real da carga de fertilizante, procuramos empobrecer ao máximo o substrato utilizado em nossos experimentos. Para isto fervemos e filtramos $5 \mathrm{~kg}$ de solo laterítico laranja da região de Ribeirão Preto peneirado e misturamo-no com $1 / 4 \mathrm{~m} / \mathrm{m}$ de areia de quartzo. A fervura foi repetida mais duas vezes afim de se reduzir ao máximo a quantidade de íons solúveis e compostos orgânicos na matriz. O substrato foi sêco por uma semana. Foram então preparadas 4 sementeiras, com 35 poços cada, contendo 10 gramas de terra cada um, com aditivos, exceto a população de controle. A quantidade de NPK e de $\beta$-CB[6] NPK corresponde a 0,02 mol de cátions para cada 10 g de solo. Esta é uma composição que deveria ser estimulante de enraizamento, de acordo com o fabricante do NPK. Cada poço recebeu uma semente de feijão carioca comum (Broto Legal).

Após 7 dias de crescimento, pudemos observar diferenças significativas entre as populações de brotos. O tamanho médio dos brotos na presença de $\beta$ - $\mathbf{C B}[6]$ sozinho foi maior do que o das outras populações em $30 \%$ (tab. 10, figs. 53 e 52). Na presença de NPK puro, sementes deram origem preferencialmente a raizes ao invés de crescerem na vertical. As sementes com $\beta$-CB[6] NPK comportaram-se de maneira parecida com as da população controle, exercendo pouca influência no processo. Em termos de taxa

1 Há diversas espécies conhecidas com o nome de agrião: Nasturtium officinalis; Lepidium sativum, Barbarea verna entre outras. Utilizamos o agrião comum, sem maiores especificações do produtor de sementes. 


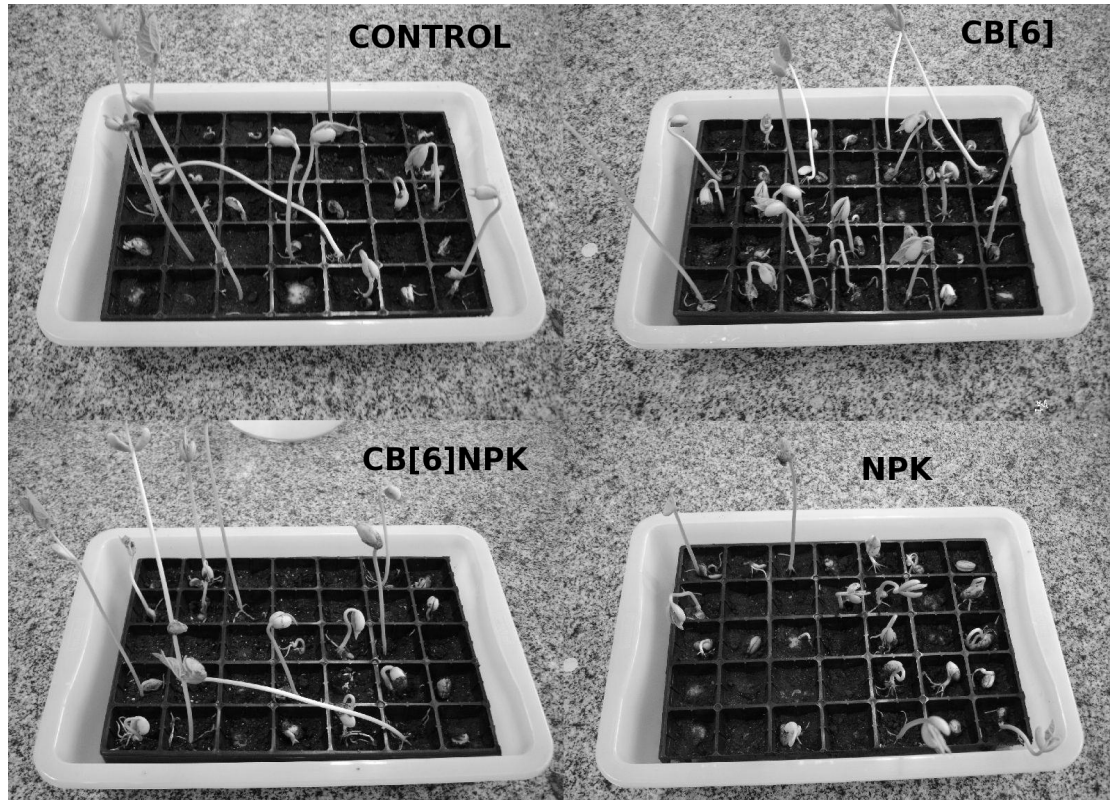

Figura 51: Testes de germinação com feijão comum em bandejas. De cima pra baixo, esquerda para a direita: Controle, $\beta-\mathrm{CB}[6], \beta-\mathrm{CB}[6]$ NPK, e NPK

de germinação, o $\beta$-CB[6] novamente, causou um aumento de $10 \%$ na viabilidade das sementes. O fato da população com $\beta$-CB[6] ser diferente da população de controle, e do $\beta$-CB[6] NPK não exercer efeito enraizador como o NPK sozinho, demonstra claramente que o macrociclo exerce um efeito importante no balanço iônico dos meios.

Tabela 10: Testes de germinação de Phaseolus Vulgaris ssp. na presença de diversos aditivos.

\begin{tabular}{ccccc}
\hline Meio & $\begin{array}{c}\text { Taxa . } \\
\text { de germin }\end{array}$ & $\begin{array}{c}\text { Formação } \\
\text { de raiz }^{2}\end{array}$ & $\begin{array}{c}\text { Tam méd.caule /cm } \\
\text { (D.pad./amplit.) }\end{array}$ & $\begin{array}{c}\text { Tam méd.raiz /cm } \\
\text { (D.pad./amplit.) }\end{array}$ \\
\hline Solo estéril & $51 \%$ & $0 \%$ & $5,88(8,36 / 27)$ & $1,45(1,77 / 5)$ \\
Solo+CB[6] & $62 \%$ & $0 \%$ & $8,65(8,06 / 24)$ & $2,00(1,66 / 5)$ \\
Solo+CB[6]NPK & $51 \%$ & $0 \%$ & $6,25(8,04 / 24)$ & $1,54(1,73 / 5)$ \\
Solo+NPK & $48 \%$ & $5,7 \%$ & $4,82(6,82 / 19)$ & $1,42(1,57 / 4)$ \\
\hline
\end{tabular}

1) raiz e caule ou só raiz. 2) Sementes que só enraizaram; não foram desconsideradas

\subsubsection{Testes de germinação hidropônica}

Por ser mais simples de se controlarem os parâmetros realizamos testes diretamente em solução em algo que se parece com cultura hidropônica. Neste caso utilizamos a água deionizada como meio de controle. Utilizamos para isto sementes de rúcula (Eruca sativa), alface (Lactuca sativa) e agrião (Spilanthes acmella), que foram distribuidos em placas de poço (spot test pots) em $3 \times 5$ sementes com $0,5 \mathrm{~mL}$ de líquido que podia ser água, suspensão de CB[6]NPK ou de CB[6] a 1,62.10-6 mol.dm ${ }^{-3}$ ou NPK em concentração equivalente. As sementeiras (ver figs. 54,56 e 55) foram colocadas no escuro por 3 


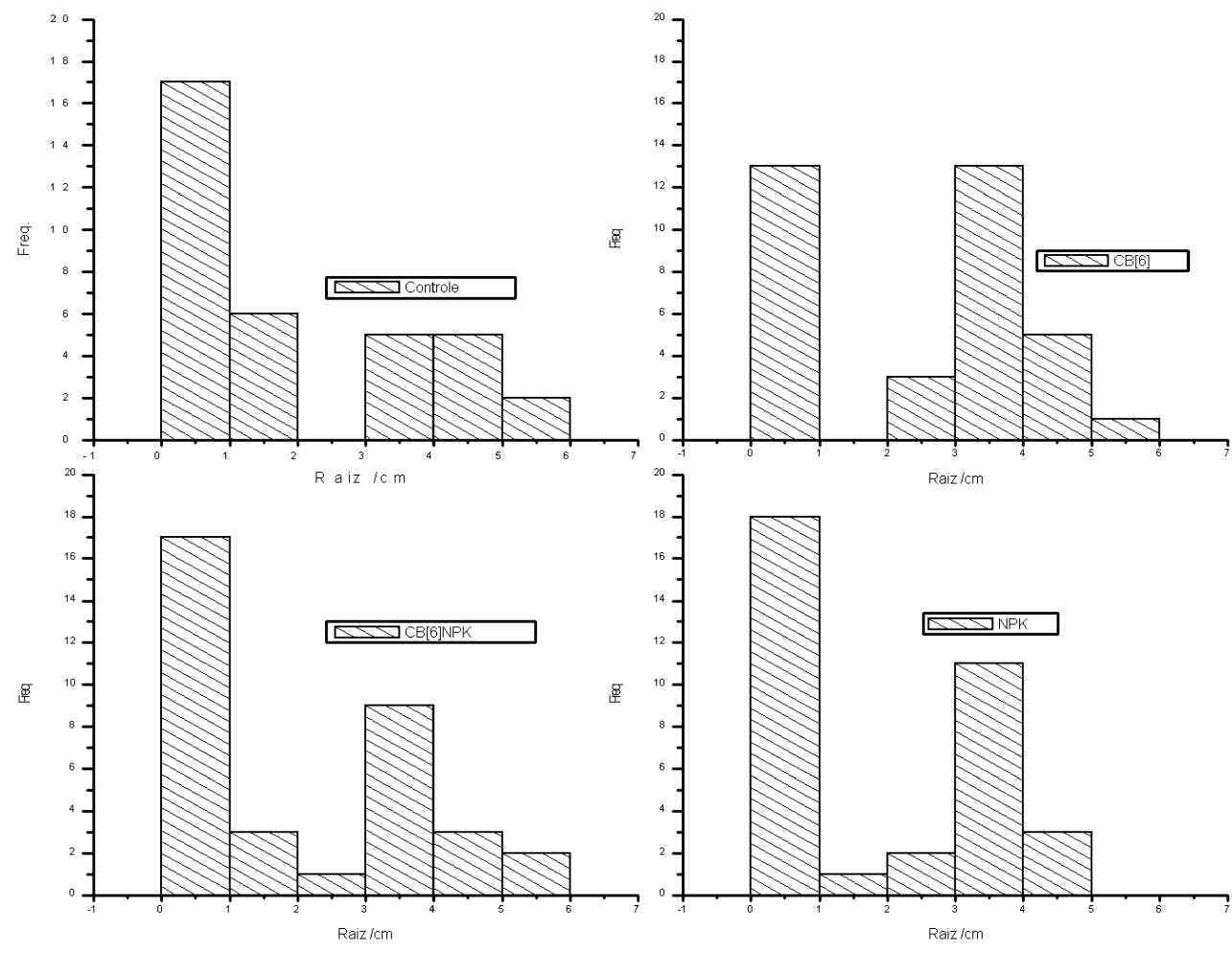

Figura 52: Desenvolvimento das raizes de feijão na presença dos aditivos.

dias, depois dos quais fotografamos e medimos os brotos. Estes procedimentos são comuns na literatura ${ }^{247-251}$.

Os resultados em água foram bastante diferentes dos obtidos em solo (ver tab. 11). As taxas de germinação com $\beta$-CB[6] em água foram muito menores em água do que em solo (exceto para a alface), indicando que o $\beta$-CB[6] está provavelmente subtraindo íons necessários à germinação das próprias sementes, inibindo seu cresciemento. Esta hipótese ganha força quando comparamos os resultados obtidos para o $\beta$ - $\mathbf{C B}[\mathbf{6}] \mathrm{NPK}$, que não foi capaz de aumentar a taxa de germinação mas deu origem a brotos maiores do que aqueles que nasceram com $\beta$-CB $[\mathbf{6}]$. Os resultados mostraram também que há espécies mais suscetíveis do que outras à presença de um sacador de íons como o $\beta$-CB[6] . A presença de NPK puro neste meio inibiu totalmente a germinação das sementes, pois provavelmente tenha tornado o meio hipertônico.

Dependendo da espécie utilizada, temos taxas de germinação crescentes na seguinte ordem (tab. 12):

É importante analisarmos a água efluente (ou eluvial) e os íons que contém para 


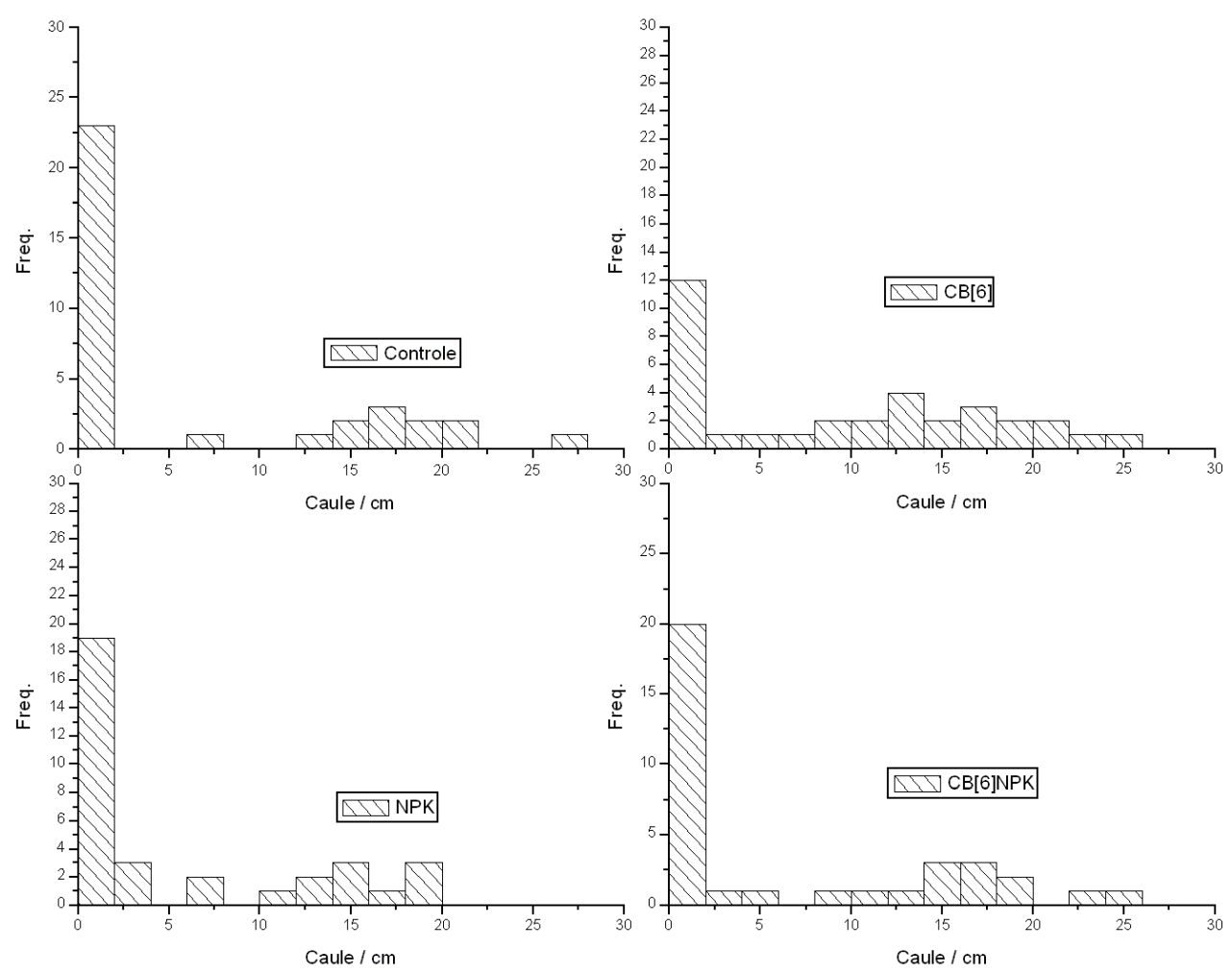

Figura 53: Desenvolvimento dos caules de feijão na presença dos aditivos.

Tabela 11: Testes de germinação hidropônica de Lactuca Sativa, Eruca Sativa e Spilanthes Acmella na presença de aditivos.

\begin{tabular}{ccc}
\hline Lactuca Sativa & Germinação \% & Tam. méd. Brotos /mm \\
\hline Água & 93 & 4 \\
Água/CB[6] & 100 & 1 \\
Água/CB[6]NPK & 86 & 2,5 \\
Água/NPK & 0 & 0 \\
\hline Eruca Sativa & & \\
\hline Água & 100 & 6 \\
Água/CB[6] & 93 & 4 \\
Água/CB[6]NPK & 93 & 0 \\
Água/NPK & 0 & \\
\hline Spilanthes Acmella & & 1 \\
\hline Água & 93 & 1 \\
Água/CB[6] & 66 & 1 \\
Água/CB $[6]$ NPK & 73 & 0 \\
Água/NPK & 0 &
\end{tabular}




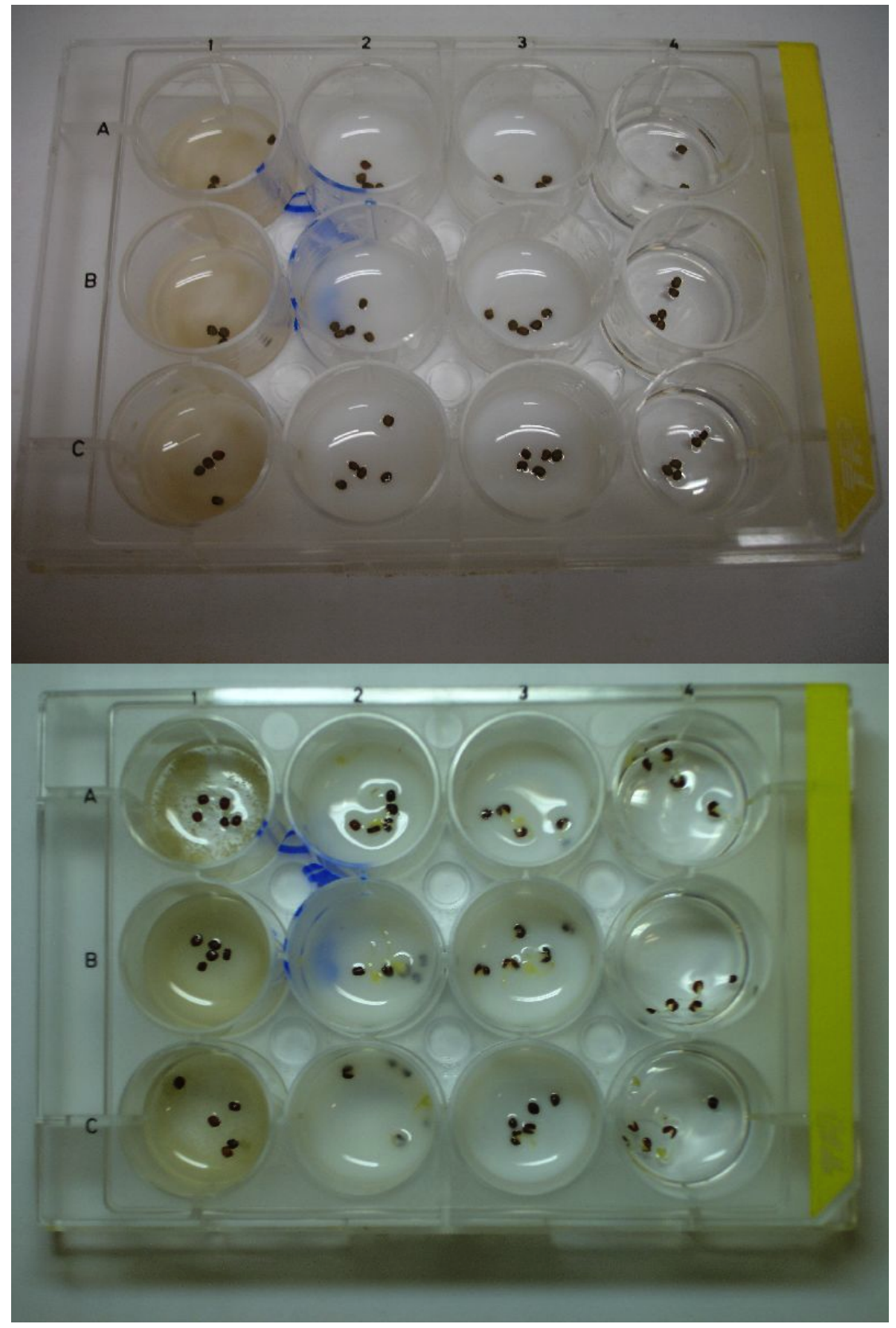

Figura 54: Testes de germinação hidropônica com Spilanthes acmella (agrião).

Tabela 12: Taxas de germinação por espécie e meio e tamanho médio dos brotos.

\begin{tabular}{|c|c|c|}
\hline Espécie & Taxa de germinação & Tam. dos brotos \\
\hline Lactuca sativa & $\mathrm{NPK}<\beta-\mathrm{CB}[\mathbf{6}] \mathrm{NPK}<\mathrm{H}_{2} \mathrm{O}<\beta-\mathrm{CB}[\mathbf{6}]$ & $\mathrm{NPK}<\beta-\mathbf{C B}[\mathbf{6}]<\beta-\mathbf{C B}[\mathbf{6}] \mathrm{NPK}<\mathrm{H}_{2} \mathrm{O}$ \\
\hline Eruca sativa & $\mathrm{NPK}<\beta-\mathbf{C B}[\mathbf{6}] \mathrm{NPK}=\beta-\mathbf{C B}[\mathbf{6}]<\mathrm{H}_{2} \mathrm{O}$ & $\mathrm{NPK}<\beta-\mathbf{C B}[\mathbf{6}]<\beta-\mathbf{C B}[\mathbf{6}] \mathrm{NPK}<\mathrm{H}_{2} \mathrm{O}$ \\
\hline Spilanthes acmella & $\mathrm{NPK}<\beta-\mathbf{C B}[\mathbf{6}]<\beta-\mathbf{C B}[\mathbf{6}] \mathrm{NPK}<\mathrm{H}_{2} \mathrm{O}$ & $\mathrm{NPK}<\beta-\mathbf{C B}[\mathbf{6}]=\beta-\mathbf{C B}[\mathbf{6}] \mathrm{NPK}=\mathrm{H}_{2} \mathrm{O}$ \\
\hline Phaseolus vulgaris* & $\mathrm{NPK}<\mathrm{H}_{2} \mathrm{O} \beta-\mathbf{C B}[\mathbf{6}] \mathrm{NPK}<\beta-\mathbf{C B}[\mathbf{6}]$ & $\mathrm{NPK}<\mathrm{H}_{2} \mathrm{O}<\beta-\mathrm{CB}[\mathbf{6}] \mathrm{NPK}<\beta-\mathrm{CB}[\mathbf{6}]$ \\
\hline
\end{tabular}




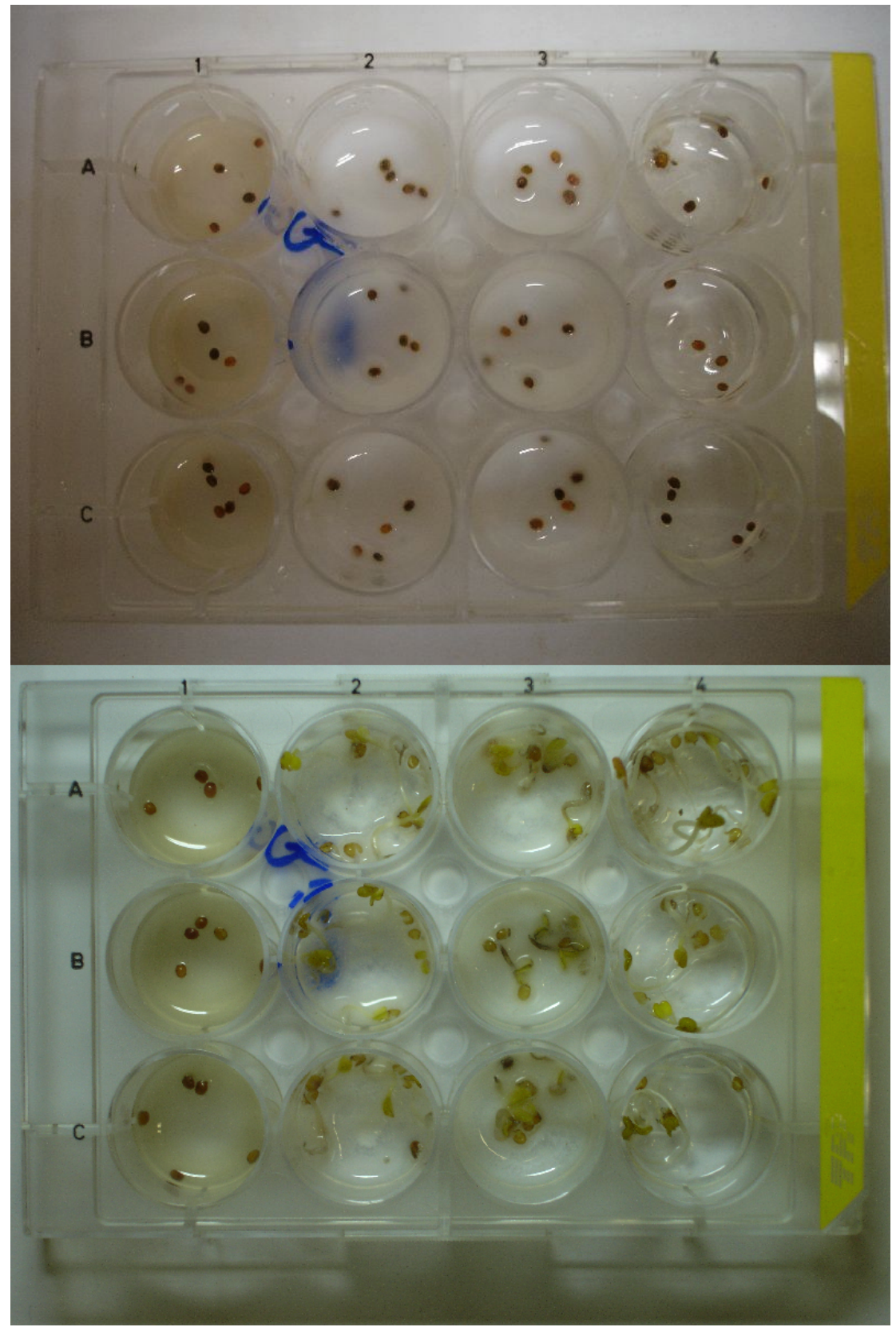

Figura 55: Testes de germinação com Eruca sativa (rúcula). 


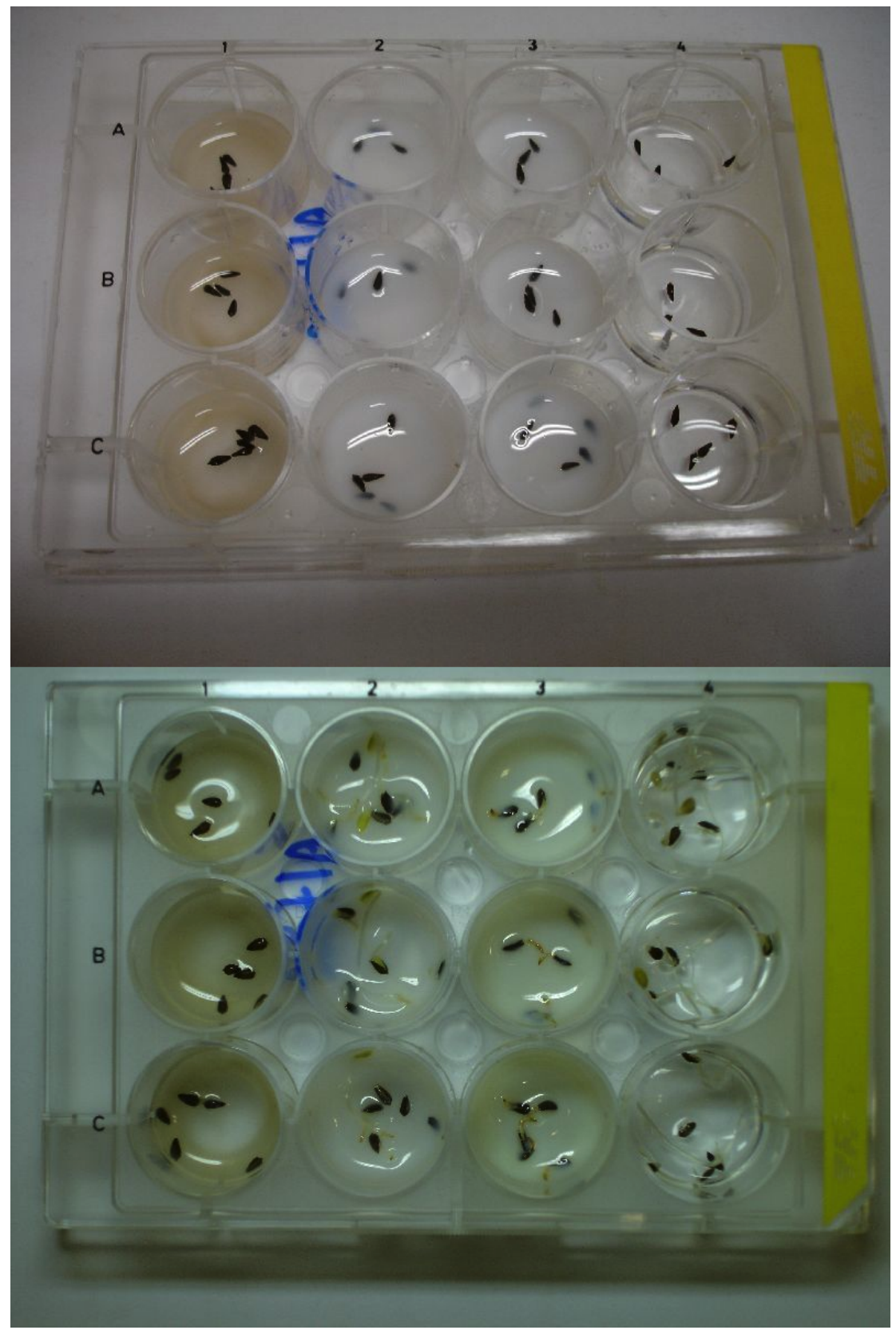

Figura 56: Testes de germinação com Lactuca sativa (alface). 
Tabela 13: Concentrações médias de P e K na água eluvial das amostras (Desv. Pad. em itálico); <:abaixo do lim. de deteç̧ão

\begin{tabular}{ccc}
\hline Amostra & $\mathrm{P} / \mathrm{ppm}$ & $\mathrm{K} / \mathrm{ppm}$ \\
\hline Água deionizada & $<0,0554(0,0003)$ & $<0,0571(0,0355)$ \\
CB[6] & $0,0554(0,0108)$ & $12,99(0,0077)$ \\
CB[6]NPK & $0,0554(0,0019)$ & $10,31(0,1111)$ \\
NPK & $0,2753(0,0157)$ & $122,8(0,787)$ \\
controle & $<0,0554(0,0039)$ & $4,365(0,2129)$ \\
\hline
\end{tabular}

entendermos melhor como agem os macrociclos na germinação e crescimento de sementes. A presença de algum ionóforo no solo deveria alterar as concentrações de íons no efluente. As quantidades de íons nos efluentes de solo (ensaios com feijões) foi estimada por condutimetria assim como os teores de P e K por ICP-OES, em colaboração com o grupo da Profa. Márcia Veiga, do nosso departamento, e os resultados constam na tabela 13.

Estes resultados indicam que o substrato tratado contém muito pouco potássio e fósforo livres, o que pode ser compreendido pela presença de íons $\mathrm{Fe}^{3+}$, e pelo fato do substrato ter sido empobrecido antes de sua utilização. A Adição de NPK ao meio aumenta muito a concentração de ambos. O $\beta$-CB[6] NPK, reduz a quantidade de íons lixiviados como poderíamos esperar em quase dez vezes, mostrando assim que de fato o $\beta$-CB $[6]$ retém os minerais no solo, evitando que sejam drenados pela água. O ponto de interesse aqui é que a presença de $\beta$ - $\mathbf{C B}[\mathbf{6}]$ sózinho também age desta forma, mas parece extrair cátions do meio, dos minerais do solo ou ainda das próprias sementes, o que explicaria seu efeito mais pronunciado sobre as sementes. O mais interessante é que os teores de $\mathrm{K}^{+}$para ambos os meios que contêm $\beta$-CB[6] são próximos, o que indica que a liberação destes cátions deve ser governada por algum equilíbrio, como acreditavamos no início do experimento. Os dados de condutividade (fig. 57) mostram que há outros íons envolvidos neste processo todo, já que as condutividades dos dois meios $(\beta-\mathbf{C B}[\mathbf{6}]$ e $\beta$-CB[6] NPK) são bem diferentes, e isto talvez seja por conta dos íons $\mathrm{NH}_{4}^{+}$que não pudemos quantificar a contento. $\mathrm{O}$ pH destes efluentes varia de 7,4 a 7,6 , indicando que a liberação eventual de prótons pelo $\beta-\mathbf{C B}[6]$ não poderia ser o responsável por estas variações de condutividade.

Estes experimentos nos levam a concluir que o $\beta$-CB[6] não inibe a germinação, nem o crescimento de plantas, sendo compatível com espécies vegetais variadas apesar de exercer algum efeito. A intensidade do efeito que exerce depende muito do meio em que se encontra e principalmente da espécie que se está a estudar, pois em alguns casos observamos brotos maiores e em outros menores na presença do macrociclo. Em termos de taxas de germinação seu efeito não é tão importante, já que são relativamente altas em sua presença. A presença de $\beta$-CB $[6]$ no solo aumenta a oferta de íons, quando com- 


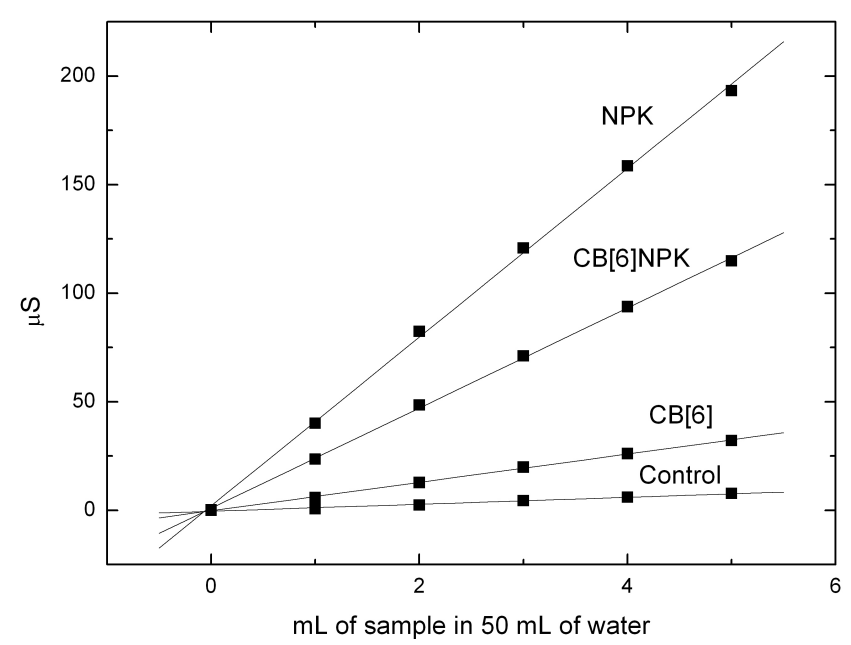

Figura 57: Condutividade da água eluvial dos testes com Phaseolus $v$. em sucessivas diluições

parada à do solo estéril, pois o macrociclo parece ser capaz de extraí-los de alguma forma do substrato, tornando-os disponíveis. Quando combinado ao NPK, consegue agir como regulador iônico, já que não inibe nenhum processo estudado aqui, mesmo em grandes quantidades, o que se mostrou inviável com NPK puro, como mostraram os dados. Apesar do espaço amostral ainda ser relativamente pequeno para dar suporte estatístico a estas constatações, estes são fortes indícios de que há bastante a ser feito no campo dos fertilizantes à base de cucurbiturilas. 


\section{Nanocompósitos e nanomateriais}

Um trabalho publicado por Corma e colaboradores foi o marco inicial para o desenvolvimento de nanopartículas utilizando cucurbiturilas. Neste artigo ${ }^{180}$, os autores utilizaram a cavidade de $\alpha$-CB[5] , $\beta$-CB[6] , e $\gamma-\mathbf{C B}[7]$ para gerarem clusteres nanométricos de ouro a partir de $\mathrm{HAuCl}_{4}$ reduzido por $\mathrm{NaBH}_{4}$ em misturas de etanol e água. Demonstraram desta forma que as cavidades de $\gamma$-CB[7] geravam clusteres de aproximadamente 0,7 nm de diâmetro, dentro destas cavidades. Apesar de não serem capazes de incluir clusteres, a $\alpha$-CB[5] e a $\beta$-CB [6] exerciam certa influência sobre a dispersidade das populações de nanopartículas (NP) obtidas em sua presença, que eram sempre menores que $7 \mathrm{~nm}$. Ficou demonstrado e posteriormente confirmado ${ }^{252,253}$ que as cucurbiturilas poderiam agir como moldes para a preparação de nanomateriais.

A partir deste momento foi iniciada uma corrida entre diversos grupos em busca de novas rotas sintéticas para outros compostos nanométricos. Nosso grupo iniciou seus trabalho já em 2008, quando nos comprometemos a desenvolver nanopartículas de prata, por suas propriedades antimicrobianas, e de semicondutores inorgânicos, na esperança de obtermos pontos quânticos.

Pontos quânticos podem ser obtidos reduzindo o tamanho de semicondutores até dimensões que provoquem confinamento quântico gerando materiais muito interessantes que encontram aplicações em diversos campos da tecnologia como por exemplo: sensores, mecanismos anti-fraude, iluminação (LEDs brancos de alta potência), medicina (como marcadores celulares), laseres, células solares entre outras ${ }^{254-257}$. Este esforço resultou na dissertação de mestrado do Sr. Érick Matheus Smaniotto dos Santos em 2010, e posteriormente em dois artigos ${ }^{258,259}$. Neste interim, Yu publicou a preparação de pontos quânticos de CdSe-ZnS preparados em cápsulas formadas por CBs e polímeros, que não utilizam a cavidade do macrociclo, mas que se aproximava bastante de nossos objetivos. Obteve assim pontos quânticos luminescentes encapsulados ${ }^{260}$. Posteriormente Scherman e seu grupo chegaram à conclusão que a $\alpha-\mathbf{C B}[5]$ interagia com NP de ouro, adsorvendo sobre sua superfície, e agindo assim como uma espécia de cola para as nanopartículas ${ }^{261}$, demonstarndo que as carbonilas dos portais do macrociclo eram capazes de se ligar à superfície fortemente, o que pode ser comprovado por efeito SERS ${ }^{262}$. Surgiram também NP de $\mathrm{Pd}$ com propriedades catalítcas, preparadas a partir de $\mathrm{PdCl}_{2}$ e $\mathrm{NaBH}_{4}$ na presença de $\beta$-CB[6] por $\mathrm{Cao}^{263}$, mas o trabalho não deixa claro qual o papel do macrociclo, mas deduz-se que só esteja adsorvido nos gérmens das nanopartículas limitando seu tamanho, e orientando seu crescimento. Geckeler em $2010^{264}$ e Masson em $2011^{14}$ publicaram dois 
trabalhos sobre o mesmo tema, onde descreviam a utilização de $\alpha-\mathbf{C B}[5], \beta-\mathbf{C B}[\mathbf{6}], \gamma-$ $\mathbf{C B}[7]$ e $\delta$-CB[8] para a preparação de NP de prata, o que acabou com nossas chances de publicar a primeira parte da dissertação de mestrado de Santos, já que conduziram aos mesmos resultados. Quando existe uma cavidade grande o suficiente, as nanopartículas podem se formar em seu interior, caso contrário, os macrociclos parecem adsorver à superfície de clusteres e posteriormente à superfície das nanopartículas, agindo frequentemente como elementos aglutinadores. O trabalho com semicondutores seguiu, e pudemos preparar estruturas como nanodiscos de $\mathrm{PbI}_{2}$, e outros iodetos de metais pesados. Neste caso há um efeito evidente da ação das cucurbiturilas, já que pudemos formar estruturas esfoliadas, circulares, e que apresentaram confinamento quântico. O mecanismo de formação destas estruturas será discutido adiante. De maneira análoga foi possível produzir nanoesferas de zincita, outro semicondutor utilizando cucurbiturilas da mesma forma.

Outro objetivo no tocante à utilização de CBs como direcionadores estruturais era a preparação de nanocompósitos com os macrociclos. Até o presente, nosso grupo foi o único a utilizar as cucurbiturilas para a preparação de materiais híbridos funcionais orgânicos/inorgânicos na forma de intercalados com hidróxidos duplos lamelares e pentóxido de vanádio lamelar. Este trabalho nos rendeu uma tese de doutoramento (Dr. L. F. Stucchi da Silva), uma dissertação de mestrado (F. de Araújo Silva) um artigo ${ }^{265}$ e outro submetido. Provamos que era possível preparar compostos de intercalação pilarizados com estes macrociclos a despeito de sua baixa solubilidade. Mostramos também que a intercalação é reversível em alguns casos, e que a presença dos macrociclos nas matrizes de intercalação altera significativamente suas propriedades, tornando estes híbridos, candidatos para veículos de liberação controlada e cátodos de baterias de íons de lítio. Serão apresentados estes resultados a seguir.

\subsection{Cucurbiturilas como molde para o preparo de nanopartículas metálicas e semicondutoras}

\subsubsection{Nanopartículas de prata}

Nossa primeira incursão na preparação de NPs metálicas suportadas por cucurbiturilas se deu utilizando $\mathrm{AgNO}_{3}$ e $\gamma$-CB[7] em meio aquoso em proporções variáveis que iam de 1:10 até 10:1 doscomponentes ${ }^{266}$. Os íons $\mathrm{Ag}^{+}$foram reduzidos com $\mathrm{NaBH}_{4}$ gerando uma série de soluções estáveis, e amarelas cuja tonalidade varia com a concentração de $\gamma$-CB[7] (fig. 58)

Fica evidente à primeira vista, que a presença de $\gamma-\mathbf{C B}[7]$ evita que se formem nanopartículas grandes demais para interagirem com a luz pelo espalhamento de Mie. A 


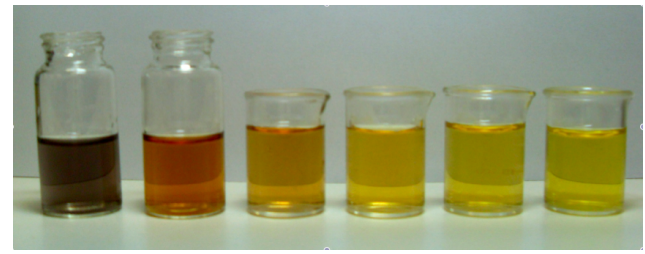

Figura 58: Soluções de nanopartículas de prata. Da esquerda para direita: Amostra sem $\gamma$-CB[7] e amostras com razões $\mathrm{Ag} / \gamma-\mathrm{CB}[7]$ de $4 ; 2 ; 1 ; 0,5 ;$ e 0,25

suspensão preta é a prova disto. Está espalhando luz por espalhamento Rayleigh em todos os comprimentos de onda, o que indica paratículas da ordem de centenas de nanometros. $\mathrm{O}$ espectro de absorção delas, comparado ao das NPs geradas com $\gamma-\mathbf{C B}[7]$ (1:1) comprova isto de fato (fig. 59). Nos espectros observamos este contínuo de absorção, que é substituído por uma ou duas bandas de plasmon na síntese com o macrociclo ${ }^{267,268}$. Fica evidente que o $\gamma$-CB[7] evitou que as NP crescecem demais, mantendo-as em tamanhos bastante reduzidos.

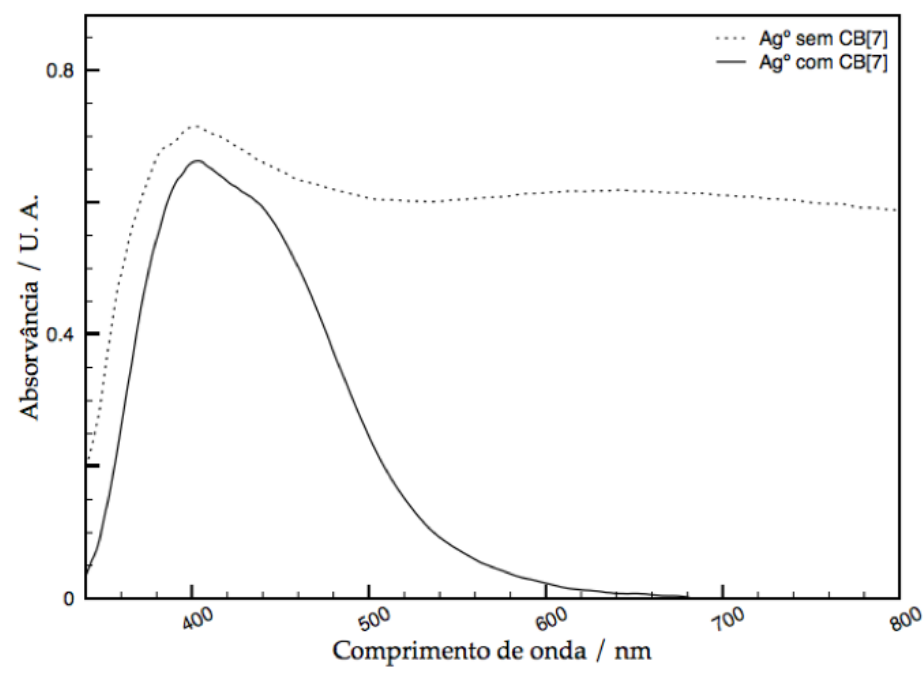

Figura 59: Espectros de absorção das nanopartículas de prata formadas na presença e na ausência de $\gamma-\mathrm{CB}[7]$ (1:1) evidenciando tamanhos de partículas menores com o macrociclo.

Observando os espectros de absorção de todas as partículas preparadas com $\gamma$ CB[7] , notamos que seus espectros são bastante parecidos, com bandas de plasmon em torno de $400 \mathrm{~nm}$ e, nos casos em que há excesso de Ag, a presença de um ombro cada vez mais intenso em torno de $450 \mathrm{~nm}$ que vai se intensificando e se delsocando para o vermelho à medida que aumenta a quantidade de Ag no meio. Estes espectros atestam crescentes quantidades de NP grandes, como na ausência de CB (figs 60 e 61).

Existem trabalhos na literatura que procuram correlacionar absorção eletrônica com o tamanho das NP 267,269 . Nestes trabalhos são utilizados basicamente dois dados: a posição da banda de plasmon, e sua largura à meia-altura. Algumas correlações foram estabelecidas entre estes parâmetros e o tamanho de NP de prata esféricas. Estas correlações 


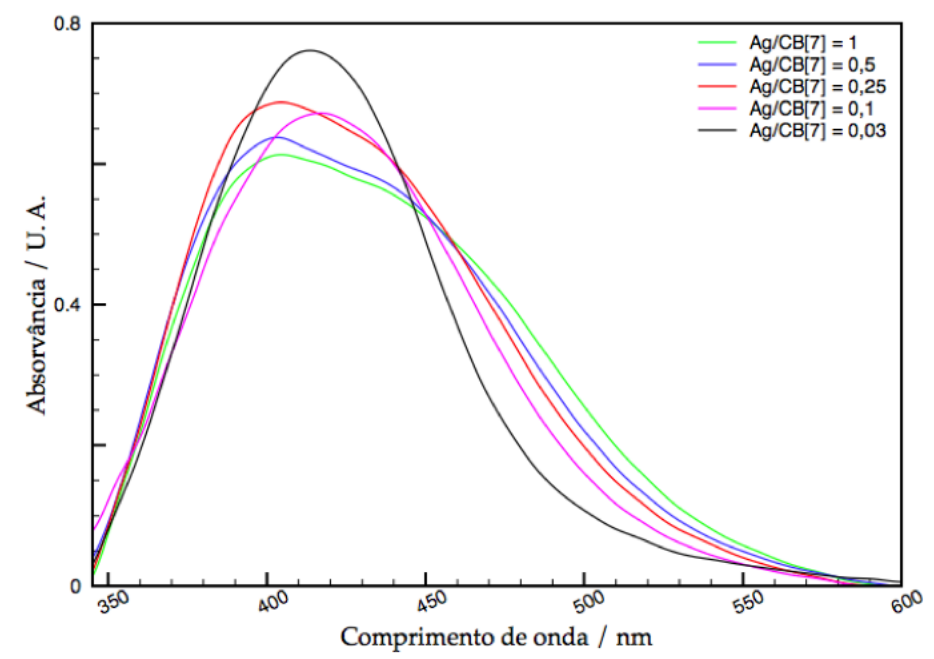

Figura 60: Espectros eletrônicos das nanopartículas de prata sintetizadas com razões $\mathbf{A g} / \gamma$ CB[7] igual ou menores que 1 .

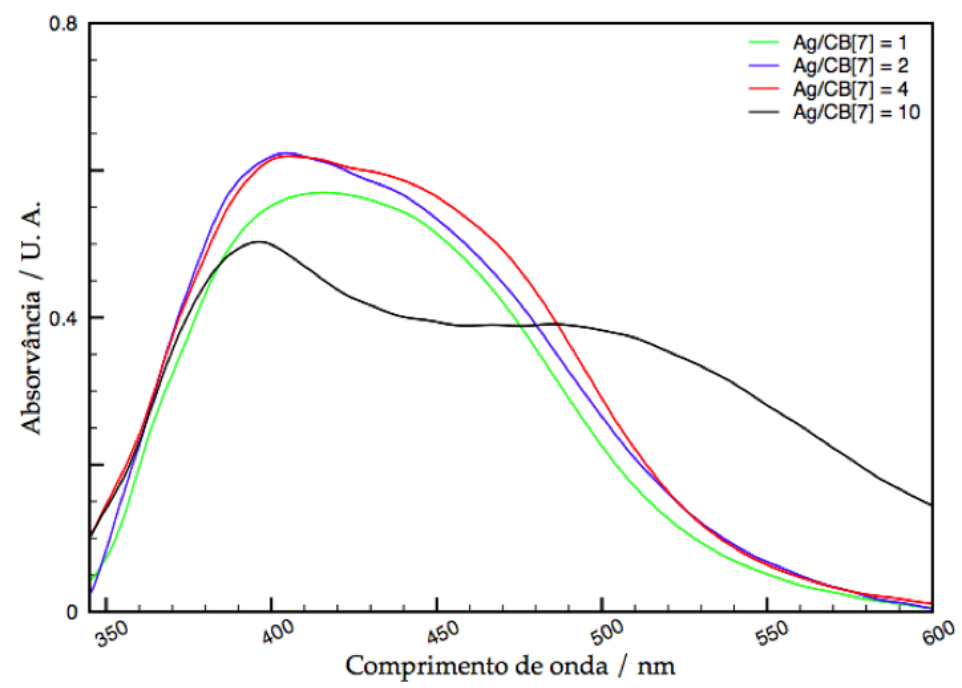

Figura 61: Espectros eletrônicos das NP de prata preparadas com razões de $\mathbf{A g} / \gamma-\mathbf{C B}[7]$ iguais ou maiores que 1 .

empíricas (fig.62 e 63) não são lineares, e a utilização dos dois parâmetros é aconselhada para estimativas de tamanho utilizando estes dados. Utilizamos este princípio para calcular o tamanho médio de nossas nanopartículas, sobre espectros não desconvoluidos. Os dados colhidos assim como os tamanhos estimados constam na tabela 14. Nela constam as posições da banda de plasmon e os tamanhos estimados por elas, assim como as larguras de meia-banda e os tamanhos estimados com elas. É fácil perceber que não há coerência aparente entre valores e composições assim como entre estimativas obtidas por um ou outro parâmetro. Os tamanhos foram medidos então por microscopia de transmissão de alta resolução.

As imagens de HRTEM (fig.64), nos mostram glóbulos quase esféricos, de tamanhos que variam entre 2 e $20 \mathrm{~nm}$ para a maioria das amostras, o que não condiz com as 


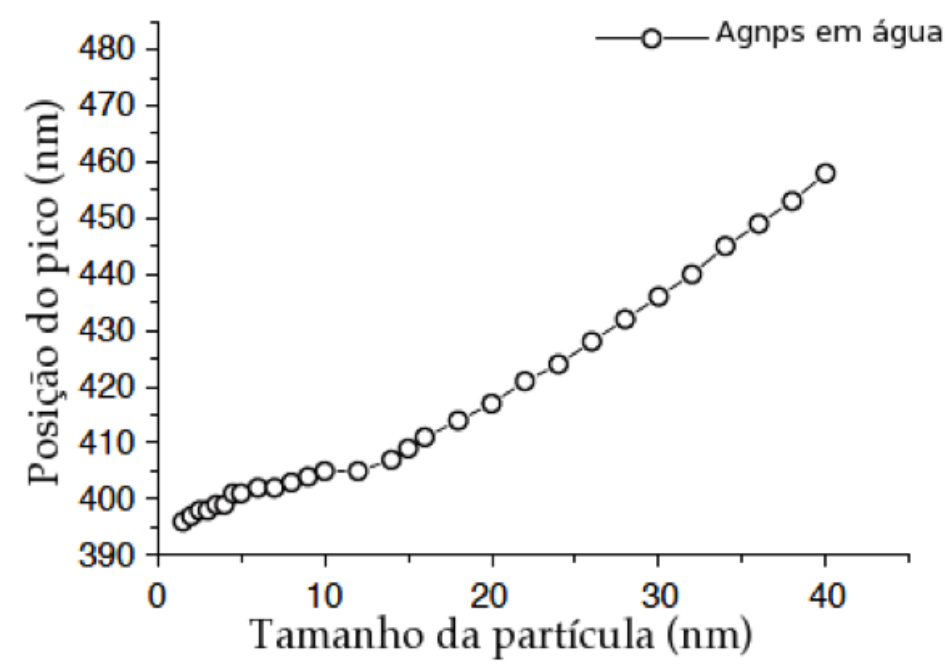

Figura 62: Correlação entre tamanho de partícula e máximo de absorção da banda de plasmon da prata. ${ }^{269}$

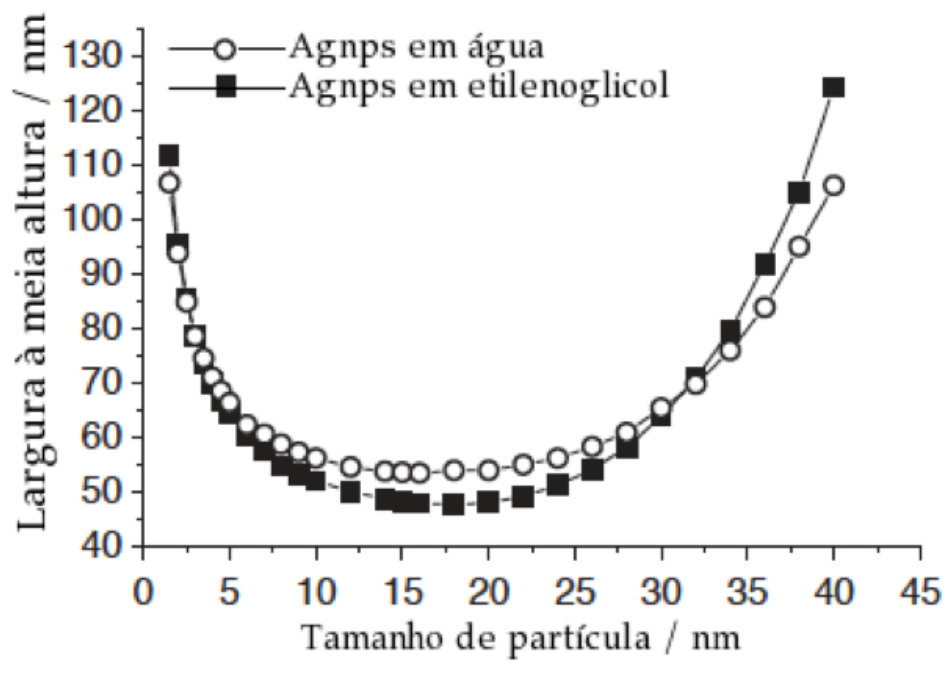

Figura 63: Correlação entre tamanho de partícula e largura de meia banda de plasmon da prata. ${ }^{269}$

Tabela 14: Estimativa do tamanho das NP de prata a partir dos dados espectrais.

\begin{tabular}{lcccc}
\hline Razão Ag/CB & $\lambda$ max $/ \mathrm{nm}$ & Tam./ $\mathrm{nm}$ & Meia largura $/ \mathrm{nm}$ & Tam./ $\mathrm{nm}$ \\
\hline 0,03 & 410 & 16 & 82 & 35 \\
0,1 & 415 & 22 & 100 & 37 \\
0,25 & 399 & 5 & 109 & 38 \\
0,5 & 395 & 2 & 116 & 40 \\
1 & 413 & 20 & 125 & 40 \\
2 & 407 & 15 & 154 & $>40$ \\
4 & 407 & 15 & 145 & $>40$ \\
10 & 395 & 2 & 180 & $>40$ \\
\hline
\end{tabular}


previsões baseadas nos espectros eletrônicos das amostras(fig. 65). Isto pode ser explicado de diversas formas: A primeira é que existam várias bandas sobrepostas no espectros, comprometendo as estimativas de valores de $\lambda$ máx. e a largura de meia banda, o que é nítido nos espectros da figura 61. A outra é que não sejam pratículas exatamente esféricas, para as quais a relação deveria ser válida. A terceira explicação é que tenham se formados partículas pequenas e grandes, e o espelhamento de Mie começa a dar lugar ao espalhamento Rayleigh, dando origem a bandas largas e mal definidas. Um fato curioso é que todas as proporções levam a dispersidade e tamanhos similares, sem diferenças significativas, a não ser quando a prata está em largo excesso, que gera partículas muito maiores além das pequenas. Isto é compreensível e reforça que o fator que gera as NPs pequenas é mesmo a $\gamma$-CB[7] .

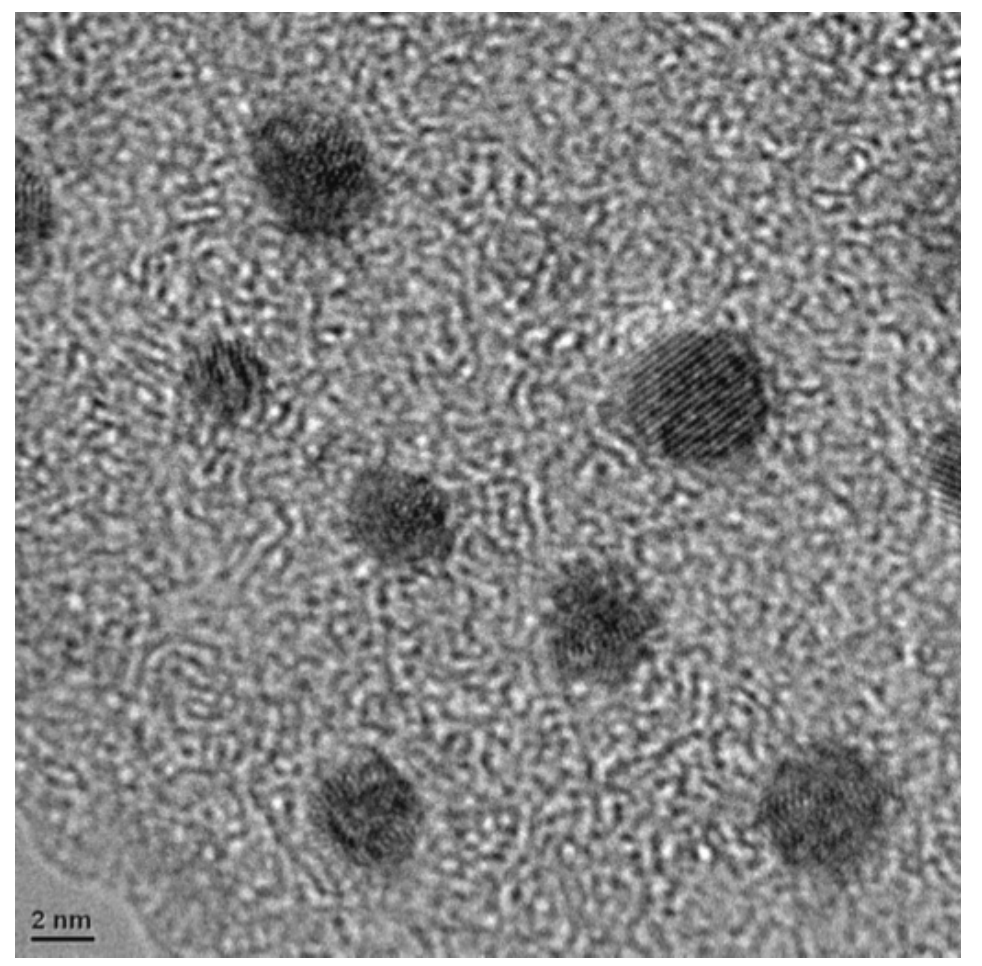

Figura 64: Fotomicrografia de transmissão eletrônica de nanopartículas Ag/ $\gamma$-CB[7] (1:1) a $800 \mathrm{k}$ vezes.

Ao que tudo indica, é muito difícil obter clusteres incluídos nas cavidades da $\gamma$ CB[7] por esta rota sintética. É possível até que tenham se formado, mas não pudemos detectá-los com as téncias que utilizamos aqui. Talvez também tenham sido eliminados das amostras durante a filtração dos precipitados que foram utilizados para a obtenção da imagens de microscopia. Todavia, percebemos nitidamente que a $\gamma$-CB[7] exerce um efeito de molde no crescimento das NPs e que gera estruturas não totalmente esféricas aparentemente, já que correlações entre dados de absorção e tamanho não parecem corresponder à realidade. Neste caso nos parece razoável imaginar que os macrociclos estejam de fato adsorvidos à superfície das NP uma vez que que este tipo de comportamento foi verificado com a $\alpha$-CB[5] em ouro ${ }^{262}$. O fato de serem extremamente estáveis, até 


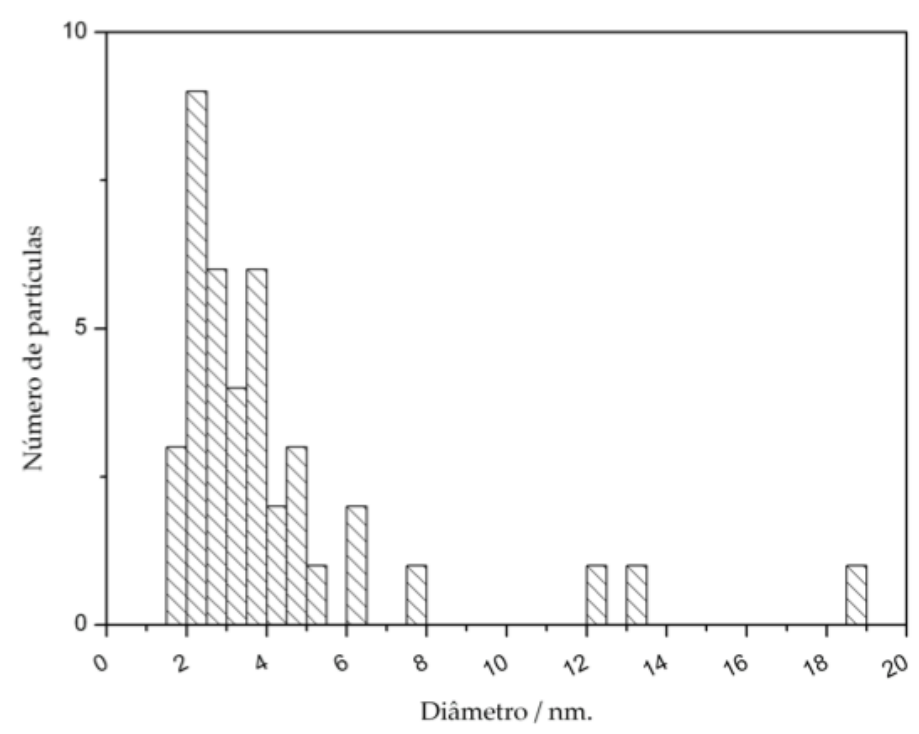

Figura 65: Dispersidade das NP de $\mathrm{Ag} / \gamma-\mathrm{CB}[7]$ 1:1 aferida por microscopia de transmissão

mesmo em meios salinos, como verificamos, indica que as CBs não estão em solução , mas sim que agem como anti-aglutinantes nas NPs, evitando que coalescam, mesmo depois de meses ${ }^{270}$. Isto só pode ser explicado se houver coordenação de cátions nos opérculos apostos à superfície das nanopartículas. Este tipo de efeito de molde é conhecido como efeito grampo, e está representado na figura 67. A figura 66 mostra um agregado de 4 nanopartículas em um empacotamento tetraédrico, estando duas delas no plano superior na horizontal e duas no plano posterior, na vertical. Em uma medição simples estimamos que estejam separadas por aproximadamente 1,9 nm, o que corresponderia e duas vezes a altura da $\gamma$-CB[7] que é de 9,1 A. Isto só corrobora com o modelo de grampo.

\subsubsection{Nanopartículas de iodetos de $\mathrm{Pbl}_{2}$}

O iodeto de chumbo é um sólido semi-condutor lamelar que admite politipos, contando com uma estrutura covalente em folhas ligadas entre si por interações fracas do tipo Van der Waals. Nas lamelas, estão presentes ânions iodeto em empacotamento compacto hexagonal, com interstícios octaédricos alternadamente ocupados por cátions $\mathrm{Pb}^{2+271}$, como consta na figura 68. Como toda matriz lamelar, o iodeto de chumbo forma uma série de compostos de intercalação, com espécies químicas variadas como hidrazina, amônia, anilina, piperidina e quinolina entre outros. Estes hóspedes, alteram significativamente as propriedades do iodeto de chumbo. De acordo com a teoria de dureza de Pearson ${ }^{179}$ os íons $\mathrm{Pb}^{2+}$ não deveriam exibir afinidade por cucurbiturilas, uma vez que são considerados íons moles por excelência. Por razões ainda desconhecidas, um resultado inusitado foi obtido por Izatt e seu grupo que constataram que a constante de formação de decametil-cucurbit[5] urila com estes íons era da ordem de $\log \mathrm{K}>9$ ! Com $\beta$-CB[6] a constante é da ordem de 3 , o mesmo que o íon $\mathrm{Na}^{+} \ldots{ }^{151}$ Outros íons similares como 


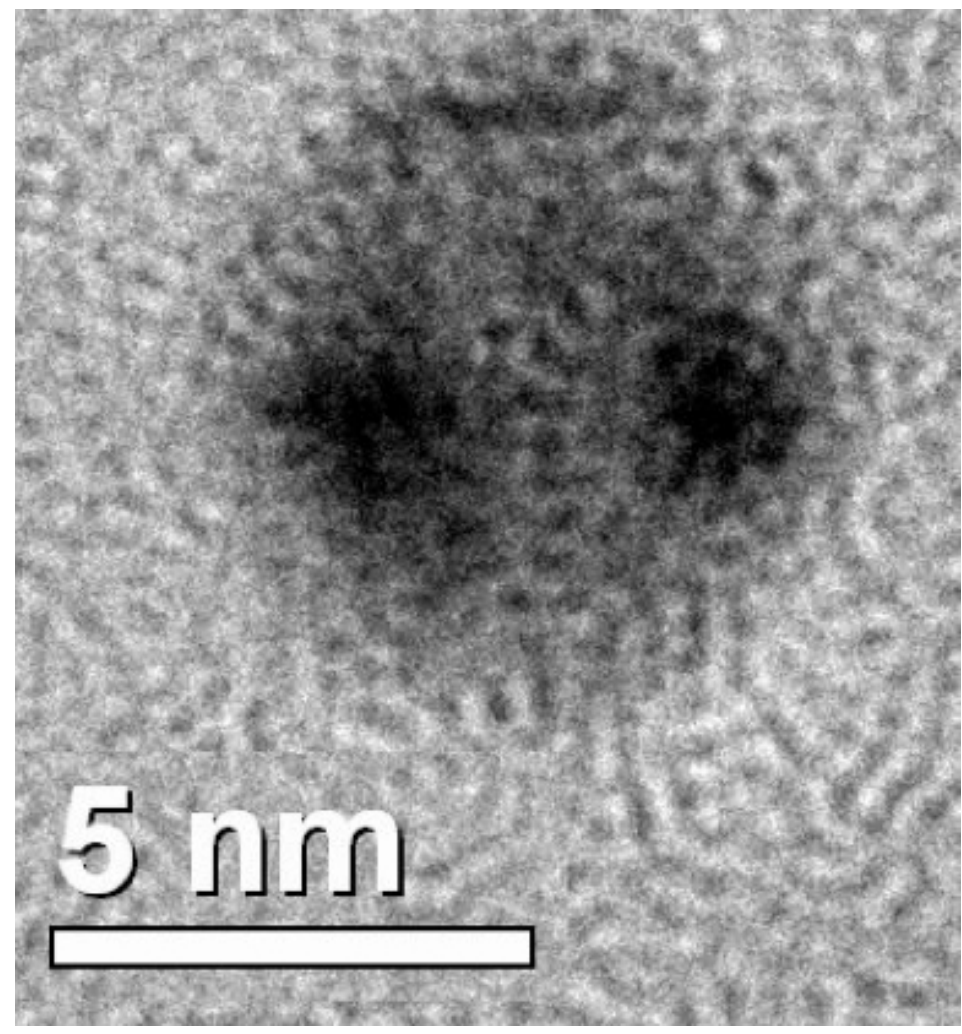

Figura 66: Fotomicrografia de transmissão eletrônica de um cluster de 4 nanopartículas Ag/ $\gamma$ $\mathrm{CB}[7](1: 1)$ a $800 \mathrm{k}$ vezes.

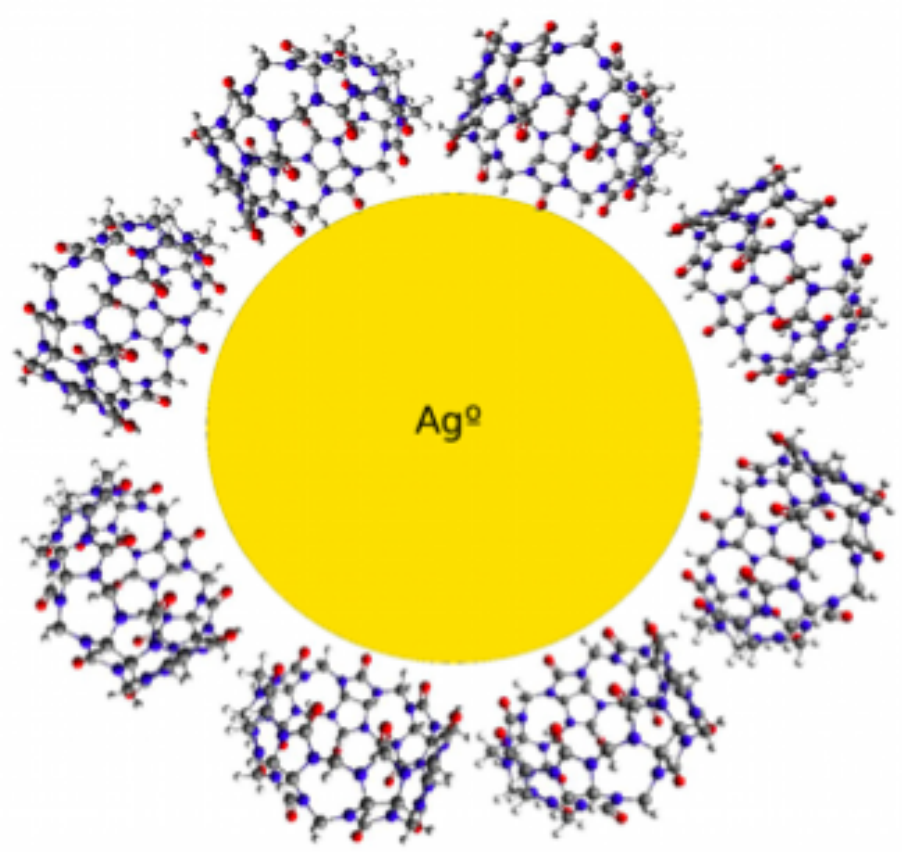

Figura 67: Representação equemática da estrutura do efeito de grampo da $\gamma$-CB[7] em nanopartículas de prata. 
o cádmio simplesmente não formam complexos com as CBs. Com isto em mente, é natural pensarmos que as CBs poderiam ligar-se a cátions de chumbo durante a formação do iodeto, direcionando assim o crescimento de seus cristais, o que poderia resultar em nanopartículas de tamanho controlado.

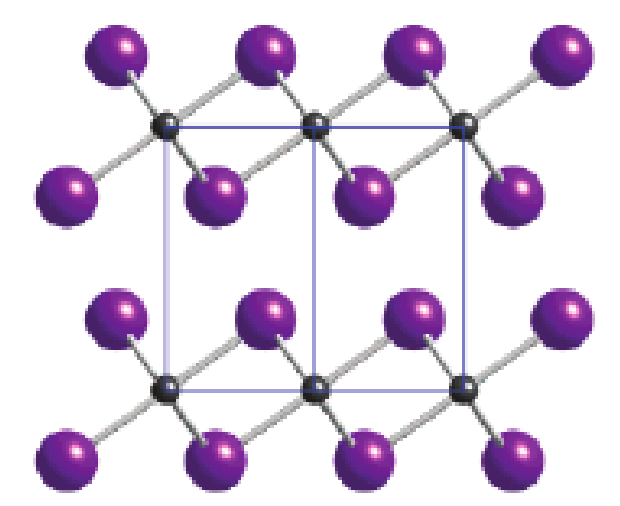

Figura 68: Representação equemática da estrutura do $\mathbf{P b I}_{2}$, onde podemos observar os átomos de iodo em violeta e os de chumbo em preto. da ref ${ }^{271}$

Um controle preciso do tamanho de nanopartículas de um semi-condutor pode dar origem a pontos quânticos, com propriedades diretamente ligadas ao seu tamanho e formato. Para verificar esta hipótese estudamos a formação de iodeto de chumbo coloidal, na presença de $\gamma-\mathbf{C B}[7]$, por ser o mais solúvel da série. A preparação é simples e está descrita no apêndice A.1.6. Consiste basicamente em misturar soluções de $\gamma$-CB[7] , KI e $\mathrm{Pb}\left(\mathrm{NO}_{3}\right)_{2}$ na proporção de 1:1:2. Um gel é formado instantaneamente que precipita depois de 48 horas. O que chama a atenção é a coloroção verde pálida deste sólido, bem diferente do que se observa com o iodeto puro, que dá origem a cristais dourados brilhantes.

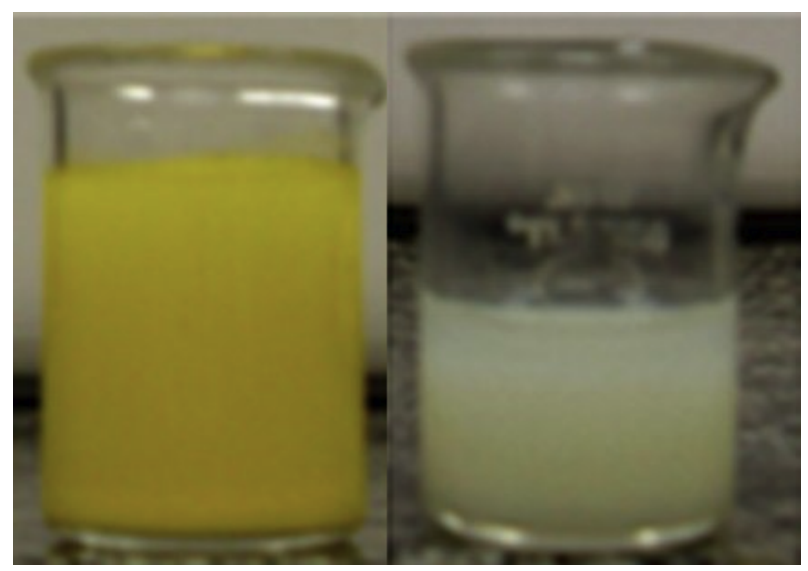

Figura 69: Fotografias do $\mathbf{P b I}_{2}$ puro (esquerda) e preparado com $\gamma-\mathbf{C B}[7]$

Espectros de reflectância difusa deixam isto claro (fig. 70), onde observamos absorções típicas de semi-condutores e um deslocamento da absorção para o azul que corresponde ao tamanho da região proibida, de mais de $0,5 \mathrm{eV}(90 \mathrm{~nm})$ com relação ao iodeto 
puro, e este é um forte indício de confinamento quântico pois é sabido que clusteres de semi-condutores de tamanho reduzido apresentam efeitos dramáticos em seus espectros de absorção ligados diretamente ao tamanho destes clusteres.

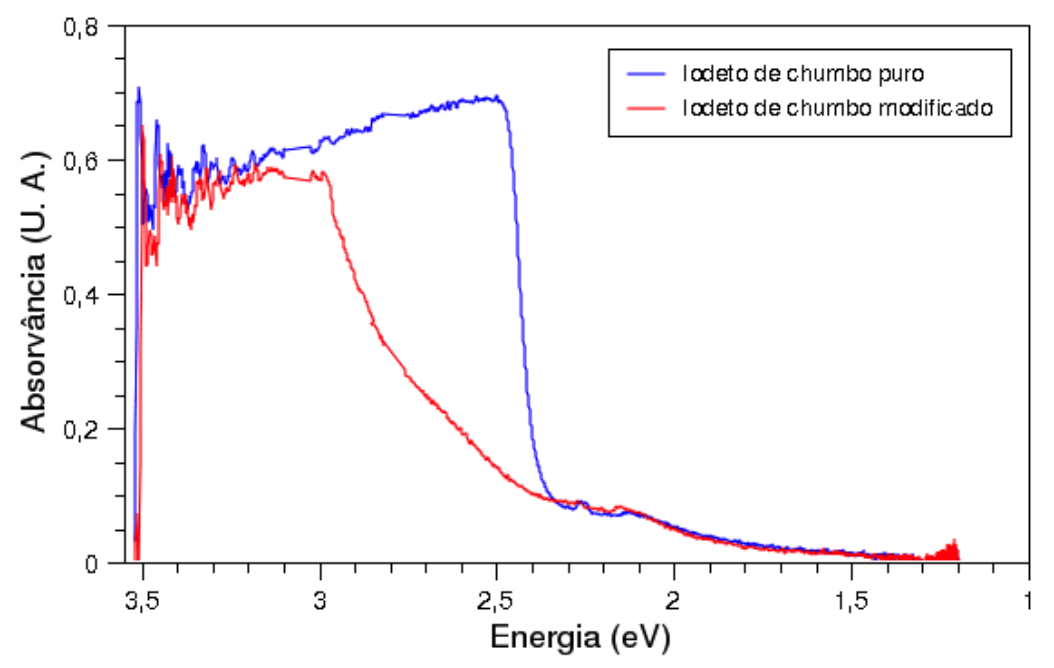

Figura 70: Espectros de reflectância difusa do $\mathrm{PbI}_{2}$ puro (azul) e preparado com $\gamma$-CB[7] (vermelho)

Esta é uma transição entre bandas (fig. 70), e ocorre muito perto da banda de exciton, pois sua energia de ligação é relativamente baixa. $\mathrm{O} C \mathrm{CB}[7]$ não absorve na região do UV-Visível e não pode contribuir para o espectro do $\mathrm{PbI}_{2}$. O confinamento de excitons pode ocorrer em uma, duas ou três dimensões em pontos quânticos ${ }^{272-277}$, dependendo do tamanho e formato da partícula. O tamanho da região proibida (Band Gap) é seriamente afetado quando o tamanho da partícula é inferior ao raio de Bohr do exciton (1,9 nm para o iodeto de chumbo), mas outras causas para deslocamentos tem sido descritas na literatura como por exemplo a intercalação de doadores de elétrons entre as lamelas de iodeto bem como alterações de polaridade do solvente ${ }^{271,277}$. Estes fenômenos estão todos correlacionados e os deslocamentos acabam refletindo o confinamento quântico. Solventes de baixa polaridade estabilizam partículas coloidais maiores, em detrimento das menores, e alteram a constante dielétrica do meio. A intercalação de moléculas pequenas no espaço interlamelar aumentam o espaçamento basal diminuindo a interação eletrônica entre as lamelas e, consequentemente, a extensão de dispersão da banda de valência dos sólidos. Isto aumenta a energia entre os níveis, promovendo o confinamento em uma dimensão ao longo da direção axial. Existe na literatura um modelo chamado de aproximação de massa efetiva, pelo qual é possível estimar o tamanho e a espessura dos cristalitos anisotrópicos a partir de seus dados de absorção eletrônica ${ }^{272,273,275}$. A equação tem a forma:

$$
\Delta E_{g}=\frac{\hbar^{2}}{2 \mu_{x y}}\left[\frac{2 \pi^{2}}{L_{x y}^{2}}\right]+\frac{\hbar^{2}}{\mu_{z}}\left[\frac{2 \pi^{2}}{L_{z}^{2}}\right]
$$


onde $\mu_{x y}$ e $\mu_{z}$ representam as massas reduzidas efetivas dos pares elétron-buraco no plano $x y$ e no eixo $z$, perpendicular a ele e $\mathrm{L}_{x y}$ e $\mathrm{L}_{z}$ são as dimensões dos cristalitos. As massas reduzidas foram determinadas experimentalmente em $0,32\left(\mu_{x y}\right)$ e $1,4\left(\mu_{z}\right)$ unidades eletrônicas de massa, por experimentos de magneto-óptica ${ }^{275,278}$. Neste caso específico, observamos um deslocamento para o azul de $3,10-2,56 \mathrm{eV}=0,54 \mathrm{eV}$. Um deslocamento hipsocrômico desta grandeza no leva a acreditar em uma estrutura esfoliada, onde não haveria comunicação eletrônica ao longo do eixo z. A equação 6.1 se simplifica então em:

$$
\Delta E_{g}=\frac{235}{L_{x y}^{2}}+0,55
$$

Quando consideramos a dimensão Lz igual a espessura de uma lamela de $\mathrm{PbI}_{2}$, ou $7 \AA$. De acordo com a equação 6.2 este valor só pode corresponder ao que se esperaria da estrutura esfoliada, onde o tamanho das lamelas é grande demais para originar qualquer tipo de deslocamento, já que o primeiro termo da equação 6.1 deve tender a zero com $L_{z}=$ $7 \AA$ para que possamos observar um valor de deslocamento compatível com o resultado experimental.

Os dados espectroscópicos sugerem portanto que houve a formação de folhelos independentes de $\mathrm{PbI}_{2}$ na presença de $\gamma-\mathbf{C B}[7]$. Sua conformação relativa é aleatória, como podemos verificar por difração de raios-X, que nos dá sinais extremamente fracos de iodeto de chumbo, atestando assim a ausência de coerência turbostrática, como é frequente em algumas argilas como a laponita ou ainda óxido lamelares (fig. 72) Este tipo de arranjo é conhecido como "castelo de cartas", onde estruturas foleadas não se sobrepoem (figura $71)^{279,280}$.

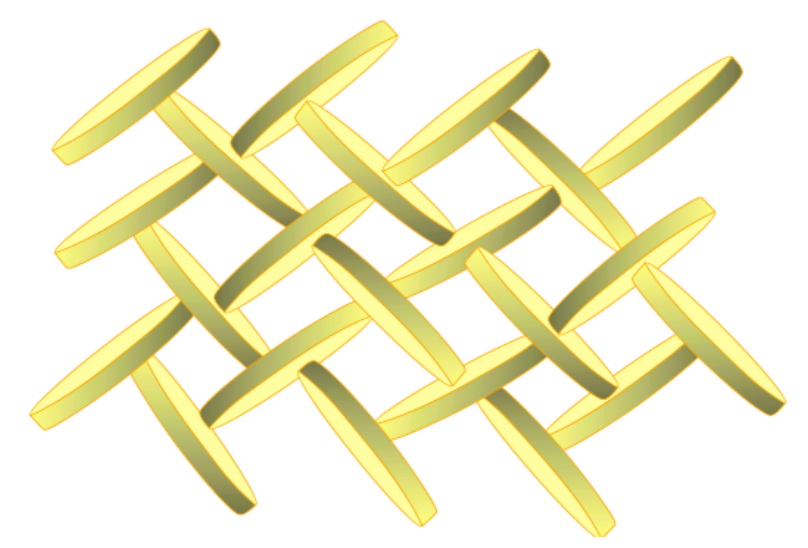

Figura 71: Arranjo aleatório de nanodiscos do tipo castelo de cartas. ${ }^{281}$

A distância interlamelar do $\mathrm{PbI}_{2}$ varia de acordo com as espécies intercaladas, mas nunca é inferior a $12 \AA$. Considerando a espessura da lamela de $7 \AA$ e a altura da $\gamma$-CB[7] que é de 9,1 $\AA$, deveria apresentar uma distância interplanar de pelo menos $21 \AA$ caso estivesse intercalado entre as lamelas, gerando uma estrutura pilarizada. Considerando uma afinidade razoável do $\gamma-\mathbf{C B}[7]$ pelos íons $\mathrm{Pb}^{2+}$ e a proporção dele na mistura, seria 


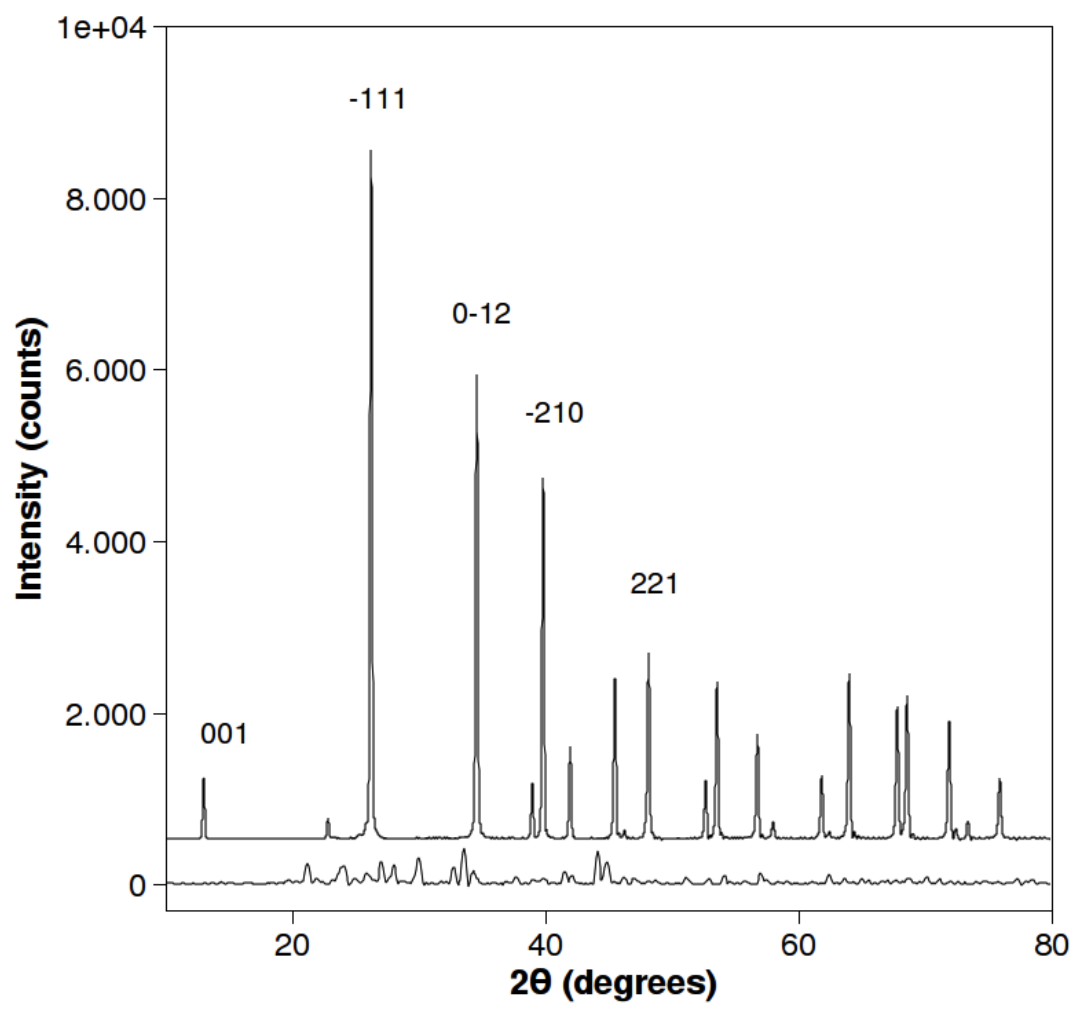

Figura 72: Difratogramas de raios-X no pó do $\mathbf{P b I}_{2}$ e das nanoprtículas com $\gamma$-CB[7]

de se esperar que por conta do grande volume do $\gamma-\mathbf{C B}[7]$, uma estrutura lamelar não seria capaz de acumular esta grande quantidade de $\gamma$-CB[7] no espaço interlamelar, sendo forçados a se acomodarem de outra maneira (fig. 73).

Outro fator proibitivo para a formação de estrutras lamelares é a presença de íons $\mathrm{K}^{+}$em grandes quantidades no meio reacional. Em uma segunda hipótese, podemos supor que os íons $\mathrm{K}^{+}$podem se ligar aos opérculos da $\gamma$-CB[7] competindo com os íons $\mathrm{Pb}^{2+}$, gerando espécies catiônicas grandes em solução, que não são bons hóspedes de intercalação no iodeto de chumbo que tem mais afinidade por doadores de elétrons. A real estrutura das nanopartículas de $\mathrm{PbI}_{2}$ foi revelada com auxílio da microscopia eletrônica de transmissão de alta resolução (HRTEM, fig. 74). Nas imagens (fig. 74) é possível ver estruturas em forma de disco, de diâmetros médios aproximados de $35 \mathrm{~nm}$. Podemos perceber claramente os átomos que compoem as lamelas de $\mathrm{PbI}_{2}$ nas maiores ampliações assim como os aglomerados de nanodiscos nas menores.

De acordo com estes resultados o $\gamma$-CB[7] não atua como um molde oco, dentro do qual é possível crescer uma nanopartícula binária, como ocorre com o ouro por exemplo. O macrociclo neste caso atua de duas formas distintas. Primeiramente ele cria estruturas esfoliadas pois a estrutura lamelar do $\mathrm{PbI}_{2}$ não é mais perceptível, e também gera partículas em forma de disco, que parecem estarem separados uns dos outros por ions de $\mathrm{K}^{+} \mathrm{e}$ moléculas de $\gamma$-CB[7] . Os dados espectroscópicos e o modelo da aproximação de massa 


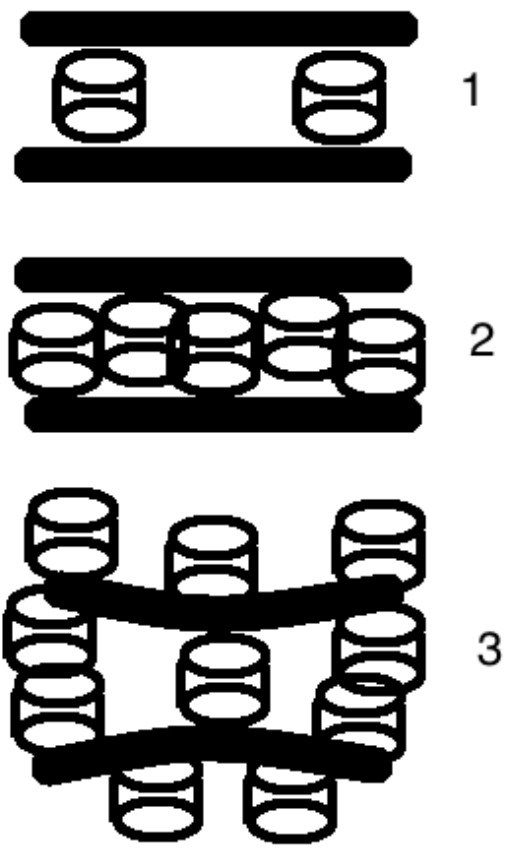

Figura 73: Mecanismo de esfoliação do $\mathrm{PbI}_{2} \operatorname{com} \gamma-\mathrm{CB}[7]$, de 1 a 3 quantidades crescentes de $\gamma$-CB $[7]$ no espaço interlamelar, forçando um rearranjo estrutural

efetiva nos forneceu informações sobre a estrutura das nanopartículas que se comprovaram pelas imagens de microscopia. A estrutura em nanodiscos, explica perfeitamente o confinamento quântico em uma dimensão. O mecanismo de formação destas nanopartículas é complexo e envolve diversas etapas ainda pouco conhecidas. Acreditamos que na primeira etapa de formação das nanopartículas, os íons de chumbo estejam ligados ao macrociclo, que limita o crescimento das folhas de iodeto de chumbo. À medida que crescem, as moléculas de $\gamma$-CB[7] são deslocadas por impedimento estérico, e passam a coordenar íons de potássio em solução, desestabilizando o gel inicial. Estes experimentos foram repetidos com iodeto de mercúrio, levando exatamente oas mesmo resultados, demonstrando que o mecanismo de ação da $\gamma-\mathbf{C B}[7]$ independe da natureza do metal pesado (fig. 75).

\subsubsection{Nanopartículas de óxido de Zinco}

O óxido de zinco é um semi-condutor transparente do tipo II-IV de grande bandgap $(\sim 3,4 \mathrm{eV})$ II-VI que apresenta alta mobilidade eletrônica e intensa luminescência à temperatura ambiente ${ }^{282}$. O $\mathrm{ZnO}$ pode cristalizar em três formas distintas: hexagonal com estrutura do tipo wurtzita, cúbica do tipo zincblenda e cúbica do tipo halita, mas a primeira é de longe a mais comum em condições normais de temperatura e pressão. É estável ao ar, atóxico e realtivamente barato. Por estes motivos é utilizado na indústria em muitas formas diferentes e para diversas aplicações como aditivo em plásticos, em cerâmicas e vidro, tintas, cosméticos e fármacos, em sensores, baterias, como catalisador, 


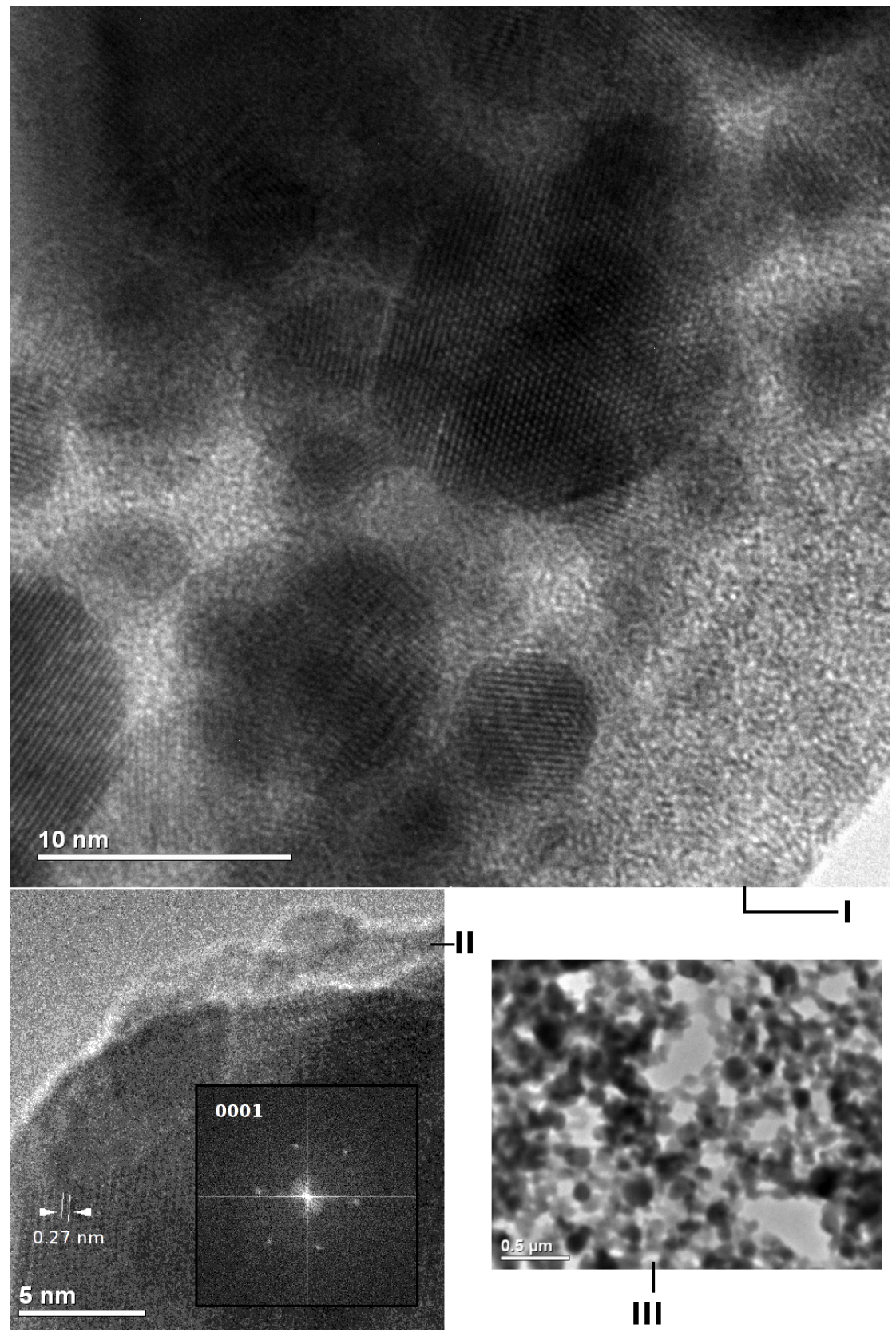

Figura 74: Fotomicrografias HRTEM do (I) $\mathbf{C B}[7] / \mathrm{PbI}_{2}$; (II) ampliação de um só nanodisco (diâmetro $=30 \mathrm{~nm}$ ), inserida: padrão de difração de elétrons; e (III) visão menos ampliada dos discos de $\mathrm{CB}[7] / \mathrm{PbI}_{2}$. 


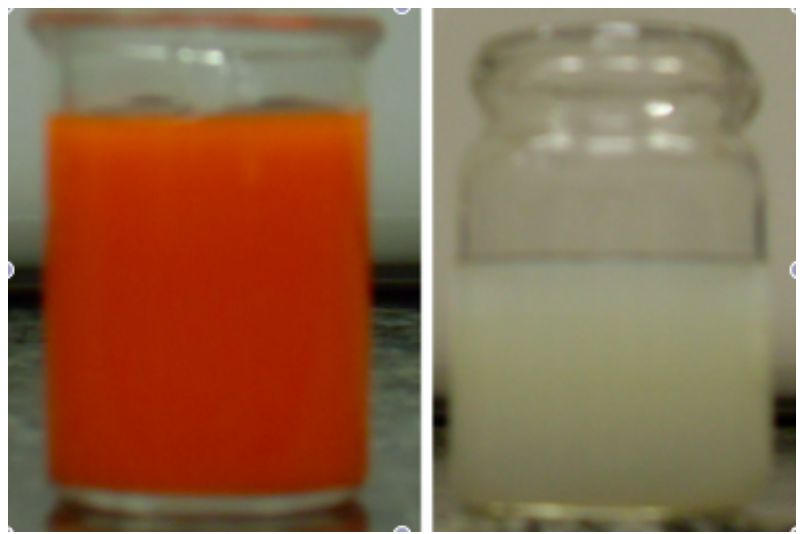

Figura 75: Fotografias de iodeto de mercúrio, e do mesmo obtido na presença de $\gamma$-CB $[7]$.

em materiais ferromagnéticos, para o preparo de materiais condutores transparentes entre outros $^{283-287}$. O ZnO também é amplamente utilizado para a fotodegradação de poluentes, como se faz com o $\mathrm{TiO}_{2}$ além de outras aplicações ${ }^{288-294}$. Sua granulometria e morfologia são importantes do ponto de vista da processibilidade do sólido nas aplicações industriais. A preparação de nanopartículas por sua vez, pode facilitar o desenvolvimento de processos mais baratos e eficientes além de novas aplicações como nano-lasers ${ }^{295,296}$, dispositivos de emissão de campo (field emission devices), cristais líquidos ${ }^{297}$ e foto-células sensibilizadas por corante ${ }^{298-300}$. Nano-partículas de semicondutores podem ser encaradas também como pontos quânticos, desde que pequenas o suficiente para promoverem confinamento quântico em uma ou mais dimensões. Pontos quânticos têm finalidades totalmente distintas como por exemplo mapeamento de células por imagem, lasers ${ }^{295}$, diodos emissores de luz de alta eficiência, e dispositivos anti-fraude ${ }^{204,301,302}$. A maioria dos processos de produção de nanopartículas de $\mathrm{ZnO}$, que consigam aliar pequenos tamanhos de partículas com baixa dispersidade envolve etapas de síntese complexas, tempos de reação muito longos e/ou a utilização de reagentes precursores tóxicos, misturas de solventes e às vezes temperaturas bastante altas $^{301-310}$. NPs de zincita são extremamente difíceis de serem preparadas à temperatura ambiente partindo de sais simples como o $\mathrm{Zn}\left(\mathrm{NO}_{3}\right)_{2}$ e não de algum organometálico e sem aditivos como tensoativos, aminas longas ou líquidos iônicos ${ }^{311-314}$. Não observamos nenhum trabalho que partisse de $\mathrm{Zn}\left(\mathrm{NO}_{3}\right)_{2}$, em condições extremamente brandas e do tipo "single pot"como nós descrevemos utilizando $\gamma-\mathbf{C B}[7]$ ou $\alpha-\mathbf{C B}[5]$. Conhecendo o efeito de grampo, que já verificamos para a prata e o iodeto de chumbo, decidimos utilizar a $\gamma-\mathbf{C B}[7]$ para moldar nanopartículas de zincita também. O processo de obtenção destas partículas é muito parecido com aquele utilizado para a obtenção de hidróxidos duplos lamelares (HDL) pelo método da co-precipitação. Método este que é bem descrito na literatura ${ }^{315}$, e consiste em precipitar os hidróxidos de dois metais, um divalente e outro trivalente em condições de controle de $\mathrm{pH}$ rígidas. A síntese de nanopartículas de zincita, é realizada da mesma forma, porém, ao invés de adicionarmos um metal trivalente, adicionamos $\gamma$-CB[7] à mistura em quantidades muito pequenas, uma 
vez que observamos anteriormente que pequenas quantidades de $\gamma-\mathbf{C B}[7]$ já são efetivas como moldes. A síntese das partículas é realizada a $\mathrm{pH}$ constante $(\mathrm{pH}=8)$ à temperatura ambiente $\left(28^{\circ} \mathrm{C}\right)$, utilizando $40 \mathrm{~cm}^{3}$ de água onde são dissolvidos $26 \mathrm{mg}\left(2,24 \times 10^{-5}\right.$ mol) de $\gamma$-CB [7] . Adiciona-se lentamente a esta solução $10 \mathrm{~cm}^{3}$ de $\mathrm{Zn}\left(\mathrm{NO}_{3}\right)_{2}$ em solução aquosa a $\left(3,0 \times 10^{-2} \mathrm{~mol} \cdot \mathrm{dm}^{-3}\right)$ numa velocidade de aproximadamente $\left(2 \mathrm{~cm}^{3} \cdot \mathrm{min}^{-1}\right)$, usando uma seringa manual. $\mathrm{O}$ pH da solução é mantido constante com pequenas adições de $\mathrm{NaOH}\left(3,0 \times 10^{-1}\right.$ mol.dm $\left.{ }^{-3}\right)$ ao meio reacional, que é monitorado com um pH-metro. A mixtura resultante é mantida sob agitação por mais 10 minutos. O óxido é então filtrado e lavado com água destilada, sendo seco a $50^{\circ} \mathrm{C}$. Este procedimento foi repetido na ausência de $\gamma$-CB[7], para obtermos um sólido de referência e avaliar o efeito da presença do macrociclo na síntese me questão. Os detalhes da síntese podem ser encontrados no apêndice desta tese. O sólido branco obtido nesta síntese foi comparado ao obtido sem a adição de $\gamma-\mathbf{C B}[7]$, seus padrões de difração de raios-X constam na figura 76 . Esta síntese foi repetida com $\alpha$-CB[5] que levou a resultados idênticos ${ }^{265,316}$.

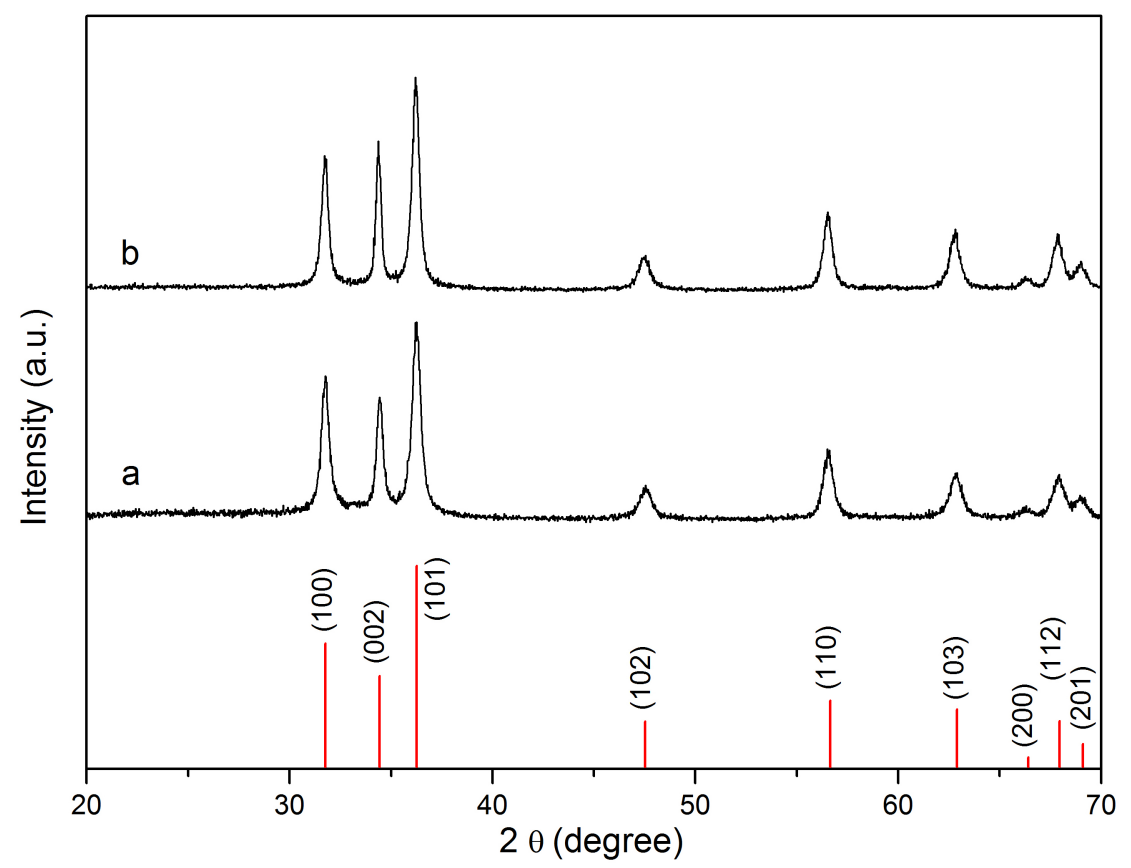

Figura 76: Padrões de difração no pó dos sólidos obtidos na ausência (a) e na presença (b) de CB[7]. As linhas em vermelho indicam a posição e a intensidade do difratograma padrão da zincita.

Observando os padrões de difração do pó destes sólidos, fica evidente que a única fase presente é a zincita, na presença ou na ausência de $\gamma$-CB[7] . Os dados experimentais foram confrontados com as informações do banco de dados de difração de raios-X (linhas vermelhas 76) ${ }^{1}$. Apesar disto, as fotomicrografias eletrônicas de varredura revelaram morfologias totalmente diferentes nos dois casos já que a síntese na ausência de

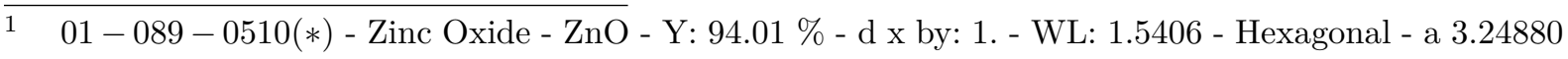
- b 3.24880 - c 5.20540 - $\alpha 90.000$ - $\beta 90.000$ - $\gamma 120.000$ - Primitive - P63mc (186) - 2 - 47.5807 - I/Ic PDF 5.4 - S-Q 1 
$\gamma$-CB[7] levou exclusivamente à formação de maclas hexagonais de zincita de $\sim 1 \mu \mathrm{m}$ enquanto que a presença do macrociclo todavia, ( $\mathrm{CB}[7] / \mathrm{ZnO})$ produziu uma multitude de aglomerados esféricos nanométricos ( $Q \sim 150 \mathrm{~nm}$ ) exatamente nas mesmas condições, exceto pela presença do $\gamma$-CB[7] (77).
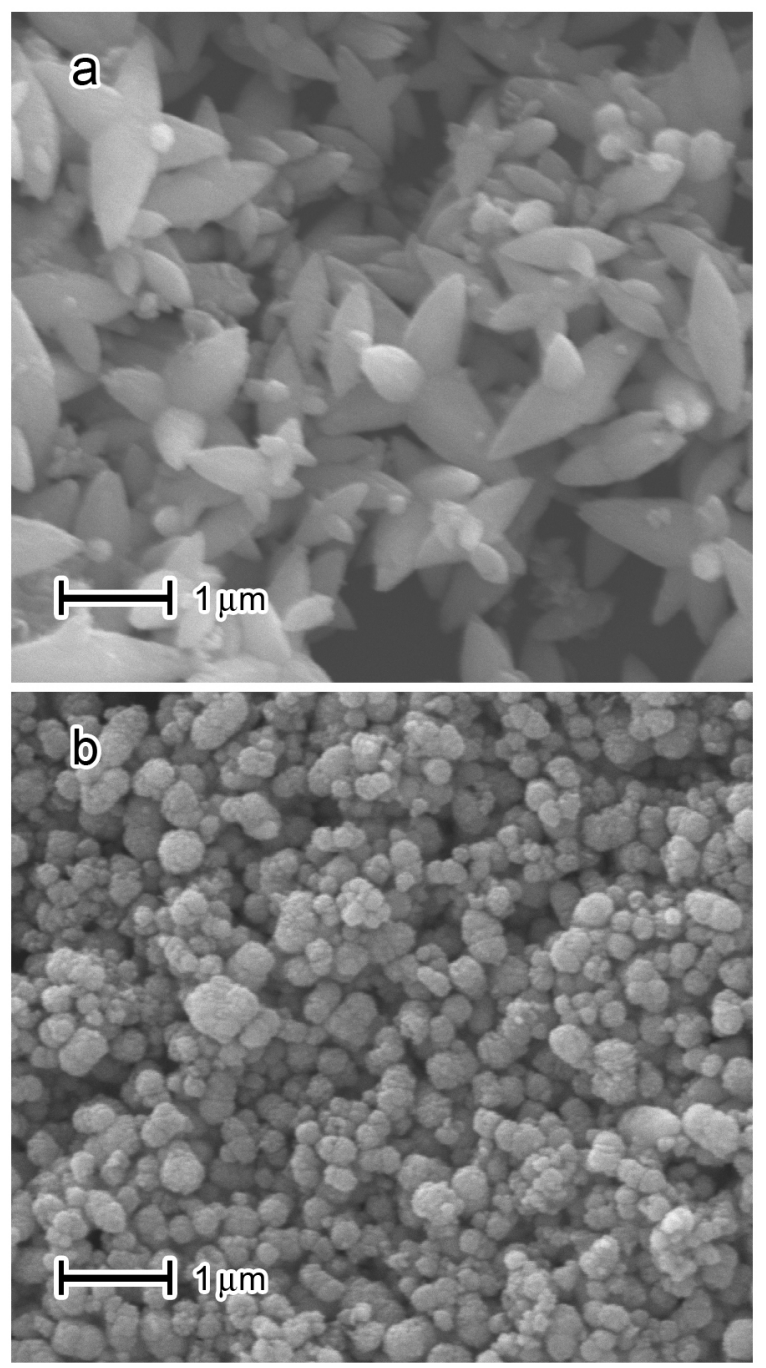

Figura 77: Fotomicrografias eletrônicas de varredura das máculas micrométricas de zincita produzidas na ausência de $\mathbf{C B}[\mathbf{7}]$ (a) e dos glóbulos de nanopartículas obtidos em sua presença (b).

Usando MFA, foi possível observar que estes aglomerados são na verdade glóbulos compostos por esferas muito menores e extremamente regulares ( $Q \sim 24 \mathrm{~nm}, 78$ ).

Não observamos a supressão da luminescência do ZnO na forma de nanoesferas, o que geralmente ocorre com outros semi-condutores na presença de $\gamma$-CB[7] (não foi verificada com as NP de prata ${ }^{14,266}$ ou de iodeto de chumbo ${ }^{259}$, paládio ${ }^{263}$, ouro ${ }^{180,261}$ ), e sua emissão em $395 \mathrm{~nm}$ atesta a pureza deste composto pois corresponde à emissão intrínseca deste óxido ${ }^{304}$. Não é observado nenhum deslocamento significativo na posição do máximo de emissão, o que demonstra que estas esferas ainda são muito grandes para demonstrarem qualquer efeito de confinamento quântico, como é o caso por exemplo dos 

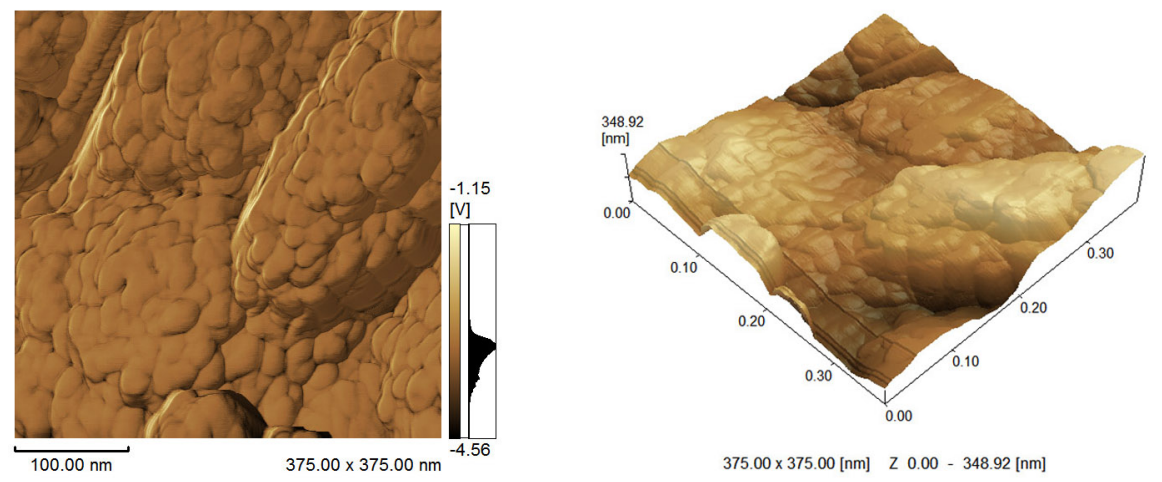

$375.00 \times 375.00[\mathrm{~nm}] \quad$ Z $0.00-348.92[\mathrm{~nm}]$

Figura 78: Fotomicrografias de força atômica dos agregados de nano-esferas de $\mathbf{C B}[\mathbf{7}] / \mathbf{Z n O}$.

nano-discos de iodeto de chumbo e mercúrio preparados com $\gamma$-CB $[7]^{259}$. Estes dados de emissão também são consistentes com o formato esférico das nanopartículas que pudemos observar, e a ausência de emissão no verde é compatível com o tamanho que medimos.

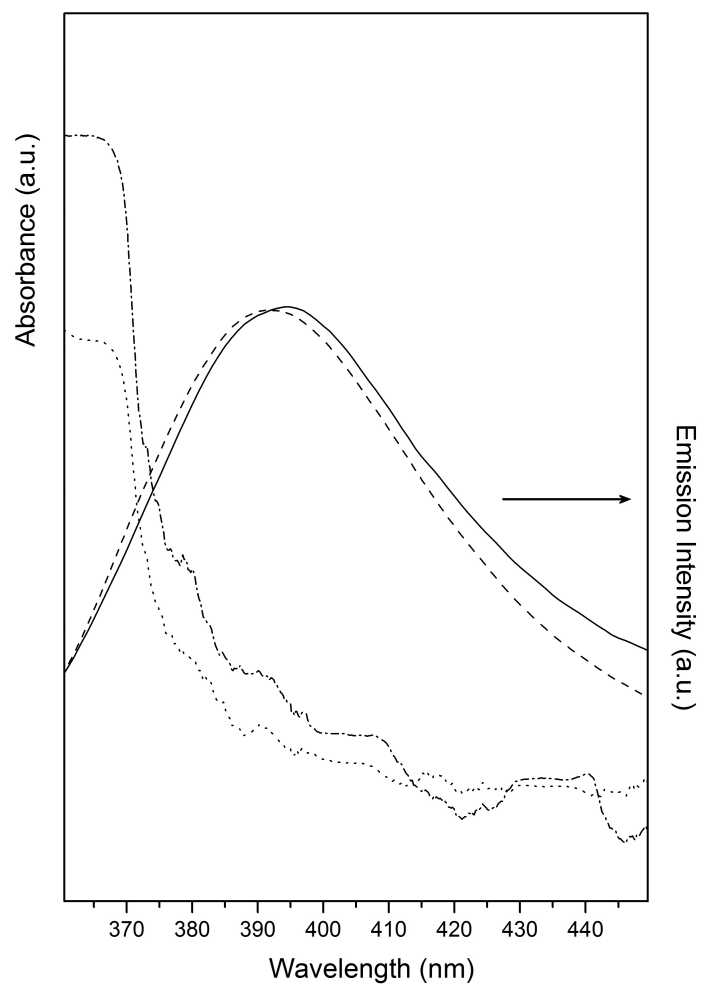

Figura 79: Espectros de absorção e emissão das maclas de $\mathrm{ZnO}$ (linhas cheias) e das nanoesferas $\mathrm{CB}[7] / \mathrm{ZnO}$ (linhas pontilhadas) $\lambda_{\text {exc }}=250 \mathrm{~nm}$.

As características das cucurbiturilas como ligantes de coordenação são bastante diferentes da maioria das moléculas ligantes, uma vez que são capazes de ligarem-se a a ácidos duros e moles também, mesmo sendo bases duras por excelência de acordo com os princípios de HSAB desenvolvidos por Pearson ${ }^{179}$. Nossa experiência nos leva a crer que o macrociclo liga-se fortemente aos íons $\mathrm{Zn}^{2+}$ logo no início do processo de nucleação do óxido, limitando o crescimento do cristal de maneira assimétrica. Esta hipótese 
é reforçada pelos dados de espectroscopia vibracional já que é bastante comum observar deslocamentos para o azul das bandas de estiramento simétrico e anti-simétrico das carbonilas (normalmente $\Delta \bar{\nu} \sim 10 \mathrm{~cm}^{-1}$ ) quando estas se ligam a cátions metálicos. Este deslocamento comparado às carbonilas livres pode ser entendido como resultado de uma restrição de liberdade decorrente da formação de ligações metal-oxigênio, resultando na alteração da força do oscilador. Apesar de fracas estas ligações, são favorecidas pelo efeito quelato, já que dependendo do tamanho do cátion, é possível ligá-lo a até seis carbonilas simultaneamente no mesmo opérculo (figura 80).

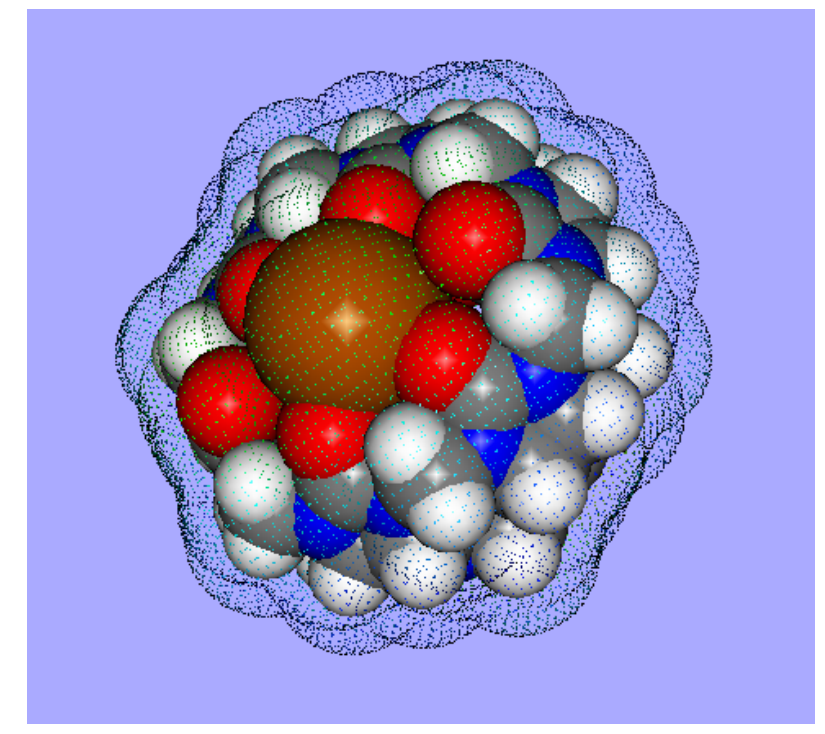

Figura 80: Representação de um cátion de $\mathrm{K}^{+}$coordenado ao opérculo de uma molécula de CB[6] deixando evidente o efeito quelato na coordenação de cátions.

A banda atribuida às carbonilas no $\mathbf{C B}[\mathbf{7}] / \mathbf{Z n O}$ situam-se em torno de 1729 $\mathrm{cm}^{-1}$, isto é, ligeiramente deslocadas quando as comparamos às bandas do $\mathbf{C B}[7]$ puro $\left(1721 \mathrm{~cm}^{-1}\right)$, o que é coerente com nosso modelo. Outro ponto de destaque é que obtemos nanoesferas muitos similares a estas descritas acima quando trocamos o $\mathrm{CB}[7]$ por $\mathrm{CB}[5]$, que é muito menor que o anterior, na síntese destas nanoesferas. Este fato deixa claro que o processo de formação das nanoesferas independe do tamanho do anel. A formação de agregados (77 b) compactos é atribuida à simetria das CBs, pois elas possuem dois portais em direções opostas o que favorece a agregação ao invés de manter a repulsão mútua das partículas, o que as manteria em suspensão.

\subsection{Cucurbiturilas como hóspedes em compostos de intercalação}

Um das propostas mais interessantes de nosso grupo de pesquisa era criar matrizes de intercalação complexas onde uma matriz de inclusão seria intercalada em uma matriz de intercalação. A forma peculiar das cucurbiturilas, pode ser explorada não só pela cavidade que delimita, mas por sua rigidez estrutural em materiais altamente organizados. 
Observando sua estrutura notamos imediatamente que, como um barril, pode muito bem servir de pilar para estruturas lamelares por exemplo, deixando entre as lamelas que qualquer material uma distância basal controlada, de no mínimo 9,1 A. Como pilares em estruturas pilarizadas, também podem apresentar uma vantagem: a rigidez angular. A maioria das espécies empregadas como sustentáculos de sólidos pilarizados, não se sustenta na vertical indefinidamente, tendendo a inclinar-se a partir de uma certa concentração no espaço interlamelar. Desta forma não garantem um espaçamento constante entre as lamelas, criando estruturas com mobilidade lateral. Partindo deste princípio, procuramos rotas sintéticas para a inserção de cucurbiturilas em diversas matrizes lamelares, como por exemplo, hidróxidos duplos lamelares (HDLs), pentóxido de vanádio, e iodeto de chumbo.

\subsubsection{Matrizes de hidróxidos duplos lamelares}

A intercalação de espécies grandes, sem carga quase insolúveis e em baixas concentrações por via úmida, parece bastante improvável em matrizes de intercalação comuns. A intercalação de cucurbiturilas em matrizes inorgânicas lamelares nunca havia sido reportada até o desenvolvimento de nossas pesquisas com hidróxidos duplos lamelares (HDL), por outro lado também não eram conhecidos exemplos de intercalados de HDLs com hóspedes neutros, muito menos insolúveis... Num trabalho recente ${ }^{265}$ demonstramos que era possível preparar nanocompósito de de HDL de $\mathrm{Zn}^{2+} / \mathrm{Al}^{3+} \operatorname{com} \beta$-CB[6] e $\gamma$-CB[7] , desde que presentes no meio reacional de síntese das matrizes por co-precipitação. Os compósitos são na verdade estruturas pilarizadas nas quais as cucurbiturilas suportam a estrutura lamelar por interações fortes com as lamelas do hidróxido. As interações são tão fortes, que nem mesmo CTAB é capaz de removê-las de dentro do espaço interlamelar, como faz com a maioria de hóspedes intercalados. Dois tipos de compósitos foram preparados: Um primeiro no qual dodecilsulfato (DS) acompanhava a $\beta$-CB[6] e a $\gamma$-CB[7] no meio reacional e um segundo onde os macrociclos iam sós. A função do dodecilsulfato era a de expandir o espaço interlamelar para facilitar a entrada dos macrociclos o que de fato ocorreu, mas sua presença não é indispensável para que isto ocorra. Assim obtivemos compósitos de fórmula: intercalados de DS com $\beta$-CB[6] ou $\gamma$ CB[7] Zn2Al/DS/CB7 (CB[7 $\left.]_{0,03} @ \mathrm{Zn}_{0,69} \mathrm{Al}_{0,31}(\mathrm{OH})_{2}(\mathrm{DS})_{0,31} .2,3 \mathrm{H}_{2} \mathrm{O}\right)$ e $\mathrm{Zn} 2 \mathrm{Al} / \mathrm{DS} / \mathrm{CB} 6$ $\left(\mathrm{CB}[6]_{0,03} @ \mathrm{Zn}_{0,67} \mathrm{Al}_{0,33}(\mathrm{OH})_{2}(\mathrm{DS})_{0,33} .2,9 \mathrm{H}_{2} \mathrm{O}\right)$ e intercalados com nitrato (contra-íon na síntese) e $\beta$-CB[6] ou $\gamma-\mathbf{C B}[7] \mathrm{Zn} 2 \mathrm{Al} / \mathrm{NO} 3-/ \mathrm{CB} 6\left(\mathrm{CB}[6]_{0,03} @ \mathrm{Zn}_{0,69} \mathrm{Al}_{0,31}(\mathrm{OH})_{2}\left(\mathrm{NO}_{3}\right)_{0,31}\right.$. $\left.0,5 \mathrm{H}_{2} \mathrm{O}\right)$ e $\mathrm{Zn} 2 \mathrm{Al} / \mathrm{NO} 3-/ \mathrm{CB} 7\left(\mathrm{CB}[7]_{0,03} @ \mathrm{Zn}_{0,69} \mathrm{Al}_{0,31}(\mathrm{OH})_{2}\left(\mathrm{NO}_{3}\right)_{0,31}\right.$. 0,6 $\left.\mathrm{H}_{2} \mathrm{O}\right)$. As composições são todas muito similares em termos de teor de CBs, e correspondem a mais ou menos um décimo de ânions que a estrutura suporta para se manter. Tratando os dados de raios-X, e utilizando o método de Patterson ${ }^{317,318}$, pudemos analisar a distrubuição de densidades eletrônicas aos longo do eixo cristalográfico z, como consta na figura 81.

Fica evidente que os macrociclos estão de pé na estrutura, mantendo-a a coesa, 


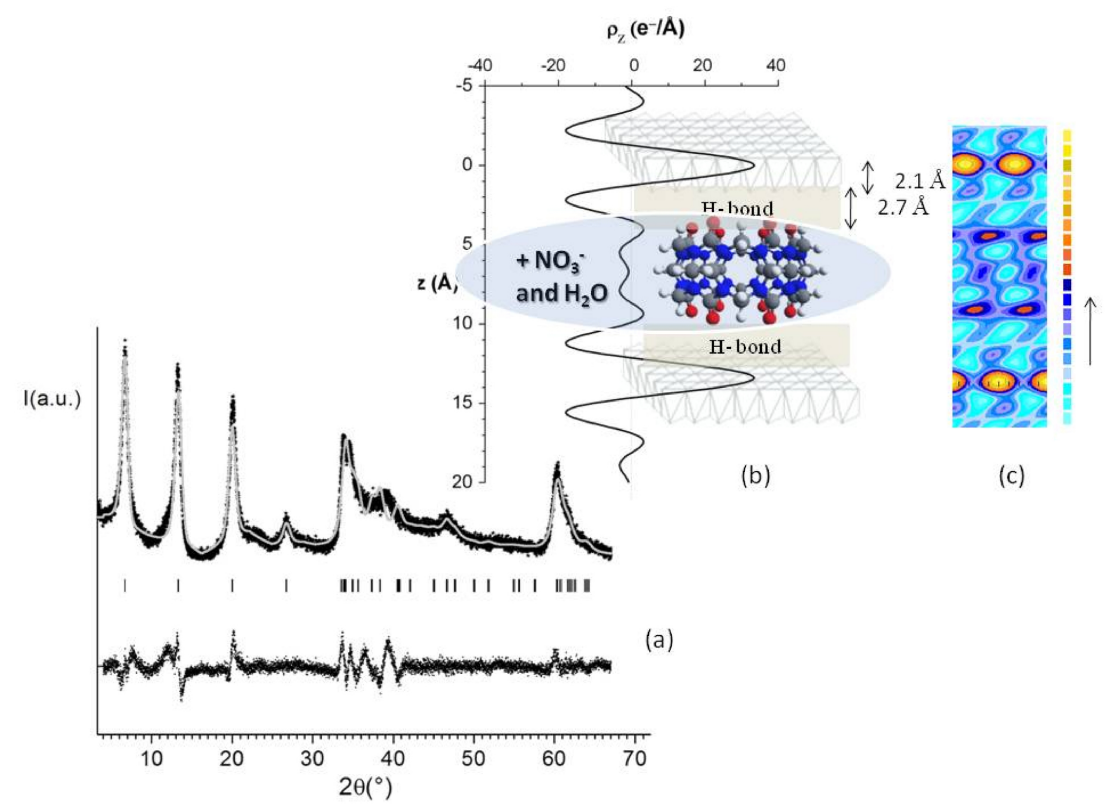

Figura 81: Distrubuição de densidades eletrônicas aos longo do eixo cristalográfico $z$, num intercalado de HDL com $\beta$-CB $[6]$

como se fossem pilares, gerando interações fortes entre as carbonilas e as camadas inorgânicas. O fato mais interessante destes intercalados é que é possível remover seja o DS da matriz, mantendo o CB intacto, seja as CBs, dependendo do reagente de sacador empregado. No caso dos intercalados com DS, é possível removê-lo utilizando o processo de dupla troca ${ }^{319}$, onde os íons dodecilsulfato são substituidos por íons cloreto mantendo CB na matriz, inalterada como mostra o esquema da figura 82. É possível também remover
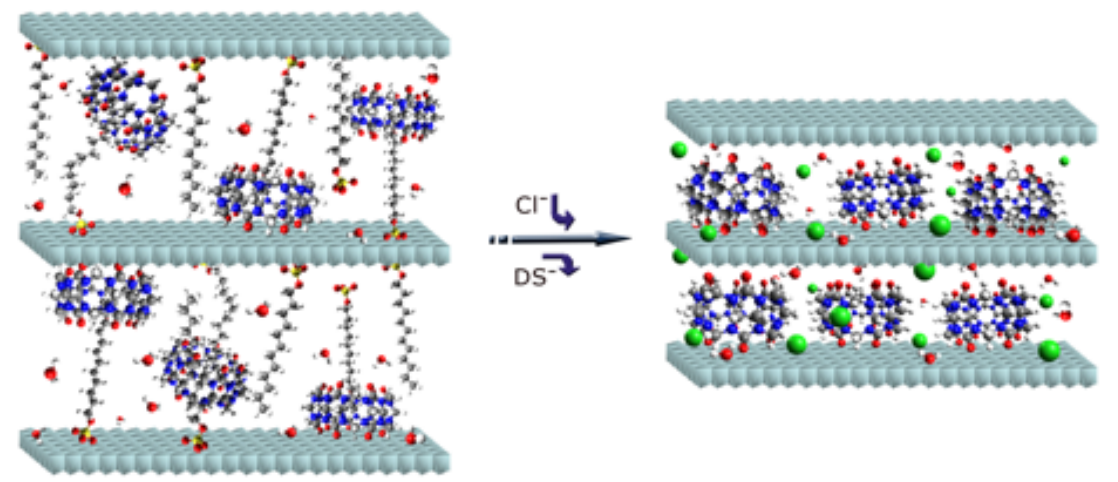

Figura 82: Remoção de íons dodecilsulfato dos intercalados de CB/HDL, da ref ${ }^{320}$

as CBs das cavidades, utilizando hexanodiamina. A alta afinidade de CBs por hexanodiamina se justifica pelo seu tamanho, que coincide perfeitamente com a distância entre os opérculos do macrociclo, criando assim caviplexos perfeitos. No caso de estar protonada a amina, mais forte é a interação e deve forçar sua saída da matriz, já que os folhelos são por si só carregados positivamente. Isto é verificado, e está representado na figura seguinte (fig. 83). 


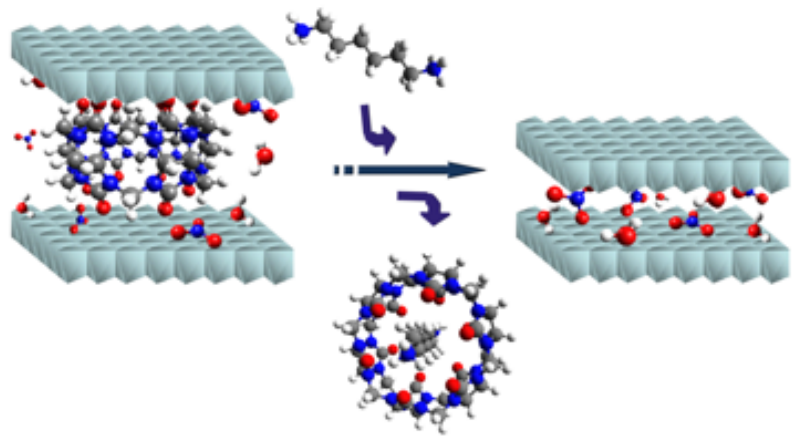

Figura 83: Extração de CBs do intercalado de CB/HDL com hexanodiamina.

Não há nada similar na literatura envolvendo HDLs ou ainda cucubriturilas. Este sistema é o ponto de partida para a criação de novos materiais para liberação controlada de substâncias, onde estas estariam duplamente confinadas. Um exemplo disto seria a liberação de gases por HDLs. O gase estaria preso nas CBs e seria liberado apenas quando a matriz inorgânica fosse destruida, em pH ácido por exemplo. Aminas específicas também reagiriam da mesma maneira, mas precisariam de dois estímulos para serem liberadas: a queda do pH seguida de um aumento do mesmo.

\subsubsection{Matrizes de pentóxido de vanádio}

$\mathrm{O}$ pentóxido de vanádio $\left(\mathrm{V}_{2} \mathrm{O}_{5} \cdot \mathrm{nH}_{2} \mathrm{O}\right)$ é um óxido polimérico de $\mathrm{V}(\mathrm{V})$ capaz de formar, entre outras estruturas, fases lamelares ${ }^{318,321,322}$. É facilmente produzido a partir de géis de ácidos metavanádico, que uma vez secos, dão origem a estas estruturas. São chamados de xerogéis de pentóxido de vanádio ou XPV. Os centros de $\mathrm{V}(\mathrm{V})$ podem ser parcial ou totalmente reduzidos a $\mathrm{V}(\mathrm{IV})$ seja química e eletroquímicamente, dado origem a um óxido de valência mista, onde coexistem centros de $\mathrm{V}(\mathrm{IV} \text { e V })^{323-331}$. A partir deste ponto é possível a transferencia de elétrons de um centro para outro em um mecanismo conhecido por electron hopping, tornando-o um excelente condutor redox. A variação de estado redox global dos xerogéis é acompanhada por variações de condutividade e de coloração, tornando este óxido muito interessante para aplicações em eletroquímica e eletrocromismo. Uma das aplicações mais interessantes é sem dúvida como material de cátodos para baterias recarregáveis de íons $\mathrm{Li}^{+}$, sendo que durante o processo de redução da matriz, cátions são necessários para compensarem cargas, conforme a eq. $6.3^{332}$. Neste caso os íons $\mathrm{Li}^{+}$entre no espaço interlamelar permanecendo lá até que a matriz seja re-oxidada, que é o que ocorre durante os processos de carga e descarga destas baterias.

$$
V_{2}^{5+/ 5+} O_{5}+e^{-}+L i^{+} \rightleftharpoons L i @ V_{2}^{4+/ 5+} O_{5}
$$

Muito materiais tem sido utilizados para este propósito, na sua maioria óxidos, mas todos eles acabam sucumbindo ao estresse estrutural que estes processos de carga e 
descarga geram durante succesivos ciclos perdendo assim a sua eficiência ${ }^{333}$. No caso do $\mathrm{XPV}$, isto se traduz por uma diminuição de cristalinidade e perda da estrutura lamelar, o que acaba acarretando na captura irreversível destes íons de eletrólito e formação de $\mathrm{LiV}_{3} \mathrm{O}_{8}$. Um dos artifícios utilizados pelos pesquisadores nesta área para contornar o problema é a inclusão de espécies químicas no espaço interlamelar que seja mantenham a estrutura lamelar, seja facilitem o trânsito dos íons $\mathrm{Li}^{+}$. Pensando nisto, e analisando os resultados obtidos com os hidróxidos duplos lamelares, decidimos utilizar as CBs como pilares para a estrutura do óxido afim de verificar se sua presença seria benéfica em termos de carga e descarga num cátodo de bateria. Existia porém um problema, que residia no fato dos opérculos de CBs serem coordenantes, o que poderia piorar o desempenho do material, pois poderia complexar com os íons $\mathrm{Li}^{+}$, aprisionando-os mais. Afim de se estabelecer um critério de comparação, utilizamos também o complexo de $\beta$-CB[6] com íons vanadila descritos na seção 5.1. Desta forma bloquearíamos um opérculo da $\beta$-CB[6] e devido à alta densidade de carga positiva tornaríamos improvável a coordenação de íons $\mathrm{Li}^{+}$no segundo. Desta forma, e comparando os resultados com aqueles obtidos nos intercalados com $\beta$-CB[6] poderíamos saber se de fato isto é importante. Para a preparação dos intercalados foram adicionadas quantidades variáveis de 1 a $10 \%$ em mol de $\beta$-CB[6] , $\gamma-\mathbf{C B}[7]$ e $[\beta-\mathbf{C B}[\mathbf{6}] \mathrm{VO}]^{2+}$ a géis recém preparados de $\mathrm{V}_{2} \mathrm{O}_{5}$ sob forte agitação até que as misturas se tornassem homogêneas. A presença do $\gamma-\mathbf{C B}[7]$ altera consideravelmente a estrutura do gel, formando grumos que não puderam ser aproveitados no experimento. Os géis com $\beta-\mathbf{C B}[\mathbf{6}]$ formaram filmes regulares, mas as propriedades eletroquímicas mais interessantes apareceram nos intercalados com menores concetrações de macrociclo. No caso do $[\beta-\mathrm{CB}[6] \mathrm{VO}]^{2+}$, devida à sua baixa solubilidade só pudemos preparar géis carregados com $1 \%$ do complexo. Vamos no ater aqui às propriedades dos compósitos com $[\beta-\mathbf{C B}[\mathbf{6}] \mathrm{VO}]^{2+}$ e $\beta$-CB[6] a $1 \%$, sempre os comparando ao xerogel puro. Os dados de difração de raios-X e de análise térmica confirmam a presença dos macrociclos no espaço interlamelar do óxido e nos indicaram fórmulas brutas $\mathbf{C B}[\mathbf{6}]_{0.02} \subset \mathrm{V}_{2} \mathrm{O}_{5} .2 \mathrm{H}_{2} \mathrm{O}$ para o intercalado com $\beta$-CB[6] e $\mathbf{C B}[\mathbf{6}] \mathbf{V O}_{0.022}^{2+} \subset \mathrm{V}_{2} \mathrm{O}_{5} .2 .2 \mathrm{H}_{2} \mathrm{O}$ para o intercalado com $[\beta-\mathbf{C B}[\mathbf{6}] \mathrm{VO}]^{2+}$. O comportamento voltamétrico do intercalado com $\beta-\mathbf{C B}[\mathbf{6}]$ é muito parecido com o XPV, com rápida diminuição das correntes catódica e anódica ao longo dos primeiros 30 ciclos, comportamento já bem descrito na literatura ${ }^{324}$. O intercalado com $[\beta-\mathbf{C B}[6] \mathrm{VO}]^{2+}$ porém, se comporta de forma oposta, apresentando ondas mais definidas e intensas neste mesmo intervalo. De acordo com os dados obtidos com auxílio da voltametria cíclica e cronopotenciometria, pudemos calcular as capacidades de carga específicas dos intercalados e a capacidade de armazenamento de $\mathrm{Li}^{+}$para cada um deles (figuras 84, 85 e 86).

A capacidade de carga específica do intercalado VXG.CB[6]VO 1\% é de aproximadamente 230 mA.h.g ${ }^{-1}$, o que é $45 \%$ mais do que o VXG (158 mA.h.g ${ }^{-1}$ ), e o VXG.CB[6] (168 mA.h.g $\left.{ }^{-1}\right)$. Os intercalados de VXG.CB[6]VO 1\% são também mais duráveis, uma 


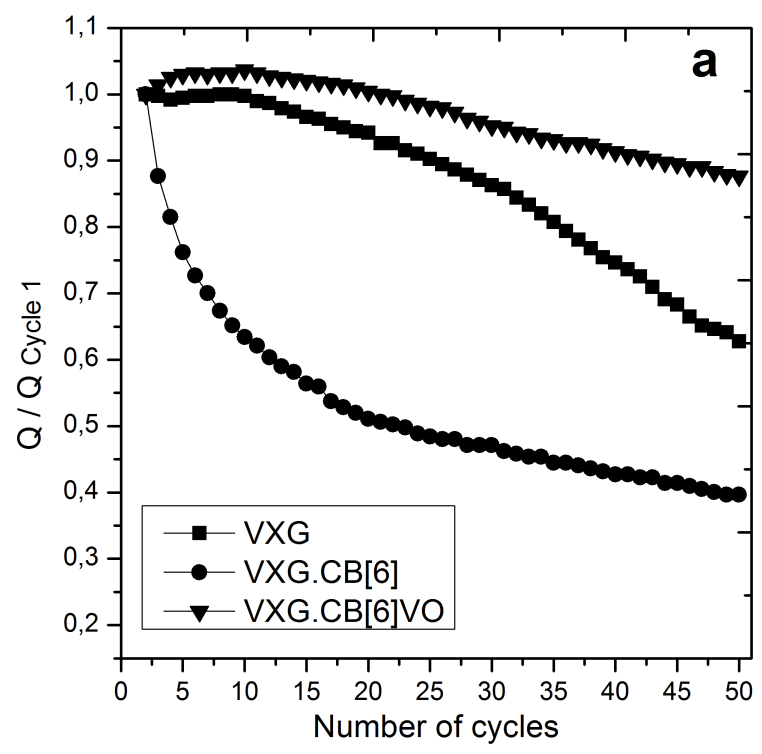

Figura 84: Variação de carga durante os $\mathbf{5 0}$ primeiros ciclos de voltametria, em função do primeiro $\left(Q_{n} / Q_{1}\right)$, com $\boldsymbol{i}=\mathbf{0 , 2} \mathbf{~ m A}$

vez que mantém até $87 \%$ de sua capacidade de carga inicial depois de 50 ciclos de carga e descarga a 0,2 mA que o intercalado com $\beta$ - $\mathbf{C B}[\mathbf{6}]$ conserva apenas $40 \%$, que é ainda menos do o XPV puro (63\%). A capacidade de armazenamento de $\mathrm{Li}^{+}$por unidades de $\mathrm{V}_{2} \mathrm{O}_{5}$ a $0,05 \mathrm{~mA}$ no intercalado VXG.CB[6]VO $1 \%$ é de 1,55 íons de lítio, muito maior do que 1,08 para o XPV e 1,15 para o VXG.CB[6]. O efeito das cucurbiturilas intercaladas em XPV é marcante. De fato pudemos constatar que a presença dos macrocilcos com opérculos livres dificulta o fluxo de $\mathrm{Li}^{+}$dentro do óxido, provavelmente pelo fato de formarem complexos no espaço interlamelar. Quando complexado a íons $\mathrm{VO}^{2+}$, integram-se à estrutura do óxido mantendo-o por mais tempo capaz de carregar e descarregar íons de $\mathrm{Li}^{+}$durante os ciclos de carga e descarga eletroquímicos. 

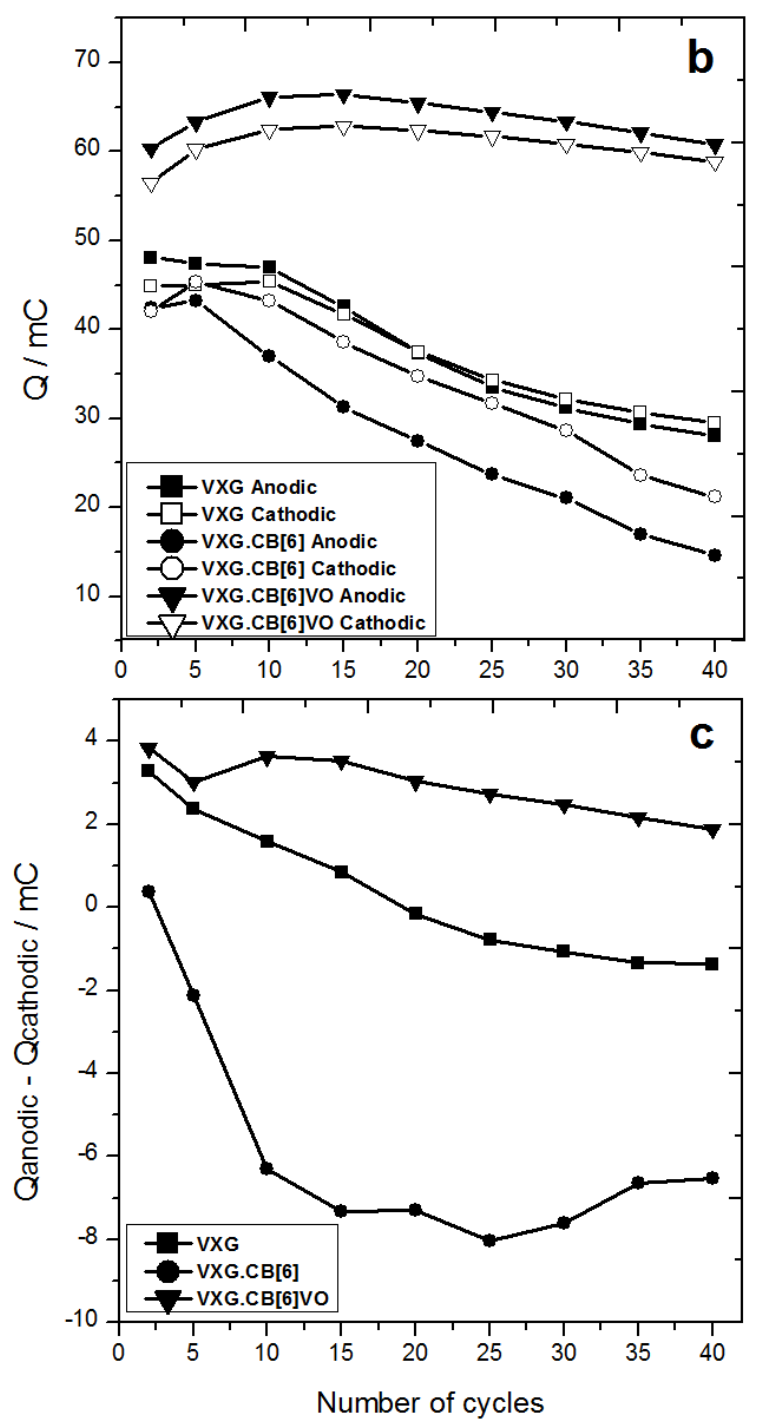

Figura 85: Cargas anódica e catódica para o VXG, VXG.CB6 1\%, e o VXG.CB6VO 1\% normalizadas pela massa do óxido, obtidas pela integração das ondas voltamétricas ( de 1,5 a $-1,5 \mathrm{~V}$ a $20 \mathrm{mV} / \mathrm{s} ; 40$ ciclos). c) Diferenças (resíduos) entre a carga anódica e catódica para as mesmas amostras. 


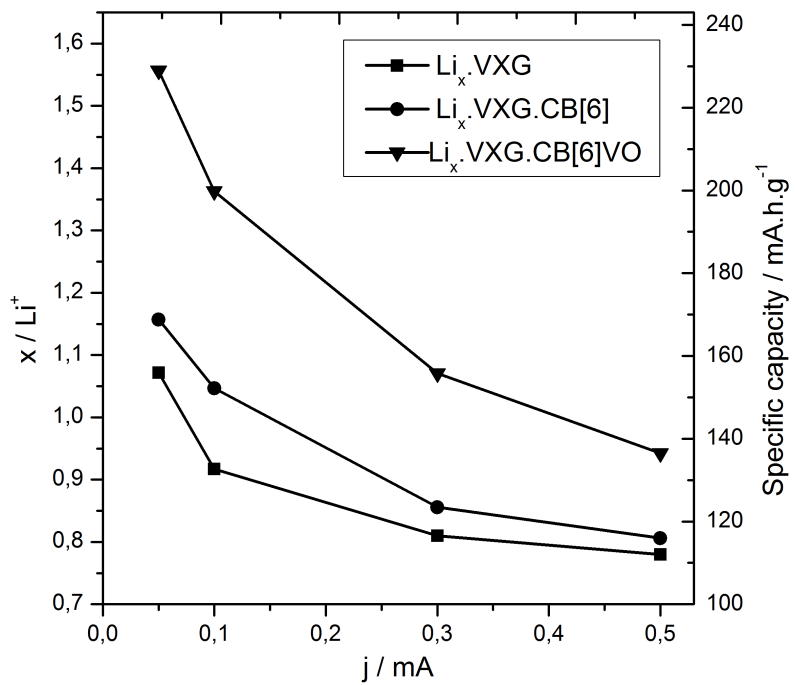

Figura 86: Capacidade de armazenamento de $\mathbf{L i}^{+}(\mathrm{xLi})$ e carga específica em função da densidade de corrente catódica (descarga) obtidos por cronopotenciometria (pot. $+\mathbf{1 , 5 \mathrm { V } \text { a }}$ $-1,5 \mathrm{~V})$ 


\section{Parte IV}

\section{Conclusões e Perspectivas}




\section{Conclusão e Perspectivas}

Tendo completado 8 anos de atividade, o trabalho de pesquisa em cucurbiturilas está maduro. Nosso grupo adquiriu o conhecimento necessário para preparar, separar, e caracterizar esta família de macrociclos, o que não é sempre trivial. Desenvolvemos trabalhos importantes nesta linhas, preparando membranas semipermeáveis, materiais adsorventes, catalisadores, moldes para síntese templates de nanopartículas, além de outros como captura e separação de gases, sensores não faradaicos entre outros. Na ocasião do primeiro congresso sobre o assunto, na Coréia em 2009, nosso grupo constava como sendo o único da América Latina a trabalhar nesta linha. Hoje a situação já começa a mudar, uma vez que diversos (pelo menos 5) grupos no Brasil já adotam estas moléculas em seus trabalhos de maneira crescente, seja na engenharia de filmes ${ }^{334}$, sensores piezelétricos e eletroquímicos ${ }^{335}$, catálise $^{336}$, trabalhos em química teórica, e veículos para fármacos e terapia fotodinâmica ${ }^{337,338}$. Isto é em parte um reflexo de nosso trabalho de divulgação desta classe de moléculas tão peculiar. Apesar de ser o assunto principal de nossas pesquisas, não é o único, uma vez que estudamos também materiais moleculares à base de imidas naftálicas, pontos quânticos de carbono, solvatocromismo, e materiais para eletrodos modificados, mas esta linha continuará forte e ganhará doravante novo impulso e direcionamento.

Recentemente Miyahara ${ }^{87}$ descreveu um macrociclo análogo, partido da etilenouréia ao invés da glicolurila, que resultou em uma estrutura que corresponde à metade de uma cucurbiturila. Obteve os homólogos com $n=6$ e 12. Batizou-os de hemicucurbit[n]urilas (fig. 1-c). No tocante às hemicucurbiturilas não existem dados na literatura sobre a formação de complexos e caviplexos, exceto para alguns ânions como $\mathrm{SCN}^{-}$ e $\mathrm{I}^{-}$que foram obtidos por espectrofotometria. Buschmann e Miyahara mostraram que esta família de compostos prefere formar compostos de inclusão com ânions, isto por conta de sua estrutura do tipo alternada que gera uma cavidade de alto potencial eletrostático positivo (fig.87).

Em 2010, Sindelar e seus colaboradores sintetizaram um macrociclo similar à cucurbit[n] urila, que formava estruturas parecidas como gomos de bambu, daí o nome bambusurilas $^{339}$. Estas estruturas são obtidas partindo da dimetil glicolurila, ao invés da glicolurila simples. Desta forma criam-se apenas duas pontes metilênicas ao invés de 4 para cada monômero ao longo do anel. Apesar de serem conhecidas há alguns anos, pouco tem sido feito com elas, e ainda é escassa a literatura sobre o assunto. Os novos projetos de pesquisa de nosso grupo envolvem estas estruturas e algumas estruturas cíclicas contendo diimidas naftálicas, e visam desenvolver uma base de conhecimento a respeito. 


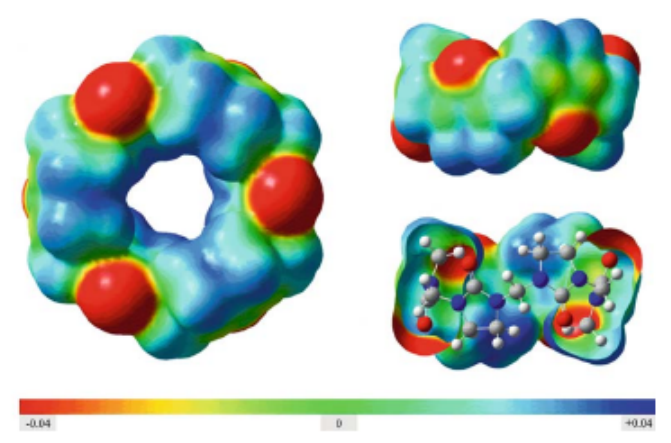

Figura 87: Mapas de potencial eletrostático da hemi-cucurbit[6]urila e sua cavidade.

Visam essencialmente caracterizar suas propriedades como matrizes de inclusão, explorar a possibilidade de formarem complexos metálicos, rotaxanos e pseudo-rotaxanos, além de estudos de catálise em meio confinado. Demos início recentemente a uma nova linha similar, envolvendo a bambus[6]urila, descrita na literatura por Sindelar e seu grupo ${ }^{339}$. Desde este primeiro artigo muito pouco tem sido publicado a seu respeito, talvez uns 15 artigos, sendo na sua maioria artigos de teoria, onde não há necessidade de se preparar o composto. Descobrimos a duras penas, que a razão disto é que a síntese descrita na literatura é pouco ou não reprodutível, e portanto, praticamente ninguém conseguiu até o momento produzir este composto. Por se tratar de um campo fértil academicamente, deve ser explorado e por isto investimos esforços em síntese orgânica e descobrimos uma rota sintética alternativa para a produção deste macrociclo. Nossa rota não é somente altamente reprodutível, mas também mais simples, o que deve dar impulso ao desenvolvimento da química das bambusurilas.

No tocante às membranas semipermeáveis, vamos avaliar o comportamento destes materiais com dois ionóforos distintos, um específico para cátions juntamente com outro para ânions. Esta será a estratégia para obtermos membranas de nanofiltração menos polarizáveis, e acreditamos que a presença de um canal para ânions, de tamanho compatível com o canal de cátions, permitirá uma despolarização mais eficiente, removendo cargas superficiais das interfaces, mantendo o desempenho dos filtros por mais tempo frente a solutos carregados como a água salobra. Um conhecimento mais aprofundado sobre o mecanismo de transporte envolvido nas membranas de Cubion é necessário para podermos aumentar sua escala de trabalho, e também conhecer quais são os gargalos de eficiência destas barreiras em processos de separação. No caso da permeação de íons por gradientes de concentração, não quantificamos o efeito da pressão osmótica nestes processos, mas sabemos que é importante quando trabalhamos com difusão natural, sem a aplicação de pressões externas. O processo de fabricação das membranas que patenteamos consiste em projetar um aerosol de uma suspensão de cucurbiturila e polímero em THF, sobre um anteparo rotatório de vidro jateado, do qual é possível retirar a película formada com fa- 
cilidade. Pudemos assim gerar filmes extramamente finos, da ordem de 40 microns, livres de furos ou trincas. Uma das aplicações deste tipo de filme é como barreira física contra agentes químicos e biológicos em pacientes com queimaduras graves. Uma grande parte dos queimados graves incorrem em complicações que levam frequentemente a óbito. Os principais causadores disto são a desidratação, falência de múltiplos órgãos, bactérias, viri e fungos, como Staphylococcus aureus, Pseudomonas aeruginosa, Enterococci, Enterobacter species, Escherichia coli entre outros ${ }^{340,341}$. Membranas ultrafinas colocadas sobre os ferimentos durante o tratamento em sua fase aguda, impedem o acesso de microorganismos ao tecido exposto além de reduzir a perda de água por evaporação sem comprometer as trocas gasosas necessárias à viabilidade das células. Além do mais, utilizamos PVC de pureza médica, o que torna os componentes destas membranas totalmente biocompatíveis. Vamos procurar colaboradores da área médica que estejam em condições de avaliar sua eficiência nos próximos anos.

As sínteses de nanopartículas em molde também prosseguirão, mas desta vez vamos preparar nanocubos de azul da Prússia. O Azul da Prússia é um polímero de coordenação onde ligantes $\mathrm{CN}^{-}$ligam alternadamente $\mathrm{Fe}^{2+}$ e $\mathrm{Fe}^{3+}$ em todas as direções, num sistema cúbico. Este polímero é interessante pois é um condutor redox, é eletrocrômico e permite o trânsito de íons como o potássio em sua estrutura, ou seja: ele também atua como canal molecular. Nanopartículas deste material em membranas podem agir da mesma forma que macrociclos, com uma área superficial enorme. Resultados preliminares mostraram que preparar estas pertículas na presença de $\beta-\mathbf{C B}[\mathbf{6}]$ e $\gamma-\mathbf{C B}[7]$ permite a obtenção de cubos nanométricos muito regulares.

A pesquisa com cucurbiturilas vai continuar nos próximos anos pois ainda há questões importantes a serem resolvidas, e vamos realizar um ciclo de estudos fundamentais abordando problemas estruturais e espectroscópicos. O primeiro deles é tentar fazer a atribuição total dos epectros de infravermelho e Raman de toda a série destes compostos, o que inclui glicolurilas, cucurbiturilas, hemi-cucrbiturilas e bambusurilas, utilizando correlações entre teoria e dados experimentais.

Estes estudos devem evoluir para estudos de UV de vácuo, pois há indícios de que uma banda em $180 \mathrm{~nm}$ se desloca para comprimentos de onda maiores quando as cucurbiturilas formam complexos metálicos. Também para as regiões do FIR e do NIR (Far infrared e Near infrared respectivamente), já que as absorções nestas regiões parecem ser característicos de cada um destes macrociclos, e também permitirão entender como é possível que haja água nas cavidades hidrofóbicas das CBs. Não existe até hoje um método de identificação das CBs, rápido, inequívoco e barato. Desenvolver um é o nosso 
grande objetivo agora.

A separação das cucurbiturilas é extremamente complicada, e o processo de preparação e purificação leva vários meses. Isto porquê são separados homólogos estruturas por diferenças de solubilidade basicamente e recristalizações. Os dados que existem na literatura sobre solubilidade das CBs são empíricos e escassos e, portanto, limitam as possibilidades em termos de separação dos homólogos. Numa abordagem to tipo QSPR (Quantitative Structure-Property Relationship) e LSER (Linear Solvation Energy Relationship) ${ }^{342-344}$, vamos buscar descritores moleculares para solutos e solventes que nos permitam prever a solubilidade das CBs em uma enorme gama de solventes nunca utilizados nestas separações. Com estes dados em mãos, será possível elaborar novas rotas de separação mais eficientes, e sobretudo rápidas. Não se sabe até hoje porquê os homólogos ímpares ( $\alpha$-CB[5] e $\gamma$-CB[7] ) das CBs são mais solúveis em água do que os pares $(\beta-\mathbf{C B}[\mathbf{6}]$ e $\delta$-CB[8] ). Também não há nenhum solvente específico para cada uma delas. Não sabemos tampouco porquê o ácido fórmico a $60 \%$ consegue dissolver a $\beta$-CB[6] , enquanto que proporções distintas destas não são tão eficientes, ou ainda porquê outros ácidos como o acético não o fazem. Para isto precisamos descrever com precisão as esferas de solvatação, interações específica com parametros de solventes HBA, HBD, polaridade, polarizabilidade etc... Para isto recorreremos a cálculos teóricos, dados da literatura e medidas experimentais.

Por razões óbvias de espaço, não foi possível apresentar todos os resultados que obtivemos com as CBs. Realizamos trabalhos interessantes com nanopartículas, captura e separação de gases como halogênios e óxidos de nitrogênio, cálculos teóricos, entre outros. Acreditamos que nossa contribuição até o momento tenha sido importante para o tema de estudo, gerando diversos artigos e três pedidos de patente, o que é bastante animador. Sabemos no entanto que restam muita questões fundamentais a serem respondidas e temos a plena convicção que há trabalho por pelo menos mais dez anos antes de que possamos considerar a linha exaurida. 


\section{Referências}

[1] Behrend, R.; Meyer, E.; Rusche, F. J.Liebigs Ann.Chem. 1905, 339, 1-37.

[2] Kim, J.; Jung, I.; Kim, S.; Lee, E.; Kang, J.; Sakamoto, S.; Yamaguchi, K.; Kim, K. J. Am. Chem. Soc. 2000, 122, 540-541.

[3] Day, A.; Arnold, A. P.; Blanch, R. J.; Snushall, B. J. Org. Chem. 2001, 66, 80948100.

[4] Masson, E.; Ling, X.; Joseph, R.; Kyeremeh-Mensah, L.; Lu, X. RSC Adv. 2012, 2, 1213-1247.

[5] Isaacs, L.; Park, S. K.; Liu, S.; Ko, Y. H.; Selvapalam, N.; Kim, Y.; Kim, H.; Zavalij, P. Y.; Kim, G. H.; Lee, H. S.; Kim, K. J. Am. Chem. Soc. 2005, 127, 18000-1.

[6] Huang, W. H.; Liu, S.; Zavalij, P. Y.; Isaacs, L. J. Am. Chem. Soc. 2006, 128, 14744-5.

[7] Isobe, H.; Sato, S.; Nakamura, E. Org. Lett. 2002, 4, 1287-1289.

[8] Burnett, C.; Witt, D.; Fettinger, J.; Isaacs, L. J. Org. Chem. 2003, 68, 6184-6191.

[9] Jon, S.; Selvapalam, N.; Oh, D.; Kang, J.; Kim, S.; Jeon, Y.; Lee, J.; Kim, K. J. Am. Chem. Soc. 2003, 125, 10186-10187.

[10] Lagona, J.; Fettinger, J.; Isaacs, L. Org. Lett. 2003, 5, 3745-3747.

[11] Liu, S. M.; Xu, L.; Wu, C. T.; Feng, Y. Q. Talanta 2004, 64, 929-934.

[12] Lagona, J.; Fettinger, J. C.; Isaacs, L. J. Org. Chem. 2005, 70, 10381-10392.

[13] Lagona, J.; Mukhopadhyay, P.; Chakrabarti, S.; Isaacs, L. Angew. Chem. Int. Ed. Engl. 2005, 44, 4844-4870.

[14] Lu, X.; Masson, E. Langmuir 2011, 27, 3051-3058.

[15] Zhang, H.; Liu, L.; Gao, C.; Sun, R.; Wang, Q. Dyes Pigm. 2012, 94, 266-270.

[16] Angelos, S.; Yang, Y.-W. . W.; Khashab, N. M.; Stoddart, J. F.; Zink, J. I. J. Am. Chem. Soc. 2009, 131, 11344+.

[17] Kennedy, A. R.; Florence, A. J.; McInnes, F. J.; Wheate, N. J. Dalton Trans. 2009, 7695-7700. 
[18] Lin, Y.; Li, L.; Li, G. Carbohydr. Polym. 2013, 92, 429 - 434.

[19] Parente Carvalho, C.; Uzunova, V. D.; Da Silva, J. P.; Nau, W. M.; Pischel, U. Chem. Commun. 2011, 47, 8793-8795.

[20] Ma, D.; Hettiarachchi, G.; Nguyen, D.; Zhang, B.; Wittenberg, J. B.; Zavalij, P. Y.; Briken, V.; Isaacs, L. Nature Chemistry 2012, 4, 503-510.

[21] Ma, D.; Glassenberg, R.; Ghosh, S.; Zavalij, P. Y.; Isaacs, L. Supramol. Chem. 2012, 24, 325-332.

[22] Pisani, M. J.; Wheate, N. J.; Keene, F. R.; Aldrich-Wright, J. R.; Collins, J. G. J. Inorg. Biochem. 2009, 103, 373-380.

[23] Sinha, M. K.; Reany, O.; Yefet, M.; Botoshansky, M.; Keinan, E. Chem. Eur. J. 2012, 18, 5589-5605.

[24] Tuncel, D.; Steinke, J. Macromolecules 2004, 37, 288-302.

[25] Shaikh, M.; Choudhury, S. D.; Mohanty, J.; Bhasikuttan, A. C.; Pal, H. Phys. Chem. Chem. Phys. 2010, 12, 7050-7055.

[26] Choudhury, S. D.; Mohanty, J.; Pal, H.; Bhasikuttan, A. C. J. Am. Chem. Soc. 2010, 132, 1395-1401.

[27] Rauwald, U.; Biedermann, F.; Deroo, S.; Robinson, C. V.; Scherman, O. A. J. Phys. Chem. B 2010, 114, 8606-8615.

[28] Plumb, J. A.; Venugopal, B.; Oun, R.; Gomez-Roman, N.; Kawazoe, Y.; Venkataramanan, N. S.; Wheate, N. J. Metallomics 2012, 4, 561-567.

[29] Wheate, N. J.; Buck, D. P.; Day, A. I.; Collins, J. G. Dalton Trans. 2006, 451-8.

[30] Dong, N.; Xue, S.-F.; Zhu, Q.-J.; Tao, Z.; Zhao, Y.; Yang, L.-X. Supramol. Chem. 2008, 20, 659-665.

[31] Park, K. M.; Suh, K.; Jung, H.; Lee, D.; Ahn, Y.; Kim, J.; Baek, K.; Kim, K. Chem. Commun. 2009, 71-73.

[32] Kim, K.; Selvapalam, N.; Oh, D. J. Inclusion Phenom. Macrocyclic Chem. 2004, $50,31-36$.

[33] Ji-Yuan, Y.; Ai-Zhuo, S.; Li-Ming, D.; Chang-Feng, L.; Hao, W.; Yin-Xia, C. Chinese Journal of Analytical Chemistry 2010, 38, 1813-1816.

[34] Chang, Y.-X.; Qiu, Y.-Q.; Du, L.-M.; Li, C.-F.; Guo, M. Analyst 2011, 136, 41684173. 
[35] Saleh, N.; Meetani, M. A.; Al-Kaabi, L.; Ghosh, I.; Nau, W. M. Supramol. Chem. 2011, 23, 654-661.

[36] Buechel, G. E.; Stepanenko, I. N.; Hejl, M.; Jakupec, M. A.; Keppler, B. K.; Arion, V. B. Inorg. Chem. 2011, 50, 7690-7697.

[37] Macartney, D. H. Isr. J. Chem. 2011, 51, 600-615.

[38] Zhao, Y.; Pourgholami, M. H.; Morris, D. L.; Collins, J. G.; Day, A. I. Org. Biomol. Chem. 2010, 8, 3328-3337.

[39] Huang, X.; Tan, Y.; Zhou, Q.; Wang, Y. e-Polymers 2008, 1-11.

[40] Wheate, N. J.; Vora, V.; Anthony, N. G.; McInnes, F. J. J. Inclusion Phenom. Macrocyclic Chem. 2010, 68, 359-367.

[41] Yan-Hui, M.; Ying, H.; Qian-Jiang, Z.; Jian-Xin, Z.; Sai-Feng, X.; Zhu, T. Chemical Journal of Chinese Universities-chinese 2011, 32, 2544-2547.

[42] Li-Fan, L.; You-Wen, L.; Zhi-Wen, H.; Hong-Bin, L. Chemical Journal of Chinese Universities-chinese 2012, 33, 282-287.

[43] Xiaozhong, F.; Ying, H.; Zhu, T.; Saifeng, X.; Chun, L.; Yu, O.; Jianxin, Z. Chinese Journal of Organic Chemistry 2010, 30, 675-683.

[44] Nan, D.; Sai-Feng, X.; Zhu, T.; Yu, Z.; Jie, C.; Hong-Cai, L. Acta Chim. Sinica 2008, 66, 1117-1122.

[45] Wheate, N. J.; Day, A. I.; Blanch, R. J.; Arnold, A. P.; Cullinane, C.; Collins, J. G. Chem. Commun. 2004, 1424-5.

[46] Croissant, J.; Zink, J. I. J. Am. Chem. Soc. 2012, 134, 7628-7631.

[47] Jeon, Y.; Kim, S.; Ko, Y.; Sakamoto, S.; Yamaguchi, K.; Kim, K. Org. Biomol. Chem. 2005, 3, 2122-2125.

[48] Wheate, N. J.; Taleb, R. I.; Krause-Heuer, A. M.; Cook, R. L.; Wang, S.; Higgins, V. J.; Aldrich-Wright, J. R. Dalton Trans. 2007, 5055-5064.

[49] Nan, D.; MeiYu, D.; AnTing, Z.; QianJiang, Z.; Zhu, T.; Yu, Z. Sci. China, Ser. B: Chem. 2010, 53, 2304-2310.

[50] Ying, H.; Zhu, T.; Sai-Feng, X.; Qian-Jiang, Z. Chemical Journal of Chinese Universities-chinese 2011, 32, 2022-2031.

[51] Park, K. M.; Lee, D.-W.; Sarkar, B.; Jung, H.; Kim, J.; Ko, Y. H.; Lee, K. E.; Jeon, H.; Kim, K. Small 2010, 6, 1430-1441. 
[52] Lim, Y. B.; Kim, T.; Lee, J. W.; Kim, S. M.; Kim, H. J.; Kim, K.; Park, J. S. Bioconjug. Chem. 2002, 13, 1181-5.

[53] Dong, N.; Cheng, L.-n.; Wang, X.-l.; Li, Q.; Dai, C.-y.; Tao, Z. Talanta 2011, 84, 684-689.

[54] Ambrogio, M. W.; Pecorelli, T. A.; Patel, K.; Khashab, N. M.; Trabolsi, A.; Khatib, H. A.; Botros, Y. Y.; Zink, J. I.; Stoddarrt, J. F. Org. Lett. 2010, 12, 3304-3307.

[55] McInnes, F. J.; Anthony, N. G.; Kennedy, A. R.; Wheate, N. J. Organic \& Biomolecular Chemistry 2010, 8, 765-773.

[56] Zhao, Y.; Buck, D. P.; Morris, D. L.; Pourgholami, M. H.; Day, A. I.; Collins, J. G. Organic $\&$ Biomolecular Chemistry 2008, 6, 4509-4515.

[57] Barooah, N.; Mohanty, J.; Pal, H.; Bhasikuttan, A. C. J. Phys. Chem. B 2012, 116, 3683-3689.

[58] Li, C.-F.; Du, L.-M.; Zhang, H.-M. Spectrochim. Acta, Part A 2010, 75, 912-917.

[59] Bhasikuttan, A. C.; Choudhury, S. D.; Pal, H.; Mohanty, J. Isr. J. Chem. 2011, 51, 634-645.

[60] Appel, E. A.; Biedermann, F.; Rauwald, U.; Jones, S. T.; Zayed, J. M.; Scherman, O. A. J. Am. Chem. Soc. 2010, 132, 14251-14260.

[61] Koner, A. L.; Ghosh, I.; Saleh, N.; Nau, W. M. Can. J. Chem. 2011, 89, 139-147.

[62] Li, C.-F.; Du, L.-M.; Wu, W.-Y.; Sheng, A.-Z. Talanta 2010, 80, 1939-1944.

[63] Vinciguerra, B.; Cao, L.; Cannon, J. R.; Zavalij, P. Y.; Fenselau, C.; Isaacs, L. J. Am. Chem. Soc. 2012, 134, 13133-13140.

[64] Walker, S.; Kaur, R.; McInnes, F. J.; Wheate, N. J. Mol. Pharm. 2010, 7, 21662172.

[65] Nau, W.; Mohanty, J. Int. J. Photoenergy 2005, 7, 133-141.

[66] Wlaker, S.; Oun, R.; McInnes, F. J.; Wheate, N. J. Isr. J. Chem. 2011, 51.

[67] Suvitha, A.; Venkataramanan, N. S.; Mizuseki, H.; Kawazoe, Y.; Ohuchi, N. J. Inclusion Phenom. Macrocyclic Chem. 2010, 66, 213-218.

[68] Jung, H.; Park, K. M.; Yang, J.-A.; Oh, E. J.; Lee, D.-W.; Park, K.; Ryu, S. H.; Hahn, S. K.; Kim, K. Biomaterials 2011, 32, 7687-7694.

[69] Hettiarachchi, G.; Nguyen, D.; Wu, J.; Lucas, D.; Ma, D.; Isaacs, L.; Briken, V. Plos One 2012, 5, 1-10. 
[70] Loh, X. J.; del Barrio, J.; Toh, P. P. C.; Lee, T.-C.; Jiao, D.; Rauwald, U.; Appel, E. A.; Scherman, O. A. Biomacromolecules 2012, 13, 84-91.

[71] Marquez, C.; Nau, W. Angew. Chem. Int. Ed. Engl. 2001, 40, 3155.

[72] Huang, Y.; Xue, S.-F.; Tao, Z.; Zhu, Q.-J.; Ma, Y.-H.; Zhong, S.-H. J. Inclusion Phenom. Macrocyclic Chem. 2011, 69, 131-137.

[73] Cheong, W. J.; Go, J. H.; Baik, Y. S.; Kim, S. S.; Nagarajan, E. R.; Selvapalam, N.; Ko, Y. H.; Kim, K. Bull. Korean Chem. Soc. 2008, 29, 1941-1945.

[74] Nagarajan, E.; Oh, D.; Selvapalam, N.; Ko, Y.; Park, K.; Kim, K. Tetrahedron Lett. 2006, 47, 2073-2075.

[75] Lai-Sheng, L.; Shang-Wen, W.; Li-Fang, H.; Miao-Fen, L. Acta Chim. Sinica 2008, $66,63-72$.

[76] Constabel, F.; Geckeler, K. Fullerenes, Nanotubes, Carbon Nanostruct. 2004, 12, 811-818.

[77] Lee, J. W.; Kim, K.; Choi, S.; Ko, Y. H.; Sakamoto, S.; Yamaguchi, K.; Kim, K. Chem. Commun. 2002, 2692-2693.

[78] Buschmann, H.; Jansen, K.; Schollmeyer, E. Acta Chim. Slov. 1999, 46, 405-411.

[79] Zhao, Y. J.; Xue, S. F.; Zhu, Q. J.; Tao, Z.; Zhang, J. X.; Wei, Z. B.; Long, L. S.; Hu, M. L.; Xiao, H. P.; Day, A. I. Chin. Sci. Bull. 2004, 49, 1111-1116.

[80] Barooah, N.; Mohanty, J.; Pal, H.; Bhasikuttan, A. C. Phys. Chem. Chem. Phys. 2011, 13, 13117-13126.

[81] Ko, Y. H.; Kim, E.; Hwang, I.; Kim, K. Chem. Commun. 2007, 1305-1315.

[82] Hua-peng, Y.; Jun-yong, S.; Lian, W.; Hong-wei, X.; Lun, W.; Yun-you, Z. Spectroscopy and Spectral Analysis 2009, 29, 1041-1044.

[83] Buschmann, H. J.; Wego, A.; Zielesny, A.; Schollmeyer, E. J. Inclusion Phenom. Macrocyclic Chem. 2006, 54, 241-246.

[84] Buschmann, H.; Schollmeyer, E. Journal of Inclusion Phenomena and Molecular Recognition in Chemistry 1992, 14, 91-99.

[85] Wu, X.-j.; Hu, K.; Meng, X.-g.; Cheng, G.-z. New J. Chem. 2010, 34, 17-20.

[86] Demets, G. J.-F. Quim. Nova 2007, 30, 1313-1322.

[87] Miyahara, Y.; Goto, K.; Oka, M.; Inazu, T. Angew. Chem. Int. Ed. Engl. 2004, 43, 5019-5022. 
[88] Chakraborty, A.; Wu, A.; Witt, D.; Lagona, J.; Fettinger, J. C.; Isaacs, L. J. Am. Chem. Soc. 2002, 124, 8297-306.

[89] Day, A.; Arnold, A.; Blanch, R. Molecules 2003, 8, 74-84.

[90] Flinn, A.; Hough, G.; Stoddart, J.; Williams, D. Angew. Chem. Int. Ed. Engl. 1992, 31, 1475-1477.

[91] Lee, J. W.; Samal, S.; Selvapalam, N.; Kim, H. J.; Kim, K. Acc. Chem. Res. 2003, $36,621-30$.

[92] Zhao, J.; Kim, H.; Oh, J.; Kim, S.; Lee, J.; Sakamoto, S.; Yamaguchi, K.; Kim, K. Angew. Chem. Int. Ed. Engl. 2001, 40, 4233-4235.

[93] Wagner, B.; Boland, P.; Lagona, J.; Isaacs, L. J. Phys. Chem. B 2005, 109, 76867691.

[94] Mock, W.; Shih, N. J. Am. Chem. Soc. 1989, 111, 2697-2699.

[95] Mock, W.; Shih, N. J. Org. Chem. 1983, 48, 3618-3619.

[96] Mock, W. L.; Shih, N. Y. J. Am. Chem. Soc. 1988, 110, 4706-4710.

[97] Rekharsky, M.; Ko, Y. H.; Selvapalam, N.; Kim, K.; Inoue, Y. Supramol. Chem. 2007, 19, 39-46.

[98] Balzani, V.; Credi, A.; Venturi, M. Molecular Devices and Machines - A Journey into the nano World; Wiley-VCH Verlag, Alemanha, 2003.

[99] Toma, H. An. Acad. Bras. Ci. 2000, 72, 5-25.

[100] Lehn, J. M. Supramolecular Chemistry, Concepts and Perspectives; VCH:Weinheim, Alemanha, 1995.

[101] Lehn, J.-M. Science 1985, 227, 849-856.

[102] Reinhoudt, D. N.; Crego-Calama, M. Science 2002, 295, 2403-2407.

[103] Zhang, H.; Pan, X.; Han, X.; Liu, X.; Wang, X.; Shen, W.; Bao, X. Chem. Sci. 2013, 4, 1075.

[104] Chang, J. C.; Tsai, W. J.; Chiu, T. C.; Liu, C. W.; Chao, J. H.; Lin, C. H. J. Mater. Chem. 2011, 21, 4605.

[105] Chiu, D. T.; Wilson, C. F.; Ryttsén, F.; Strömberg, A.; Farre, C.; Karlsson, A.; Nordholm, S.; Gaggar, A.; Modi, B. P.; Moscho, A.; Garza-López, R. A.; Orwar, O.; Zare, R. N. Science 1999, 283, 1892. 
[106] Ward, M. D. Nat. Chem. 2010, 2, 610.

[107] Bullara, D.; Decker, Y. D.; Lefever, R. Phys. Rev. 2013, 87, 062923.

[108] Basilio, N.; Garcia-Rio, L.; Moreira, J. A.; Pessego, M. J. Org. Chem. 2010, 75, $848-855$.

[109] Wieland, M.; Mieusset, J. L.; Brinker, U. H. Tetrahed. Lett. 2012, 53, 4351-4353.

[110] Jon, S.; Ko, Y.; Park, S.; Kim, H.; Kim, K. Chem. Commun. 2001, 1938-1939.

[111] de Lima, S. M.; Gomez, J. A.; Barros, V. P.; Vertuan, G. d. S.; Assis, M. d. D.; Graeff, C. F. O.; Demets, G. J. F. Polyhedron 2010, 29, 3008-3013.

[112] Marquez, C.; Huang, F.; Nau, W. IEEE Trans. Nanobiosci. 2004, 3, 39-45.

[113] Mock, W.; Irra, T.; Wepsiec, J.; Manimaran, T. J. Org. Chem. 1983, 48, 3619-3620.

[114] Mock, W.; Irra, T.; Wepsiec, J.; Adhya, M. J. Org. Chem. 1989, 54, 5302-5308.

[115] Pemberton, B.; Raghunathan, R.; Volla, S.; Sivaguru, J. Chem. Eur. J. 2012, 18, 12178-12190.

[116] Taketsuji, K.; Tomioka, H. Nippon Kagaku Kaishi 1998, 10, 670-678.

[117] Wu, J.; Isaacs, L. Chem. Eur. J. 2009, 15, 11675-11680.

[118] Zheng, D.; Cong, H.; Tao, Z.; Xue, S. F.; Zhu, Q. J. Chin. J. Inorg. Chem. 2008, 24, 1684-1689.

[119] Krasia, T.; Steinke, J. Chem. Commun. 2002, 22-23.

[120] Cao, M.; Wei, Y.; Gao, S.; Cao, R. Cat. Sci. Technol. 2012, 2, 156-163.

[121] Chakrabarti, S.; Isaacs, L. Supramol. Chem. 2008, 20, 191-199.

[122] Carlqvist, P.; Maseras, F. Chem. Commun. 2007, 748-750.

[123] Bakovets, V. V.; Nadolinnyi, V. A.; Erenburg, S. B.; Kuznetsov, A. M.; Dolgovesova, I. P. Russ. J. Inorg. Chem. 2010, 55, 1897-1902.

[124] Berbeci, L. S.; Wang, W.; Kaifer, A. E. Org. Lett. 2008, 10, 3721-3724.

[125] Wu, X. L.; Luo, L.; Lei, L.; Liao, G. H.; Wu, L. Z.; Tung, C. H. J. Org. Chem. 2008, 73, 491-494.

[126] Cramer, F.; Kampe, W. Tetrahed. Lett. 1962, 353-356.

[127] Cramer, F.; Kampe, W. J. Am. Chem. Soc. 1965, 87, 1115-1120. 
[128] Hennrich, N.; Cramer, F. J. Am. Chem. Soc. 1965, 87, 1121-1126.

[129] Cramer, F. Angew. Chem. 1956, 68, 115-118.

[130] Cramer, F. Angew. Chem. Int. Ed. Engl. 1956, 68, 115-120.

[131] Frank, S. G. Journal of Pharmaceutical Sciences 1975, 64, 1585-1604.

[132] Steed, J.; Turner, D.; Wallace, K. Core Conceptsin Supramolecular Chemistry and Nanochemistry; John Wiley and Sons, Chicester, Inglaterra, 2007.

[133] Rodnikova, M. Russ. J. Phys. Chem. 2006, 80, 1806-1808.

[134] Catalán, J.; Díaz, C.; García-Blanco, F. J. Org. Chem. 1999, 64, 6512-6514.

[135] Cramer, R. I. J. Am. Chem. Soc. 1977, 99, 5408-5412.

[136] Cecil, R. Nature 1967, 214, 369-370.

[137] Winstein, S.; Grunwald, E.; Jones, H. J. Am. Chem. Soc. 1951, 73, 2700.

[138] Grunwald, E.; Winstein, S. J. Am. Chem. Soc. 1948, 70, 846.

[139] Solov'ev, V.; Strakhova, N. N.; Raevsky, O.; Rüdiger, V.; Schneider, H.-J. J. Org. Chem. 1996, 61, 5221-5226.

[140] Schneider, H.-J.; Sangwan, N. K. J. Chem. Soc. Chem. Commun. 1986, 1787-1789.

[141] Yaacobi, M.; Ben-Naim, A. J. Phys. Chem. 1974, 78, 175-178.

[142] Abraham, M. H.; Grellier, P. L.; McGill, R. A. J. Chem. Soc. Perkin Trans. 2 1988,

[143] Reichardt, C. Pure Appl. Chem. 1982, 54, 1867-1884.

[144] Marcus, Y. Chem. Soc. Rev. 1993, 409-416.

[145] Cramer, F.; Saenger, W.; Spatz, H. J. Am. Chem. Soc. 1967, 89, 14-20.

[146] Barone, G.; Castronuovo, G.; Del Vecchio, P.; Elia, V.; Muscetta, M. J. Chem. Soc. Faraday Trans. I 1986, 82, 2089-2101.

[147] Pedersen, C. J. Am. Chem.Soc. 1967, 89, 7017-7036.

[148] Buschmann, H.; Cleve, E.; Jansen, K.; Wego, A.; Schollmeyer, E. J. Inclusion Phenom. Macrocyclic Chem. 2001, 40, 117-120.

[149] Buschmann, H.; Jansen, K.; Schollmeyer, E. Inorg. Chem. Commun. 2003, 6, 531534. 
[150] Izatt, R.; Bradshaw, J.; Nielsen, S. A.; Lamb, J.; Christensen, J.; Sen, D. Chem. Rev. 1985, 85, 271-339.

[151] Zhang, X.; Krakowiak, K.; Xue, G.; Bradshaw, J.; Izatt, R. Ind. Eng. Chem. Res. 2000, 39, 3516-3520.

[152] Mainicheva, E. A.; Gerasko, O. A.; Sheludyakova, L. A.; Naumov, D. Y.; Karsanova, I. I.; Amirov, R. R.; Fedin, V. P. Russ. Chem. Bull. 2006, 55, 1956-1965.

[153] Gerasko, O. A.; Virovets, A. V.; Samsonenko, D. G.; Tripol'skaya, A. A.; Fedin, V. P.; Fenske, D. Russ. Chem. Bull. 2003, 52, 585-593.

[154] Heo, J.; Kim, S. Y.; Whang, D.; Kim, K. Angew. Chem. Int. Ed. Engl. 1999, 38, $641-643$.

[155] Whang, D.; Heo, J.; Park, J.; Kim, K. Angew. Chem. Int. Ed. Engl. 1998, 37, 78-80.

[156] Gerasko, O.; Virovets, A.; Sokolov, M.; Dybtsev, D.; Gerasimenko, A.; Fenske, D.; Fedin, V. Russ. Chem. Bull. 2002, 51, 1800-1805.

[157] Sokolov, M.; Dybtsev, D.; Virovets, A.; Clegg, F.; Fedin, V. Russ. Chem. Bull. 2001, 50, 1144-1147.

[158] Hernandez-Molina, R.; Sokolov, M.; Esparza, P.; Vicent, C.; Llusar, R. Dalton Trans. 2004, 847-51.

[159] Sokolov, M.; Dybtsev, D.; Fedin, V. Russ. Chem. Bull. 2003, 52, 1041-1060.

[160] Gerasko, O.; Samsonenko, D.; Sharonova, A.; Virovets, A.; Lipkowski, J.; Fedin, V. Russ. Chem. Bull. 2002, 51, 346-349.

[161] Fedin, V.; Sokolov, M.; Lamprecht, G.; Hernandez-Molina, R.; Seo, M.; Virovets, A.; Clegg, W.; Sykes, A. Inorg. Chem. 2001, 40, 6598-6603.

[162] Fedin, V.; Sokolov, M.; Dybtsev, D.; Gerasko, O.; Virovets, A.; Fenske, D. Inorg. Chim. Acta 2002, 331, 31-38.

[163] Chubarova, E.; Samsonenko, D.; Platas, J.; Sokolov, M.; Fedin, V. J. Struct. Chem. 2004, 45, 906-911.

[164] Sokolov, M.; Hernandez-Molina, R.; Dybtsev, D.; Chubarova, E.; Solodovnikov, S.; Pervukhina, N.; Vicent, C.; Llusar, R.; Fedin, V. Z. Anorg. Allg. Chem. 2002, 628, $2335-2339$.

[165] Samsonenko, D.; Gerasko, O.; Lipkowski, J.; Virovets, A.; Fedin, V. Russ. Chem. Bull. 2002, 51, 1915-1918. 
[166] Samsonenko, D.; Sokolov, M.; Gerasko, O.; Virovets, A.; Lipkowski, J.; Fenske, D.; Fedin, V. Russ. Chem. Bull. 2003, 52, 2132-2139.

[167] Mitkina, T. V.; Naumov, D. Y.; Gerasko, O. A.; Dolgushin, F. M.; Vicent, C.; Llusar, R.; Sokolov, M. N.; Fedin, V. P. Russ. Chem. Bull. 2004, 53, 2519-2524.

[168] Samsonenko, D.; Geras'ko, O.; Mit'kina, T.; Lipkowski, J.; Virovets, A.; Fenske, D.; Fedin, V. Russ. J. Coord. Chem. 2003, 29, 166-174.

[169] Arnold, A.; Day, A. Cucurbiturils and method for synthesis; 2000; WO Patent App. $\mathrm{PCT} / \mathrm{AU} 2000 / 000,412$.

[170] Arnold, A.; Blanch, R.; Day, A. Method for preparing cucurbiturils; 2005; WO Patent App. PCT/AU2004/001,232.

[171] Day, A. I.; Arnold, A. P.; Blanch, R. J. Cucurbiturils and method for binding gases and volatiles using cucurbiturils Cucurbiturils and method for binding gases and volatiles using cucurbiturils; 2002; US6869466.

[172] Kim, K.; Kim, J.; Jung, I.; Kim, S.; Lee, E.; Kang, J. Cucurbituril derivatives, their preparation methods and uses; 2002; US Patent 6,365,734.

[173] Kim, K.; Jon, S. Y.; Jeon, Y. J.; Oh, D. H.; Selvapalam, N. Nano-particles comprising cucurbituril derivatives, pharmaceutical composition cantining the same, and process for the preparation thereof; 2008; US20080279950.

[174] Kim, K.; Jon, S.; Selvapalam, N.; Oh, D. Enhanced solubility in common solvents; ion sensor; removal odors; water and air pollution control; 2011; US Patent $8,058,451$.

[175] Kim, K.; Shashadhar, S.; Raju, N.; Narayanan, S.; Oh, D. Processes of preparing glycolurils and cucurbiturils using microwave; 2012; US Patent 8,293,922.

[176] Kim, K.; Oh, D. H.; Nagarajan, E. R.; Ko, Y. H.; Samal, S. Cucurbituril-containing polymer, stationary phase and column using the same; 2009; US7520982.

[177] Cram, D. J. Nature 1992, 356, 29.

[178] Cram, D. J.; Cram, J. M. Container Molecules and Their Guests; Royal Society of Chemistry, Cambridge U.K., 1994.

[179] Pearson, R. Inorg. Chem. 1988, 27, 734-740.

[180] Corma, A.; Garcia, H.; Montes-Navajas, P.; Primo, A.; Calvino, J. J.; Trasobares, S. Chem. Eur. J. 2007, 13, 6359-6364. 
[181] Kellersberger, K.; Anderson, J.; Ward, S.; Krakowiak, K.; Dearden, D. J. Am. Chem. Soc. 2001, 123, 11316-11317.

[182] Rabinowitch, E.; Epstein, L. J. Am. Chem. Soc. 1941, 63, 69-78.

[183] Bergmann, K.; O’Konski, C. T. J. Phys. Chem. 1963, 67, 2169-2177.

[184] Patil, K.; Pawar, R.; Talap, P. Phys. Chem. Chem. Phys. 2000, 2, 4313-4317.

[185] Demets, G. J.-F.; Schneider, B. V. S.; Correia, H. D.; Goncalves, R. R.; Nobre, T. M.; Zaniquelli, M. E. D. J. Nanosci. Nanotechnol. 2008, 8, 432-435.

[186] An, Q.; Li, G.; Tao, C.; Li, Y.; Wu, Y.; Zhang, W. Chem. Commun. 2008, 19891991.

[187] Jeon, Y. J.; Kim, H.; Jon, S.; Selvapalam, N.; Oh, D. H.; Seo, I.; Park, C. S.; Jung, S. R.; Koh, D. S.; Kim, K. J. Am. Chem. Soc. 2004, 126, 15944-15945.

[188] Correia, H. D.; Demets, G. J. F. Electrochem. Commun. 2009, 11, 1928-1931.

[189] Bard, A. J. J. Chem. Educ. 1983, 60, 302-304.

[190] Nunes, S.; Peinemann, K. Membrane Technology in the Chemical Industry; WileyVCH Verlag, Alemanha.

[191] Baker, R. Membrane Technology and Applications; John Wiley \& Sons, Chicester, Inglaterra, 2004.

[192] Teodósio, T. M. B.; Cavallini, T. d. S.; Jardim, L. V.; Demets, G. J. F. Orbital Elec. J. Chem. Campo Grande 2011, 3, 204-211.

[193] Teodósio, T. M. B. Membranas Semi-permeáveis a Base de Cucurbit[6]urila e Poli(cloreto de vinila). Masters thesis, Universidade de São Paulo, Av Bandeirantes 3900, DQ-FFCLRP-USP, 2009.

[194] Meher, L.; Sagar, D.; S.N., N. Renew. Sustain. Energ. Rev. 2006, 10, 248-268.

[195] http://www.aneel.gov.br/arquivos/PDF/atlas_par3_cap7.pdf.

[196] Chien, H.; Kao, C.; Surampalli, R.; Huang, W. Y.; Hou, F. J. Env. Eng. 2011, 137, 602.

[197] Santos, H. F.; Carmo, F.; Paes, J.; Rosado, A.; Peixoto, R. Wat. Air Soil Pollut. 2011, 216, 329 .

[198] de Lima, S. M. Novos catalisadores à base de oxovanádio (IV) e Cucurbit[6]urila. Dissertação de Mestrado, Universidade de São Paulo, 2009. 
[199] Abramov, P. A.; Sokolov, M. N.; Virovets, A. V.; Peresypkina, E. V.; Fedin, V. P. J. Cluster Sci. 2007, 18, 597-605.

[200] Sokolov, M.; Gerasko, O.; Dybtsev, D.; Chubarova, E.; Virovets, A.; Vicent, C.; Llusar, R.; Fenske, D.; Fedin, V. Eur. J. Inorg. Chem. 2004, 63-68.

[201] Sokolov, M.; Dybtsev, D.; Virovets, A.; Hegetschweiler, K.; Fedin, V. Russ. Chem. Bull. 2000, 49, 1877-1881.

[202] Chubarova, E. V.; Sokolov, M. N.; Samsonenko, D. G.; Vicent, C.; Fedin, V. P. J. Struct. Chem. 2006, 47, 939-945.

[203] Liu, J.; Long, L.; Huang, R.; Zheng, L.; Ng, S. Acta Crystallogr., Sect. E: Struct. Rep. Online 2005, 61, M1021-M1023.

[204] Lin, R.; Long, L.; Huang, R.; Zheng, L.; Ng, S. Acta Crystallogr., Sect. E: Struct. Rep. Online 2005, 61, M885-M888.

[205] Samsonenko, D.; Sokolov, M.; Virovets, A.; Pervukhina, N.; Fedin, V. Eur. J. Inorg. Chem. 2001, 167-172.

[206] Samsonenko, D.; Virovets, A.; Sharonova, A.; Fedin, V.; Fenske, D. Russ. Chem. Bull. 2001, 50, 494-496.

[207] Fedin, V. P.; Gramlich, V.; Wörle, M.; Weber, T. Inorg. Chem. 2001, 40, 1074-1077.

[208] Abramov, P. A.; Gushchin, A. L.; Sokolov, M. N.; Fedin, V. P. J. Struct. Chem. 2010, 51, 378-381.

[209] Fedin, V. P.; Virovets, A. V.; Dybtsev, D.; Gerasko, O. A.; Hegetschweiler, K.; Elsegood, M. R. J.; Clegg, W. Inorg. Chim. Acta 2000, 304, 301-304.

[210] Gerasko, O. A.; Mainicheva, E. A.; Naumov, D. Y.; Fedin, V. P. Russ. Chem. Bull. 2007, 56, 1972-1977.

[211] Fedin, V. P.; Virovets, A. V.; Sokolov, M. N.; Dybtsev, D. N.; Gerasko, O. A.; Clegg, W. Inorg. Chem. 2000, 39, 2227-2230.

[212] Freeman, W. Acta Crystallogr., Sect. B:Struct. Sci. 1984, 40, 382-387.

[213] Fedin, V. Russ. J. Coord. Chem. 2004, 30, 151-158.

[214] Abramov, P. A.; Adonin, S. A.; Peresypkina, E. V.; Sokolov, M. N.; Fedin, V. P. J. Struct. Chem. 2010, 51, 731-736.

[215] Abramov, P. A.; Sokolov, M. N.; Hernandez-Molina, R.; Vicent, C.; Virovets, A. V.; Naumov, D. Y.; Gili, P.; Gonzalez-Platas, J.; Fedin, V. P. Inorg. Chim. Acta 2010, 363, 3330-3337. 
[216] Sokolov, M. N.; Chubarova, E. V.; Kovalenko, K. A.; Mironov, I. V.; Virovets, A. V.; Peresypkina, E. V.; Fedin, V. P. Russ. Chem. Bull. 2005, 54, 615-622.

[217] Sokolov, M.; Mitkina, T.; Gerasko, O.; Fedin, V.; Virovets, A.; Llusar, R. Z. Anorg. Allg. Chem. 2003, 629, 2440-2442.

[218] Mainicheva, E. A.; Gerasko, O. A.; Sheludyakova, L. A.; Naumov, D. Y.; Naumova, M. I.; Fedin, V. P. Russ. Chem. Bull. 2006, 55, 267-275.

[219] Rehder, D. Bioinorganic Vanadium Chemistry, A Willey Series of Advanced Textbooks; Willey, Univesität Hamburg, Germany, 2007.

[220] Everett, R.; Kanofsky, J.; Butler, A. J. Biol. Chem. 1990, 265, 4908-4914.

[221] Kojima, M.; Taguchi, H.; Tsuchimoto, M.; Nakajima, K. Coord. Chem. Rev. 2003, 237, 183-196.

[222] Ligtenbarg, A.; Hage, R.; Feringa, B. Coord. Chem. Rev. 2003, 237, 89-101.

[223] Maity, D.; Marek, J.; Sheldrick, W.; Mayer-Figge, H.; Ali, M. J. Mol. Catal. A: Chem. 2007, 270, 153-159.

[224] Mizuno, N.; Nakagawa, Y.; Yamaguchi, K. J. Mol. Catal. A: Chem. 2006, 251, $286-290$.

[225] Ando, R.; Yagyu, T.; Maeda, M. Inorg. Chim. Acta 2004, 357, 2237-2244.

[226] Schuchardt, U.; Guerreiro, M.; Shul'pin, G. Russ. Chem. Bull. 1998, 47, 247-252.

[227] Si, T.; Chowdhury, K.; Mukherjee, M.; Bera, D.; Bhattacharyyaa, R. J. Mol. Catal. A: Chem. 2004, 219, 241-247.

[228] Mishra, G.; AJL, P. Appl. Catal.,A 2006, 304, 185-194.

[229] Germain, P.; Letoffe, J.; Merlin, M.; Buschmann, H. Thermochim. Acta 1998, 315, 87-92.

[230] Wang, X.; Zhang, X.; Liu, H. Polyhedron 1995, 14, 293-296.

[231] Ballhausen, C.; Gray, H. Inorg. Chem. 1962, 1, 111-122.

[232] Selbin, J. Chem. Rev. 1965, 65, 153-175.

[233] Grybos, R.; Samotus, A.; Lasocha, W. Transition Met. Chem. 2003, 28, 568-571.

[234] Ophardt, C.; S, S. J. Chem. Educ. 1984, 61, 1102-1103.

[235] Boucher, L.; Yen, T. Inorg. Chem. 1968, 1968, 2665-2667. 
[236] Cornman, C.; Geiser-Bush, K.; Rowley, S.; PD, B. Inorg. Chem. 1997, 36, 64016408.

[237] Ravikumar, R.; Reddy, V.; Chandrasekhar, A.; Reddy, B.; Reddy, Y.; Rao, P. J. Alloys Compd. 2002, 337, 272-276.

[238] Dodwad, S.; Dhamnaskar, R.; Prabhu, P. Polyhedron 1989, 8, 1748-1750.

[239] Kivelson, D.; Lee, S. J. Chem. Phys. 1964, 41, 1896-1903.

[240] Reuben, J.; Fiat, D. Inorg. Chem. 1969, 8, 1821-1823.

[241] Raman, N.; Raja, Y.; Kulandaisamy, A. J. Chem. Sci. 2001, 113, 183-189.

[242] Salagram, M.; Satyanarayana, N.; Radhakrishna, S. Polyhedron 1986, 5, 1171-1181.

[243] Rayati, S.; Koliaei, M.; Ashouri, F.; Mohebbi, S.; Wojtczak, A.; Kozakiewicz, A. Appl. Catal.,A 2008, 346, 65-71.

[244] Conte, F.; Di Furia, F.; G., L. Appl. Catal.,A 1997, 157, 335-361.

[245] Shetti, V.; Rani, N.; Srinivas, D.; Ratnasamy, P. J. Phys. Chem. B 2006, 110, 677-679.

[246] Uzunova, V. D.; Cullinane, C.; Brix, K.; Nau, W. M.; Day, A. I. Organic Es Biomolecular Chemistry 2010, 8, 2037-2042.

[247] Alves, E. U.; de Oliveira, A. P.; Bruno, R. d. L. A.; Sader, R.; Alves, A. U. Rev. Bras. Sementes 2005, 27, 132-137.

[248] Ambrosiano, E. J.; Wutke, E. B.; Ambrosiano, G. M. B.; Bulisani, E. A.; Bortoletto, N.; Martins, A. L. M.; Pereira, J. C. V. N. A.; de Sordi, G. Sci. Agric. Pirac. 1996, 53, 1-10.

[249] Bovi, M. L. A.; Godoy Jr., G.; Spiering, S. H. Sci. Agric. 2002, 59, 161-166.

[250] Bremner, J. M.; Krogmeier, M. J. Proc. Natl. Acad. Sci. U. S. A. 1988, 85, 46014604.

[251] Saini, H. S.; Bassi, P. K.; Spencer, M. S. Plant Physiol. 1985, 77, 940-943.

[252] Montes-Navajas, P.; Damonte, L. C.; Garcia, H. ChemPhysChem 2009, 10, 812-6.

[253] Montes-Navajas, P.; Garcia, H. J. Phys. Chem. C 2010, 114, 18847-18852.

[254] Michalet, X.; Pinaud, F. F.; Bentolila, L. A.; Tsay, J. M.; Doose, S.; Li, J. J.; Sundaresan, G.; Wu, A. M.; Gambhir, S. S.; Weiss, S. Science 2005, 307, 538-44. 
[255] Hendrick, E.; Frey, M.; Herz, E.; Wiesner, U. J. Eng. Fibers Fabr. 2010, 5, 21-30.

[256] Tang, J.; Sargent, E. H. Advanced materials (Deerfield Beach, Fla.) 2010, 20, 12-29.

[257] Xu, T.; Nikiforov, A. Y.; France, R.; Thomidis, C.; Williams, A.; Moustakas, T. D. Phys. Status Solidi A 2007, 204, 2098.

[258] da Silva, L.; Leroux, F.; Taviot-Guého, C.; Valim, J.; Demets, G. Synth. React. Inorg. Metal-Organic Nano-Metal Chem. 2013, 43, 1078-1082.

[259] dos Santos, E. M. S.; Pereira, L. S.; Demets, G. J.-F. J. Braz. Chem. Soc. 2011, 22, 1595-1600.

[260] Li, M.; Zaman, M.; Bardelang, D.; Wu, X.; Wang, D.; Margeson, J.; Leek, D.; Ripmeester, J.; Ratcliffe, C.; Lin, Q.; Yang, B.; Yu, K. Chem. Commun. 2009, 44, 6807-6809.

[261] Lee, T.-C.; Scherman, O. A. Chem. Commun. 2010, 46, 2438-2440.

[262] Taylor, R. W.; Lee, T.-C.; Scherman, O. A.; Esteban, R.; Aizpurua, J.; Huang, F. M.; Baumberg, J. J.; Mahajan, S. Acs Nano 2011, 5, 3878-3887.

[263] Cao, M.; Lin, J.; Yang, H.; Cao, R. Chem. Commun. 2010, 46, 5088-5090.

[264] Premkumar, T.; Lee, Y.; Geckeler, K. E. Chemistry - A European Journal 2010, $16,11563-11566$.

[265] Stucchi da Silva, L. F.; Demets, G. J.-F.; Taviot-Gueho, C.; Leroux, F.; Valim, J. B. Chem. Mater. 2011, 23, 1350-1352.

[266] dos Santos, E. M. S. Nanopartículas de prata, iodeto de chumbo, e iodeto de mercúrio obtidas por síntese assistida de macrociclos do tipo cucurbiturila. Masters thesis, Universidade de São Paulo, Av Bandeirantes 3900, DQ-FFCLRP-USP, 2010.

[267] Zhang, H.; Zhang, L.; Wang, J. J. Am. Chem. Soc. 2009, 131, 13206-13207.

[268] Dadosh, T. Materials Letters 2009, 63, 2236-2238.

[269] Slistan-Grijalva, A.; Herrera-Urbina, R.; Rivas-Silva, J.; Ávalos-Borjad, M.; Castillón-Barraza, F.; Posada-Amarillas, A. Physica E: Low-dimensional Systems and Nanostructures 2005, 27, 104-112.

[270] Solomon, S. D.; Bahadory, M.; Jeyarajasingam, A. V.; Rytkowsky, S. A.; C., B. Journal of Chemical Education 2007, 84, 322-325.

[271] Coleman, C.; Goldwhite, H.; Tikkanen, W. Chem. Mater. 1998, 10, 2794-2800.

[272] Mallik, K.; Dhami, T. Phys. Rev. B 1998, 58, 13055-13059. 
[273] Finlayson, C.; Sazio, P. J. Phys. D: Appl. Phys. 2006, 29, 1477-1480.

[274] Nozue, Y.; Tang, Z.; Goto, T. Solid State Commun. 1990, 73, 531-534.

[275] Sandroff, C.; Kelty, S.; Hwang, D. J. Chem. Phys. 1986, 85, 5337-5340.

[276] Artemyev, M.; Rakovich, Y. P.; Yablonski, G. J. Cryst. Growth 1997, 171, 447-452.

[277] Ghorayeb, A.; Coleman, C.; Yoffe, A. J. Phys. C. 1984, 17, L715-719.

[278] Sandroff, C.; Hwang, D.; Chung, W. Phys. Rev. B 1986, 33, 5953-5955.

[279] Scheaffer, R.; Ardelean, M. Powder Diff. 2001, 16, 16-19.

[280] Kroon, M.; Vos, W.; Wegdam, G. Int. J. Thermophys. 1998, 19, 887-894.

[281] Additives, R. Communiclay 2001, 1, 1.

[282] Erdal, S.; Kjolseth, C.; Norby, T. J. Phys. Chem. C 2010, 114, 16785-16792.

[283] Klingshirn, C. ChemPhysChem 2007, 8, 782-803.

[284] Klingshirn, C. Phys. Status Solidi B 2007, 244, 3019-3019.

[285] He, Y. N.; Shi-guang, S.; Wuyuan, C.; Xin, L.; Chang-chun, Z.; Xun, H. Microelectron. J. 2009, 40, 517 - 519, Workshop of Recent Advances on Low Dimensional Structures and Devices (WRA-LDSD).

[286] Ge, L.; Jing, X.; Wang, J.; Wang, J.; Jamil, S.; Liu, Q.; Liu, F.; Zhang, M. J. Mater. Chem. 2011, 21, 10750-10754.

[287] Hosseini-Sarvari, M.; Sharghi, H. J. Org. Chem. 2006, 71, 6652-6654.

[288] Eslami, A.; Nasseri, S.; Yadollahi, B.; Mesdaghinia, A.; Vaezi, F.; Nabizadeh, R.; Nazmara, S. J. Chem. Technol. Biotechnol. 2008, 83, 1447-1453.

[289] Wang, R.; Macartney, D. H. Organic E Biomolecular Chemistry 2008, 6, 1955-1960.

[290] Su, S.; Lu, S.; Xu, W. Mater. Res. Bull. 2008, 43, 2172-2178.

[291] Hariharan, C. Appl. Catal. A: Gen. 2006, 304, 55-61.

[292] Haase, M.; Weller, H.; Henglein, A. J. Phys. Chem. 1988, 92, 482-487.

[293] Georgekutty, R.; Seery, M. K.; Pillai, S. C. J. Phys. Chem. C 2008, 112, 1356313570.

[294] Wang, L.; Chang, L.; Zhao, B.; Yuan, Z.; Shao, G.; Zheng, W. Inorg. Chem. 2008, $47,1443-1452$. 
[295] Li, L.; Beniash, E.; Zubarev, E. R.; Xiang, W.; Rabatic, B. M.; Zhang, G.; Stupp, S. I. Nat. Mater. 2003, 2, 689-694.

[296] Fallert, J.; Stelzl, F.; Zhou, H.; Reiser, A.; Thonke, K.; Sauer, R.; Klingshirn, C.; Kalt, H. Opt. Express. 2008, 16, 1125-1131.

[297] Saliba, S.; Coppel, Y.; Davidson, P.; Mingotaud, C.; Chaudret, B.; Kahn, M. L.; Marty, J.-D. J. Mater. Chem. 2011, 21, 6821-6823.

[298] Keem, K.; Kim, H.; Kim, G.-T.; Lee, J. S.; Min, B.; Cho, K.; Sung, M.-Y.; Kim, S. Appl. Phys. Lett. 2004, 84, 4376-4378.

[299] Foreman, J. V.; Li, J.; Peng, H.; Choi, S.; Everitt, H. O.; Liu, J. Nano Lett. 2006, $6,1126-1130$.

[300] Gonzalez-Valls, I.; Lira-Cantu, M. Energy Environ. Sci. 2009, 2, 19-34.

[301] Koch, U.; Fojtik, A.; Weller, H.; Henglein, A. Chem. Phys. Lett. 1985, 122, 507-510.

[302] Wang, W.; Kaifer, A. E. Supramol. Chem. 2010, 22, PII 929521033.

[303] Hartlieb, K. J.; Raston, C. L.; Saunders, M. Chem. Mater. 2007, 19, 5453-5459.

[304] Gong, Y.; Andelman, T.; Neumark, G.; O’Brien, S.; Kuskovsky, I. Nanosc. Res. Lett. 2007, 2, 297-302, 10.1007/s11671-007-9064-6.

[305] Meulenkamp, E. A. J. Phys. Chem. B 1998, 102, 5566-5572.

[306] Vafaee, M.; Ghamsari, M. S. Mater. Lett. 2007, 61, 3265 - 3268.

[307] Bahnemann, D. W.; Kormann, C.; Hoffmann, M. R. J. Phys. Chem. 1987, 91, 3789-3798.

[308] Zhang, J.; Zhang, Z.; Wang, T. Chem. Mater. 2004, 16, 768-770.

[309] Cozzoli, P.; Curri, M.; Agostiano, A.; Leo, G.; Lomascolo, M. J. Phys. Chem. B 2003, 10\%, 4756-4762.

[310] Shen, L.; Bao, N.; Yanagisawa, K.; Domen, K.; Gupta, A.; Grimes, C. A. Nanotechnology 2006, 17, 5117.

[311] Kahn, M. L.; Cardinal, T.; Bousquet, B.; Monge, M.; Jubera, V.; Chaudret, B. ChemPhysChem 2006, 7, 2392-2397.

[312] Kahn, M.; M., M.; Collière, V.; Senocq, F.; Maisonnat, A.; Chaudret, B. Adv. Funct. Mater. 2005, 15, 458-468. 
[313] Monge, M.; Kahn, M.; Maisonnat, A.; Chaudret, B. Angew. Chem. Int. Ed. Engl. 2003, 42, 5321-5324.

[314] Hambrock, J.; Rabe, S.; Merz, K.; Birkner, A.; Wohlfart, A.; Fischer, R. A.; Driess, M. J. Mater. Chem. 2003, 13, 1731-1736.

[315] Crepaldi, E.; Valim, J. Quim. Nova 1998, 21, 300-311.

[316] Miyata, S. Clays Clay Miner. 1980, 28, 50-56.

[317] Liu, Y.-J.; Schindler, J. L.; DeGroot, D.; Kannerwurf, C. R.; Hirpo, W.; Kanatzidis, M. Chem. Mater. 1996, 8, 525-534.

[318] Yao, T.; Oka, Y.; Yamamoto, N. Mater. Res. Bull. 1992, 27, 669-675.

[319] Crepaldi, E.; Pavan, P.; Valim, J. Chem. Commun. 1999, 2.

[320] da Silva, L. F. S. ntercalação de cucurbiturilas em compostos lamelares- Preparação, Caracterização e Aplicações. PhD, Universidade de São Paulo, 2010.

[321] Legendre, J.-J.; Livage, J. J. Colloid Interface Sci. 1982, 94, 75-83.

[322] Legendre, J.-J.; Aldebert, P.; Baffier, N.; Livage, J. J. Colloid Interface Sci. 1982, $94,84-89$.

[323] Anaissi, F.; Demets, G.; Toma, H.; Coelho, A. J. Electroanal. Chem. 1999, 464, $48-53$.

[324] Anaissi, F.; Demets, G. J. F.; Toma, H. Electrochem. Commun. 1999, 1, 332-335.

[325] Demets, G.; Anaissi, F.; Toma, H. Electrochim. Acta 2000, 46, 547-554.

[326] Anaissi, F.; Demets, G. J. F.; Toma, H.; Dovidauskas, S.; Coelho, A. Mater. Res. Bull. 2001, 36, 286-306.

[327] Demets, G. J. F. Desenvolvimento de Interfaces Eletroquímicas à Base de Nanocompósitos de Poli(Pirrol) e Xerogel Lamelar de Pentóxido de Vanádio. Ph.D. thesis, Universidade de São Paulo, 2001.

[328] Anaissi, F.; Demets, G.; Alvarez, E.; Politi, M.; Toma, H. Electrochim. Acta 2001, $47,441-450$.

[329] Demets, G.; Anaissi, F.; Toma, H.; Fontes, M. Mater. Res. Bull. 2002, 37, 683-695.

[330] Anaissi, F.; Demets, G. J. F.; Timm, R.; Toma, H. Mater. Sci. Eng., A 2003, 347, $374-381$.

[331] Demets, G. J. F.; Toma, H. Electrochem. Commun. 2003, 5, 73-77. 
[332] Benmoussa, M.; Outzourhit, A.; Bennouna, A.; Ihlal, A. Eur. Phys. J. Appl. Phys. 2009, 48, $10502-10506$.

[333] Whittingham, M. S. Chem. Rev. 2004, 104, 4271-4301.

[334] Tovani, C.; de Souza, J.; Cavallini, T.; Demets, G.; Ito, A.; Barioni, M.; Pazin, W.; Zaniquelli, M. Colloids and Surfaces B: Biointerfaces 2013, 111, 398-406.

[335] Tadini, M.; Balbino, M.; Eleoterio, I.; de Oliveira, L.; Dias, L.; Demets, G.; de Oliveira, M. Electrochim. Acta 2014, 121, 188-193.

[336] Reddy, K.; T. S. Cavallini, T.; Demets, G.; Silva Jr., L. New J. Chem. 2014, 38, 2262-2264.

[337] Bolfarini, G.; Siqueira-Moura, M.; Demets, G.; Morais, P.; Tedesco, A. J. Photochem. Photobiol. B: Biol. 2012, 115, 1-4.

[338] Bolfarini, G.; Siqueira-Moura, M.; Demets, G.; Tedesco, A. Dyes Pigm. 2014, 100, 162-167.

[339] Svec, J.; Necas, M.; Sindelar, V. Angew. Chem. Int. Ed. Engl. 2010, 49, 2378-2381.

[340] D’Avignon, L.; Hogan, B.; Murray, C.; Loo, F.; Hospenthal, D.; Cancio, L.; Kim, S.; Renz, E.; Barillo, D.; Holcomb, J.; Wade, C.; Wolf, S. Burns 2010, 36, 773-779.

[341] Mayhall, C. Healthcare Epidem. 2003, 37, 543-550.

[342] Ali, J.; Camilleri, P.; Brown, M.; Hutt, A.; Kirton, S. J. Chem. Inf. Model. 2012, 52, 2950-2957.

[343] Gao, H.; Shanmugasundaram, V.; Lee, P. Pharm. Res. 2002, 19, 497-503.

[344] Duchowicz, P.; Castro, E. A. Int. J. Mol. Sci. 2009, 10, 2558-2577.

[345] Silva, F. A. Intercalados de pentóxido de vanádio com cucurbit[n]urilas e hemicucurbit[6]urila. Masters thesis, Universidade de São Paulo, 2014.

[346] Bagatin, I.; Cruz, A.; Toma, H.; Politi, M.; Demets, G. J. Inclusion Phenom. Macrocyclic Chem. 2005, 52, 189-193.

[347] Anonimo, Benesi-Hildebrand Method. 2014; http://en.wikipedia.org/wiki/ Benesi \T1\textendashHildebrand_method.

[348] Complexation Titrations. 2014; http://chemwiki.ucdavis.edu/Analytical_ Chemistry/Analytical_Chemistry_2.0/09_Titrimetric_Methods/9C_ Complexation_Titrations. 
[349] White, T. Supramolecular Chemistry and Synthesis of Cucurbit[n]uril. Ph.D. thesis, University of New South Wales, 2012.

[350] Day, A.; Blanch, R.; Coe, A.; Arnold, A.; scipline: Chemistry, M. C. J. Incl. Phenom. Macrocyclic Chem. 2002, 43, 247-250. 
Apêndices 


\section{APÊNDICE A - Procedimentos Experimen- tais Gerais e de Rotina}

\section{A.1 Sínteses}

\section{A.1.1 Síntese das cucurbit[n]urilas}

\section{A.1.1.1 Rota 1}

Esta rota foi descrita por Kim e colaboradores em $2000^{2}$. Foi utilizada por muito tempo em nossos trabalhos, sendo substituida pelas rotas descritas por Day. A rota de Kim utiliza ácido sulfúrico a quente. Utiliza-se 6,68 g de glicoluril (40 mmol) que são dissolvidos em $20 \mathrm{~mL}$ de $\mathrm{H}_{2} \mathrm{SO}_{4} 9$ mol.dm ${ }^{-3}$ em um erlenmeyer de $50 \mathrm{~mL}$ a $70^{\circ} \mathrm{C}$ em banho de óleo. À solução quente são adicionados $7 \mathrm{~mL}$ de formaldeído em solução aquosa a 37 \% (91 mmol). A mistura é agitada por $24 \mathrm{~h}$ a $70-75^{\circ} \mathrm{C}$. Ao final deste período a temperatura é elevada a $100{ }^{\circ} \mathrm{C}$ por mais 12 horas. Após este período a msitura reacional é despejada em $200 \mathrm{~mL}$ de água e, em seguida, em $1 \mathrm{~L}$ de água. O precipitado formado (Ppt1) é deixado em repouso por 15 min. O sobrenadante (Sob1) é retirando por decantação. O Ppt1 é lavado duas vezes com um litro de mistura água/acetona 1:4. O Ppt1 lavado é colocado em $200 \mathrm{~mL}$ de uma mistura de água e acetona 1:1, onde é agitado por alguns minutos. A suspensão é filtrada gerando um sólido (Ppt2) que é reservado e lavado com $100 \mathrm{~mL}$ de água. Ppt2 (4 g) é essencialmente $\beta$-CB[6] . Ao sobrenadante (Sob2) anterior são adicionados $800 \mathrm{~mL}$ de acetona que dão origem a um novo precipitado (Ppt3, 1,42 g) que é composto principalmente de $\alpha-\mathbf{C B}[5]$ e $\gamma-\mathbf{C B}[7]$ em proporção de 1:1,5. O sobrenadante desta etapa (Sob3) contém $\delta$-CB[8] , $\zeta$-CB[10] e $\eta$-CB[11] . o Ppt3 é dissolvido em $75 \mathrm{~mL}$ de água com ajuda de ultrassom. À solução aquosa são adicionados $75 \mathrm{~mL}$ de metanol que geram um precipitado (Ppt4, $648 \mathrm{mg}$ ). Trata-se de $\gamma-\mathbf{C B}[7]$, que é lavado com pequenas quantidades de metanol. Ao sobrenadante (Sob4) adicionam-se $300 \mathrm{~mL}$ de acetona para precipitar $\alpha$-CB[5] com pequenas quantidade de $\gamma-\mathbf{C B}[7]$ (Ppt5, $369 \mathrm{mg}$ ). $\gamma$-CB[7] e $\alpha$-CB[5] são purificadas por recristalização. $220 \mathrm{mg}(2,2 \%)$ de $\alpha$-CB[5] são recuperados a partir de uma solução diluida em ácido sulfúrico na geladeira por um dia (cristais retangulares). Por difusão de vapor de THF/acetona em uma solução sulfúrica diluida é possível recolher cristais em placas de $\gamma$-CB[7] (245 mg, 2,8\%) 


\section{A.1.1.2 Rota 2}

Descrita por Day e seus colaboradores esta rota envolve a formação de um gel, como consta na referência ${ }^{3}$. É descrita pelos autores da seguinte forma:

\section{A.1.1.3 Rota 2- R2V1}

Nesta rota são utilizados diversos ácidos, como clorídrico, sulfúrico e nítrico. 77 mg de glicolurila $(0,54 \mathrm{mmol})$ são dissolvidos em $0,4 \mathrm{~mL}$ de ácido a $25-30{ }^{\circ} \mathrm{C}$, com auxílio de banho ultrassônico, quando formaldeído é adicionado, seja na forma de solução aquosa a $40 \%(85 \mu \mathrm{L})$ ou de paraformaldeído sólido (34 mg), e a solução é misturada imediatamente. Em alguns casos forma-se um gel após 20 min. Em todos os casos as reações são exotérmicas, sendo necessário resfriar o meio reacional com banho de gêlo durante a adição do formaldeído. A mistura é aquecida a $100{ }^{\circ} \mathrm{C}$ por $3 \mathrm{~h}$, ou até que se complete, o que é mostrado por RMN. Reações nesta escala podem ser realizadas nos próprios tubos de $\mathrm{RMN}$ e as misturas reacionais podem ser analisadas por $\mathrm{RMN}$ de ${ }^{13} \mathrm{C}$ utilizando $\mathrm{D}_{2} \mathrm{O}$ como trava externa. Produtos de reações feitas em maiores escalas, são resfriados e vertidos em metanol e os precipitados são recolhidos por filtração a vácuo. Depois de secos ao ar os componentes das misturas são separados por cristalização fracionada de soluções de ácido clorídrico.

\section{A.1.1.4 Rota 2 variação 2- R2V2}

São utilizados $1000 \mathrm{~g}$ de glicolurila em pó fino ( 7,04 mol) e paraformaldeído em pó (422 g, 14,07 mol) muito bem misturados a seco. Em seguida, são adicionados 1420 $\mathrm{mL}$ de $\mathrm{HCl}$ concentrado gelado enquanto a mistura é agitada vigorosamente. A agitação é mantida até que a mistura forme um gel. Depois de $30 \mathrm{~min}$, o gel é aquecido a $100^{\circ} \mathrm{C}$ por 18 h. Passado este tempo a composição da mistura é de $9,48,23,14$, e $6 \%$ em massa de $\alpha-\mathbf{C B}[5], \beta-\mathbf{C B}[6], \gamma-\mathbf{C B}[7], \delta$-CB[8] e $\zeta-\mathbf{C B}[10]$, respectivamente. A mistura é resfriada e filtrada para se recolher a primeira fração de sólidos incolores $(\mathbf{F} 1)$ que totalizam $278 \mathrm{~g}$ sendo eles compostos por 10, 40, 4, 32, e $14 \%$ em massa de $\alpha$ $\mathbf{C B}[5], \beta-\mathbf{C B}[6], \gamma-\mathbf{C B}[\mathbf{7}], \delta-\mathbf{C B}[8]$ e $\zeta-\mathbf{C B}[\mathbf{1 0}]$, respectivamente. O sobrenadante é então evaporado até um quarto de seu volume inicial. São então adicionados $500 \mathrm{~mL}$ de água, o que dá origem a uma suspensão cristalina incolor, que é recolhida por uma segunda filtração (F2), totalizando 324 g. Sua composição é de 5, 82, 6, e 7\% em massa de $\alpha-\mathbf{C B}[5], \beta-\mathbf{C B}[6], \gamma-\mathbf{C B}[7], \delta-\mathbf{C B}[8]$, respectivamente. O segundo sobrenadante contém $57 \%$ de $\gamma$-CB[7]. Seu volume é reduzido até $1,2 \mathrm{~L}$, é depois vertido em 3,5 $\mathrm{L}$ de metanol e deixado em repouso à temperatura ambiente por $18 \mathrm{~h}$. O precipitado branco é recolhido por filtração gerando $654 \mathrm{~g}$ de sólido (F3). Através de um processo repetitivo de fracionamento por diferença de solubilidade e recristalização de soluções de $\mathrm{HCl}$, é possível isolar cada componente na sua forma pura, a partir dos sólidos F1, F2 
e F3. Fracionamentos repetitivos em ácido fórmico a $60 \%$ permitem separar o $\delta$-CB[8] e o caviplexo $\alpha @ \zeta$-CB[5]@CB[10] das outras $\mathrm{CB}[\mathrm{n}]$, onde são insolúveis $(F 4)$. Glicerol aquoso a $20 \%$ quente é empregado para separar o $\gamma$-CB[7] dos outros componentes para gerar produto com mais de $95 \%$ de pureza. O $\gamma$-CB[7] é separado do glicerol aquoso pela adição de $\mathrm{MeOH}$ e o precipitado é recolhido por filtração. Três lavagens com metanol são suficientes para remover o glicerol. O sólido é seco a $60^{\circ} \mathrm{C}$ por $12 \mathrm{~h}$ dando $276 \mathrm{~g}$ $(24 \%)$ de sólido branco $(\gamma-\mathbf{C B}[7])$.O $\beta$-CB[6] e $\alpha-\mathbf{C B}[5]$ dissolvidos no ácido fórmico são separados por cristalização fracionada de soluções de $\mathrm{HCl}$, dando $\beta$-CB[6] , $541 \mathrm{~g}$ (46\%), e $\alpha-\mathbf{C B}[5], 94 \mathrm{~g}(8 \%)$. As frações insolúveis em ácido fórmico $(\delta-\mathbf{C B}[8]$ e $\alpha @ \zeta-$ CB[5]@CB[10] ) também são separadas por cristalização fracionada de soluções de $\mathrm{HCl}$, dando 146 g de $\delta$-CB[8] (12\%) e 65 g de $\alpha @ \zeta-C B[5] @ \mathbf{C B}[\mathbf{1 0}](5 \%)$

\section{A.1.1.5 Rota 2 variação 3- R2V3}

1,02 g de glicolurila em pó sêca $(7,2 \mathrm{mmol})$ e $442 \mathrm{mg}$ de paraformaldeído $(14,7$ mmol) são misturados para formarem uma pasta com a adição de 0,6 mL de $\mathrm{HCl}$. A pasta sólida é então aquecida em reator fechado a $100{ }^{\circ} \mathrm{C}$ por $15 \mathrm{~h}$, sendo este ocasionalmente agitado manualmente. O produto de reação misto analisado por $\mathrm{RMN}{ }^{13} \mathrm{C}$ mostra proporções típicas de $3,44,33,12$, e $8 \%$ de $\alpha-\mathbf{C B}[5], \beta-\mathbf{C B}[\mathbf{6}], \gamma-\mathbf{C B}[7], \delta$-CB[8] , e $\zeta$-CB[10], respectivamente.

\section{A.1.2 Síntese de hemi[6]cucurbiturila}

O método de obtenção de hemicucurbit[n] urilas corresponde ao descrito por Miyahara e colaboradores ${ }^{87}$. Quantidades equimolares de etilenouréia e formalina (37\%) são misturados em $\mathrm{HCl} 4$ mol.dm ${ }^{-3}$ à temperatura ambiente. A mistura gera uma suspensão turva, e após 30 minutos é possível recolher cristais do macrociclo, que são lavados com água fria e secos a vácuo a $80{ }^{\circ} \mathrm{C}$. Pf: $315^{\circ} \mathrm{C}$ (dec). Análise elementar (calc.): $\left(\mathrm{C}_{24} \mathrm{H}_{36} \mathrm{O}_{6} \mathrm{~N}_{12}: \mathrm{C}=\right.$ $48,97 \% ; \mathrm{H}=6,16 \% ; \mathrm{N}=28,56 \%) . \operatorname{RMN}\left(\mathrm{CDCl}_{3}\right){ }^{1} \mathrm{H}: \delta \quad 3,37 \quad 4,64 \mathrm{ppm}$.

${ }^{13} \mathrm{C}: \delta \quad 41,90 \quad 52,49 \quad 160,95 \mathrm{ppm}$. IV(nujol) $\nu_{C=O}: 1694 \quad \mathrm{~cm}^{-1}$.

\section{A.1.3 Separação e purificação das cucurbiturilas}

O processo de separação das cucurbiturilas é bastante trabalhoso e complicado, envolvendo dezenas de etapas. Existem vários métodos de separação descritos na literatura mas todos se dão basicamente por diferenças de solubilidade entre os homólogos15. Ao término da síntese de CBs, seja qual for a rota, geralmente elimina-se um largo excesso de ácido por evaporação simples, nas rotas que utilizam HCl. O volume reacional é reduzido a um quarto do original. Em seguida é mais simples despejar a pasta em água, sob agitação afim de isolar os CBs solúveis em água que são o $\alpha$-CB[5] e o $\gamma-\mathbf{C B}[7]$. O filtrado (sólido A) conterá agora principalmente $\beta-\mathbf{C B}[\mathbf{6}], \boldsymbol{i}-\beta-\mathbf{C B}[\mathbf{6}] \delta-\mathbf{C B}[\mathbf{8}]$ e $\alpha @ \zeta-\mathbf{C B}[\mathbf{5}] @ \mathbf{C B}[\mathbf{1 0}]$. 
O sobrenadante (líquido A) é reduzido ao máximo antes de precipitar. Ao seu volume é adicionado o mesmo volume de metanol e o líquido é deixado em repouso por doze horas. Ao término deste período observa-se o $\gamma$-CB[7] precipitado, que é filtrado, gerando um segundo sobrenadante (líquido B), do qual se pode extrair o solvente deixando o $\alpha$-CB[5] . O sólido A é então tratado com HCL 3 mol.dm ${ }^{-3}$, no qual os CBs exceto o $\delta$-CB[8] são solúveis. O mesmo é recolhido por mais uma filtração, levando a um terceiro sobrenadante (líquido $\mathbf{C}$ ) que contém agora $\beta$-CB[6], $\boldsymbol{i}$ - $\beta$-CB $[\mathbf{6}]$ e $\alpha @ \zeta-\mathbf{C B}[5] @ \mathbf{C B}[\mathbf{1 0}]$. Estes são reuperados após sucessivas recritstalizações com acetona.

\section{A.1.4 Síntese do pentóxido de vanádio em gel}

O gel pentóxido de vanádio foi preparado partindo de $\mathrm{NH}_{4} \mathrm{VO}_{3}$, metavanadato de amônio, em água a 0,1 mol.dm ${ }^{-3}$. A solução foi percolada por uma coluna de troca iônica (50 mL de resina catiônica 50W-2x Dowex, previamente hidratada, lavada com HCl 1M e água para o controle do $\mathrm{pH}=4$ ) formando assim o ácido metavanádico, $\mathrm{HVO}_{3}$. A solução obtida, de coloração laranja, torna-se mais viscosa com o tempo, adquirindo a forma de gel em 7 dias. Mais detalhes podem ser obtidos nas refs. ${ }^{323-331,345}$

\section{A.1.5 Síntese de nanopartículas de zincita}

As nanopartículas de zincita foi realizada a $\mathrm{pH}$ constante 8 e à temperatura ambiente $\left(28^{\circ} \mathrm{C}\right)$, começando com $40 \mathrm{~cm}^{3}$ de água e $26 \mathrm{mg}\left(2,24 \times 10^{-5} \mathrm{~mol}\right)$ de $\gamma$-CB[7] . Nesta solução foram vertidos muito lentamente $10 \mathrm{~cm}^{3}$ de $\mathrm{Zn}\left(\mathrm{NO}_{3}\right)_{2}$ aquoso $\left(3,0 \times 10^{-2}\right.$ mol.dm ${ }^{-3}$ ) a $2 \mathrm{~cm}^{3} \cdot \mathrm{min}^{-1}$ com auxílio de uma seringa. Durante o período, o $\mathrm{pH}$ da solução foi mantido constante com pequenas adições de $\mathrm{NaOH}\left(3,0 \times 10^{-1} \mathrm{~mol}_{\mathrm{dm}}{ }^{-3}\right)$ ao meio reacional. A mistura é mantida sob agitação por mais 10 minutos. O óxido é filtrado e lavado com água, em seguida seco a $50^{\circ} \mathrm{C}$. O mesmo procedimento é repetido na ausência de $\gamma$-CB[7] para comprovar o efeito de molde.

\section{A.1.6 Síntese de nanopartículas de iodeto de chumbo}

As $\mathrm{NP}$ de $\mathrm{PbI}_{2}$ foram obtidas a partir de soluções de $\mathrm{Pb}\left(\mathrm{NO}_{3}\right)_{2} \quad 0,1$ mol.dm ${ }^{-3}$ (Synth) KI a 0,1 mol.dm ${ }^{-3}$ (Synth) e CB[7] a $1 \times 10-3$ mol.dm ${ }^{-3}$. À solução de macrociclo em água $(10 \mathrm{~mL})$, mantida sob agitação a $27{ }^{\circ} \mathrm{C}$ foram adicionados $100 \mathrm{~mL}$ da solução de $\mathrm{Pb}\left(\mathrm{NO}_{3}\right)_{2}$, e em seguida $200 \mathrm{~mL}$ de solução de $\mathrm{KI}$, mantendo a proporção molar de reagentes $C B[7] / P b 2+/ I-$ em 1:1:2. Forma-se um gel verde pálido imediatamente, totalmente diferente dos cristais dourados que nromalmente se formam nestas condições sem a presença de $\gamma$-CB[7]. O gel é instável e precipita em dois dias e o sólido verde claro é lavado para retirar o excesso de reagentes e $\mathrm{KNO}_{3}$ e seco a vácuo. Para efeito de comparação o $\mathrm{PbI}_{2}$, politipo 2-H é produzido da mesma forma, mas sem a presença de $\gamma-\mathrm{CB}[7]$. 


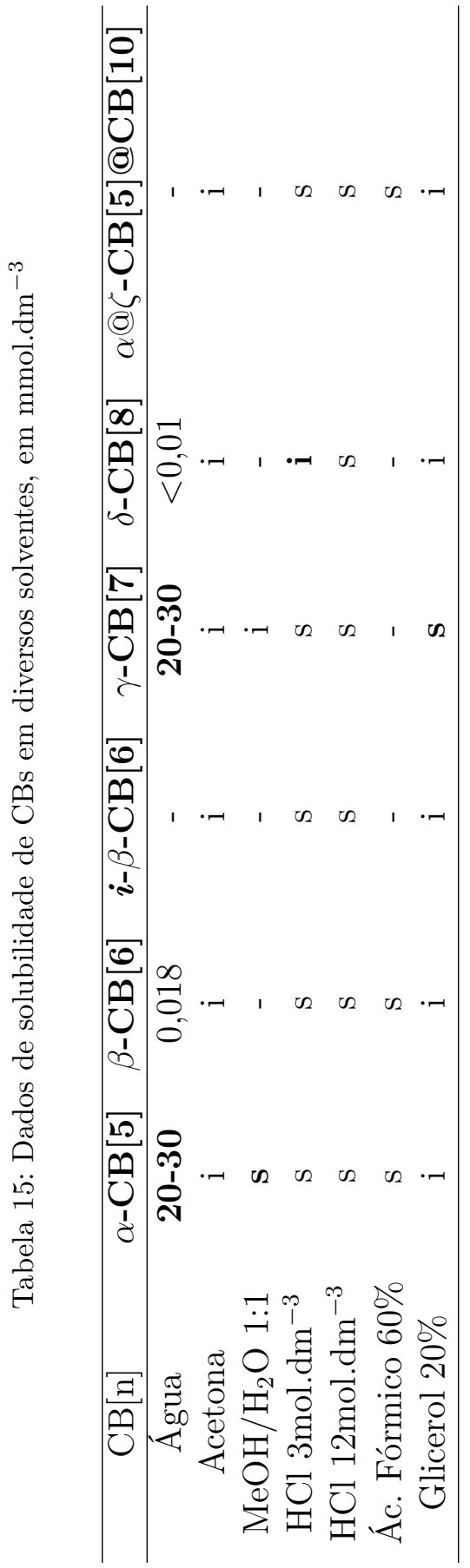




\section{A.1.7 Síntese de nanopartículas de prata}

Foi preparada uma solução mãe de $\mathrm{AgNO}_{3}$, a 0,1 mol.dm ${ }^{-3} \cdot 2,3$ miligramas de $\gamma$-CB[7] são dissolvidos em $20 \mathrm{~mL}$ de água deionizada à temperatura ambiente em um béquer gerando uma solução a $1 \cdot 10^{-4}$ mol.dm ${ }^{-3}$. Sob vigorosa agitação adiciona-se à solução $10 \mu \mathrm{L}$ da solução mãe de nitrato de prata, resultando também uma concentração de $1.10^{-4}$ mol.dm ${ }^{-3}$ de íons prata e manteve-se a transparência do meio reacional. Nesta reação, portanto, a razão estequiométrica entre o cátion metálico e o macrocíclico é de 1:1 $(\mathrm{Ag}+$ : $\mathrm{CB}[7])$. Após mais dez minutos de agitação foi adicionado borohidreto de sódio ao meio, $10 \mu \mathrm{L}$ de uma solução alcoólica $0,1 \mathrm{~mol} . \mathrm{dm}^{-3}$ previamente preparada para a redução da prata. Parte do produto formado foi precipitado com acetona afim de se recolher o sólido.

\section{A.2 Caracterização de compostos de inclusão}

\section{A.2.1 Métodos espectroscópicos}

\section{A.2.1.1 Método da variação contínua}

O método da variação contínua, ou método de Job, é antigo e bem conhecido, sendo utilizado para a formação de agregados de diversos tipos. Ele nos fornece a proporção, consequentemente a estequiometria, entre os componentes do agregado que se forma. Para que seja utilizado é necessário que se analise alguma propriedade fisico-química particular ao agregado que venha a surgir, ou ainda alguma de seus componentes que desapareça à medida que forma o agregado. Em outras palavras podemos utilizar bandas de absorção, bandas de emissão, deslocamentos químicos de ressonância magnética nuclear (para ${ }^{1} H$, também a integração de sinal) etc... típicas do agregado ou ainda monitorar o desaparecimento dos mesmos que correspondam a reagentes.

Para determinar a proporção Host/Guest $(\mathrm{H} / \mathrm{G})$ em caviplexos são preparadas misturas em diversas proporções de cada um dos componentes de forma que sejam expressas em frações molares $\left(\chi_{H o u G}\right)$ e que:

$$
\begin{gathered}
\chi_{\text {HouG }}=\frac{n_{H o u G}}{n_{H+G}} \\
\chi_{H}+\chi_{G}=1 \\
n_{H O S T}+n_{G U E S T}=\text { cste }
\end{gathered}
$$

onde $n_{H o u G}$ é o número de mol de cada um. O método é baseado nos seguintes princípio: 
- Para a reação $H+x G \leftrightarrow G_{n} @ H+x-n G$, mais produto é formado quando a razão entre eles é igual a $n$.

- Considerando que o número de mol de $\mathrm{H}$ seja igual a $x$, e que o número total de mol seja 1, teremos: $x=n_{H}$ e $1-x=n_{G}$.

- Se H estiver em excesso, o reagente limitante para a formação do produto será G, e vice-versa, se H estiver em excesso, o limitante será H. Isto equivale a dizer que à medida que aumentamos a quantidade de hóspede na solução $(1-x)$, o máximo de produto que pode ser formado só pode ser $1-x$. Portanto a quantidade de produto formado aumenta com [G]. Uma vez que passamos do ponto estequiométrico, quem começa a faltar em solução é H e a formação de produto passa a depender de [H]. Portanto qualquer propriedade que dependa da concentração de $G_{n} @ H$ atinge o máximo de intensidade no ponto estequimétrico $n$. No caso de $n=1$, o máximo deve ocorrer em frações molares de 0,5 por exemplo ${ }^{346}$.

Este método é amplamente utilizado para caracterizar caviplexos dos mais diversos tipos.

\section{A.2.1.2 Método de Benesi-Hildebrand}

Um pouco mais complexo é o método de Benesi-Hildebrand, desenvolvido para determinar constantes de formação e estequiometrias de caviplexos. É utilizada tipicamente com dados de absorção, mas também pode ser utilizado com outras técnicas, e nem sempre é aplicável por conta das aproximações em que se baseia. Considerando um caviplexo de estequiometria 1:1, o método considera que qualquer pequenos excesso de reagentes, seja $\mathrm{H}$ ou $\mathrm{G}$, frente à abundância do caviplexo não interfere significativamente no espectro de absorção da mistura. Portanto medindo a absorção do conjunto imediatamente antes e imediatamente depois de atingido o equilíbrio na formação do caviplexo, é possível calcular sua constante de formação. O procedimento experimental consiste em adicionar pequenas alíquotas de um dos reagentes (o hospedeiro $\mathrm{H}$ neste caso) a uma solução de hóspede $(\mathrm{G})$, partindo do pressuposto que a maior parte dele seja imediatamente consumida na formação de um caviplexo ${ }^{347}$. Isto porquê temos que a abosrção total da mistura corresponde a soma da absorção de seus componentes:

$$
A=A^{H G}+A^{G}+A^{H}
$$

Assumindo que a $[G]_{0}>>[H]_{0}$, pode-se negligenciar a absorção do hospedeiro, reduzindo a expressão anterior a:

$$
A=A^{H G}+A^{G}
$$

À medida que adicionamos pequenas alíquotas de $\mathrm{H}$, este vai sendo consumido e a absorção total do sistema muda com relação à absorção inicial:

$$
\Delta A=A-A_{0}
$$


Considerando a equação de Beer-Lambert-Bouguer que nos relaciona absorvância e concentração de qualquer espécie x, $A=\epsilon \times b \times c$, a absorvância total pode ser decomposta em concentrações e absortividades molares individuais como segue:

$$
\Delta A=\epsilon^{H G}[H G] b+\epsilon^{G}[G] b-\epsilon^{G}[G]_{0} b
$$

Onde b corresponde ao caminho óptico da cubeta. Para simplificar, consideramos que $b=1 \mathrm{~cm}$. Por conta do grande excesso de $\mathrm{G}$, espera-se e considera-se que $[G] \simeq[G]_{0}$ e simplificamos a expressão:

$$
\Delta A=\Delta \epsilon[H G]
$$

Correlacionamos então a variação de absorção com a variação de absortividades molares do conjuto $\left(\epsilon^{H G} e \epsilon^{G}\right)$. Considerando agora a equação do equilíbrio químico envolvido temos:

$$
[H G]=\frac{[H]_{0} K_{a}[G]}{1+K_{a}[G]}
$$

Substituindo novamente, com a eq. A.8 obtemos um relação de absorvância com a constante de equilíbrio:

$$
\Delta A=\Delta \epsilon \frac{[H]_{0} K_{a}[G]_{0}}{1+K_{a}[G]_{0}}
$$

Graficamente, confronta-se os valores de $\frac{1}{\Delta A}$ em função de $\frac{1}{1 /[H]}, \Delta \epsilon$ é obtido na interseção, enquanto que $K_{a}$ pode ser calculado pela inclinação da reta.

$$
\frac{1}{\Delta A}=\frac{1}{\Delta \epsilon[G]_{0}[H]_{0} K_{a}}+\frac{1}{\Delta \epsilon[H]_{0}}
$$

Rose e Drago modificaram o método de Banesi-Hildebrand que corrige algumas inconsistências, onde correlacionam $\epsilon_{H G} \operatorname{com} K^{-1}$ :

$$
K^{-1}=\frac{A}{\epsilon_{H G}}-[H]_{0}-[G]_{0}+\frac{C_{H} C_{G}}{A} \epsilon_{H G}
$$

\section{A.2.1.3 Titulações espectrofotométricas}

Muito utilizada também, para se determinar proporções entre H e G, além de cálculos de constantes de equilíbrio. O método pode ser utilizado com substâncias que apresentem cromóforos ou luminóforos em qualquer região do espectro eletromagnético que desejemos utilizar. Neste método uma solução (de H ou G) (em geral) é titulada com outra de reagente complementar $(\mathrm{G}$ ou H$)$. Alguma propriedade que dependa da formação do caviplexo ou do desaparecimento de reagentes é medida em função da quantidade de titulante. A técnica mais usual é a espectrofotometria UV-vis, por sua simplicidade e baixo custo. Após corrigidas as diluições resultantes da titulação podemos obter diversas curvas de titulação como mostra a figura abaixo. A utilização de curvas analíticas, aplicando a lei de Beer-Lambert é possível obter as concentrações relativas de H, G e G@H em mistura. Desta forma a obtenção de constantes de equilíbrio é possível utilizando os dados das titulações espectrofotométricas. 

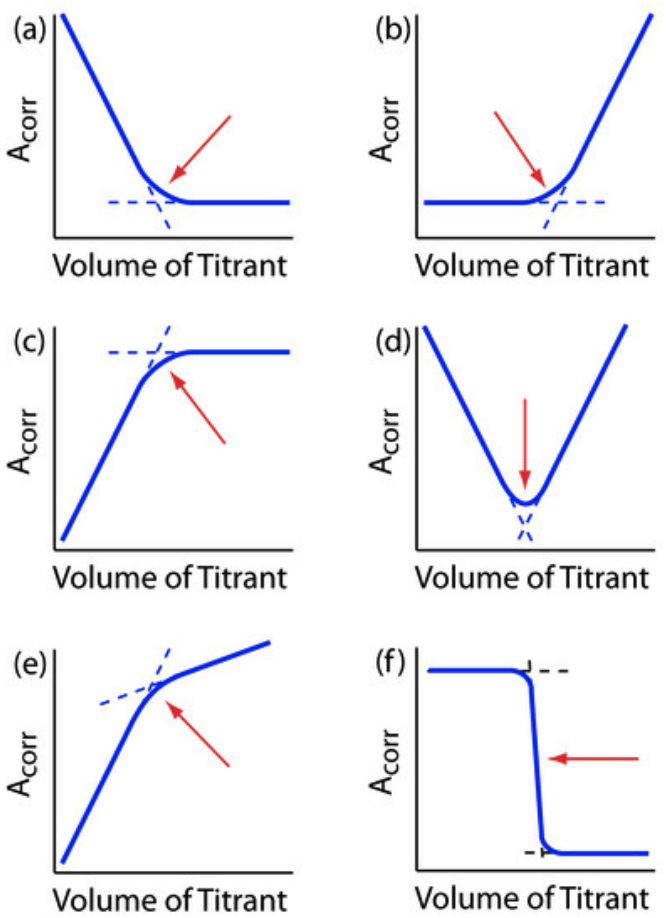

Figura 88: Diversas curvas de titulação e seus pontos de equivalência (setas vermelhas) da ref ${ }^{348}$. a) Só o titulado absorve, b) só o titulante, c) só o produto absorve, d) o titulado e o titulante absorvem, e) o produto e o titulante absorvem $\mathrm{f}$ ) um indicador externo absorve

\section{A.3 Ensaios de permeação em membranas}

Os ensaios de permeação por membranas foram realizados em uma célula especialmente concebida para este fim ${ }^{192}$. Esta célula (figura 89) é um protótipo universal, pois é possível utilizá-la para ensaios de difusão de fluxo lateral em meio líquido, ensaios em meio gasoso à pressão ambiente ou ainda um meio líquido e outro gasoso. A célula tamém permite a utilização de até oito sensores diferentes simultaneamente e de qualquer tipo como por exemplo eletrodos de $\mathrm{pH}$, de condutivímetros, eletrodos íons-seletivos, amostradores automáticos de cromatografia ou espectrometria de massas, sondas de reflectância difusa de fibras ópticas entre outros. Podemos também utilizar eletrodos que gerem diferenças de potencial para ensaios de eletro-difusão. A célula de difusão é composta por dois compartimentos cilíndricos de vidro idênticos (semi-células, $\oslash=85 \mathrm{~mm} \mathrm{~h}=92 \mathrm{~mm}$ ), comportando 4 entradas de vidro esmerilhado cada, localizadas na parte superior de cada cilindro, sendo 3 de $\oslash=28 . \mathrm{h}=60 \mathrm{~mm}$ e uma de $\oslash=34 . \mathrm{h}=60 \mathrm{~mm}$. Cada semi-célula apresenta uma saída lateral $(\oslash=21 \mathrm{~mm}, \mathrm{l}=50 \mathrm{~mm})$, por onde se unem as duas, para formarem a célula completa.

Entre as semi-células é imobilizada a membrana em teste $(\varnothing=21 \mathrm{~mm})$, com a ajuda de um grampo de inox (figura 89, quadro), que se prende às bordas das saídas (3x3 mm) de cada semi-célula. A superfície vertical das bordas deve ser perfeitamente plana para garantir o encaixe perfeito e sem vazamentos de líquido. As duas semi-células são coloca- 

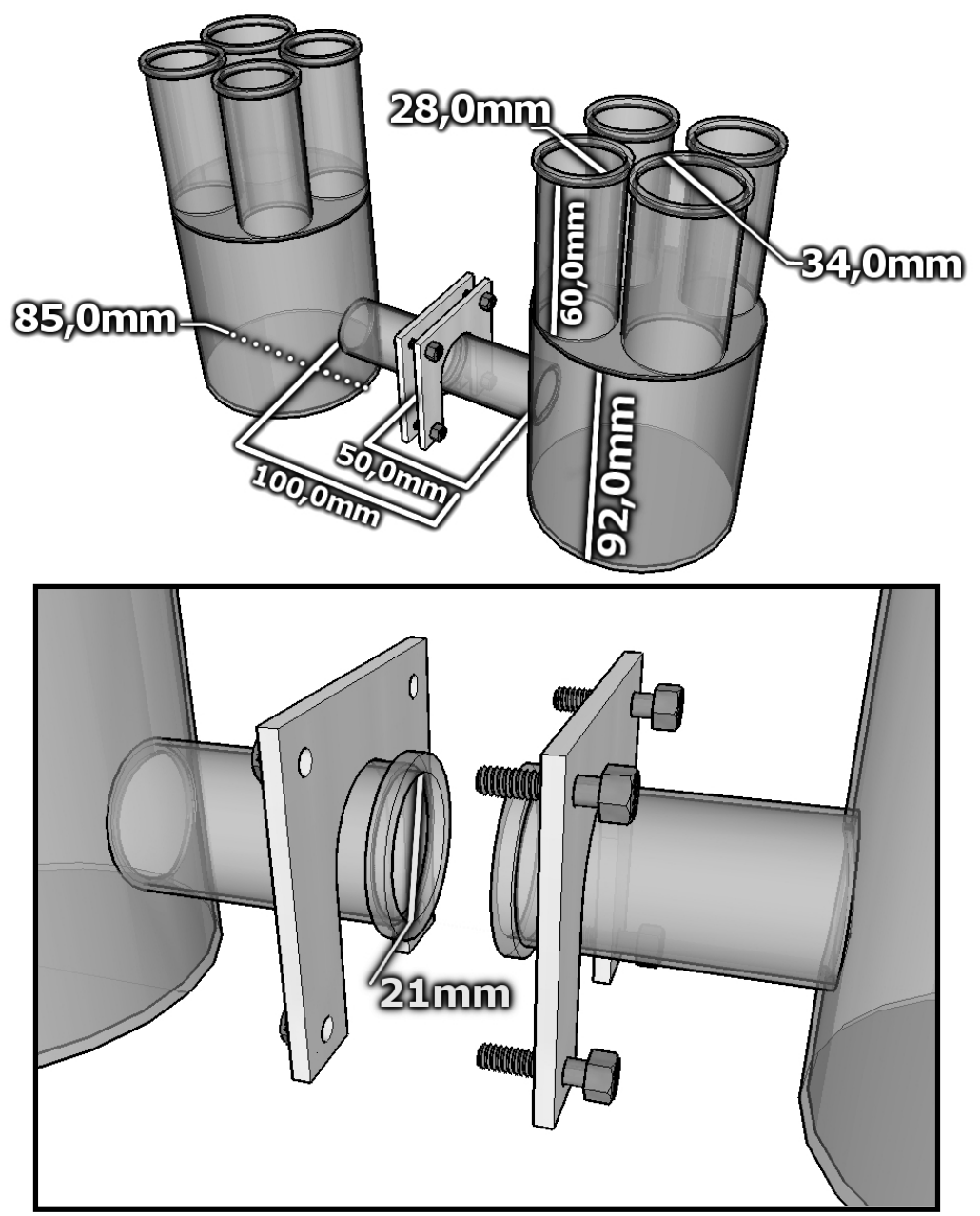

Figura 89: Desenho da célula de difusão com as dimensões. No quadro, detalhe do grampo de inox, que prende as semi-células no ponto de inserção da membrana em teste.

das sobre dois pequenos agitadores magnéticos idênticos, à mesma velocidade com duas barras de agitação magnéticas idênticas com revestimento de teflon (20 mm). Procuramos sempre manter o sistema em regime laminar utilizando velocidades de rotação de até 200 rpm. Os experimentos mais comuns neste trabalho são experimentos de difusão controlados por gradientes de concentração, portanto difusão natural através de membranas que estudamos aqui. Para sua realização são criados dois meios, um hipotônico que contém somente água destilada, separado por uma membrana semipermeável de outro chamado de hipertônico, onde é dissolvida alguma substância. O gradiente de concentração dá origem a uma pressão osmótica mas também à difusão das espécies do meio hipertônico para o hipotônico, afim de neutralizar este gradiente.

\section{A.4 Ensaios de catálise}

Todos ensaios catalíticos foram realizados à temperatura ambiente, com adição de bromobenzeno como padrão interno. Os produtos de reação foram quantificados por cro- 
matografia gasosa em um aparelho Hewlett-Packard 6890, utilizando ar sintético, oxigênio ou hidrogênio a $30 \mathrm{~mL} \cdot \mathrm{min}^{-1}$ como gases de arraste. A coluna utilizada tinha $30 \mathrm{~m}$ por 0,25 mm, feita de poly(etilenoglicol) com ligações cruzadas HP-INNOWAX. Outro aparelho utilizado foi o Varian Star 3400CX com detetro de ionização por chama de hidrogênio e coluna capilar megabore DB-wax (30 m x $0.538 \mathrm{~mm}$, espessura=1 $\mu \mathrm{m})$ e nitrogênio como gas de arraste. A medidas de concentração foram realizadas após 1, 2, 3 e 48 horas de reação. A proporção de catalisador/oxidante/substrato foram de 1:250:750 ou $2 \times 10^{-6}$ $\mathrm{mol} / 5 \times 10^{-4} \mathrm{~mol} / 1.5 \times 10^{-3} \mathrm{~mol}$. Os solventes utilizados foram o benzeno (Synth), acetonitrila (Burdick and Jackson-HPLC), acetona (Synth), e o diclorometano (J.T. Baker). Como oxidante foram utilizados tanto peróxido de hidrogênio a $30 \%$ (Vetec) como iodosilbenzeno (PhIO) e os substratos seguintes: $z$-cicloocteno (Acros organics), ciclohexano (J.T. Baker), estireno (Acros Organics), e n-pentano (J. T. Baker).

\section{A.5 Preparo e eletrodos modificados com membranas semipermeá- veis}

Os EQMs foram preparados em substratos de carbono vítreo, FTO, ou ainda sobre platina ou ouro. Para tal foram preparadas dispersões de $\beta$-CB[6] em PU, ou PVC ou PTFE em tetrahidrofurano em diversas proporções. A solução viscosa foi depositada na superfície do eletrodo por deposição simples ou ainda por puxamento "dip-coating". Estes então são tratados em estufa por 10 minutos, para remoção completa do solvente.

\section{A.6 Instrumentação}

\section{A.6.1 Espectroscopia}

\section{A.6.1.1 Espectroscopia eletrônica de absorção}

Os espectros eletrônicos no estado sólido foram obtidos em um espectrofotômetro USB4000 da marca Ocean Optics, utilizando sondas de fibras ópticas do tipo "wand probe" quando da aquisição por reflectância difusa. Alguns espectros de filmes foram obtidos por transmissão, utilizando um arranjo de duas fibras ópticas. Os espectros em solução, bem como experimentos de cinética, ensaios de variação contínua (método de Job) e método de Benesi-Hildebrand foram realizados em um aparelho de marca Hewlett-Packard modelo HP-8543, utilizando cubetas de quartzo de $1 \mathrm{~cm}$ de caminho óptico.

\section{A.6.1.2 Espectroscopia eletrônica de emissão}

Os espectros de emissão foram registrados em um fluorímetro SPEX fluorolog F2121 equipado com lâmpada de xenônio de 450 Watts, fotomultiplicadora Hamamatsu 
Tabela 16: Dados de RMN para as diversas cucurbiturilas. Das refs. ${ }^{87,349,350}$

\begin{tabular}{|c|c|c|c|c|}
\hline Espécie & ${ }^{13} \mathrm{C}_{\text {metino }}$ & ${ }^{13} \mathrm{C}_{\text {metileno }}$ & ${ }^{13} \mathrm{C}_{\text {carbonila }}$ & ${ }^{1} \mathrm{H}_{\text {metino }}$ \\
\hline$\alpha$-CB $[\mathbf{5}]$ & 70,6 & 51,8 & 157,9 & $4,2(\mathbf{d}) ; 5,26$ e $5,38(\mathbf{s})$ \\
\hline$\beta$-CB $[\mathbf{6}]$ & 71,7 & 53,2 & 158,0 & 4,31 e $5,87(\mathbf{d}) ; 5,59(\mathbf{s})$ \\
\hline$\gamma$-CB $[\mathbf{7}]$ & 72,7 & 54,4 & 158,3 & $\bullet$ \\
\hline$\delta$-CB $[\mathbf{8}]$ & 73,6 & 55,4 & 158,6 & $\bullet$ \\
\hline$\zeta-\mathbf{C B}[\mathbf{1 0}]$ & 74 & 56 & 159 & 4,0 e $5,4(\mathbf{d})$ \\
\hline$\eta$-CB $[\mathbf{1 1}]$ & $\bullet$ & $\bullet$ & $\bullet$ & $\bullet$ \\
\hline$\alpha @ \zeta-\mathbf{C B}[\mathbf{5}] \mathbf{C B}[\mathbf{1 0}]$ & 68,5 & 51 & 156 & 3,66 e $5,09(\mathbf{d}) ; 4,89(\mathbf{s})$ \\
\hline $\boldsymbol{h e m i} \boldsymbol{\beta}-\mathbf{C B}[\mathbf{6}] \dagger$ & 52,5 & 41,9 & 160,95 & $\bullet$ \\
\hline hemi- $\theta-\mathbf{C B}[\mathbf{1 2}] \dagger$ & 53,0 & 41,9 & 160,8 & $\bullet$ \\
\hline
\end{tabular}

$\dagger:$ em $\mathrm{CDCl}_{3}$, ref. ${ }^{87}$

R918 e um monocromadores duplos de excitação e de emissão. Espectros de luminescência qualitativos foram obtidos com o espectrofotômetro USB4000 com excitação externa de uma lâmpada de UV convencional de bancada.

\section{A.6.1.3 Espectroscopia vibracional}

Os espectros de absorção no inframvermelho foram obtidos em um equipamento Bomem modelo ABB. Os espectros de ATR foram obtidos no mesmo aparelho utilizando um prisma de Ge e/ou ZnSe.

\section{A.6.1.4 Espectroscopia de fluorescência de raios-X}

Espectros de EDS (Energy Dispersive Spectroscopy) foram medidos em um microscópio Zeiss EVO 50.

\section{A.6.1.5 Ressonância magnética nuclear}

A caracterização por RMN foi realizada nos aparelhos disponíveis em nosso departamento. Os deslocamentos químicos característicos das CBs estão relacionados abaixo.

\section{A.6.1.6 Ressonância de elétrons paramagnéticos-R.E.P.}

As medidas de R.E.P. foram obtidas no Depto. de Física de nossa unidade em um equipamento modelo Jeol FA-200 banda-X ( 9,45 GHz) à temperatura ambiente, salvo indicação contrária. Os valores dos parâmetros g e A values, froam obtidos por simulação utilizando o programa de computador EPR/NMR. Os procedimentos de interpretação e simulação estão descritos na ref. ${ }^{111}$. 


\section{A.6.2 Espectrometria de massas-M.S.}

Os homólogos de cucurbiturilas podem ser observados por espectrometria de massas por electronspray (EM-ES) quando compostos são observados com um cátion, dois cátions e dois cátions e um haleto. As análises são realizadas geralmente em soluções de cloreto de césio, tab. 17. Não se observam na forma protonada ${ }^{349}$.

\section{A.6.3 Análise térmica}

As curvas de termogravimetria e análise térmica diferencial foram obtidas em um equipamento de marca Shimadzu SDT 2960, situado no IQ-USP de São Paulo. Os experimentos foram realizados em atmosfera de nitrogênio ou ar sintético, segundo a descrição no texto.

\section{A.6.4 Microscopia}

\section{A.6.4.1 Microscopia eletrônica de varredura (MEV)}

Fotomicrografias eletrônicas de varredura foram obtidas em dois aparelhos. O primeiro é um Zeiss modelo EVO 50 acoplado a um analisador elementar de fluorescência de raios-X (EDS). O segundo, mais simples, é um Shimadzu modelo SS-550. As amostras não condutoras de eletricidade foram recobertas com um filme fino de ouro ou carbono condutor.

\section{A.6.4.2 Microscopia eletrônica de transmissão de alta resolução (METAR)}

As imagens foram coletadas no Laboratório Nacional de Luz Síncrotron, Campinas, em um aparelho modelo TEM-JEM 2100 ARP. Para tal, as amostras foram depositadas por evaporação à temperatura ambiente sobre minigrades de cobre recobertas com carbono de 300 mesh.

\section{A.6.4.3 Microscopia de força atômica}

As micrografias de força atômica foram realizadas no DQ-FFCLRP em um microscópio Shimadzu SPM9600 (em modo contato em sua maioria ou modo de varredura dinâmico).

\section{A.6.5 Difratometria de raios- $X$}

Os experimentos de difração de raios-X no pó foram realizados em um equipamento de marca SIEMENS modelo 5005 utilizando a radiação $\mathrm{K}_{\alpha}$ do cobre $(\lambda=1,54 \AA$ ), salvo indicação contrária. 


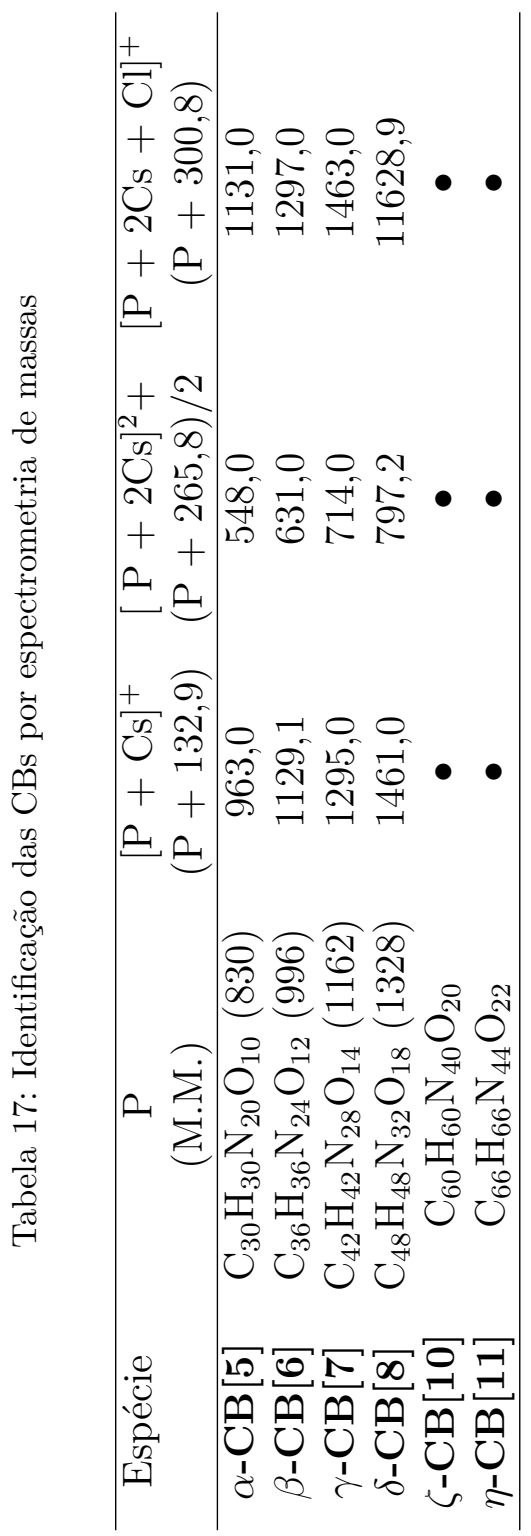




\section{A.6.6 Métodos Teóricos}

Os cálculos semi-empíricos, DFT e de mecânica molecular foram realizados em diversos microcomputadores utilizando diversos programas para tal fim. Um deles é o Ghemical V. 2.0.1, Gaussian V. 03, Spartan V. 11 e 14 e Hyperchem V. 8. Detalhes específicos de cada cálculo estão descritos no texto.

\section{A.6.7 Eletroquímica}

Os ensaios eletroquímicos foram realizados em um Potenciostato $\mu$ AutoLab Type III/FRA2, em uma célula de três componentes utilizando o par Ag|AgCl ( $\mathrm{KCl}$ 3,0 mol. dm ${ }^{-3}$ , $\mathrm{E}_{\text {ref }}^{\ominus}=+0,22 \mathrm{~V}$ vs EPH) como eletrodo de referência (RE), $\mathrm{KCl} 0,1$ mol.dm ${ }^{-3}$ como eletrólito de suporte e um fio de platina em espiral como eletrodo auxiliar (CE). O eletrólito de suporte é desaerado com nitrogênio durante 30 minutos antes de cada análise, salve indicação contrária. Estas foram as condições instrumentais para a maioria dos experimentos de voltametria cíclica (VC), espectroscopia de impedância eletroquímica (EIE), e técnicas em função do tempo como a cronopotenciometria $(\mathrm{CA})$ e a cronocoulombimetria (CC). Detalhes e parâmetros específicos de cada medida estão no texto.

\section{A.6.7.1 Cronocondutimetria}

As medidas de cronocondutimetria foram realizadas utilizando um condutivímetro Tecnopon mod mCA150 interfaceado a um micro-computador via interface serial RS-232. Por meio de uma rotina de aquisição de dados, os valores foram transferidos automaticamente para uma planilha de cálculo, utilizando um o protocolo descrito em detalhes na ref. ${ }^{192}$. As medidas duram de 24 a 72 horas. Foi necessária uma reprogramação da EPROM do aparelho, de modo a neutralizar o processo de compensação de flutuação de leitura, pos as variações de condutividade em nossos experimentos eram pequenas e lentas, o que era interpretado pelo aparelho como oscilações em torno de um valor determinado. 
Anexos 


\section{ANEXO A - Artigos de Referência por Ano de Publicação.}

Por conta de direitos resevrados de cópia, alguns artigos na íntegra foram removidos deste documento em sua versão online. Todos foram citados aqui nesta tese ${ }^{111,188,258,265}$ , 189 . 


\section{CUCURBITURILAS}

\section{Grégoire Jean-François Demets*}

Departamento de Química, Faculdade de Filosofia, Ciências e Letras de Ribeirão Preto, Universidade de São Paulo, Av. Bandeirantes, 3900, 14040-901 Ribeirão Preto - SP, Brasil

Recebido em 7/8/06; aceito em 9/11/06; publicado na web em 17/7/07

CUCURBITURILS. This review article describes the properties and the main applications of the glicol[n]urils. These compounds are cavitands made of $n$ glycolurilic units arranged in circles, giving rise to extremely symmetric toroidal molecules. The cucurbit[n]urils create this way variable-sized hydrophobic cavities and the glycolurilic carbonyles delimit two portals on these cavities, slightly narrower than their internal radii. Their structure, physical and chemical properties favor the formation of inclusion compounds, and turn them into important building blocks for supramolecular chemistry and nanotechnology.

Keywords: cucurbiturils; cucurbitands; inclusion compounds.

\section{INTRODUÇÃO}

As cucurbiturilas foram sintetizadas pela primeira vez por Behrend e colaboradores ${ }^{1}$ em 1905, como resultado da condensação da uréia e do glioxal, formando glicolurila e análogos poliméricos na presença de formaldeído. A tecnologia da época não permitiu uma caracterização inequívoca e a estrutura peculiar destes polímeros só foi elucidada pelo grupo de Mock, 80 anos mais tar$\mathrm{de}^{2}$. Pela primeira vez demonstrou-se que os cucurbitandos, outra designação desta família de compostos (abreviados também por $\mathrm{CB}[\mathrm{n}]$ ), eram estruturas cíclicas toroidais, compostas por 6 unidades de glicolurila, ligadas por grupos $-\mathrm{CH}_{2}-$ em suas aminas de simetria $D_{6 H}$ (Figura 1).

A nomenclatura oficial deste composto é complexa* e a sua forma de abóbora deu origem a seu nome, de cucurbita em latim (* segundo a IUPAC, o nome da cucurbit[6]urila ou $\mathrm{CB}[6]$ seria: dodecaidro- $1 \mathrm{H}, 4 \mathrm{H}, 14 \mathrm{H}, 17 \mathrm{H}-2,16: 3$, 15-dimetano-5H, $6 \mathrm{H}, 7 \mathrm{H}$, $8 \mathrm{H}, 9 \mathrm{H}, 10 \mathrm{H}, 11 \mathrm{H}, 12 \mathrm{H}, 13 \mathrm{H}, 18 \mathrm{H}, 19 \mathrm{H}, 20 \mathrm{H}, 21 \mathrm{H}, 22 \mathrm{H}, 23 \mathrm{H}$, 24H, 25H, 26H-2, 3-4a, 5a, 6a, 7a, 8a, 9a, 10a, 11a, 12a, 13a, 15, 16, 17a, 18a, 19a, 20a, 21a, 22a, 23a, 24a, 2 - 3 - 5a, 26a -

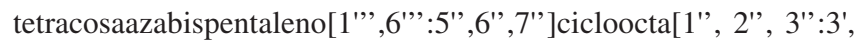
4']pentaleno(1',6':5,6,7)cicloocta(1,2,3-gh:1',2',3'-g'h')cicloocta(1, 2, 3-cd:5, 6, 7-c'd')dipentaleno-1, 4, 6, 8, 10, 12, 14, 17, 19, 21, 23, 25-dodecona).

Esta estrutura, além de ser simétrica, possui uma cavidade central hidrofóbica relativamente grande, que é capaz de acomodar espécies variadas para a formação de compostos de inclusão, também chamados de caviplexos, como o fazem outras famílias de cavitandos como as ciclodextrinas ou calixarenos. Na cucurbit[6]urila, existem 12 carbonilas orientadas para fora das cavidades, 6 de cada lado, formando assim dois portais para as cavidades, e conferindo à molécula um caráter básico de Lewis. Os métodos mais modernos de análise constataram que não eram formados apenas anéis de 6 membros nas sínteses de cucurbiturilas, mas que outros análogos cíclicos com 5 a 11 unidades glicolurílicas também eram formados durante as sínteses. Os recentes avanços em química orgânica sintética permitiram a elaboração de novas rotas, resultando em rendimentos diferenciados na produção destes homólogos. O maior controle sobre a distribuição dos produtos síntese tornou viável a síntese de CB[7]

*e-mail: greg@usp.br e $\mathrm{CB}[8]$, por ex., ainda que em pequenas quantidades, fato que expandiu as possibilidades na química das cucurbiturilas ${ }^{3}$.

Por terem uma estrutura em forma de barril, serem simétricos além de possuirem cavidades hidrofóbicas, os cucurbitandos constituem um importante e versátil bloco de montagem para estruturas supramoleculares. Muitos exemplos de utilização dos cucurbitandos e derivados em supramoléculas podem ser encontrados na literatura, na forma de rotaxanos e pseudo-rotaxanos, chaveadores moleculares, carreadores de fármacos, modificadores de colunas cromatográficas, "rolamentos moleculares", complexos de inclusão, compostos de coordenação e adutos e outras estruturas que têm sido obtidas em diversos grupos de pesquisa do mundo, com enfoque em química supramolecular e nanotecnologia.

O objetivo deste artigo foi apresentar de forma sucinta, e pela primeira vez em português, as principais características desta família de compostos que vem ganhando cada vez mais espaço na literatura, e que tem mostrado uma química tão rica e versátil quanto a das ciclodextrinas ou calixarenos. Começaremos enfocando a síntese e as principais características dos cucurbitandos, descrevendo em seguida seu comportamento frente à química de compostos de inclusão. Prosseguiremos descrevendo as principais aplicações e áreas de estudo que envolvem os cucurbitandos, e encerraremos com algumas considerações e as novas perspectivas para esta classe de compostos.

\section{SÍNTESE E PROPRIEDADES FÍSICO-QUÍMICAS}

Os procedimentos de síntese de cucurbiturilas são bastante simples, consistindo basicamente na reação de glicolurila com formaldeído em meio ácido ${ }^{2}$ (Figura 1a e b). As primeiras sínteses de cucurbitandos deram origem exclusivamente a macrocíclicos hexaméricos, e só recentemente foi possível sintetizar em quantidades representativas e isolar seus análogos superiores e inferiores. É possível alterar a distribuição dos produtos, ou seja a concentração relativa de $\mathrm{CB}[\mathrm{n}]$, controlando alguns parâmetros de síntese, como por ex., a pressão e a natureza do ácido empregado, como verificado por Kim e outros ${ }^{3-7}$. A síntese em autoclave, por exemplo, aumenta muito o rendimento em $\mathrm{CB}$ [8], enquanto que a síntese à pressão atmosférica, utilizando $\mathrm{HCl}$ ou $\mathrm{H}_{2} \mathrm{SO}_{4}$ dá origem a $\mathrm{CB}[6]$, principalmente. Sínteses em gel aumentam muito o rendimento em CB[7] ${ }^{4}$. Kim e Day observaram assim a formação de macrocíclicos maiores com $n$ podendo chegar a 11 , e compostos do tipo $\mathrm{CB}[5] @ \mathrm{CB}[10]$ 
em outras condições de síntese ${ }^{8}$. Isto leva a crer que exista até um mecanismo do tipo template na formação dos cavitandos maiores, que dificilmente manteriam uma estrutura circular perfeita devido à tensão angular das ligações das pontes metilênicas ${ }^{5 ; 9}$. O CB[10] foi isolado pela primeira vez por Isaacs e seu grupo ${ }^{10}$ em 2005 , pois só era encontrado até então na forma que mencionamos acima ${ }^{8}$. O $\mathrm{CB}[11]$, por sua vez, aparece apenas em diminutas quantidades como subproduto de síntese e sua existência é comprovada por técnicas espectroscópicas. O CB[9], até onde é de nosso conhecimento, ainda não foi isolado e descrito na literatura.
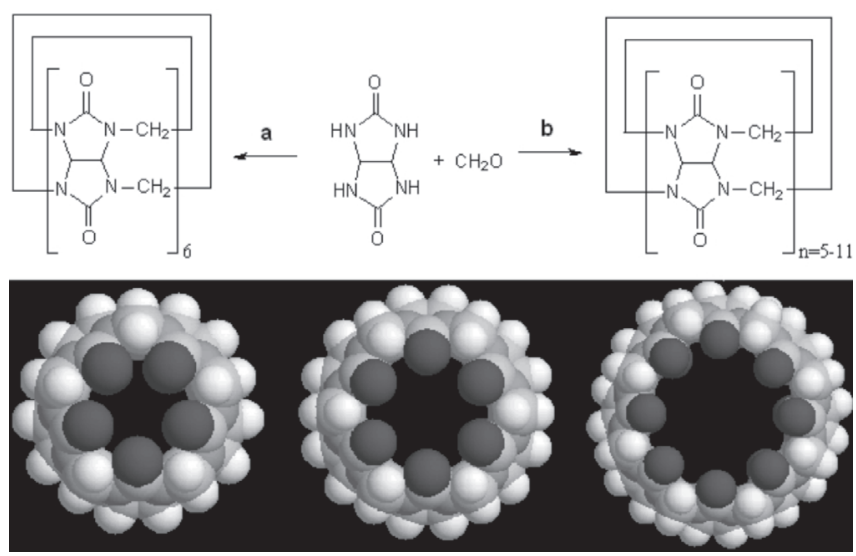

Figura 1. Esquema de síntese (em cima, $a=$ Mock e Behrend ${ }^{l ; 2}, b=K_{\text {im }}^{3}$ ) $e$ representações das Cucurbit[5, 6 e 8]urilas, vistas de cima

Como é de se esperar, quanto maior o número de unidades glicolurílicas, maior é o tamanho da cavidade e dos opérculos dos cavitandos, sendo que todos mantêm a mesma altura, de $9,1 \AA$. O tamanho dos opérculos é aproximadamente $2 \AA$ menor que o diâmetro das cavidades internas, portanto representam a principal barreira estérica para a formação de compostos de inclusão (caviplexos). A Tabela 1 apresenta as dimensões dos principais $\mathrm{CB}[\mathrm{n}]$ e algumas de suas propriedades físicas. Os dados de difração de raios-X atestam dimensões ligeiramente menores que as obtidas por alguns métodos de cálculo de mecânica molecular, além da presença de moléculas de água nas cucurbiturilas no estado sólido presas por ligações de hidrogênio. Estas águas são bastante lábeis na presença de outras moléculas coordenantes.

A baixa solubilidade e a inércia química são dois fatores bem característicos dos cucurbitandos. Pequenas variações de solubilidade podem ser observadas entre as estruturas análogas. Os $\mathrm{CB}$ [6] e CB[8] são essencialmente insolúveis em água, enquanto que seus análogos ímpares inferiores $(n=5$ e 7$)$ são pouco solúveis. Em solventes orgânicos uma relação similar é observada e torna bastante trabalhosa a separação dos análogos. A basicidade destes compostos é bastante baixa sendo verificados pKa's do ácido conjugado do $\mathrm{CB}[6]$ da ordem de 3, sendo desconhecida para os outros cucurbitandos. Uma das estratégias para contornar o problema de solubilidade é a utilização de meios salinos ou ácidos para aumen- tar a solubilidade destes compostos pela formação de complexos com ácidos duros ou, ainda, pela protonação das carbonilas dos opérculos destas estruturas ${ }^{12}$. A utilização de sais de amônio também facilita sua solubilização (Tabela 1). A estabilidade térmica destas moléculas, como é de se esperar de estruturas regulares como estas, é bastante alta, sendo que os cucurbitandos decompõem-se acima de $400{ }^{\circ} \mathrm{C}^{13}$.

Mapas de potencial eletrostático revelam que os cucurbitandos possuem uma elevada densidade eletrônica em seus opérculos, explicando por sua afinidade por cátions, e não moléculas neutras ou aniônicas como é o caso das ciclodextrinas ${ }^{15}$. A cavidade dos cucurbitandos, totalmente hidrofóbica, favorece a inclusão de compostos apolares ou pouco polares.

A inércia química dos cucurbitandos limitou as possibilidades em termos da formação de estruturas supramoleculares tendo cucurbiturilas como blocos de construção até o fim dos anos 90. Kim e seus colaboradores assim como Isaacs, Day, Stoddart, Wu e outros autores obtiveram recentemente cucurbiturilas modificadas, tanto partindo de glicolurilas funcionalizadas como de macrocíclicos já formados ${ }^{4,7,16-27}$. A reação de $\mathrm{CB}[6]$, por exemplo com $\mathrm{K}_{2} \mathrm{~S}_{2} \mathrm{O}_{8}$, dá origem a 12 grupos $\mathrm{OH}$ radiais nos carbonos terciários em meio aquoso $^{22,28}$, enquanto que a utilização de dimetil glicolurila como monômero precursor dá origem à decametil- $\mathrm{CB}[5]^{21}$. Este é o ponto de partida para a fixação de muitos outros radicais orgânicos, como por exemplo, aminas, tióis, grupos aromáticos, ou fosfinas. A partir daí é possível formar uma variedade de materiais moleculares quase que infinita, aproveitando a estrutura peculiar das cucurbiturilas.

Os cucurbitandos não funcionalizados são todos sólidos incolores e absorvem luz intensamente abaixo de $200 \mathrm{~nm}$, no que se acredita serem transições $\pi \rightarrow \pi *$ nas carbonilas. Esta banda, no entanto, costuma deslocar-se para maiores comprimentos de onda quando ligada a metais, passando a constar em torno de $200 \mathrm{~nm}^{29,30}$. A espectroscopia de RMN é a mais empregada na caracterização destes compostos, que são solubilizados em misturas de ácidos e água deuterados. Por serem altamente simétricos seus espectros são bastante simples ${ }^{31,32}$. Nos espectros de ${ }^{1} \mathrm{H}$ são observados para o $\mathrm{CB}[6]$ somente 3 sinais, indicativos de uma estrutura não aromática altamente simétrica. ( $\delta \mathrm{Me} \mathrm{Si}_{4}\left(90 \% \mathrm{HCOOH} / \mathrm{D}_{2} \mathrm{O}\right.$-freq. desc.) 5,75 (s, metinos de glicolurila), 4,43 e 5,972. Os espectros de ${ }^{13} \mathrm{C}$ são igualmente simples, contando com 3 sinais também em $\delta=55,3 ; 74,2$ e $160\left(\mathrm{D}_{2} \mathrm{O} / \mathrm{CF}_{3} \mathrm{CO}_{2} \mathrm{D} / \mathrm{D}_{2} \mathrm{SO}_{4}-125 \mathrm{MHz}\right)^{3}$. O espectro infravermelho destes compostos é bastante complicado, sendo mais marcantes duas bandas localizadas em 1720 e $1470 \mathrm{~cm}^{-1}$ correspondendo, respectivamente, aos modos de estiramento $\mathrm{C}=\mathrm{O}$ e $\mathrm{C}-\mathrm{N}$.

\section{COMPOSTOS DE INCLUSÃO COM CUCURBITANDOS}

Existem essencialmente quatro fatores que governam a formação de compostos de inclusão com cucurbiturilas. $O$ primeiro são as interações solvofóbicas, uma vez que o interior das cavidades é hidrofóbico e procura acomodar espécies com segmentos compatíveis com esta natureza. O segundo são as interações do tipo íon-dipolo que são responsáveis, por exemplo, pela formação de complexos entre

Tabela 1. Dimensões de alguns cucurbitandos ${ }^{3,11}$ e algumas propriedades físicas dos cucurbitandos ${ }^{11,13,14,197}$

\begin{tabular}{|c|c|c|c|c|c|c|c|}
\hline $\mathrm{CB}[\mathrm{n}]$ & $\begin{array}{c}\varnothing \\
\text { Opérculo/Å }\end{array}$ & $\begin{array}{c}\varnothing \\
\text { Interno/Å }\end{array}$ & $\underset{\AA^{3}}{\text { Volume }}$ & $\begin{array}{l}\mathrm{T} \mathrm{dec} . /^{\circ} \mathrm{C} \\
\text { (ref. } 197 \text { ) }\end{array}$ & $\begin{array}{l}\text { Solub. em } \\
\text { ácidos/mM }\end{array}$ & $\begin{array}{l}\text { Solub. em } \\
\mathrm{H}_{2} \mathrm{O} / \mathrm{mM}\end{array}$ & $\begin{array}{l}\text { M.M./ } \\
\text { g mol- }^{-1}\end{array}$ \\
\hline $\mathrm{CB}[5]$ & 2,4 & 4,4 & 82 & $>420$ & $60(\mathrm{HCl} 3 \mathrm{M})$ & $20-30$ & 830 \\
\hline $\mathrm{CB}[6]$ & 3,9 & 5,8 & 164 & 425 & $61\left(\mathrm{HCO}_{2} \mathrm{H}_{2} \mathrm{H}_{2} \mathrm{O} 1: 1\right)$ & 0,018 & 996 \\
\hline $\mathrm{CB}[7]$ & 5,4 & 7,3 & 279 & 370 & $700\left(\mathrm{HCl}^{2} \mathrm{M}\right)$ & $20-30$ & 1163 \\
\hline $\mathrm{CB}[8]$ & 6,9 & 8,8 & 479 & $>420$ & $1,5(\mathrm{HCl} 3 \mathrm{M})$ & $<0,01$ & 1329 \\
\hline $\mathrm{CB}[10]$ & $\sim 10$ & $\sim 12$ & 870 & - & - & - & 1661 \\
\hline
\end{tabular}


cátions e as carbonilas glicolurílicas. O terceiro são óbviamente as ligações de hidrogênio, responsáveis pela formação de adutos pelos opérculos dos cavitandos ${ }^{33,34}$. Outro fator, que determina a seletividade por tamanho, são as dimensões dos portais dos cucurbitandos. Desta forma, os cucurbitandos são capazes de formar compostos de inclusão, complexos e adutos com uma enorme variedade de espécies químicas $^{35,36}$. Podemos citar entre elas as aminas ${ }^{12,14,34,37-39}$, compostos aromáticos ${ }^{40,41}$, heterocíclicos ${ }^{42-44}$, viologênios ${ }^{44-49}$, poliaminas, peptídios e aminoácidos ${ }^{50-52}$, álcoóiis ${ }^{50,53,54}$, surfatantes ${ }^{53,55}$, tióis, gases como $\mathrm{CO}_{2}$, $\mathrm{O}_{2}, \mathrm{Kr}, \mathrm{N}_{2}$ e Xe $\mathrm{Xe}^{31,32,56-58}$, metais, complexos e muitas outras, como corantes ${ }^{59,60}$ e fármacos ${ }^{59-62}$ (Tabela 2). Em termos de constantes de formação médias de caviplexos de CB[6] com um grande número de compostos, como álcoóis por exemplo, são geralmente uma ordem de grandeza superiores às obtidas com $\alpha$-ciclodextrinas, mostrando que também exibem uma grande afinidade por moléculas neutras, além de maior seletividade por conta dos fatores mencionados anteriormente. Este comportamento também é observado na formação de complexos com metais alcalinos e alcalino-terrosos quando comparada com o éter 18-coroa-6 como apresentaremos mais adiante. A adição de áci-

Tabela 2. Constantes de formação relativas de caviplexos de CB[6] com diversos hóspedes ${ }^{12,34,36-38,63}$ e de complexos metálicos de $\mathrm{CB}[6]$ e vários íons ${ }^{29,145}$

\begin{tabular}{|c|c|}
\hline Hóspede & $\mathrm{K}_{\text {form }}\left(\mathrm{rel}^{*}\right)$ \\
\hline $\mathrm{NH}_{3}$ & 0,25 \\
\hline \multicolumn{2}{|c|}{ Substituintes n-alquílicos } \\
\hline $\begin{array}{l}\mathrm{MeNH} \\
\mathrm{EtNH} \\
\mathrm{Me}\left(\mathrm{CH}_{2}\right)_{2} \mathrm{NH}_{2} \\
\mathrm{Me}\left(\mathrm{CH}_{2}\right)_{3} \mathrm{NH}_{2} \\
\mathrm{Me}\left(\mathrm{CH}_{2}\right)_{4} \mathrm{NH}_{2} \\
\mathrm{Me}\left(\mathrm{CH}_{2}\right)_{5} \mathrm{NH}_{2} \\
\mathrm{Me}\left(\mathrm{CH}_{2}\right)_{6} \mathrm{NH}_{2} \\
\mathrm{Me}_{2} \mathrm{CHCH}_{2} \mathrm{NH}_{2} \\
\mathrm{Me}_{2} \mathrm{CH}\left(\mathrm{CH}_{2}\right)_{2} \mathrm{NH}_{2} \\
\mathrm{Me}_{2} \mathrm{CH}\left(\mathrm{CH}_{2}\right)_{3} \mathrm{NH}_{2} \\
\mathrm{EtCH}(\mathrm{Me}) \mathrm{CH}_{2} \mathrm{NH}_{2} \\
\mathrm{EtCH}(\mathrm{Me})\left(\mathrm{CH}_{2}\right)_{2} \mathrm{NH}_{2}\end{array}$ & $\begin{array}{c}0,25 \\
0,3 \\
37,6 \\
307 \\
74 \\
7,0 \\
0,3 \\
67 \\
109 \\
13 \\
6,0 \\
3,5\end{array}$ \\
\hline \multicolumn{2}{|c|}{ Substituintes cicloalquílicos } \\
\hline $\begin{array}{l}\text { Ciclo- }\left(\mathrm{CH}_{2}\right)_{2} \mathrm{CHCH}_{2} \mathrm{NH}_{2} \\
\text { Ciclo- }\left(\mathrm{CH}_{2}\right)_{3} \mathrm{CHCH}_{2} \mathrm{NH}_{2} \\
\text { Ciclo- }\left(\mathrm{CH}_{2}\right)_{4} \mathrm{CHCH}_{2} \mathrm{NH}_{2} \\
\text { Ciclo- }\left(\mathrm{CH}_{2}\right)_{2} \mathrm{CHNH}_{2} \\
\text { Ciclo- }\left(\mathrm{CH}_{2}\right)_{3} \mathrm{CHNH}_{2}\end{array}$ & $\begin{array}{c}45 \\
1130 \\
1040 \\
1,2 \\
9,2 \\
\end{array}$ \\
\hline \multicolumn{2}{|c|}{ Tioéteres } \\
\hline $\begin{array}{l}\mathrm{MeS}\left(\mathrm{CH}_{2}\right)_{2} \mathrm{NH}_{2} \\
\mathrm{EtS}\left(\mathrm{CH}_{2}\right)_{2} \mathrm{NH}_{2} \\
\text { Ciclo- }\left(\mathrm{CH}_{2} \mathrm{~S}\right) \mathrm{CHCH}_{2} \mathrm{NH}_{2}\end{array}$ & $\begin{array}{c}52 \\
105 \\
1810\end{array}$ \\
\hline \multicolumn{2}{|c|}{ Alcanodiaminas } \\
\hline $\begin{array}{l}\mathrm{NH}_{2}\left(\mathrm{CH}_{2}\right)_{3} \mathrm{NH}_{2} \\
\mathrm{NH}_{2}\left(\mathrm{CH}_{2}\right)_{4} \mathrm{NH}_{2} \\
\mathrm{NH}_{2}\left(\mathrm{CH}_{2}\right)_{5} \mathrm{NH}_{2} \\
\mathrm{NH}_{2}\left(\mathrm{CH}_{2}\right)_{6} \mathrm{NH}_{2} \\
\mathrm{NH}_{2}\left(\mathrm{CH}_{2}\right)_{7} \mathrm{NH}_{2} \\
\mathrm{NH}_{2}\left(\mathrm{CH}_{2}\right)_{8} \mathrm{NH}_{2} \\
\mathrm{NH}_{2}\left(\mathrm{CH}_{2}\right)_{9} \mathrm{NH}_{2} \\
\mathrm{NH}_{2}\left(\mathrm{CH}_{2}\right)_{10} \mathrm{NH}_{2}\end{array}$ & $\begin{array}{c}2,8 \\
480 \\
7600 \\
8600 \\
135 \\
28 \\
1,5 \\
0,3\end{array}$ \\
\hline
\end{tabular}

Tabela 2. continuação

\begin{tabular}{lc}
\hline Hóspede & $\mathrm{K}_{\text {form }}\left(\mathrm{rel}^{*}\right)$ \\
\hline \multicolumn{3}{c}{ Substituintes aromáticos } \\
\hline$\phi-\mathrm{NH}_{2}$ & 0,8 \\
$\mathrm{p}_{2} \mathrm{MeC}_{6} \mathrm{H}_{4} \mathrm{CH}_{2} \mathrm{NH}_{2}$ & $\mathbf{1 , 0 *}$ \\
$\left(2-\mathrm{C}_{4} \mathrm{H}_{3} \mathrm{~S}\right) \mathrm{CH}_{2} \mathrm{NH}_{2}$ & 710 \\
\hline
\end{tabular}

\begin{tabular}{lc}
\hline \multicolumn{2}{c}{ Diversos } \\
\hline $\mathrm{Bu}^{\mathrm{t}}\left(\mathrm{CH}_{2}\right)_{2} \mathrm{NH}_{2}$ & $<0,1$ \\
$\mathrm{Me}\left(\mathrm{CH}_{2}\right)_{3} \mathrm{NHMe}$ & 340 \\
$\mathrm{Me}\left(\mathrm{CH}_{2}\right)_{3} \mathrm{~N}(\mathrm{Me})_{2}$ & 2,3 \\
$\mathrm{NH}_{2}\left(\mathrm{CH}_{2}\right)_{6} \mathrm{OH}$ & 3,6 \\
$\mathrm{~N}_{3}\left(\mathrm{CH}_{2}\right)_{2} \mathrm{NH}_{2}$ & 1,2 \\
$\mathrm{MeO}_{2}\left(\mathrm{CH}_{2}\right)_{2} \mathrm{NH}_{2}$ & 5,4 \\
$\mathrm{NH}_{2}\left(\mathrm{CH}_{2}\right)_{2} \mathrm{~S}\left(\mathrm{CH}_{2}\right)_{2} \mathrm{NH}_{2}$ & 1300 \\
$\mathrm{NH}_{2}\left(\mathrm{CH}_{2}\right)_{4} \mathrm{NH}\left(\mathrm{CH}_{2}\right)_{3} \mathrm{NH}_{2}$ & 4200 \\
$\left.\mathrm{NH}_{2}\left(\mathrm{CH}_{2}\right)_{3} \mathrm{NH}\left(\mathrm{CH}_{2}\right)_{4} \mathrm{NH}_{(} \mathrm{CH}_{2}\right)_{3} \mathrm{NH}_{2}$ & 40000 \\
\hline
\end{tabular}

$\uparrow$ Cstes relativas ao $\mathrm{p}-\mathrm{MeC}_{6} \mathrm{H}_{4} \mathrm{CH}_{2} \mathrm{NH}_{2} \uparrow$

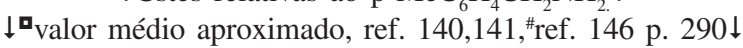

\begin{tabular}{lccc}
\hline Cátion & $\mathrm{r} / \AA$ & $\mathrm{CB}[6]$ & 18-crown-6 \\
\hline $\mathrm{Na}^{+}$ & 1,02 & 3,69 & 0,8 \\
$\mathrm{~K}^{+}$ & 1,38 & 3,96 & 2,03 \\
$\mathrm{Rb}^{+}$ & 1,49 & 4,41 & 1,56 \\
$\mathrm{Cs}^{+}$ & 1,7 & 4,82 & 0,99 \\
$\mathrm{Ca}^{2+}$ & 1,0 & 4,57 & 0,48 \\
$\mathrm{NH}_{4}^{+}$ & 1,7 & 3,97 & 1,23 \\
$\mathrm{H}^{+}$ & 1,38 & 3,02 & 1,28 \\
$\mathrm{Ln}^{3+}$ & $0,86-1,03$ & $\sim 3$ 口 & $1,32-8,75^{\#}$ \\
\hline
\end{tabular}

dos para solubilizá-los cria mecanismos competitivos entre a formação de caviplexos e adutos e a protonação das carbonilas, e os dados referentes à formação destes compostos podem variar segundo o meio em que ocorre.

Pode-se observar na Figura 2 que relaciona constantes de formação relativas de caviplexos de $\mathrm{CB}[6]$ com hóspedes do tipo amina e diamina de cadeias alquílicas simples, que o tamanho da cadeia exerce um papel fundamental com relação à sua afinidade por cucurbitandos. Neste exemplo observa-se que as maiores constantes de formação

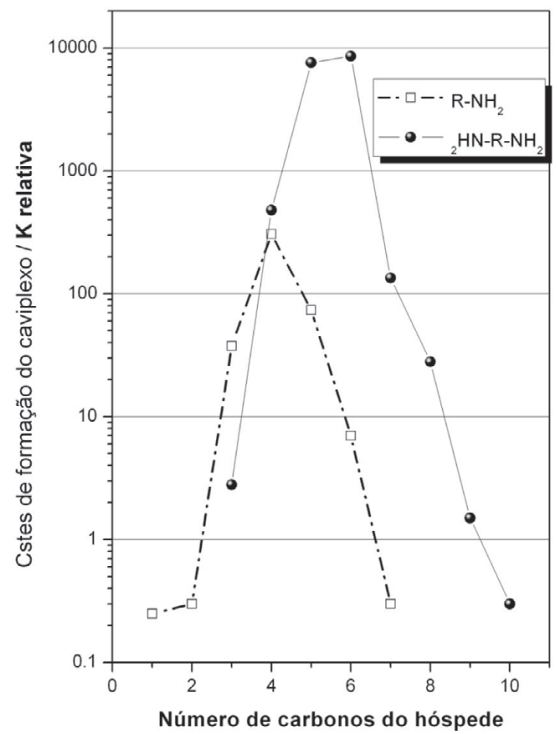

Figura 2. Constantes de formação relativas de CB[6] com aminas e diaminas alifáticas. Meio ácido; adaptado das refs. 36-38 e 64 
de caviplexos com sais de aminas simples são obtidas para cadeias entre 3 e 5 carbonos. Isto é compreensível quando se pensa em termos de interações solvofóbicas, uma vez que quanto maior o tamanho da cadeia hidrofóbica, mais forte será sua interação com a cavidade dos macrocíclicos. Em contrapartida, quando estas cadeias são grandes demais, parte delas aproxima-se dos oxigênios carbonílicos do segundo opérculo, podendo até chegar a atravessar completamente o cavitando, tornando o processo energéticamente desfavorável. No caso das diaminas, um comportamento muito similar é observado, mas desta vez se constata uma maior afinidade por diaminas com cadeias de 5 e 6 carbonos, para as quais são verificadas altíssimas constantes de formação. Este fato também é compreensível, uma vez que estas correspondem ao tamanho ideal para a formação de complexos duplos com os íons de amônio, um em cada opérculo, mantendo ainda o segmento alquílico na porção hidrofóbica do macrocíclico. Cadeias maiores e menores encontram dificuldade para preencher a cavidade e satisfazer os requisitos das interações solvofóbicas e íon-dipolo ${ }^{64}$. As evidência experimentais atestam que é possível incluir cadeias ramificadas pequenas (com grupos metila, por ex.) e até mesmo anéis de cinco membros no interior de $\mathrm{CB}[6]$. Cadeias ramificadas e anéis maiores são proibitivas (um anel benzênico tem 600 pm de raio de van der Waals) ${ }^{34,65}$. Um fator muito importante para a formação de cavitandos com sais de amônio é o alinhamento do íon com os oxigênios carbonílicos, uma vez que desta maneira passam a realizar ligações de hidrogênio com os oxigênios carbonílicos. Isto significa que é necessário no mínimo um grupo $-\mathrm{CH}_{2}$ - separando o íon de amônio do restante destes grupos mais volumosos (Tabela 2).

A mesma lógica é seguida pelos análogos de maior e menor diâmetro, sendo preponderante agora o fator estérico na formação de caviplexos. Os CB[7 e 8] são capazes, no entanto, de incluir em suas estruturas anéis aromáticos, viologênios, derivados do naftaleno entre outros, possibilitando a formação de sistemas mais complexos, como por exemplo, a inclusão de fluoróforos grandes, como se verá adiante. Muitos autores exploram também a possibilidade de inclusão de mais de um hóspede, formando por exemplo complexos de transferência de carga no interior dos macrocíclicos e explorando as variações espectrais que ocorrem na formação competitiva destes complexos com mais de um hóspede ${ }^{66}$. Os opérculos das cucurbiturilas menores, como a $\mathrm{CB}$ [5] e a decametil-CB[5], possuem tamanhos compatíveis com o tamanho dos íons $\mathrm{NH}_{4}^{+}$e $\mathrm{Cs}^{+}$para o $\mathrm{CB}[6]^{67}$. Estes íons acabam, portanto, preenchendo toda a área dos opérculos, atuando como "tampas da abóbora" ${ }^{57}$, que podem ser removidas em meio básico. Assim sendo, é possível inserir espécies dentro das cavidades e lacrá-las posteriormente. Este procedimento de encapsulação e abertura destas cápsulas é interessante para o desenvolvimento de sistemas de liberação controlada de fármacos e gases e não somente sistemas de liberação sustentada ${ }^{68}$.

As cucurbiturilas maiores $(n>6)$ também têm sido estudadas como potenciais carreadoras de fármacos e drogas; Kim demonstrou que complexos de Pt como a oxaliplatina tornam-se mais estáveis frente à reatividade com guanina e L-metionina, que diminuem a eficácia da droga. Testes in vitro, todavia, demonstram que sua eficácia antitumoral também é reduzida com a encapsulação ${ }^{61}$. Melhores resultados foram obtidos com derivados das cisplatina em $\mathrm{CB}$ [7] por Collins e seu grupo ${ }^{62}$. Buschmann realizou alguns testes na formação de compostos de inclusão com alguns aminoácidos e dipeptídeos com CB[6], obteve constantes de formação da ordem de 3 (log K) e verificou que a glicina não forma tais compostos ${ }^{52,69}$.

\section{Aspectos dinâmicos da formação de caviplexos}

Os cucurbitandos podem, em geral, acomodar moléculas peque- nas de solvente em seu interior, como é o caso do THF, freqüentemente incluído em reações neste meio. Geralmente estas trocas entre o interior das cavidades e o meio externo são bastante lentas, isto quando se as compara à escala de tempo das medidas de RMN, freqüentemente utilizadas nos estudos de formação de caviplexos. Existem basicamente dois mecanismos plausíveis para a formação de compostos de inclusão quando se adiciona um hóspede ao sistema contendo o macrocíclico e solvente ou contendo o macrocíclico e outro hóspede com menor afinidade. Pode-se imaginar que a substituição do solvente ou de outra molécula qualquer pelo novo hóspede ocorra somente após a saída do solvente ou de um hópsede anterior, caracterizando assim um mecanismo dissociativo, ou ainda que ocorra um mecanismo de substituição em uma única etapa, onde um hóspede acaba deslocando outro, em um mecanismo associativo. Estes mecanismos têm consequiências diretas na cinética destas reações de inclusão, uma vez que um mecanismo associativo deveria se traduzir por um aumeto de velocidade proporcional ao aumento da concentração do novo hóspede, o que é característico de uma reação de segunda ordem, o que não ocorreria em mecanismos dissociativos. $\mathrm{O}$ que se observa na prática, porém, não é consistente com mecanismos associativos. Na troca de $\mathrm{Me}_{2} \mathrm{CHCH}_{2} \mathrm{CH}_{2} \mathrm{NH}_{3}{ }^{+}$incluso em $\mathrm{CB}[6]$ por $\left(2-\mathrm{C}_{4} \mathrm{H}_{3} \mathrm{O}\right) \mathrm{CH}_{2} \mathrm{NH}_{3}{ }^{+}$por ex., observa-se uma constante cinética de pseudo-primeira ordem de $0,37.10^{-3} \mathrm{~s}^{-1}$. Um aumento de 10 vezes da concentração do novo hóspede diminui esta constante, que chega a $0,24.10^{-3} \mathrm{~s}^{-1}$, como observou Mock e seu grupo ${ }^{38}$. Este fenômeno ocorre com muitas outras moléculas hóspedes, levando a crer que o mecanismo de inclusão é essencialmente dissociativo, sendo a saída do hóspede original a etapa limitante do processo de troca de hóspede.

No caso de hóspedes duplamente carregados, como é o caso dos sais duplos de amônio, o processo de saída envolve a travessia de um cátion amônio por um ambiente apolar, o que contribui grandemente para a barreira energética do processo. A desprotonação do íon amônio facilitaria muito a saída deste hóspede. Assim sendo, seria de se esperar uma dependência da velocidade da reação com o pH, o que não é verificado experimentalmente. $\mathrm{O} \mathrm{pH}$ é importante, no entanto, para a formação de caviplexos pois cria cátions, mas não se pode afirmar que a desprotonação deste tipo de molécula não é necessária a sua saída ${ }^{70,71}$. Também é de se esperar que hóspedes mais volumosos levem mais tempo para deixar a cavidade dos CBs, jutificando o fenômeno pelo estreitamento da cavidade nos opérculos, e isto é verificado experimentalmente.

\section{ALGUMAS APLICAÇÕES DAS CUCURBITURILAS}

\section{Catálise em cucurbitandos}

Por causa de suas propriedades de matriz de intercalação, a cavidade dos cucurbitandos serve também como suporte para diversas reações orgânicas, como direcionadora de reações topotáticas $^{72}$. Em outras palavras, os CBs são catalisadores eficientes para uma série de reações orgânicas como Mock e seu grupo demonstraram em 1983, quando começaram a estudar a formação de triazóis dentro destas cavidades ${ }^{72,73}$. Partindo de uma azida e de um alcino, ambos contendo grupos amônio terminais, viabilizaram a formação de caviplexos ternários, colocando frente a frente os grupos insaturados propiciando, assim, a formação de anéis triazólicos, que têm menor afinidade com a cavidade que os reagentes em arranjo ternário (Figura 3). Constatou-se também um aumento da velocidade desta reação de cerca de $5,5.10^{4}$ vezes, sendo que a saída do heterocíclico é a etapa limitante da reação. Este tipo de comportamento é típico de enzimas, uma vez que exibem uma menor afinidade com os produtos em relação aos reagentes da reação que catalisam, e que a saída dos mesmos libera seus sítios 
prostéticos para que a reação prossiga. Os cucurbitandos são ambientes ideais quando se pensa em alta regiosseletividade. Poucas reações têm sido investigadas na literatura utilizando este tipo de receptor sintético desde os anos 80 , mas certamente há muito o que ser descoberto ainda neste campo ${ }^{74}$.
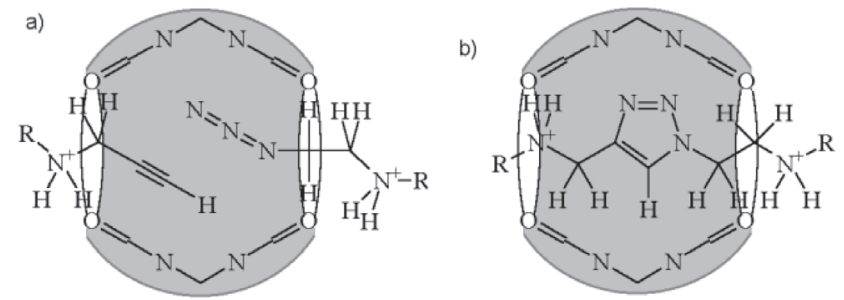

Figura 3. Esquema de formação de triazóis dentro das cavidades da CB[6]. Adaptado da ref. 73

\section{Rotaxanos, pseudo-rotaxanos, rolamentos e chaveadores moleculares}

Utilizando poliaminas lineares é possível criar rotaxanos bi- e poliestáveis, isto é, moléculas que podem adotar duas ou mais configurações espaciais. Mock $^{75}$ e seu grupo mostraram, pela primeira vez em 1990, que era possível sintetizar compostos deste tipo, capazes de interconverter-se em uma forma ou outra, simplesmente alterando o $\mathrm{pH}$ do meio. Utilizando triaminas lineares e assimétricas (Figura 4) é possível protonar os grupos amina seletivamente, contando com as diferenças de $\mathrm{pK}$ existentes entres os diferentes íons de amônio da molécula. Por conta de sua afinidade por cátions e das dimensões ideais da triamina, o cucurbitando no qual ela está inserida desloca-se de um grupo para o outro, reversivelmente. Este é um chaveador molecular bastante simples, mas que deu origem a diversos outros, como os chaveadores contendo fluoróforos, que permitem a leitura de seus estados lógicos, que podem ser revertidos por controle de $\mathrm{pH}$ ou ação da temperatura. Estes são chamados de "molecular shuttles" que são como vagões moleculares percorrendo um trilho, no caso o eixo do hóspede ${ }^{75,76}$.

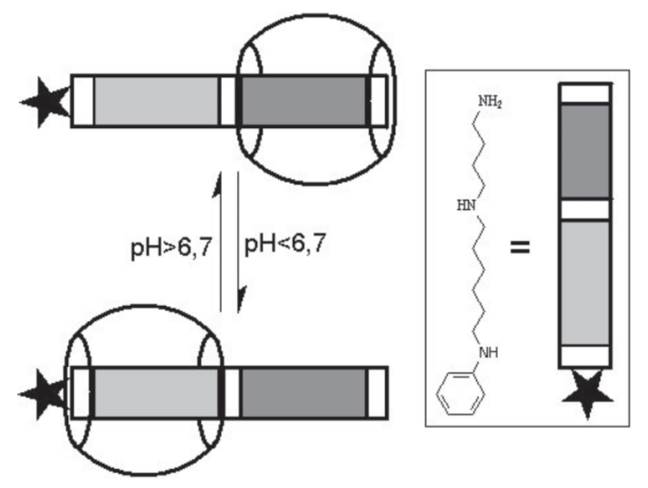

Figura 4. Funcionamento de um chaveador molecular biestável a partir de um pseudo-rotaxano assimétrico. Adaptado da ref. 75

Os rotaxanos são compostos que oferecem analogia a sistemas mecânicos constituídos por um ou mais anéis capazes de percorrer, por translação, um eixo linear em determinadas condições do meio em que se encontram. Compostos deste tipo também são importantes para o planejamento de nanomáquinas mecânicas e são um dos principais interesses da química supramolecular atual. É possível sintetizar, graças à estrutura peculiar dos cucurbitandos, uma grande série de rotaxanos, com moléculas lineares cujas di- mensões ultrapassem a profundidade destes cavitandos $(9,1 \AA$ A-Figura 5a). Inicialmente tratam-se de pseudo-rotaxanos ${ }^{77}$ (Figura 5b), pois não existe nenhum grupo volumoso o suficiente nas pontas desta molécula linear que a impeça de sair de dentro da cavidade (caso contrário, nem sequer seria formado). Após a formação destes pseudo-rotaxanos é possível ligar tais grupos, criando travas nestes eixos, tornando estáveis estas estruturas supramoleculares (Figuras 5c, d). A maioria dos métodos de síntese são essencialmente variantes deste ${ }^{65,78-81}$.
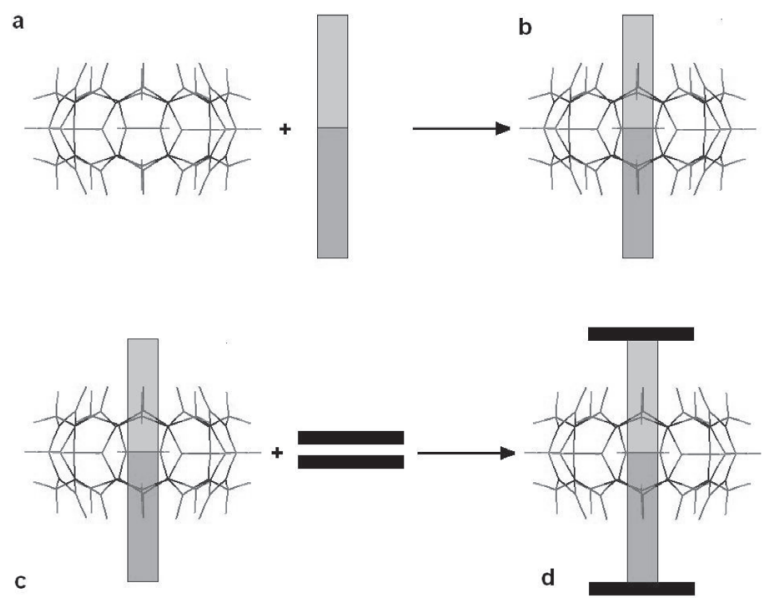

Figura 5. Representação esquemática do procedimento de síntese de pseudorotaxanos ( $b$ e c c) e rotaxanos (d) com cucurbitandos

A partir daí é possível criar estruturas maiores, como poli$\operatorname{rotaxanos}^{82-84}$ e polipseudorotaxanos ${ }^{85}$ ou até catenanos, dependendo da natureza dos grupos bloqueadores terminais, do procedimento de síntese e da natureza de seus eixos. Geralmente procede-se, com o $\mathrm{CB}[6]$, a cicloadições dipolares com grupos dinitrofenila e à formação de amidas, entre outras, para criar grupo bloqueantes em pseudo-rotaxanos. Alguns grupos bloqueadores são complexos metálicos, que são ligados aos eixos dos rotaxanos, quando estes possuem pontos de coordenação ${ }^{86-94}$. É possível criar estruturas do tipo colar de pérolas ${ }^{95-97}$, montando polirotaxanos a partir de oligômeros de poliacrilamidas e poliestirenos, além de estruturas tridimensionais como dendrímeros ${ }^{83,98,99}$. Pelo seu tamanho menor, os $\mathrm{CB}[5]$ e $\mathrm{CB}[6]$ são os mais utilizados para este propósito, uma vez que os grupos bloqueadores podem ser menores do que seriam com anéis mais largos sendo, portanto, mais facilmente sintetiza$\operatorname{dos}^{65}$. Os rotaxanos têm encontrado um grande número de aplicações em potencial, podem agir como âncoras em $\mathrm{ADN}^{100}$, mediadores de reações enzimáticas com o $\mathrm{ADN}^{101}$, carreadores de genes ${ }^{102}$, nanomáquinas e diversas outras ${ }^{103}$.

Em 2004, Geckeler e Constabel elaboraram uma metodologia para a inclusão de fulereno $\mathrm{C}_{60}$ dentro da cavidade de $\mathrm{CB}$ [7] com rendimentos superiores a $70 \%$. Este procedimento é realizado em moinhos ultra-rápidos, no estado sólido ${ }^{104,105}$. A molécula hóspede deste tipo de composto, assim como os caviplexos de Day (CB[5]@CB[10]), pode girar livremente no interior do hospedeiro como se fosse um rolamento ${ }^{8}$, mostrando que é possível se obter um sistema molecular análogo a uma articulação femural. Este tipo de mecanismo, e o do tipo dos rotaxanos, é muito importante quando se pensa no desenvolvimento de máquinas moleculares, capazes de realizar movimentos em determinadas condições. Estruturas similares, desta vez com $o$-carborano foram obtidas com $\mathrm{CB}$ [7] por Blanch e colaboradores quando tentavam desenvolver uma metodologia de síntese por template ${ }^{106}$. 


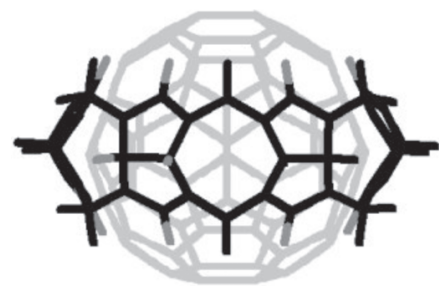

Figura 6. Representação esquemática do C60@CB[7]: um rolamento molecular. Adaptada da ref. 104

\section{Processos de automontagem envolvendo cucurbiturilas}

Não é raro se encontrar processos de automontagem na literatura das cucurbiturilas, uma vez que são facilitados por suas simetrias do tipo $D_{n h}$, o que simplifica muito a sua organização em retículos mono, bi e tridimensionais ${ }^{107-109}$. Uma prova disto é a extensa lista de adutos poliméricos obtidos por Fedin e seus colaboradores ${ }^{110-114}$. O que governa a formação destes retículos em suma, é a simetria das moléculas ponte ou dos hóspedes e os ambientes de coordenação dos ácidos de Lewis na formação de complexos e adutos.

Cucurbitandos foram recentemente imobilizados na superfície de vesículas por um processo de automontagem, por Kim e colaboradores, que demonstra a possibilidade de modificação não covalente da superfície das vesículas utilizando análogos de espermina ${ }^{115}$. CB[6] e CB[5] foram utilizados também como ionóforos em membranas de vesículas pelo mesmo grupo e apresentaram permeabilidade seletiva para $\mathrm{H}^{+}$e $\mathrm{K}^{+}$, formando assim estruturas automontadas biomiméticas ${ }^{116-118}$.

O grupo de Kim desenvolveu uma metodologia de modificação de superfícies de eletrodos utilizando pseudo-rotaxanos de $\mathrm{CB}[6]$ com diamino butano funcionalizado com grupos 1,2ditiolanos terminais em uma de suas extremidades ${ }^{119,120}$. Estes pseudo-rotaxanos, devido à presença de enxofre, conseguem adsorver fortemente em superfícies de ouro, formando monocamadas altamente organizadas, cobrindo praticamente toda a superfície do metal. Estas monocamadas, por preencherem a totalidade da superfície do eletrodo, são bloqueadoras de íons evitando, por exemplo, a redução e oxidação de sondas redox reversíveis grandes, como o $\left[\mathrm{Fe}(\mathrm{CN})_{6}\right]^{3-} \mathrm{em} \mathrm{pH}=5$. Um aumento do $\mathrm{pH}$, no entanto, desprotona os íons amônio, tornando os cucurbitandos lábeis e desestabilizando os pseudo-rotaxanos imobilizados, que acabam se desmontando. Após a saída destas moléculas volumosas, parte da superfície do eletrodo acaba sendo exposta, tornando possível a reação redox. Um tratamento posterior com ácido tióctico, com o intuito de preencher as lacunas deixadas na monocamada, acaba liquidando o processo eletroquímico, provando mais uma vez que este ocorre nas regiões intersticiais da monocamada. O processo de montagem e desmontagem dos pseudo-rotaxanos imobilizados é reversível, o que pode ser comprovado por ressonância de plasmons de superfície e, conseqüentemente, também o é o controle da reação eletroquímica. Desta forma, obtém-se uma pequena máquina molecular, capaz de bloquear e desbloquear mecanicamente o acesso de espécies à superfície de metais.

Compostos supramoleculares automontados para carreamento de genes também têm sido objeto de estudo do mesmo grupo, utilizando $\mathrm{CB}[6]$, dendrímeros e $\mathrm{ADN}^{102}$. Utilizando rotaxanos, Nolte e seu grupo vêm desenvolvendo helicatos e polirotaxanos cíclicos usando piridinas terminais no eixo dos rotaxanos e metais de transição, como prata e platina, dando origem a uma série de estruturas automontadas complexas ${ }^{86}$.

Outra vertente dos materiais automontados explora a formação
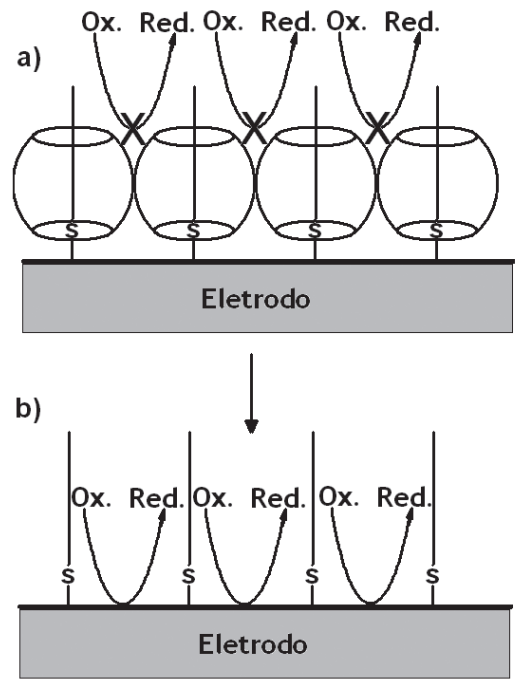

Figura 7. Formação de filmes automontados com pseudo-rotaxanos na superfície de eletrodos de ouro. Adaptada da ref. 119

de complexos de transferência de carga entre doadores e aceptores de elétrons. Uma série de sistemas envolvendo este tipo de interação foi desenvolvido por Lee e $\mathrm{Kim}^{121}$. Em um dos primeiros trabalhos envolvendo estes complexos foi explorada a formação de complexos de TC intramoleculares dentro de uma só cavidade de $\mathrm{CB}$ [8], como mostra a Figura 8. Apesar de um tanto difícil de se conceber, foi comprovada a estrutura de um caviplexo contendo ambas espécies (D e A), formando um complexos de TC e dobrando a cadeia da díade" original. A utilização de um aceptor (A2) com afinidades maiores pelo doador (D) é capaz de desmembrar esta estrutura, formando um outro par D-A2, sempre dentro do cavitando. Tem-se aqui um outro tipo de sistema que pode apresentar diversas conformações, e ambas são detectáveis, uma vez que os espectros de absorção dos dois complexos de TC (D-A e D-A2) são distintos. Eis outro tipo de chaveamento molecular ${ }^{45,66,108,117,122,123}$.
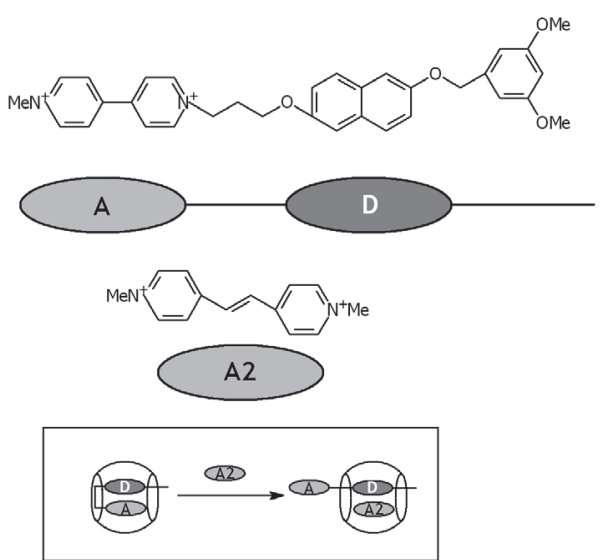

Figura 8. Formação de complexos de transferência de carga dentro de CB[8]. Adaptado da ref. 66

\section{Processos fotoquímicos confinados}

As cavidades dos cucurbitandos oferecem a oportunidade de se estudar reações fotoquímicas e as propriedades fotofísicas de fluoróforos em meio confinado. A polaridade das cavidades em que se encontram os hóspedes e a rigidez rotacional e vibracional, que lhes é imposta na inclusão, geram microambientes bem particulares 
para o estudo de estados excitados ${ }^{124}$. O que se observa de maneira geral, para uma grande série de hóspedes fotoativos, são aumentos de rendimentos quânticos e de tempos de vida dos estados excitados. A inclusão de anilinonaftaleno-sulfonatos em CB[6], por exemplo, intensifica a sua fluorescência em até 5 vezes $^{124-126}$. Mudanças similares são observadas para moléculas como a rodamina 6G, rodamina 123 , tetrametilrodamina, violeta de cresila, fluoresceína, cumarina 102, pirronina $\mathrm{B}$, pirronina $\mathrm{Y}$, derivados de cianinas 3 e 5 , IR140 e IR14 em meio aquoso incluídos em $\mathrm{CB}[7]^{127}$. Este fato é facilmente compreensível, uma vez que a rigidez dos caviplexos diminui a eficiência dos mecanismos de desativação vibracionais, além de dificultar o acesso aos cromóforos envolvidos nas transições de moléculas supressoras, como solventes ou oxigênio. Nos casos em que os cromóforos são passíveis de fotodegradação, a inclusão lhes garante uma estabilidade fora do comum, pelo mesmo motivo mencionado anteriormente ${ }^{127,128}$. Outro mecanismo importante que altera as propriedades espectroscópicas dos hóspedes é a alta densidade eletrônica das carbonilas, que é capaz de perturbar toda a estrutura eletrônica do cromóforo, principalmente se o hóspede é incluído apenas parcialmente no cucurbitando. Este tipo de estudo já tem sido realizado com outros hospedeiros de inclusão, como as ciclodextrinas ou ainda os calixarenos ${ }^{129-131}$, mas por serem melhores hospedeiros que as ciclodextrinas e calixarenos e por apresentarem cavidades mais regulares que as destes compostos, obtêm-se melhoras mais significativas com os cucurbitandos. Muitos trabalhos ilustram estes fatores, como é o caso da curcumina e as 1 e 2anilinonaftaleno-6-sulfonatos em CBn estudadas por Wagner e colaboradores ${ }^{132}$, além de outros fluoróforos ${ }^{55,126,130,133,134}$. Utilizando esta propriedade, Nau et al. conseguiram aumentar significativamente a estabilidade do 2,3-diazabiciclo[2.2.2] oct-2-eno (DBO) frente a supressores externos, para aplicações em biofluoroensaios ${ }^{22,124,133,135}$.

Por poder acomodar mais de um hóspede, como mostrado anteriormente, não é raro observar a formação de complexos de transferência de carga dentro das cavidades, agregados por empilhamento $\pi^{66,108,122}$. Vários autores mostraram em diversas situações que a inserção de mais de um hóspede é possível ${ }^{74,123}$ e constitui uma boa oportunidade de se estudar reações fotoquímicas bimoleculares em microambiente, o que restringe os modos rotacionais dos fluoróforos grandes ${ }^{125}$. A inclusão de mais de uma molécula nestas condições é muito proveitosa para algumas reações fotoquímicas que se tornam estereosseletivas e são aceleradas, como é o caso da fotoreação [2+2] do diidrocloreto de (E)-diaminoestilbeno dentro de $\mathrm{CB}$ [8], estudada por Kim e seu grupo ${ }^{136,137}$ e do ácido trans-cinâmico, estudado por Ramamurthy et al. ${ }^{138}$.

A síntese de macrocíclicos análogos ao $\mathrm{CB}[6]$ contendo grupos ftalidrazida em suas paredes confere a estes novos hospedeiros propriedades fotofísicas interessantes, uma vez que estes passam a emitir luz e que esta emissão pode ser alterada pela presença de hóspedes, o que é típico de sistemas semióforos ${ }^{26}$.

Alguns fluoróforos apresentam atividade eletroquímica sendo passíveis de oxidação ou redução, alterando todo o seu comportamento fotofísico, como é o caso por exemplo dos viologênios. Kaifer demonstraram que é possível incluir metil viologênios e dimetil diazapirênios em $\mathrm{CB}[7]$, mantendo suas propriedades eletroquímicas ${ }^{47,139}$.

\section{Formação de complexos metálicos e adutos inorgânicos}

A estrutura dos cucurbitandos lembra, de certa forma, a de um éter coroa, ou melhor, a de dois éteres coroa sobrepostos, de forma que não é de se surpreender que se comportem como bases duras frente à coordenação com íons metálicos. Possuem uma grande afinidade por metais alcalinos e alcalino-terrosos, assim como por lantanídeos ${ }^{29,40,113,140-143}$. Os fatores que governam a complexação das $\mathrm{CB}[\mathrm{n}]$ com estes metais são principlamente estéricos, sendo observadas diferentes constantes globais de formação com cátions de diferentes raios. Os lantanídeos, da mesma forma, possuem constantes muito similares na formação de compostos do tipo $[\mathrm{ML}]^{\mathrm{n}+}$, o que se explica pela semelhança entre seus raios (Tabela 2). As reações de complexação com $\mathrm{CB}[6]$ em solução aquosa envolvem fatalmente o ligante protonado, pois caso contrário não seria solúvel, e podem depender do $\mathrm{pH}$. Os prótons dificultam a formação de complexos, mas mesmo assim é possível realizar as reações de complexação em soluções ácidas. Izatt, Buschmann e Zhang foram os pioneiros neste estudo obtendo os primeiros dados referentes à formação de complexos metálicos com cucurbitandos $29,40,140,144,145$.

Os complexos de cucurbitandos com metais formam compostos com estequiometrias variáveis, muitas vezes envolvendo moléculas de água e formando adutos freqüentemente poliméricos (Figura 9). Virovets, Gerasko e Fedin demonstraram por exemplo, que o estrôncio ${ }^{142}$ forma complexos do tipo $\left[\mathrm{M}_{4}\left\{\left(\mathrm{NO}_{3}\right) @ \mathrm{~L}\right\}\right]^{7+}$, enquanto que o $\mathrm{Rb}^{+}$forma complexos poliméricos colunares ${ }^{107,147}$ do tipo $\left[\mathrm{M}_{2}(\mathrm{~m}-\mathrm{OH})_{2}\left(\mathrm{H}_{2} \mathrm{O}\right)_{2} \mathrm{~L}\right]^{2+}$ onde $\mathrm{L}=\mathrm{CB}[6]$, diferentemente dos outros metais alcalinos que formam complexos do tipo $\left[\mathrm{M}_{2} \mathrm{~L}\right]^{2+}$, como é o caso do $\mathrm{Cs}^{+}$com $\mathrm{CB}[8]^{67}$.

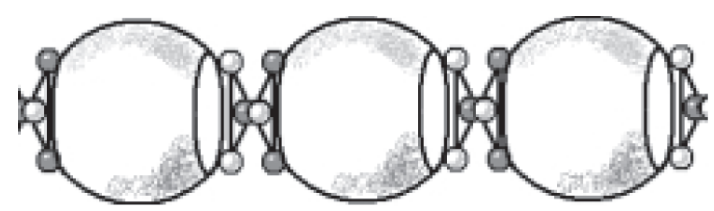

Figura 9. Representação estilizada de um aduto polimérico de $C B[6]$ e

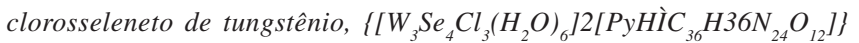
$\mathrm{Cl}_{3} \cdot 18 \mathrm{H}_{2} \mathrm{O}$

Fedin, Sokolov e outros autores têm estudado também a formação de materiais moleculares híbridos, formando policomplexos e adutos do cavitando com diversos íons e moléculas contendo metais, como por ex., sulfeto e seleneto de tungstênio ${ }^{148}$, índio ${ }^{112} \mathrm{e}$ tungstênio ${ }^{150,151}$, cloreto de uranila ${ }^{150-152}$, molibdatos ${ }^{110,149,153-159}, \mathrm{Sm}$ IIII $^{160}$, Tório (IV) ${ }^{161}, \mathrm{Zr}$ (IV) e Hf (IV) ${ }^{162}, \mathrm{Cr}$ (III) e Ni (II) ${ }^{110,159,163}$ entre outros ${ }^{111,114,164-169}$. A maioria destes compostos com estruturas mais complicadas têm sido obtidos por co-cristalização, permitindo assim a formação de adutos poliméricos e, freqüentemente os trabalhos limitam-se à síntese e caracterização cristalográfica destes compostos. Pouco tem sido feito no sentido de explorar as propriedades físico-químicas destes complexos, explorando por exemplo o seu potencial em catálise ou elementos de síntese de organometálicos. Foram relados na literatura alguns complexos de CBs com metais de transição $d$, mas ainda assim de maneira muito incipiente. Buschmann, Kim e Schollmeyer demonstraram a formação de complexos estáveis de CBs com lantanídeos, alcalinos e alcalino-terrosos $29,40,107,140,141,143,144 ; 170,171$ juntamente com Izatt, que estudou a formação de complexos de decametil-CB[5] com chumbo e alcalinos ${ }^{145}$. Outros complexos com Bi III ${ }^{169}$ e Cu II ${ }^{109}$ e compostos de inclusão com ferrocenos e cobaltocenos ${ }^{172}$, metal-ciclen e metal-ciclam ${ }^{173}$ além de outras espécies inorgânicas também foram obtidos, mostrando que é possível inserir e sintetizar complexos dentro das cavidades dos cucurbitandos ${ }^{174}$.

\section{Os cucurbitandos em remediação ambiental e em química analítica}

A habilidade de formarem compostos de inclusão pouco solúveis, torna os $\mathrm{CB}[\mathrm{n}]$ bons candidatos a agentes seqüestrantes de poluentes 
em efluentes, por exemplo. Krasher e colaboradores assim como Taketsuji e seu grupo vêm estudando recentemente a remoção de corantes e metais perniciosos como íons cromato e dicromato, compostos aromáticos e corantes usuais da indústria têxtil ${ }^{175-179}$. Desenvolveram também um estudo sobre as condições ideais de tratamento, verificando a influência de parâmetros como $\mathrm{pH}$, presença de tensoativos e temperatura, na extração destes compostos. Feng e seu grupo também desenvolveram uma metodologia de fixação de CBs em resinas poliméricas para a confecção de colunas cromatográficas com aplicações em química analítica ${ }^{28}$. Outras metodologias foram desenvolvidas com fins analíticos e para a purificação de compostos, dentre os quais os próprios cucurbitandos ${ }^{39,180,181}$.

\section{CONSIDERAÇÕES FINAIS}

As cucurbiturilas são moléculas com propriedades extremamente úteis em diversas áreas, como catálise, fotoquímica, síntese orgânica e inorgânica, materiais e química supramolecular, e são ainda muito pouco estudadas. Esta família de compostos oferece uma química extremamente rica, como é o caso de outros cavitandos como hemicarcerandos, ciclodextrinas e calixarenos entre outros, e há de desempenhar um papel cada vez maior na química de materiais moleculares automontados e de compostos supramoleculares, como vem mostrando a literatura. Apesar de seus 100 anos, só agora estão sendo investigados e o grande impulso na química dos cucurbitandos foi dado recentemente, há menos de 10 , com a descoberta de análogos, com tamanhos de anel maiores. A evolução do número de publicações por ano sobre o tema deixa clara esta tendência, passando de 1 em 1994 para 20 em 2000 e para mais de 70 em 2005, segundo o ISI.

Os países que mais se destacam na investigação destes compostos são a Coréia do Sul, China, Alemanha e Rússia. No Brasil temos investigado a química dos cucurbitandos em materiais moleculares, filmes, complexos metálicos e sistemas para liberação sustentada de moléculas bioativas, além de aplicações voltadas para a eletroquímica e dispositivos moleculares. Muitos artigos em idioma chinês e russo não puderam ser citados neste trabalho por estarem inacessíveis.

\section{AGRADECIMENTOS}

Ao CNPq pelo apoio financeiro. Proc. num. 55.524/2005-8, 400618/2004-4 FVA 01/2003, RENAMI, IMMC, FAPESP proc. num. 2005/02042-6 e à Comunidade Européia, Rede Alfa-MEDIS. Aos Profs. K. Araki pela ref. 179 e Dr. J. Tronto pela ref. 10.

\section{REFERÊNCIAS}

1. Behrend, R.; Meyer, E.; Rushe, F.; J. Liebigs Ann.Chem. 1905, 339, 1.

2. Freeman, W. A.; Mock, W. L.; Shih, N. Y.; J. Am.Chem.Soc. 1981, 103, 7367.

3. Kim, J.; Jung, I. S.; Kim, S. Y.; Lee, E.; Kang, J. K.; Sakamoto, S.; Yamaguchi, K.; Kim, K.; J. Am. Chem. Soc. 2000, 122, 540.

4. Day, A.; Arnold, A. P.; Blanch, R. J.; Snushall, B.; J. Org.Chem. 2001, 66, 8094.

5. Day, A. I.; Blanch, R. J.; Coe, A.; Arnold, A. P.; J. Inclusion Phenom. Macrocyclic Chem. 2002, 43, 247.

6. Krakowiak, K. E.; Izatt, R. M.; Bradshaw, J. S.; J. Heterocycl.Chem. 2001, $38,1239$.

7. Miyahara, Y.; Goto, K.; Oka, M.; Inazu, T.; Angew. Chem., Int. Ed. 2004, $43,5019$.

8. Day, A. I.; Blanch, R. J.; Arnold, A. P.; Lorenzo, S.; Lewis, G. R.; Dance, I.; Angew. Chem., Int. Ed. 2001, 41, 275.

9. Oh, K. S.; Yoon, J.; Kim, K. S.; J. Phys. Chem. B 2001, 105, 9726.

10. Liu, S.; Zavalij, P. Y.; Isaacs, L.; J. Am. Chem. Soc. 2005, 127, 16798.

11. Lagona, J.; Mukhopadhyay, P.; Chakrabarti, S.; Isaacs, L.; Angew. Chem., Int. Ed. 2005, 44, 4844.

12. Mock, W. L.; Shih, N. Y.; J. Am. Chem. Soc. 1988, 110, 4706.
13. Germain, P.; Letoffe, J. M.; Merlin, M. P.; Buschmann, H. J.; Thermochim. Acta 1998, 315, 87.

14. Jansen, K.; Buschmann, H. J.; Wego, A.; Dopp, D.; Mayer, C.; Drexler, H. J.; Holdt, H. J.; Schollmeyer, E.; J. Inclusion Phenom. Macrocyclic Chem. 2001, 39, 357.

15. Pichierri, F.; Chem. Phys. Lett. 2004, 390, 214.

16. Burnett, C. A.; Witt, D.; Fettinger, J. C.; Isaacs, L.; J. Org. Chem. 2003, $68,6184$.

17. Burnett, C. A.; Lagona, J.; Wu, A. X.; Shaw, J. A.; Coady, D.; Fettinger, J. C.; Day, A. I.; Isaacs, L.; Tetrahedron 2003, 59, 1961.

18. Buschmann, H. J.; Cleve, E.; Schollmeyer, E.; Inorg. Chem. Commun. 2005, 8, 125.

19. Chakraborty, A.; Xu, A. X.; Witt, D.; Lagona, J.; Fettinger, J. C.; Isaacs, L.; J. Am. Chem. Soc. 2002, 124, 8297.

20. Day, A. I.; Arnold, A. P.; Blanch, R. J.; Molecules 2003, 8, 74.

21. Flinn, A.; Hough, G. C.; Stoddart, J. F.; Williams, D. J.; Angew. Chem., Int. Ed. 1992, 31, 1475.

22. Jon, S. Y.; Selvapalam, N.; Oh, D. H.; Kang, J. K.; Kim, S. Y.; Jeon, Y. J.; Lee, J. W.; Kim, K.; J. Am. Chem. Soc. 2003, 125, 10186.

23. Lagona, J.; Fettinger, J. C.; Isaacs, L.; Org.Lett. 2003, 5, 3745.

24. Lee, J. W.; Samal, S.; Selvapalam, N.; Kim, H. J.; Kim, K.; Acc. Chem. Res. 2003, 36, 621

25. Liu, S. M.; Wu, X. J.; Zhang, S. W.; Yao, J. H.; Liang, F.; Wu, C. T.; New J. Chem. 2004, 28, 562.

26. Wagner, B. D.; Boland, P. G.; Lagona, J.; Isaacs, L.; J. Phys. Chem. B 2005, $109,7686$.

27. Zhao, J. Z.; Kim, H. J.; Oh, J.; Kim, S. Y.; Lee, J. W.; Sakamoto, S.; Yamaguchi, K.; Kim, K.; Angew. Chem., Int. Ed. 2001, 40, 4233.

28. Liu, S. M.; Xu, L.; Wu, C. T.; Feng, Y. Q.; Talanta 2004, 64, 929.

29. Buschmann, H. J.; Cleve, E.; Schollmeyer, E.; Inorg. Chim. Acta 1992, 193, 93.

30. Buschmann, H. J.; Cleve, E.; Jansen, K.; Wego, A.; Schollmeyer, E.; Mater. Sci. Eng., C 2001, 14, 35.

31. El Haouaj, M.; Ko, Y. H.; Luhmer, M.; Kim, K.; Bartik, K.; J. Chem. Soc., Perkin Trans. 2 2001, 2104.

32. El Haouaj, M.; Luhmer, M.; Ko, Y. H.; Kim, K.; Bartik, K.; J. Chem. Soc., Perkin Trans. 2 2001, 804.

33. Bernal, I.; Mukhopadhyay, U.; Virovets, A. V.; Fedin, V. P.; Clegg, W.; Chem. Commun. 2005, 3791.

34. Mock, W. L.; Shih, N. Y.; J. Am. Chem. Soc. 1989, 111, 2697.

35. Mock, W. L.; Top. Curr. Chem. 1995, 175, 1.

36. Mock, W. L. Em Comprehensive Supramolecular Chemistry; Vögtle, F., ed.; Elsevier: New-York, 1996, p. 477-493.

37. Mock, W. L.; Shih, N. Y.; J. Org. Chem. 1983, 48, 3618.

38. Mock, W. L.; Shih, N. Y.; J. Org. Chem. 1986, 51, 4440.

39. Wei, F.; Liu, S. M.; Xu, L.; Cheng, G. Z.; Wu, C. T.; Feng, Y. Q.; Electrophoresis 2005, 26, 2214.

40. Hoffmann, R.; Knoche, W.; Fenn, C.; Buschmann, H. J.; J. Chem. Soc., Faraday Trans 1994, 90, 1507.

41. Neugebauer, R.; Knoche, W.; J. Chem. Soc., Perkin Trans. 2 1998, 529.

42. Fu, H. Y.; Xue, S. F.; Zhu, Q. J.; Tao, Z.; Zhang, J. X.; Day, A.; J. Inclusion Phenom. Macrocyclic Chem. 2005, 52, 101.

43. Samsonenko, D. G.; Virovets, A. V.; Lipkowski, J.; Geras'ko, O. A.; Fedin, V. P.; J. Struct. Chem. 2002, 43, 664.

44. Sindelar, V.; Moon, K.; Kaifer, A. E.; Org. Lett. 2004, 6, 2665.

45. Jeon, W. S.; Kim, E.; Ko, Y. H.; Hwang, I. H.; Lee, J. W.; Kim, S. Y.; Kim, H. J.; Kim, K.; Angew. Chem., Int. Ed. 2005, 44, 87.

46. Kim, H. J.; Jeon, W. S.; Ko, Y. H.; Kim, K.; PNAS 2002, 99, 5007.

47. Moon, K.; Kaifer, A. E.; Org. Lett. 2004, 6, 185.

48. Ong, W.; Gomez-Kaifer, M.; Kaifer, A. E.; Org. Lett. 2002, 4, 1791.

49. Ong, W.; Kaifer, A. E.; J .Org. Chem. 2004, 69, 1383.

50. Buschmann, H. J.; Jansen, K.; Schollmeyer, E.; Thermochim. Acta 1998 , $317,95$.

51. Buschmann, H. J.; Mutihac, L.; Jansen, K.; Schollmeyer, E.; J. Inclusion Phenom. Macrocyclic Chem. 2005, 53, 281.

52. Buschmann, H. J.; Mutihac, L.; Mutihac, R. C.; Schollmeyer, E.; Thermochim. Acta 2005, 430, 79.

53. Buschmann, H. J.; Jansen, K.; Schollmeyer, E.; Thermochim. Acta 2000, $346,33$.

54. Buschmann, H. J.; Wego, A.; Jansen, K.; Schollmeyer, E.; Dopp, D.; J. Inclusion Phenom. Macrocyclic Chem. 2005, 53, 183.

55. Buschmann, H. J.; Jansen, K.; Schollmeyer, E.; J. Inclusion Phenom. Macrocyclic. Chem. 2000, 37, 231.

56. Dantz, D. A.; Meschke, C.; Buschmann, H. J.; Schollmeyer, E.; Supramol. Chem 1998, 9, 79

57. Kellersberger, K. A.; Anderson, J. D.; Ward, S. M.; Krakowiak, K. E.; Dearden, D. V.; J. Am. Chem. Soc. 2001, 123, 11316 
58. Miyahara, Y.; Abe, K.; Inazu, T.; Angew. Chem., Int. Ed. 2002, 41, 3020.

59. Buschmann, H. J.; Schollmeyer, E.; J. Inclusion Phenom. Mol. Recognit. Chem. 1992, 14, 91

60. Buschmann, H. J.; Schollmeyer, E.; J. Inclusion Phenom. Mol. Recognit. Chem. 1997, 29, 167

61. Jeon, Y. J.; Kim, S. Y.; Ko, Y. H.; Sakamoto, S.; Yamaguchi, K.; Kim, K. Org. Biomol. Chem. 2005, 3, 2122.

62. Wheate, N. J.; Day, A. I.; Blanch, R. J.; Arnold, A. P.; Cullinane, C.; Collins, J. G.; Chem. Commun. 2004, 1424.

63. Buschmann, H. J.; Mutihac, L.; Jansen, K.; J. Inclusion Phenom. Macrocyclic Chem. 2001, 39, 1.

64. Meschke, C.; Buschmann, H. J.; Schollmeyer, E.; Thermochim. Acta 1997, 297, 43.

65. Jansen, K.; Buschmann, H. J.; Zliobaite, E.; Schollmeyer, E.; Thermochim. Acta 2002, 385, 177.

66. Lee, J. W.; Kim, K.; Choi, S.; Ko, Y. H.; Sakamoto, S.; Yamaguchi, K.; Kim, K.; Chem. Commun. 2002, 2692.

67. Whang, D.; Heo, J.; Park, J. H.; Kim, K.; Angew. Chem., Int. Ed. 1998, 37,78 .

68. Jeon, Y. M.; Kim, H.; Whang, D.; Kim, K.; J. Am. Chem. Soc. 1996, 118, 9790.

69. Buschmann, H. J.; Schollmeyer, E.; Mutihac, L.; Thermochim. Acta 2003, 399, 203.

70. Marquez, C.; Nau, W. M.; Angew. Chem., Int. Ed. 2001, 40, 3155.

71. Marquez, C.; Hudgins, R. R.; Nau, W. M.; J. Am. Chem. Soc. 2004, 126, 5806.

72. Mock, W. L.; Irra, T. A.; Wepsiec, J. P.; Manimaran, T. L.; J. Org. Chem. 1983, 48, 3619.

73. Mock, W. L.; Irra, T. A.; Wepsiec, J. P.; Adhya, M.; J. Org. Chem. 1989, 54,5302 .

74. Krasia, T. C.; Steinke, J. H. G.; Chem. Commun. 2002, 22

75. Mock, W. L.; Pierpont, J.; Chem. Commun. 1990, 1509.

76. Lee, J. W.; Kim, K. P.; Kim, K.; Chem. Commun. 2001, 1042.

77. Zhang, H. Z.; Paulsen, E. S.; Walker, K. A.; Krakowiak, K. E.; Dearden, D. V.; J. Am. Chem. Soc. 2003, 125, 9284.

78. Buschmann, H. J.; Cleve, E.; Mutihac, L.; Schollmeyer, E.; Microchem. J. 2000, 64, 99.

79. Buschmann, H. J.; Mutihac, L.; Schollmeyer, E.; J. Inclusion Phenom. Macrocyclic Chem. 2005, 53, 85 .

80. Lee, J. W.; Choi, S.; Ko, Y. H.; Kim, S. Y.; Kim, K.; Bull. Korean Chem Soc. 2002, 23, 1347.

81. Tuncel, D.; Steinke, J. H. G.; Chem. Commun. 2002, 496.

82. Choi, S.; Lee, J. W.; Ko, Y. H.; Kim, K.; Macromolecules 2002, 35, 3526.

83. Lee, E.; Kim, J.; Heo, J.; Whang, D.; Kim, K.; Angew. Chem., Int. Ed. 2001, $40,399$.

84. Meschke, C.; Buschmann, H. J.; Schollmeyer, E.; Polymer 1999, 40, 945.

85. Tuncel, D.; Steinke, J. H. G.; Chem. Commun. 2001, 253.

86. Elemans, J. A. A. W.; Rowan, A. E.; Nolte, R. J. M.; Ind. Eng. Chem. Res. 2000, 39, 3419

87. Heo, J.; Kim, S. Y.; Roh, S. G.; Park, K. M.; Park, G. J.; Whang, D.; Kim, K.; Mol. Cryst. Liq. Cryst. 2000, 342, 29.

88. Lee, E. S.; Heo, J. S.; Kim, K.; Angew. Chem., Int. Ed. 2000, 39, 2699.

89. Park, K. M.; Roh, S. G.; Lee, E.; Kim, J.; Kim, H. J.; Lee, J. W.; Kim, K.; Supramol. Chem. 2002, 14, 153.

90. Park, K. M.; Whang, D.; Lee, E.; Heo, J.; Kim, K.; Chem. Eur. J. 2002, 8, 498.

91. Park, K. M.; Lee, E.; Roh, S. G.; Kim, J.; Kim, K.; Bull. Korean Chem. Soc. 2004, 25, 1711.

92. Whang, D.; Jeon, Y. M.; Heo, J.; Kim, K.; J. Am. Chem. Soc. 1996, 118, 11333 .

93. Whang, D.; Heo, J.; Kim, C. A.; Kim, K.; Chem. Commun. 1997, 2361.

94. Whang, D.; Kim, K.; J. Am. Chem. Soc. 1997, 119, 451.

95. Park, K. M.; Kim, S. Y.; Heo, J.; Whang, D.; Sakamoto, S.; Yamaguchi, K.; Kim, K.; J. Am. Chem. Soc. 2002, 124, 2140.

96. Roh, S. G.; Park, K. M.; Park, G. J.; Sakamoto, S.; Yamaguchi, K.; Kim, K.; Angew. Chem., Int. Ed. 1999, 38, 638.

97. Whang, D. M.; Park, K. M.; Heo, J.; Ashton, P.; Kim, K.; J. Am. Chem. Soc. 1998, 120, 4899 .

98. Lee, J. W.; Ko, Y. H.; Park, S. H.; Yamaguchi, K.; Kim, K.; Angew. Chem., Int. Ed. 2001, 40, 746

99. Ong, W.; Kaifer, A. E.; Angew. Chem., Int. Ed. 2003, 42, 2164

100. Isobe, H.; Tomita, N.; Lee, J. W.; Kim, H. J.; Kim, K.; Nakamura, E.; Angew. Chem., Int. Ed. 2000, 39, 4257.

101. Isobe, H.; Sato, S.; Lee, J. W.; Kim, H. J.; Kim, K.; Nakamura, E.; Chem. Commun. 2005, 1549 .

102. Lim, Y. B.; Kim, T.; Lee, J. W.; Kim, S. M.; Kim, H. J.; Kim, K.; Park, J. S.; Bioconjugate Chem. 2002, 13, 1181.
103. Jeon, W. S.; Ziganshina, A. Y.; Lee, J. W.; Ko, Y. H.; Kang, J. K.; Lee, C.; Kim, K.; Angew. Chem., Int. Ed. 2003, 42, 4097.

104. Constabel, F.; Geckeler, K. E.; Tetrahedron Lett. 2004, 45, 2071.

105. Constabel, F.; Geckeler, K. E.; Fullerenes, Nanotubes, Carbon Nanostruct. 2004, 12, 811.

106. Blanch, R. J.; Sleeman, A. J.; White, T. J.; Arnold, A. P.; Day, A. I.; Nano Lett. 2002, 2, 147

107. Heo, J.; Kim, S. Y.; Whang, D.; Kim, K.; Angew. Chem., Int. Ed. 1999, 38,641 .

108. Ko, Y. H.; Kim, K.; Kang, J. K.; Chun, H.; Lee, J. W.; Sakamoto, S.; Yamaguchi, K.; Fettinger, J. C.; Kim, K.; J. Am. Chem. Soc. 2004, 126, 1932.

109. Zhang, F.; Yajima, T.; Li, Y. Z.; Xu, G. Z.; Chen, H. L.; Liu, Q. T.; Yamauchi, O.; Angew. Chem. Int. Ed. 2005, 44, 3402.

110. Fedin, V. P.; Sokolov, M.; Lamprecht, G. J.; Hernandez-Molina, R.; Seo, M. S.; Virovets, A. V.; Clegg, W.; Sykes, A. G.; Inorg. Chem. 2001, 40, 6598.

111. Fedin, V. P.; Russ. J. Coord. Chem. 2004, 30, 151

112. Sokolov, M. N.; Dybtsev, D. N.; Virovets, A. V.; Clegg, F.; Fedin, V. P.; Russ. Chem. Bull. 2001, 50, 1144.

113. Tripolskaya, A. A.; Gerasko, O. A.; Naumov, D. Y.; Lipkowski, J.; Logvinenko, V. A.; Fedin, V. P.; J. Struct. Chem. 2004, 45, 269.

114. Virovets, A. V.; Samsonenko, D. G.; Dybtsev, D. N.; Fedin, V. P.; Clegg, W.; J. Struct. Chem. 2001, 42, 319.

115. Lee, H. K.; Park, K. M.; Jeon, Y. J.; Kim, D.; Oh, D. H.; Kim, H. S.; Park C. K.; Kim, K.; J. Am. Chem. Soc. 2005, 127, 5006

116. Braha, O.; Webb, J.; Gu, L. Q.; Kim, K.; Bayley, H.; ChemPhysChem 2005 $6,889$.

117. Jeon, Y. J.; Bharadwaj, P. K.; Choi, S. W.; Lee, J. W.; Kim, K.; Angew. Chem., Int. Ed. 2002, 41, 4474.

118. Jeon, Y. J.; Kim, H.; Jon, S.; Selvapalam, N.; Oh, D. H.; Seo, I.; Park, C. S.; Jung, S. R.; Koh, D. S.; Kim, K.; J. Am. Chem. Soc. 2004, 126, 15944.

119. Kim, K.; Jeon, W. S.; Kang, J. K.; Lee, J. W.; Jon, S. Y.; Kim, T.; Kim, K.; Angew. Chem., Int. Ed. 2003, 42, 2293.

120. Kim, K.; Kim, D.; Lee, J. W.; Ko, Y. H.; Kim, K.; Chem. Commun. 2004, 848.

121. Kim, H. J.; Heo, J.; Jeon, W. S.; Lee, E.; Kim, J.; Sakamoto, S.; Yamaguchi, K.; Kim, K.; Angew. Chem., Int. Ed. 2001, 40, 1526.

122. Jeon, W. S.; Kim, H. J.; Lee, C.; Kim, K.; Chem. Commun. 2002, 1828.

123. Ziganshina, A. Y.; Ko, Y. H.; Jeon, W. S.; Kim, K.; Chem. Commun. 2004, 806.

124. Marquez, C.; Nau, W. M.; Angew. Chem., Int. Ed. 2001, 40, 4387.

125. Buschmann, H. J.; Wolff, T.; J. Photochem. Photobiol., A 1999, 121, 99.

126. Wagner, B. D.; Fitzpatrick, S. J.; Gill, M. A.; Macrae, A. I.; Stojanovic, N.; Can. J. Chem. 2001, 79, 1101.

127. Mohanty, J.; Nau, W. M.; Angew. Chem., Int. Ed. 2005, 44, 3750.

128. Nau, W. M.; Mohanty, J.; Int. J. Photoenergy 2005, 7, 133.

129. Bagatin, I. A.; Cruz, A. T.; Toma, H. E.; Politi, M. J.; Demets, G. J. F.; J. Inclusion Phenom. Macrocyclic Chem. 2005, 52, 189.

130. Baglole, K. N.; Boland, P. G.; Wagner, B. D.; J. Photochem. Photobiol., A $\mathbf{2 0 0 5}, 173,230$

131. Brochsztain, S.; Rodrigues, M. A.; Politi, M. J.; J. Photochem. Photobiol., A 1997, 107, 195.

132. Wagner, B. D.; Stojanovic, N.; Day, A. I.; Blanch, R. J.; J. Phys. Chem. B 2003, 107, 10741.

133. Mohanty, J.; Nau, W. M.; Photochem. Photobiol. Sci. 2004, 3, 1026.

134. Rankin, M. A.; Wagner, B. D.; Supramol. Chem. 2004, 16, 513.

135. Marquez, C.; Huang, F.; Nau, W. M.; IEEE Trans. Nanobiosci. 2004, 3, 39.

136. Choi, S.; Park, S. H.; Ziganshina, A. Y.; Ko, Y. H.; Lee, J. W.; Kim, K.; Chem. Commun. 2003, 2176.

137. Jon, S. Y.; Ko, Y. H.; Park, S. H.; Kim, H. J.; Kim, K.; Chem. Commun. 2001, 1938.

138. Pattabiraman, M.; Natarajan, A.; Kaanumalle, L. S.; Ramamurthy, V.; Org. Lett. 2005, 7, 529.

139. Sindelar, V.; Cejas, M. A.; Raymo, F. M.; Kaifer, A. E.; New J. Chem. 2005, 29, 280.

140. Buschmann, H. J.; Cleve, E.; Jansen, K.; Wego, A.; Schollmeyer, E. J. Inclusion Phenom. Macrocyclic Chem. 2001, 40, 117.

141. Buschmann, H. J.; Jansen, K.; Schollmeyer, E.; Inorg. Chem. Commun. 2003, 6, 531.

142. Gerasko, O. A.; Virovets, A. V.; Samsonenko, D. G.; Tripol'skaya, A. A.; Fedin, V. P.; Fenske, D.; Russ. Chem. Bull. 2003, 52, 585.

143. Samsonenko, D. G.; Lipkowski, J.; Gerasko, O. A.; Virovets, A. V.; Sokolov, M. N.; Fedin, V. P.; Platas, J. G.; Hernandez-Molina, R.; Mederos, A.; Eur J. Inorg. Chem. 2002, 2380.

144. Buschmann, H. J.; Cleve, E.; Jansen, K.; Schollmeyer, E.; Anal. Chim. Acta 2001, 437, 157. 
145. Zhang, X. X.; Krakowiak, K. E.; Xue, G. P.; Bradshaw, J. S.; Izatt, R. M.; Ind. Eng. Chem. Res. 2000, 39, 3516.

146. Izatt, R. M.; Bradshaw, J. S.; Nielsen, S. A.; Lamb, J. D.; Christensen, J. J.; Sen, D.; Chem. Rev. 1985, 85, 271.

147. Pichierri, F.; Chem. Phys. Lett. 2005, 403, 252

148. Gerasko, O. A.; Virovets, A. V.; Sokolov, M. N.; Dybtsev, D. N.; Gerasimenko, A. V.; Fenske, D.; Fedin, V. P.; Russ.Chem.Bull. 2002, 51, 1800

149. Fedin, V. P.; Sokolov, M. N.; Dybtsev, D. N.; Gerasko, O. A.; Virovets, A. V.; Fenske, D.; Inorg. Chim. Acta 2002, 331, 31

150. Hernandez-Molina, R.; Sokolov, M.; Esparza, P.; Vicent, C.; Llusar, R.; Dalton Trans. 2004, 847.

151. Sokolov, M. N.; Dybtsev, D. N.; Fedin, V. P.; Russ. Chem. Bull. 2003, 52, 1041.

152. Gerasko, O. A.; Samsonenko, D. G.; Sharonova, A. A.; Virovets, A. V.; Lipkowski, J.; Fedin, V. P.; Russ. Chem. Bull. 2002, 51, 346.

153. Chubarova, E. V.; Samsonenko, D. G.; Platas, J. H.; Sokolov, M. N.; Fedin, V. P.; J. Struct. Chem. 2004, 45, 906.

154. Dybtsev, D. N.; Geras'ko, O. A.; Virovets, A. V.; Sokolov, M. N.; Weber, T.; Fedin, V. P.; Russ. J. Inorg. Chem. 2001, 46, 806.

155. Fedin, V. P.; Virovets, A. V.; Sokolov, M. N.; Dybtsev, D. N.; Gerasko, O. A.; Clegg, W.; Inorg. Chem. 2000, 39, 2227.

156. Fedin, V. P.; Gramlich, V.; Worle, M.; Weber, T.; Inorg. Chem. 2001, 40, 1074 .

157. Samsonenko, D. G.; Virovets, A. V.; Sharonova, A. A.; Fedin, V. P.; Fenske, D.; Russ. Chem. Bull. 2001, 50, 494.

158. Sokolov, M. N.; Virovets, A. V.; Dybtsev, D. N.; Chubarova, E. V.; Fedin, V. P.; Fenske, D.; Inorg. Chem. 2001, 40, 4816.

159. Sokolov, M. N.; Hernandez-Molina, R.; Dybtsev, D. N.; Chubarova, E. V.; Solodovnikov, S. F.; Pervukhina, N. V.; Vicent, C.; Llusar, R.; Fedin, V.; Z. Anorg. Allg. Chem. 2002, 628, 2335.

160. Samsonenko, D. G.; Gerasko, O. A.; Lipkowski, J.; Virovets, A. V.; Fedin, V. P.; Russ. Chem. Bull. 2002, 51, 1915.

161. Samsonenko, D. G.; Sokolov, M. N.; Gerasko, O. A.; Virovets, A. V.; Lipkowski, J.; Fenske, D.; Fedin, V. P.; Russ. Chem. Bull. 2003, 52, 2132.

162. Mit'kina, T. V.; Gerasko, O. A.; Sokolov, M. N.; Naumov, D. Y.; Fedin, V. P.; Russ. Chem. Bull. 2004, 53, 80.
163. Samsonenko, D. G.; Geras'ko, O. A.; Mit'kina, T. V.; Lipkowski, J.; Virovets, A. V.; Fenske, D.; Fedin, V. P.; Russ. J. Coord. Chem. 2003, 29 , 166.

164. Chubarova, E. V.; Samsonenko, D. G.; Sokolov, M. N.; Gerasko, O. A.; Fedin, V. P.; Platas, J. G.; J. Inclusion Phenom. Macrocyclic Chem. 2004, $48,31$.

165. Dybtsev, D. N.; Gerasko, O. A.; Virovets, A. V.; Sokolov, M. N.; Fedin, V. P.; Inorg. Chem. Commun. 2000, 3, 345 .

166. Fedin, V. P.; Virovets, A. V.; Dybtsev, D. N.; Gerasko, O. A.; Hegetschweiler, K.; Elsegood, M. R. J.; Clegg, W.; Inorg. Chim. Acta 2000, $304,301$.

167. Samsonenko, D. G.; Sokolov, M. N.; Virovets, A. V.; Pervukhina, N. V.; Fedin, V. P.; Eur. J. Inorg. Chem. 2001, 167.

168. Sokolov, M. N.; Virovets, A. V.; Dybtsev, D. N.; Gerasko, O. A.; Fedin, V. P.; Hernandez-Molina, R.; Clegg, W.; Sykes, A. G.; Angew. Chem., Int. Ed. 2000, 39, 1659 .

169. Sokolov, M. N.; Mitkina, T. V.; Gerasko, O. A.; Fedin, V. P.; Virovets, A. V.; Llusar, R.; Z. Anorg. Allg. Chem. 2003, 629, 2440.

170. Buschmann, H. J.; Jansen, K.; Meschke, C.; Schollmeyer, E.; J. Solution Chem. 1998, 27, 135.

171. Heo, J.; Kim, J.; Whang, D.; Kim, K.; Inorg. Chim. Acta 2000, 297, 307.

172. Ong, W.; Kaifer, A. E.; Organometallics 2003, 22, 4181.

173. Kim, S. Y.; Jung, I. S.; Lee, E.; Kim, J.; Sakamoto, S.; Yamaguchi, K.; Kim, K.; Angew. Chem., Int. Ed. 2001, 40, 2119.

174. Mitkina, T. V.; Naumov, D. Y.; Gerasko, O. A.; Dolgushin, F. M.; Vicent, C.; Llusar, R.; Sokolov, M. N.; Fedin, V. P.; Russ. Chem. Bull. 2004, 53, 2519.

175. Karcher, S.; Kornmuller, A.; Jekel, M.; Water Sci. Technol. 1999, 40, 425.

176. Karcher, S.; Kornmuller, A.; Jekel, M.; Acta Hydrochim. Hydrobiol. 1999, 27, 38.

177. Karcher, S.; Kornmuller, A.; Jekel, M.; Water Res. 2001, 35, 3309.

178. Kornmuller, A.; Karcher, S.; Jekel, M.; Water Res. 2001, 35, 3317.

179. Taketsuji, K.; Tomioka, H.; Nippon Kagaku Kaishi 1998, 670.

180. Sasmal, S.; Sinha, M. K.; Keinan, E.; Org. Lett. 2004, 6, 1225.

181. Xu, L.; Liu, S. M.; Wu, C. T.; Feng, Y. Q.; Electrophoresis 2004, 25, 3300. 


\title{
Quantum Confinement in $\mathrm{PbI}_{2}$ Nanodisks Prepared with Cucurbit[7]uril
}

\author{
Erick M. S. dos Santos, Lourivaldo S. Pereira and Grégoire J.-F. Demets*
}

\author{
DQ-FFCLRP, Departamento de Química, Universidade de São Paulo, 14040-901 Ribeirão Preto-SP, Brazil
}

\begin{abstract}
Este trabalho apresenta uma rota alternativa para a preparação de nanodiscos de iodeto de

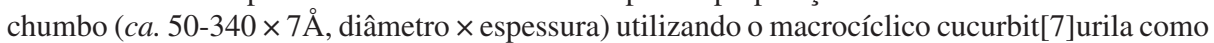
molde de síntese e agente estabilizante. Estas nanopartículas apresentam um deslocamento para o azul de gap óptico consistente com seu tamanho reduzido e confinamento quântico 1D. Suas espessuras são compatíveis com a de uma camada de iodeto de chumbo esfoliado, indicando que cucurbit[7]urila impede a formação de estruturas lamelares e limita o crescimento das nanopartículas. A estrutura, a morfologia e as propriedades destes discos foram verificadas por difratometria de raios X em pó (XRD), espectroscopia no UV-Visível, microscopia de força atômica (AFM), microscopia eletrônica de varredura com análise de fluorescência de raios X por dispersão de energia (SEM-EDS) e microscopia eletrônica de transmissão de alta resolução (HRTEM).
\end{abstract}

This work presents an alternative route for the preparation of heavy metal iodide nanoparticles, particularly lead iodide nanodisks ( $c a .50-340 \times 7 \AA$, diameter $\times$ thickness), using the macrocycle cucurbit[7]uril as a synthetic template and stabilizing agent. These nanoparticles exhibit an opticalgap blue shift consistent with their small size and 1D quantum confinement. Their thicknesses are compatible with an exfoliated single layer of lead iodide, indicating that cucurbit[7]uril, preventing the stacking and formation of tactoids, thus limiting nanoparticles growth in the $\mathrm{z}$ direction. The structure, morphology and properties of these disks were analyzed by X-ray powder diffractometry (XRD), UV-Visible spectroscopy, atomic force microscopy (AFM), scanning electron microscopy with analysis of energy dispersive X-ray fluorescence (SEM-EDS) and high resolution transmission electron microscopy (HRTEM).

Keywords: lead iodide, cucurbit[7]uril, synthetic template, nanodisks, quantum confinement

\section{Introduction}

Lead iodide is a lamellar solid consisting of layers of metal and iodide ions united by covalent bonds. Weak van der Waals interactions hold these layers together in a three dimensional sandwich-like semiconductor. This structure can be described as a hexagonal close-packed array of iodide anions with alternate layers of octahedral interstices occupied by lead(II) cations. Therefore, each layer can be described as a I-Pb-I sequence layer. ${ }^{1}$ Very interesting materials can be obtained by diminishing the $\mathrm{PbI}_{2}$ particle size to the nanoscale in order to favor the appearance of new properties resultant of quantum confinement, such as those observed in zero-dimensional solids, quantum dots and other N-dimensional, quantumconfined nanomaterials. Quantum dots encounter many applications in several technological fields such as sensor

*e-mail: greg@usp.br devices and anti-counterfeiting systems, illumination (as high efficiency white-light emitting diodes), medicine (as cellular markers), lasers, solar cells and others. ${ }^{2-5}$ Another important property of lead iodide is its ability to form intercalation compounds with many chemical species, such as hydrazine, ammonia, aniline, butylamine, pyperidine and quinoline, among others. ${ }^{1}$ The insertion of guest molecules in the interlamellar gap considerably affects the chemical and physical properties of the material.

Cucurbiturils $(\mathrm{CB}[\mathrm{n}])$ are pumpkin-shaped thoroidal molecules with two distal portals separated by $9.1 \AA$. They are produced by condensation of glycoluril and formaldehyde in acidic medium and were synthesized for the first time by Behrend et al. in 1905. ${ }^{6}$ However, their structure remained uncertain until the findings of Freeman et al., 75 years later. ${ }^{7}$ Since then, many improvements in cucurbituril synthesis, as well as in new homologue separation methods and in derivatives, have been developed by several research groups. ${ }^{8-11}$ 
The general reaction based on the condensation of glycoluril derivatives and formaldehyde leads to several homologues containing mainly 5, 6, 7 and 8 glycolurilic moieties ( $\mathrm{CB}[5], \mathrm{CB}[6], \mathrm{CB}[7]$ and $\mathrm{CB}[8]$, respectively). Among these, $\mathrm{CB}[7]$ is the only homologue with considerable solubility in water $\left(c a .30 \mathrm{mmol} \mathrm{L}^{-1}\right){ }^{12}$ The portals are composed by carbonyl groups and behave as Pearson's hard bases. Obviously, the portal sizes vary with the number of monomeric units, ranging from 2.4 to $6.9 \AA$ in the $\mathrm{CB}[5]-\mathrm{CB}[8]$ series. ${ }^{8,12,13}$ Cucurbituril cavities are hydrophobic and can accommodate many guest molecules in a series of inclusion compounds, just like cyclodextrins and calixarenes (see molecular structure in Figure 1). ${ }^{11}$
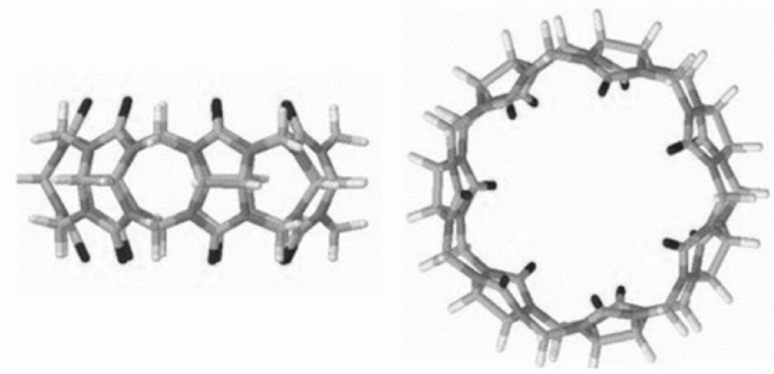

Figure 1. Representation of the chemical structure of cucurbit[7]uril.

Corma et al. ${ }^{14}$ have recently synthetized gold nanoparticles using CB cavities as templates, obtaining almost monodisperse particle populations, a very important aspect when one aims at absolute size control. The size control in this level is even more important during the production of quantum dots, since their physical and physicochemical properties are strongly size- and shapedependent. According to Pearson's HSAB concept, ${ }^{15} \mathrm{~Pb}^{2+}$ ions should exhibit low affinity for cucurbiturils. However, other scientists have reported high formation constants for $\mathrm{Pb}^{2+}$ and decamethylcucurbit[5] uril complexes, which is a slightly different, smaller homologue. ${ }^{16}$ There are very few works in the literature reporting on $\mathrm{CB}[\mathrm{n}]$-containing nanostructured materials, but few others encompassing gold, palladium and cadmium sulfide can be cited. ${ }^{17-19}$

In this context, we have studied the formation of colloidal lead iodide usingCB[7] acting as an external template, generating lead iodide particles with extremely reduced dimensions. We have observed the formation of randomly stacked discoid nanostructures with 1-D quantum confinement instead of small clusters.

\section{Experimental}

Cucurbit[7]uril (CB[7]) was prepared and purified as described in the literature. ${ }^{20}$ Lead iodide/CB[7] nanoparticles were prepared using $\mathrm{Pb}\left(\mathrm{NO}_{3}\right)_{2} 0.1 \mathrm{~mol} \mathrm{~L}^{-1}$ (Synth), KI (Synth) and cucurbit[7]uril $1 \times 10^{-3} \mathrm{~mol} \mathrm{~L}^{-1}$. The cucurbituril solution $(10 \mathrm{~mL})$ was kept under vigorous stirring at $27{ }^{\circ} \mathrm{C}$ and received the addition of $100 \mu \mathrm{L}$ of the $\mathrm{Pb}\left(\mathrm{NO}_{3}\right)_{2}$ solution, followed by $200 \mu \mathrm{L}$ of the KI solution. The molar ratio between the reactants $\mathrm{CB}[7] / \mathrm{Pb}^{2+} / \mathrm{I}^{-}$ was $1: 1: 2$, respectively. The resulting mixture immediately formed a pale greenish-yellow colloid with gel-like consistence in a reproducible way, quite different from the large golden yellow crystals obtained when no $\mathrm{CB}$ [7] is present in the solution. This colloidal suspension was unstable and precipitated after two days. The resulting solid had the same greenish-yellow color and was washed three times with water (in order to remove the excess of $\mathrm{KNO}_{3}$ ) and dried under vacuum. For comparison purposes, reference colloidal $\mathrm{PbI}_{2}$ (2H-polytype) was synthesized exactly in the same way, except for the addition of the macrocycle.

The powder X-ray diffraction (XRD) measurements were carried out on a Siemens 5005 equipment using $\mathrm{Cu} \mathrm{K}_{\alpha}$ radiation $(\lambda=1.54 \AA)$. The diffuse reflectance spectra were measured with an Ocean optics USB 4000 spectrometer at $77 \mathrm{~K}$ (the absorption intensities were not corrected for the powder size, which is relevant for using the Kubelka-Munk function). The luminescence experiments were registered at $77 \mathrm{~K}$ using a Fluorog SPEX F2121 spectrometer equipped with a $450 \mathrm{~W}$ Xe lamp, a cooled Hamamatsu R918 photomultiplier and double excitation and emission monochromators. The atomic force microscopy images were collected on a Shimadzu SPM-9600 scanning probe microscope (contact mode). The scanning electron microscopy and energy-dispersive $\mathrm{X}$-ray spectroscopy (EDS) measurements were carried out on a Zeiss EVO 50 microscope. The samples were covered with gold by sputtering. High resolution transmission electron microscopy (HRTEM) images were obtained with a TEM-JEM 2100 ARP electron microscope. TEM sample grids were prepared by placing $1 \mu \mathrm{L}$ of the particle suspension on a carbon-coated copper grid (300 meshes) and evaporating the solvent at room temperature.

\section{Results and Discussion}

Absorption spectra of both bulk and $\mathrm{CB}$-assisted $\mathrm{PbI}_{2}$ display typical semiconductor absorption profile, except for their typical absorption edge at $c a .3 \mathrm{eV}$, which is blue-shifted by $0.5 \mathrm{eV}(\mathrm{ca} .90 \mathrm{~nm})$ for the hybrid material (Figure 2). This band to band transition is frequently very close to the exciton band, since the binding energy is very small (see Supplementary Information, SI). CB[7] does not absorb in the UV-Visible region and does not contribute to the $\mathrm{PbI}_{2}$ spectrum. It is well known that small clusters of 


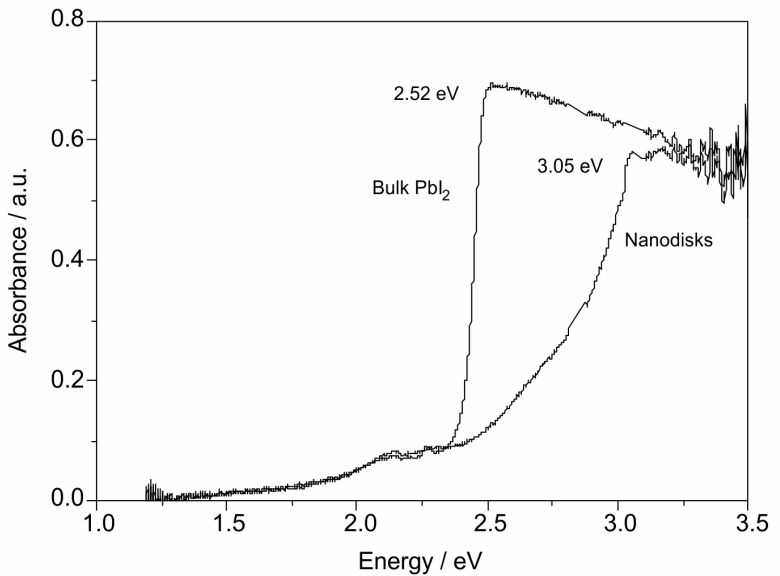

Figure 2. Absorption spectra (converted from diffuse reflectance data) of bulk $\mathrm{PbI}_{2}$ and the $\mathrm{CB}[7] / \mathrm{PbI}_{2}$ sample at $77 \mathrm{~K}$.

semi-conducting materials lead to quantum confinement of excitons in one, two or three dimensions, depending on the shape and size of the particles. ${ }^{21-29}$ In fact, the size affects the band-gap energy when the dimension becomes inferior to the bulk-exciton Bohr radius ( $c a .1 .9 \mathrm{~nm}$ for $\left.\mathrm{PbI}_{2}\right),{ }^{21,22}$ although literature reveals that $\mathrm{PbI}_{2}$ absorption edge shifts can be assigned to many other factors, from intercalation of electron-donor species between the iodide layers in few atoms clusters to ripening processes, and in low-polarity solvents. ${ }^{1,25}$ In fact, all these phenomena are interconnected and the shift is always related to quantum confinement mechanisms. Normally, low-polarity solvents tend to stabilize larger colloidal particles in detriment of the smaller ones as shown by Sandroff et al. ${ }^{24}$ but also change the dielectric constant of the medium. Small molecules can be easily intercalated into $\mathrm{PbI}_{2}$, once the layers are weakly held together, essentially by van der Waals interactions. The insertion of guest species between the layers has the same effect of that produced by negative pressure on this kind of lamellar material. In other words, the intercalation increases the interlamellar distances, lowering the electronic interaction between layers and the extent of the dispersion in the valence band. This increases considerably the energy, promoting 1D quantum confinement in the axial direction..$^{25}$

Using the effective mass approximation model, it is possible to estimate the crystallite size and thickness, as did Sandroff et al..$^{24}$ and others..$^{21,22}$ Thus, in such anisotropic nanomaterial, the equation governing the band-gap shifts has the form:

$\Delta \mathrm{E}_{\mathrm{g}}=\frac{\hbar^{2}}{2 \mu_{\mathrm{xy}}}\left[\frac{2 \pi^{2}}{\mathrm{~L}_{\mathrm{xy}}^{2}}\right]+\frac{\hbar^{2}}{\mu_{\mathrm{z}}}\left[\frac{2 \pi^{2}}{\mathrm{~L}_{\mathrm{z}}^{2}}\right]$

where the effective reduced masses of the electron-hole pairs in the xy plane and in the axis perpendicular to them are represented by $\mu_{x y}$ and $\mu_{z}$, respectively, and $L_{x y}$ and $L_{z}$ are the dimensions of the crystallites. The reduced masses have been experimentally determined as $0.32\left(\mu_{\mathrm{xy}}\right)$ and $1.4\left(\mu_{z}\right)$ electron mass units, according to magneto-optic experiment data. ${ }^{24,30}$ Taking into account the absorption shift, it is reasonable to consider that almost no electronic interaction exists between the layers of $\mathrm{PbI}_{2}$ in our case, meaning that the thickness of the nanoparticles should not be larger than a single layer of $\mathrm{PbI}_{2}$. When considering a single layer of the material ( $7 \AA$ ), equation 1 becomes:

$$
\Delta \mathrm{E}_{\mathrm{g}}=\frac{235}{\mathrm{~L}_{\mathrm{xy}}^{2}}+0.55
$$

In our case, the shift observed is $3.10-2.56 \mathrm{eV}=0.54 \mathrm{eV}$. According to equation 2, this value corresponds to the shift caused by the exfoliation of the structure, independently of the size of layers, which are too large to produce any spectral shift (the first term of such equation tends to 0 when $L_{z}=7 \AA$ ). Thus, the spectral shift observed for the $\mathrm{CB}[7] / \mathrm{PbI}_{2}$ sample is consistent with nanoflakes constituting of $\mathrm{PbI}_{2}$ monolayers stabilized by the macrocycle. No fluorescence at all could be measured for the hybrid solid $\mathrm{CB}[7] / \mathrm{PbI}_{2}$, indicating that the electron-hole pairs in these crystals are captured by surface traps and quenched by nonradiatively recombination processes. This is a quite common phenomenon in quantum-confined nanocrystals. ${ }^{26,31,32}$

The X-ray diffraction patterns of the pure $\mathrm{PbI}_{2}$ and $\mathrm{CB}[7] / \mathrm{PbI}_{2}$ sample are compared in Figure 3. Pure $\mathrm{PbI}_{2}$ exhibits very sharp and intense peaks characteristic of crystalline materials, while $\mathrm{CB}[7] / \mathrm{PbI}_{2}$ reveals an amorphous structure, with a total loss of structural

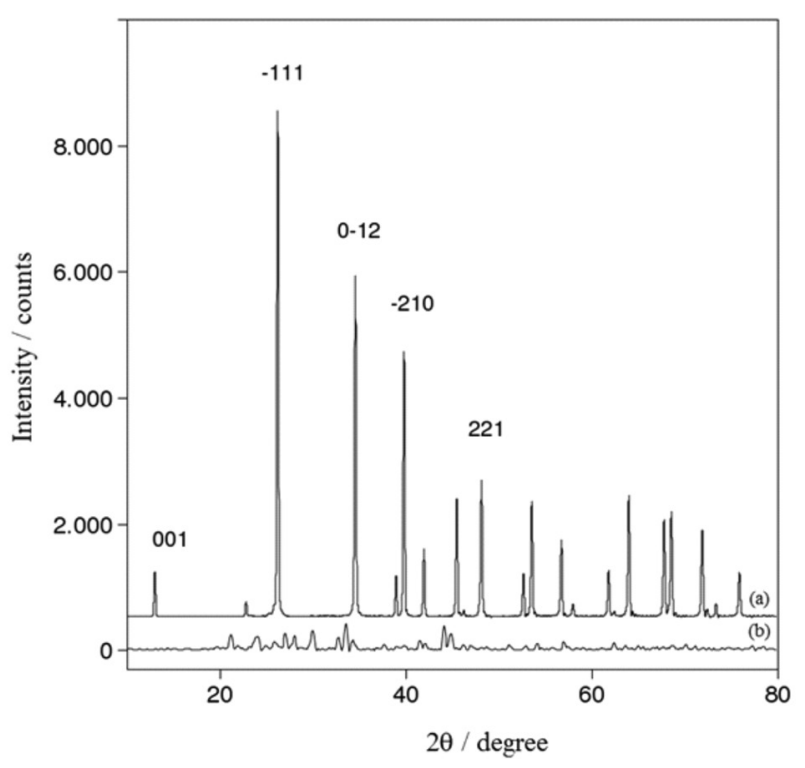

Figure 3. $\mathrm{XRD}$ patterns of pure $\mathrm{PbI}_{2}$ (a) and of the $\mathrm{CB}[7] / \mathrm{PbI}_{2}$ sample (b). 
coherence. In fact, the absence of the 001 peak for the hybrid structure suggests the absence of a regular ordering of the $\mathrm{PbI}_{2}$ layers and it is expected for more or less randomly-oriented isolated nanoflakes consisting of iodide monolayers. According to this, it is possible to conclude that no continuous turbostratic structure can be present, because the size of the clusters is too small for this. According to Sandroff et al.,$^{24}$ the interlayer distance of lead iodide can vary depending on the synthetic procedure, but it is never inferior to $12 \AA$, while the thickness of a single layer is $7 \AA$. The height of $\mathrm{CB}$ [7] molecule is $9.1 \AA$ and should provoke an expansion of the basal distance of this magnitude if it is intercalated between the layers, acting as a pillar in the structure. An important factor that must be considered is sterical hindrance: cucurbit[7]uril is a very large molecule (ca. $9 \AA$ ) and it is geometrically impossible to keep a 1:1 $\mathrm{Pb}^{2+} / \mathrm{CB}$ [7] ratio inside a lamellar structure. Therefore, part of the macrocycle molecules would be pushed out from the structure or the iodide would be forced to adopt a crystalline configuration different from the lamellar one. Furthermore, $\mathrm{K}^{+}$ions are present in large amounts in the reaction medium and it is certain that they bind the macrocycle portals, forming large cationic species in solution. These positively charged species may interact with iodine ions by electrostatic interactions, but it was verified that electron-donor species are better guests for intercalation in lead iodide. In other words, nothing favors the formation of lamellar structures in this case. ${ }^{33-38} \mathrm{~A}$ few and very weak signals may be observed in the diffraction pattern of the hybrid material. Even using the best acquisition methods, it is impossible to state, with our equipment, that these signals are peaks and not noise, since they are not reproducible. Furthermore, the signal does not correspond to any known $\mathrm{PbI}_{2}$ polytype.

Medium resolution SEM micrographs $(\times 2,000$ magnification) reveal overlaid sheets of $\mathrm{PbI}_{2}$, just as in the case of re-crystallized matrices. ${ }^{33}$ A SEM image obtained with high magnification $(\times 200,000)$ shows that these sheets are made of small disks measuring around $50 \mathrm{~nm}$ (Figure 4). EDS spectra display strong lead, iodine, carbon, oxygen and potassium signals arising from the sample (data not shown). The detected potassium is probably reminiscent from the $\mathrm{KI}$ starting material. This fact is easily understood once, as already mentioned, $\mathrm{K}^{+}$ions form very stable coordination compounds with cucurbiturils. ${ }^{39}$

The presence of the nanodisks was confirmed by AFM imaging, making clear that the sheets are composed by aggregates of regular disk-like particles. The average size was estimated to be around $34 \mathrm{~nm}$ (Figure 5). HRTEM images show these disks as single sheets of lead iodide that are totally exfoliated, forming a "house of cards" structure (Figure 6). This kind of structure is frequently observed in

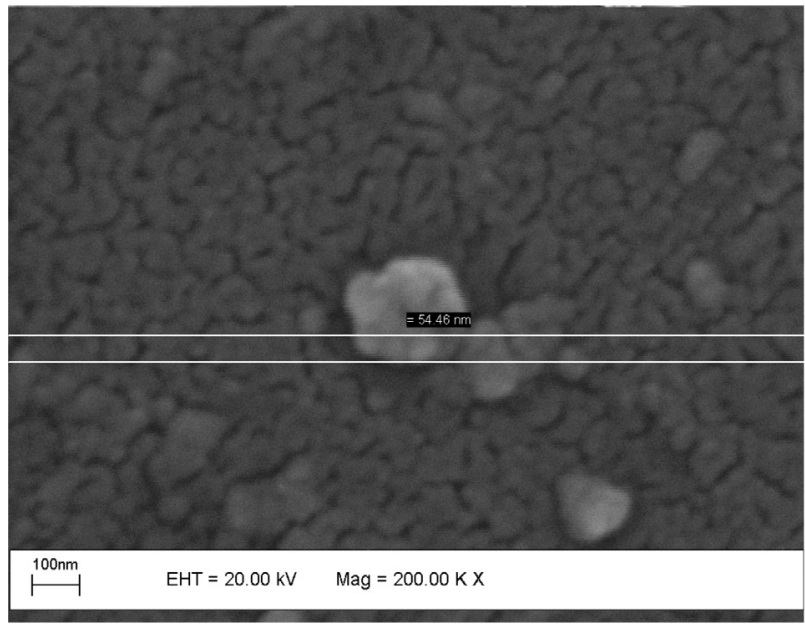

Figure 4. SEM image of the $\mathrm{CB}[7] / \mathrm{PbI}_{2}$ sample with aggregates under $\times 200,000$ magnification. The grain size estimated in $54 \mathrm{~nm}$.

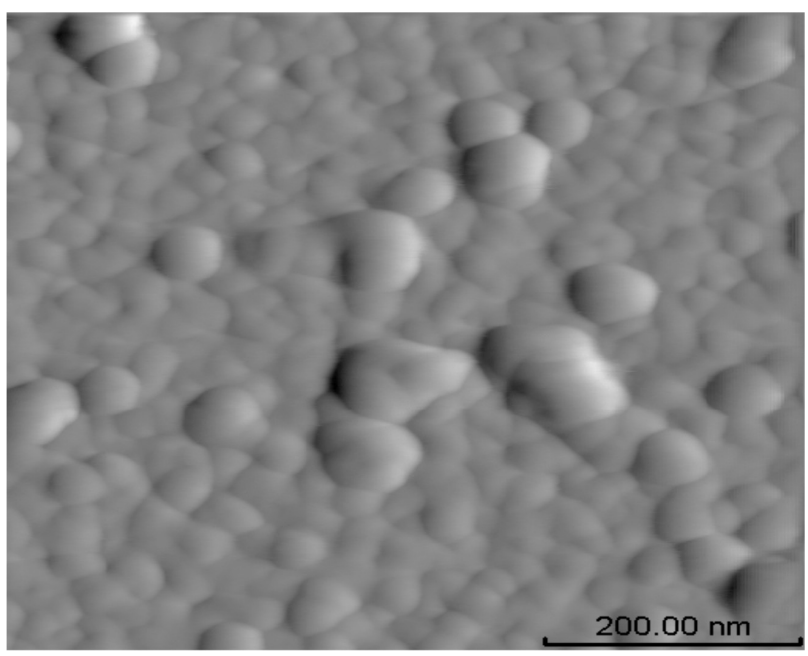

Figure 5. AFM micrograph of the $\mathrm{CB}[7] / \mathrm{PbI}_{2}$ sample with $\mathrm{CB}[7] / \mathrm{PbI}_{2}$ nanoparticle aggregates.

exfoliated clay gels, for instance Laponite ${ }^{\circledR}$. In this synthetic smectite, the gel is formed by weak interactions between $1 \times 25$ nm disks. ${ }^{40}$

\section{Conclusions}

$\mathrm{CB}$ [7] does not act as a hollow shell template for lead iodide formation as it does in the case of metal nanoparticles. The present work indicates that the macrocycle forms a random structure composed of small $\mathrm{PbI}_{2}$ disks separated by $\mathrm{CB}[7]$ and $\mathrm{K}^{+}$ions. The hybrid material presents reduced interlayer coupling terms, which affect its absorption spectrum when compared to pure $2 \mathrm{H}-\mathrm{PbI}_{2}$. The mechanism involved in the formation of this nanomaterial is complex, since it starts from an unstable colloid, which then sediments. A possible mechanism could be proposed with three major steps: the first is the formation of $\mathrm{K}_{2} \mathrm{CB}[7]^{2+}$ 


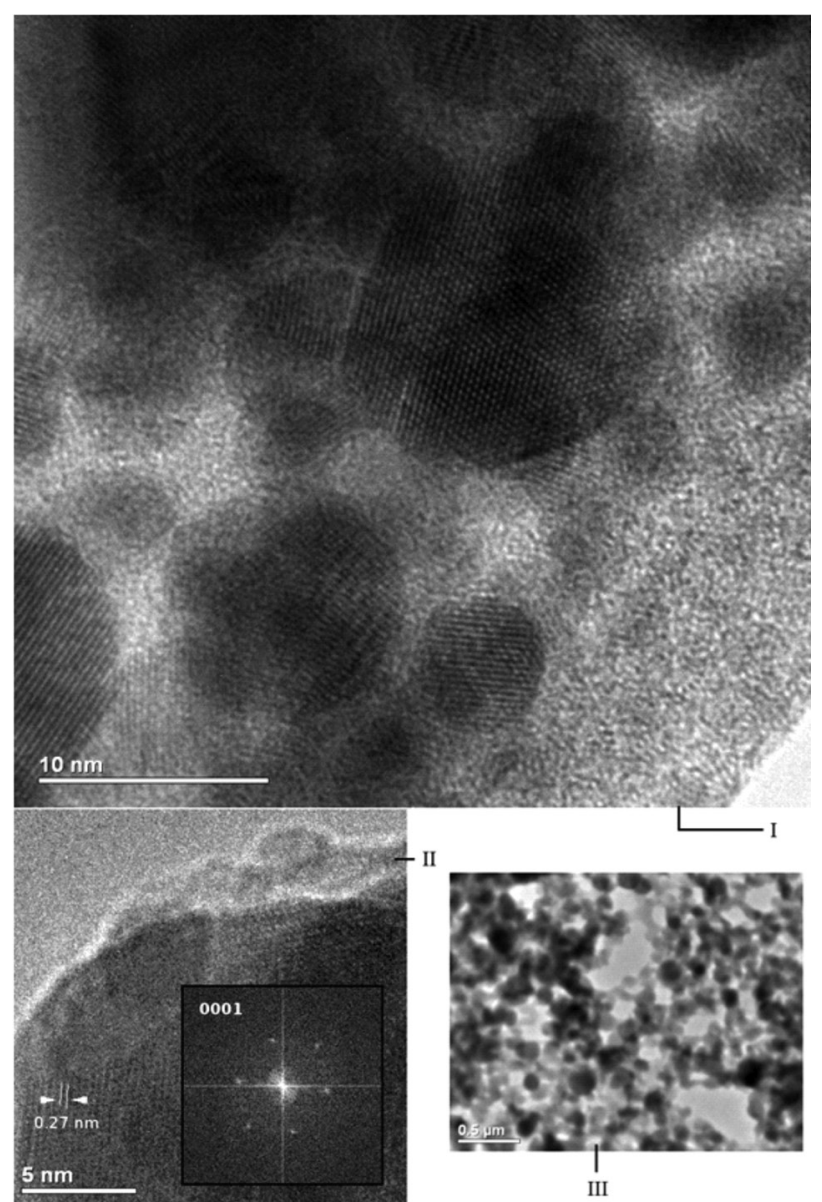

Figure 6. HRTEM micrographs of (I) the $\mathrm{CB}[7] / \mathrm{PbI}_{2}$ sample; (II) a single $\mathrm{PbI}_{2}$ nanodisk (diameter $c a .30 \mathrm{~nm}$ ), inset: electron diffraction pattern; and (III) $\mathrm{CB}[7] / \mathrm{PbI}_{2}$ sample under higher magnification, with random nanodisks in a "house of cards" arrangement.

cations which interact with iodine ions in solution. Then, lead ions bind the halogens forming nucleation centers for lead iodide single layers. As the single layers grow, $\mathrm{CB}$ [7] becomes too bulky and is gradually pushed to their borders, limiting nanoparticle growth. Another possibility is the formation of adducts with water molecules and $\mathrm{Pb}^{2+}$ ions instead of potassium complexes during the nucleation process, because this kind of structure has already been observed in many cases and with several metal ions. The nanodisk formation mechanism is still being investigated with other metal halides and will be the subject of another paper.

\section{Supplementary Information}

Additional information about the exciton band of lead iodide, including the absorption spectra of solid $\mathrm{PbI}_{2}$ and $\mathrm{PbI}_{2}$ nanodisks (Figure $\mathrm{S} 1$ ), is available free of charge at http://jbcs.sbq.org.br as PDF file.

\section{Acknowledgements}

We sincerely thank Dr. Ivana Aparecida Borin and Dr. Rodrigo Ferreira Silva for microscopy images, as well as Prof. Koiti Araki, Prof. Antonio Osvaldo Serra and Prof. Paulo César da Souza Filho for fluorescence measurements. This work was sponsored by the Conselho Nacional de Desenvolvimento Científico e Tecnológico (CNPq), Coordenação de Aperfeiçoamento de Pessoal de Nível Superior (CAPES) and Fundação de Amparo à Pesquisa do Estado de São Paulo (FAPESP). HRTEM images were obtained at Laboratório Nacional de Luz Síncrotron (LNLS, Campinas-SP, Brazil)(TEM-MSC-9054).

\section{References}

1. Coleman, C. C.; Goldwhite, H.; Tikkanen, W.; Chem. Mater. 1998, 10, 2794.

2. Michalet, X.; Pinaud, F. F.; Bentolila, L. A.; Tsay, J. M.; Doose, S.; Li, J. J.; Sundaresan, G.; Wu, A. M.; Gambhir, S. S.; Weiss, S.; Science 2005, 307, 538.

3 Xu, T.; Nikiforov, A. Y.; France, R.; Thomidis, C.; Williams, A.; Moustakas, T. D.; Phys. Status Solidi A 2007, 204, 2098.

4. Tang, J.; Sargent, E. H.; Adv. Mater. 2010, 20, 1.

5. Hendrick, E.; Frey, M.; Herz, E.; Wiesner, U.; J. Eng. Fibers Fabr. 2010, 5, 21.

6. Behrend, R.; Meyer, E.; Rusche, F.; Liebigs J.; Ann. Chem. 1905, 339, 1.

7. Freeman, W. A.; Mock, W. L.; Shih, N.-Y.; J. Am. Chem. Soc. 1981, 103, 7367.

8. Day, A.; Arnold, A. P.; Blanch, R. J.; Snushall, B.; J. Org. Chem. 2001, 66, 8094.

9. Day, A. I.; Blanch, R. J.; Arnold, A. P.; Lorenzo, S.; Lewis, G. R.; Dance, I.; Angew. Chem., Int. Ed. 2001, 41, 275

10. Kim, J.; Jung, I.-S.; Kim, S.-Y.; Lee, E.; Kang, J.-K.; Sakamoto, S.; Yamaguchi, K.; Kim, K.; J. Am. Chem. Soc. 2000, 122, 540.

11. Liu, S.; Ruspic, C.; Mukhopadhyay, P.; Chakrabarti, S.; Zavalij, P. Y.; Isaacs, L.; J. Am. Chem. Soc. 2005, 127, 15959.

12. Lagona, J.; Mukhopadhyay, P.; Chakrabarti, S.; Isaacs, L.; Angew. Chem., Int. Ed. 2005, 44, 4844.

13. Demets, G. J.-F.; Quim. Nova 2007, 30, 1313.

14. Corma, A.; Garca, H.; Montes-Navajas, P.; Primo, A.; Calvino, J. J.; Trasobares, S.; Chem. Eur. J. 2007, 13, 6359.

15. Pearson, G. R.; Inorg. Chem. 1988, 27, 734.

16. Zhang, X. X.; Krakowiak, K. E.; Xue, G.; Bradshaw, J. S.; Izatt, R. M.; Ind. Eng. Chem. Res. 2000, 39, 3516.

17. Lee, T.-C.; Scherman, O. A.; Chem. Commun. 2010, 46, 2438. 18. Li, M.; Zaman, M. B.; Bardelang, D.; Wu, X.; Wang, D.; Margeson, J. C.; Leek, D. M.; Ripmeester, J. A.; Ratclife, C. I.; Lin, Q.; Yange, B.; Yu, K.; Chem. Commun. 2009, 44, 6807. 
19. Cao, M.; Lin, J.; Yang, H.; Cao, R.; Chem. Commun. 2010, 46, 5088.

20. Day, A. I.; Arnold, A. P.; Blanch, R. J.; Snushall, B.; J. Org. Chem. 2001, 66, 8094.

21. Mallik, K.; Dhami, T. S.; Phys. Rev. B: Condens. Matter Mater. Phys. 1998, 58, 13055.

22. Finlayson, C. E.; Sazio, P. J. A.; J. Phys. D: Appl. Phys. 2006, $39,1477$.

23. Nozue, Y.; Tang, Z. K.; Goto, T.; Solid State Commun. 1990, $73,531$.

24. Sandroff, C. J.; Kelty, S. P.; Hwang, D. M.; J. Chem. Phys. 1986, $85,5337$.

25. Ghorayeb, A. M.; Coleman, C. C.; Yoffe, A. D.; J. Phys. C: Solid State Phys. 1984, 17, L715.

26. Artemyev, M. V.; Rakovich, Y. P.; Yablonski, G. P.; J. Cryst. Growth 1997, 171, 447.

27. Barnakov, Y. U.; Ito, S.; Dmitruk, I.; Tsunekawa, S.; Kasuya, A.; Scr. Mater. 2001, 45, 273.

28. Micic, O. I.; Zongguan, L.; Mills, G.; Sullivan, J. C.; Meisel, D.; J. Phys. Chem. 1987, 91, 6221.

29. Tubbs, M. R.; Forty, A. J.; J. Phys. Chem. Solids 1965, 26, 711.

30. Sandroff, C. J.; Hwang, D. M.; Chung, W. M.; Phys. Rev. B: Condens. Matter Mater. Phys. 1986, 33, 5953.

31. Dag, I.; Lifshitz, E.; J. Phys. Chem. 1996, 100, 8962.
32. Sengupta, A.; Jiang, B.; Mandal, K. C.; Zhang, J. Z.; J. Phys. Chem. B 1999, 103, 3128.

33. Schaefer, R. W.; Ardelean, M.; Powder Diffr. 2001, 16, 16.

34. Agrawal, V. K.; Chadha, G. K.; Trigunayat, G. C.; Acta Cryst. 1970, $A 26,140$.

35. Chand, M.; Trigunayat, G. C.; Acta Cryst. 1975, B31, 1222.

36. Flahaut, E.; Sloan, J.; Friedrichs, S.; Kirkland, A. I.; Coleman, K. S.; Williams, V. C.; Hanson, N; Hutchison, J. L.; Green, M. L. H.; Chem. Mater. 2006, 18, 2059.

37. Kasi, G. K.; Dollahon, N. R.; Ahmadi, T. S.; J. Phys. D: Appl. Phys. 2007, D40, 1778.

38. Koutselas, I.; Dimos, K.; Bourlinos, A.; Gournis, D.; Avgeropoulos, A.; Agathopoulos, S.; Karakassides, M. A.; J. Optoelectron. Adv. Mater. 2008, 10, 311.

39. Buschmann, H. J.; Cleve, E.; Schollmeyer, E.; Inorg. Chim. Acta 1992, 193, 93.

40. Kroon, M.; Vos, W. L.; Wegdam, G. H.; Int. J. Thermophys. 1998, 19, 887.

Submitted: August 21, 2010

Published online: May 24, 2011

FAPESP has sponsored the publication of this article. 


\title{
Quantum Confinement in $\mathrm{PbI}_{2}$ Nanodisks Prepared with Cucurbit[7]uril
}

\author{
Erick M. S. dos Santos, Lourivaldo S. Pereira and Grégoire J.-F. Demets*
}

DQ-FFCLRP, Departamento de Química, Universidade de São Paulo, 14040-901 Ribeirão Preto-SP, Brazil

\section{On lead iodide exciton band}

The exciton band of lead iodide does not appear always as a sharp and intense peak. Its shape and intensity may vary with crystal form, polytype, temperature, light polarization, synthetic procedure, crystallite size and especially with the purity of the material. ${ }^{1}$ Many authors have reported similar spectra, for which the absorption edge is associated with the excitonic level, separated from gap transitions by few meV, since the binding energy is very small. The presence of electron donors in solution also affects exciton absorption bands, as demonstrated in other papers. ${ }^{2-5}$ It is well described in the literature that the first excitonic band may undergo blue shifts when extremely small particles are obtained. ${ }^{1,6-8}$ In the present work, a set of optical fibers and a light source essentially designed for Vis-NIR region were used in the first attempts to obtain absorption spectra. This could be the reason for the lack of spectral resolution. Furthermore, the Kubelka-Munk function could not be used since no information about the powder size of the samples after drying the colloid was known. The UV-Vis absorption measurements were repeated at room temperature (Figure S1), using another set of optical fibers designed for working in the UV region. This time the bands clearly appear. Using the Tauc equation, the $\mathrm{E}_{\mathrm{g}}$ value was calculated, being 2.34 and $2.80 \mathrm{eV}(\operatorname{diff}=0.46 \mathrm{eV})$ for bulk $\mathrm{PbI}_{2}$ and the nanodisks, respectively.

For pure lead iodide, the exciton band is located at the absorption edge $(499 \mathrm{~nm})$, which is coherent with the literature (490-500 nm). For the nanodisks, it is blue-shifted to $387 \mathrm{~nm}$ and a small shoulder is observable at $499 \mathrm{~nm}$, which could be assigned to larger aggregates or to heteronuclear excitons. ${ }^{3}$ As mentioned before, these new values were obtained at room temperature, but the onset absorption energies do not vary considerably from our previous measurements at $77 \mathrm{~K}$ (see Figure 2 in the main text), and would not affect the presented conclusions from the effective mass model. Probably, the problem is related to our experimental apparatus.

*e-mail: greg@usp.br

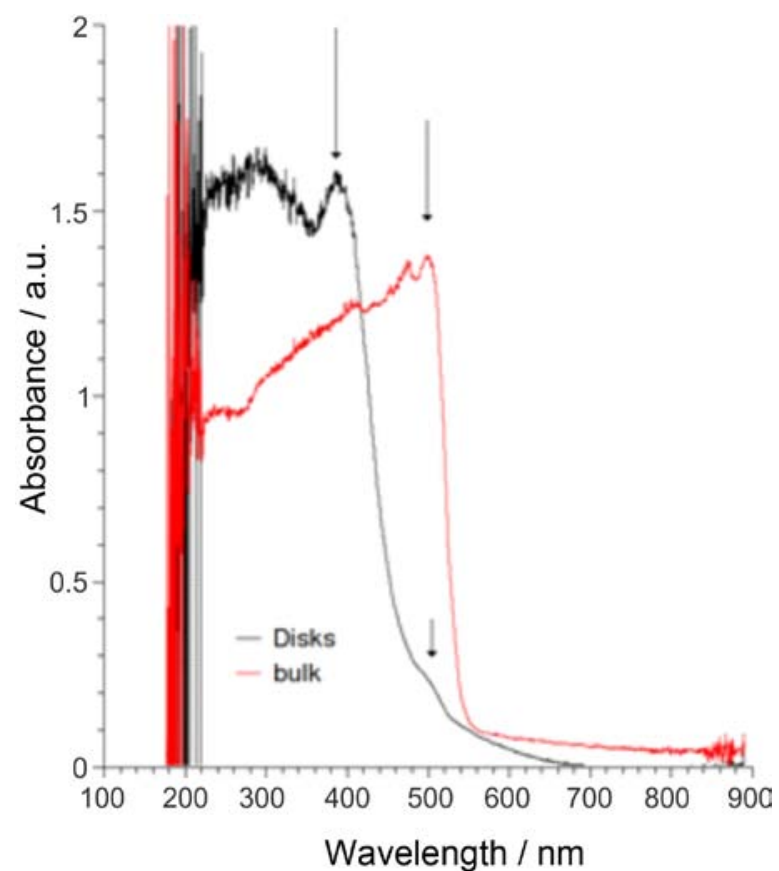

Figure S1. Absorption spectra of solid $\mathrm{PbI}_{2}$ and $\mathrm{PbI}_{2}$ nanodisks at room temperature.

\section{References}

1. Tubbs, M. R.; Forty, A. J.; J. Phys. Chem. Sol. 1965, 26, 711. (29 in the Article text).

2. Sengupta, A.; Jiang, B.; Mandal, K. C.; Zhang, J. Z.; J. Phys. Chem. B 1999, 103, 3128. (32 in the Article text).

3. Bhavsar, D. S.; Saraf, K. B.; J. Mater. Sci.: Mater Electron. 2003, 14, 195.

4. Koutselas, I.; Dimos, K.; Bourlinos, A.; Gournis, D.; Avgeropoulos, A.; Agathopoulos, S.; Karakassides, M. A.; J. Optoelectron. Adv. Mat. 2008, 10, 311.

5. Nozue, Y.; Tang, Z. K.; Goto, T.; Solid State Commun. 1990, 73, 531. (23 in the Article text).

6. Kasi, G. K.; Dollahon, N. R.; Ahmadi, T. S.; J. Phys. D: Appl. Phys. 2007, 40, 1778. (37 in the Article text).

7. Artemyev, M. V.; Rakovich, Y. P.; Yablonski, G. P.; J. Cryst. Growth 1997, 171, 447. (26 in the Article text).

8. Micic, O. I.; Li, Z.; Mills, G.; Sullivan, J. C.; Meisel, D.; J. Phys. Chem. 1987, 91, 6221. 


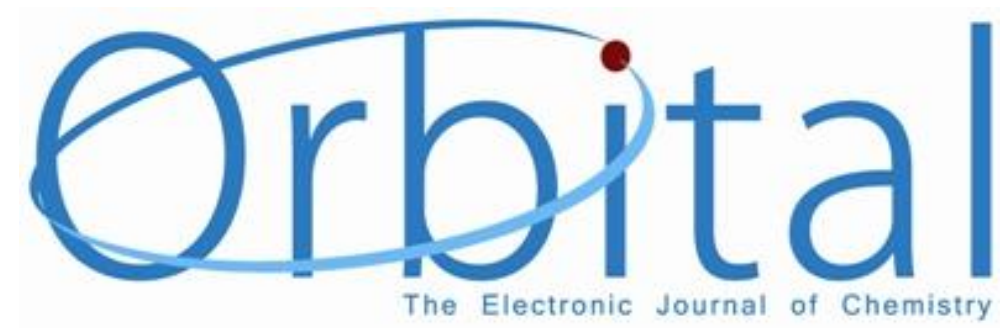

\title{
Montagem de uma célula universal para ensaios de permeação em membranas semipermeáveis sólidas em escala laboratorial
}

Tiago M. B. Teodósio, Thiago de S. Cavallini, Lucas V. Jardim e Grégoire J. F. Demets*

Departamento de Química, Faculdade de Filosofia Ciências e Letras de Ribeirão Preto, Universidade de São Paulo. Av. Bandeirantes 3900, Ribeirão Preto SP, CEP 14040-901 Brasil, telefone: (16) 36024860 fax (16) 36023851.

Received: 11 October 2011; revised: 27 December 2011; accepted: 27 December 2011. Available online: 19 January 2012.

\begin{abstract}
This technical note describes the assembly of a glass-made universal cell that was designed for solid-state membrane permeation or electrodiffusion experiments. It can be used to measure the permeation rates of practically any molecule or ion in solution and even in gas phase through solid membranes. The experiments, driven by concentration gradients or electric fields, may be followed and recorded in real time over long periods of time using serial data acquisition programs. The cell itself allows the utilization of a wide range of different chemical sensors and up to eight of them simultaneously.
\end{abstract}

Keywords: permeation assays; semipermeable membranes; universal cell

Membranas semipermeáveis encontram uma série de aplicações em processos de filtração, osmose inversa, purificação de gases, células de combustível, para citar somente alguns. Muitas vezes o custo de produção deste tipo de membrana acaba inviabilizando a produção desta ou daquela instalação ou dispositivo, tornando-os pouco competitivos comprovando que muito ainda há de ser feito neste segmento [1-3]. A investigação das propriedades e o desenvolvimento de membranas deste tipo dependem de uma série de características e parâmetros que devem ser avaliados e quantificados como, por exemplo, fatores de discriminação de solutos, coeficientes de difusão, influência da temperatura, dependência da morfologia na permeação, entre outras propriedades, afim de que se possa caracterizar e garantir o bom funcionamento destas membranas nas aplicações que se deseja [4-8]. Nem sempre é simples obter este tipo de informação 
quantitativamente por meio de procedimentos padrão de maneira reprodutível e em escala laboratorial. Os equipamentos de teste e validação são geralmente artefatos de engenharia que apresentam dimensões consideráveis.

Nosso laboratório vem desenvolvendo membranas sólidas semipermeáveis de nanofiltração, que permitem a difusão de espécies químicas pequenas retendo as maiores, e nos vimos constantemente defrontados com a dificuldade em obter dados experimentais confiáveis e reprodutíveis envolvendo estes materiais, utilizando apetrechos de medição comuns [9].

Um dos experimentos mais importantes em certos casos consiste em quantificar a difusão natural de diversas espécies químicas através destas membranas, dirigida exclusivamente por gradientes de potencial químico. Esta é uma das formas de calcularmos coeficientes de partição, coeficientes de difusão e outros parâmetros de extrema importância para a caracterização de membranas. Os experimentos consistem simplesmente em separar por estas membranas, dois meios: um hipertônico e outro hipotônico, e observar como evoluem as concentrações de diversos solutos e misturas de solutos nestes meios. Para realizar estas medidas de forma confiável tivemos de elaborar e montar um protótipo de célula de difusão universal, onde diversos tipos de testes e medidas podem ser realizados simultaneamente. Apesar de ser conceitualmente simples este tipo de experimento, existem alguns problemas de ordem prática, que conseguimos contornar e descrevemos a seguir. Existem diversos tipos de células de difusão para líquidos e gases, que trabalham em fluxo lateral ou em fluxo frontal, conhecido como "dead-end". No primeiro caso, as espécies a difundir tangenciam a membrana, enquanto no segundo, estas transitam na perpendicular como ilustra a Figura 1.

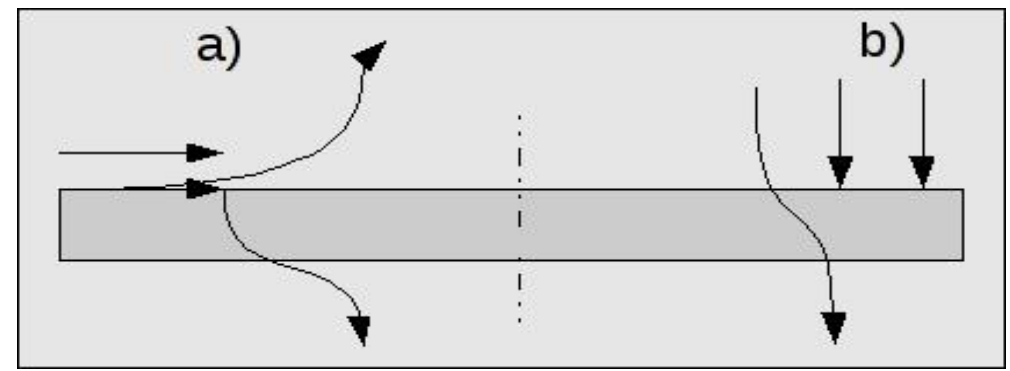

Figura 1. Difusão por membrana em fluxo a) lateral, e b) "dead-end".

Foi demonstrado em diversos estudos que os processos de difusão por fluxo lateral são mais eficientes do que aqueles chamados de "dead end" onde o fluxo de massa é perpendicular à superfície da membrana e limitado em parte por conta do acúmulo de material retido na barreira física [10]. O processo de permeação neste tipo de célula pode ser separado em 5 etapas que são: a difusão de espécies do seio da solução até a interface de alimentação da membrana (face da membrana em contato com o meio hipertônico), a adsorção desta espécie nesta interface, a permeação propriamente dito, a 
dessorção da espécie da interface de permeação (face da membrana em contato com o meio hipotônico) e a difusão da espécie até o detector. A fim de eliminar dois destes componentes é interessante que estes meios estejam em constante agitação, para que desta forma eliminemos a primeira e última contribuição às medidas de fluxo de matéria. Via de regra, as etapas de adsorção de dessorção são muito mais rápidas do que a permeação, não constituindo assim uma etapa limitante para o processo como um todo [11].

A célula que apresentamos aqui (Figura 2) é um protótipo universal, já que permite tanto medidas de difusão em fluxo lateral em meio líquido, quanto gasoso a pressão ambiente ou misto (um meio de cada tipo). Além disso, permite experimentos de eletrodifusão, osmometria e ainda que sejam monitoradas as espécies móveis por qualquer tipo de sonda analítica, como por exemplo, eletrodos de $\mathrm{pH}$, de condutivímetros, eletrodos íons-seletivos, amostradores automáticos de cromatografia ou espectrometria de massas, sondas de reflectância difusa de fibras ópticas entre outros. A célula de difusão é composta por dois compartimentos cilíndricos de vidro idênticos ( $\varnothing=85 \mathrm{~mm} \mathrm{h=92}$ $\mathrm{mm}$ ), dotados de 4 entradas cada ( $3 \times \varnothing=28 . \mathrm{h}=60 \mathrm{~mm}$ e $1 \times \varnothing=34 . \mathrm{h}=60 \mathrm{~mm}$ ), localizadas em suas partes superiores. Estas entradas são esmerilhadas e são utilizadas pelas sondas de medição, termômetro ou ainda para a adição de algum reagente. Uma das entradas é mais larga para poder comportar eletrodos ou sondas mais largos. Cada semicélula apresenta uma saída lateral $(\varnothing=21 \mathrm{~mm}, l=50 \mathrm{~mm})$, por onde se juntam as duas, para formarem o conjunto experimental (Figura 2). Entre as semi-células é imobilizada a membrana em teste $(\varnothing=21 \mathrm{~mm}$ ), com a ajuda de um grampo de inox (Figura 2, quadro), que se prende às bordas das saídas $(3 \times 3 \mathrm{~mm})$ de cada semi-célula. A superfície vertical das bordas deve ser perfeitamente plana para garantir o encaixe perfeito e sem vazamentos de líquido. As semi-células são colocadas sobre agitadores magnéticos pequenos e idênticos. Duas barras magnéticas idênticas de agitação com revestimento de teflon (20 mm) são utilizadas para agitar ambos os meios da mesma forma. Procuramos sempre manter o sistema em regime laminar utilizando velocidades de rotação de 200 rpm.

Um dos principais ensaios que realizamos nesta célula é o teste de capacidade de diversas membranas de reter ou não diversas espécies iônicas, por exemplo, $\mathrm{NaCl}, \mathrm{KCl}$, $\mathrm{LiCl}$ e outros para fins de dessalinização. Estes ensaios de difusão natural (ou permeação) são realizados utilizando apenas gradientes de concentração como força motriz e permitem a utilização de um simples condutivímetro para monitoramento em tempo real. É claro que parâmetros como temperatura, viscosidade dos meios e outros também exercem influência e as devidas correções devem ser levadas em consideração ao longo das medidas. Para as medidas em meio aquoso utilizamos então um meio hipotônico, que consiste em preencher uma semi-célula com água deionizada e um meio hipertônico, que contém as espécies de interesse, que devem difundir. 

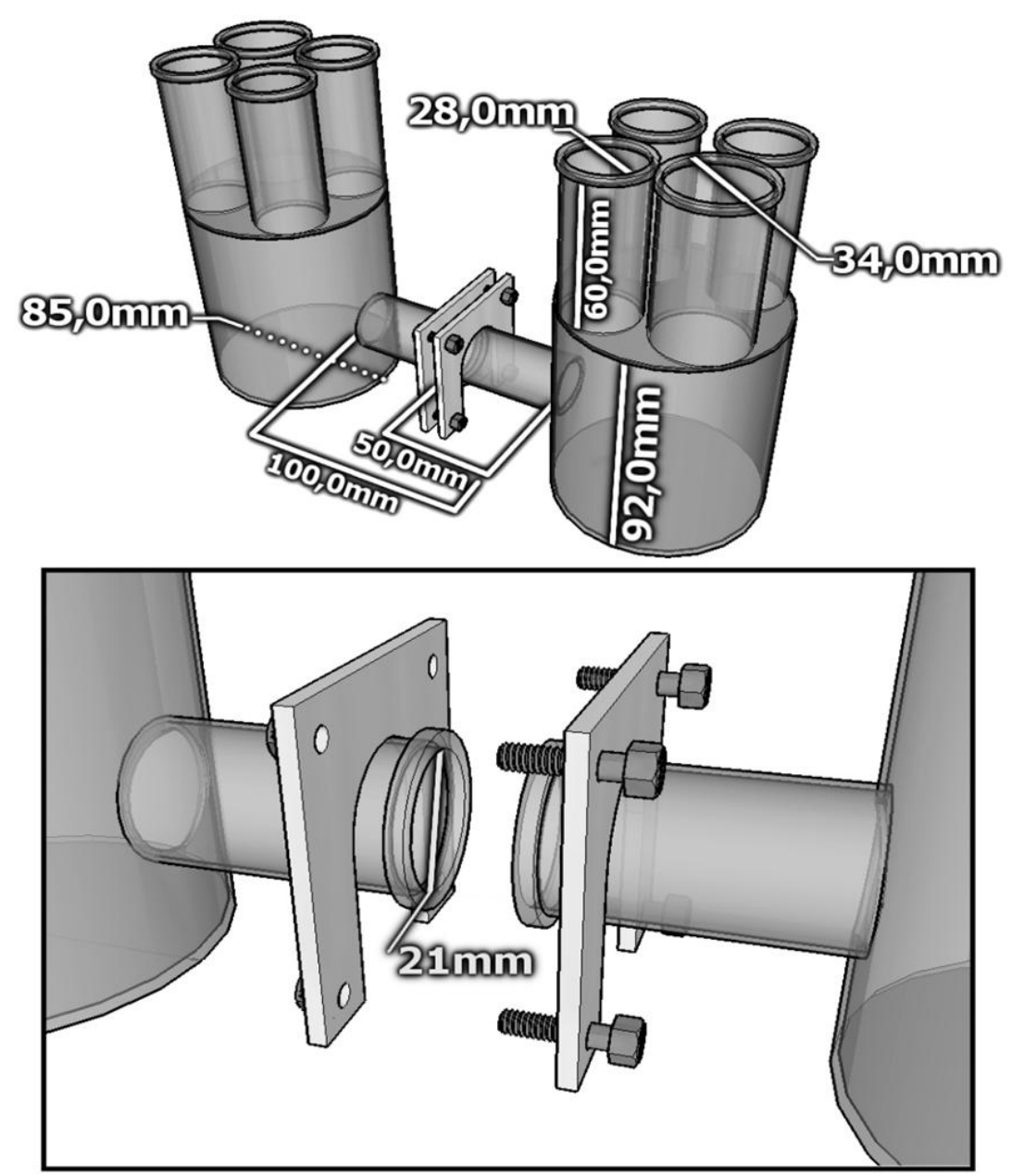

Figura 2. Desenho da célula de difusão com as dimensões. No quadro, detalhe do grampo de inox, que prende as semi-células no ponto de inserção da membrana em teste.

Processos deste tipo, que utilizam apenas gradientes de concentração como força motriz, podem levar vários dias e normalmente o fazem. Nossos experimentos duram tipicamente de 24 a 48 horas, mas isto pode variar dependendo apenas da barreira física em questão. Isto torna a aquisição de dados manual inviável e utilizamos um computador para tal. Alguns condutivímetros comerciais costumam utilizar o protocolo RS-232 para se comunicarem com microcomputadores. Desta forma também é possível medir a variação de temperatura, $\mathrm{pH}$ ou qualquer outro parâmetro automaticamente. O processamento serial de dados em baixa velocidade é mais que suficiente para a aquisição dos resultados deste tipo de equipamento (os microcomputadores mais novos e potentes não possuem mais conectores seriais padrão DB9, mas só USB que necessitam de um adaptador, que custa menos de 30 reais). Existem diversos programas no mercado para realizar a leitura destes dados, filtrá-los e enviá-los para uma planilha de cálculos qualquer e gerar gráficos em tempo real. São muito úteis para quem não é programador profissional ou (R) versado em programas mais sofisticados como o LabView ${ }^{\circledR}$. São conhecidos como programas de "wedging". Entre vários podemos citar o Winwedge ${ }^{\circledR}$, o Windmill ${ }^{\circledR}$, o CPS 
(

plus Pro e muitos outros. Dentre eles o segundo, apesar de mais complicado, é gratuito e pode ser utilizado sem custos. Nosso condutivímetro é um Tecnopon mod. mCA 150. A equipe técnica da empresa fez a gentileza de reprogramar o microcontrolador do equipamento, de modo que a função de estabilização da leitura fosse desabilitada. Isto porque, em casos como o nosso, as variações de condutividade são lentas e podem ser interpretadas pelo equipamento como flutuações em torno de um valor que o aparelho acaba fixando. Assim variações inferiores a $10 \%$ do referido valor acabavam sendo descartadas e não eram observadas variações coerentes de condutividade. Outro parâmetro que fora reprogramado, foi a frequência com que o aparelho envia dados para a saída serial, pois o padrão de fábrica é mais ou menos uma medida por segundo. No caso de medidas ao longo de vários dias, a quantidade de dados acaba sendo grande demais para uma planilha de cálculos convencional. Desta forma as medidas foram espaçadas de 10 segundos a 5 minutos, o que reduz enormemente a carga do equipamento.

Para evitar a redundância de dados, é possível também elaborar um pequeno macro na planilha de cálculo, que instrui o computador a gravar um novo dado somente se for diferente em valor numérico do anterior. A Figura 3 apresenta o resultado de um experimento típico de difusão de ácido clorídrico por uma membrana permeável a prótons, realizado nesta célula.

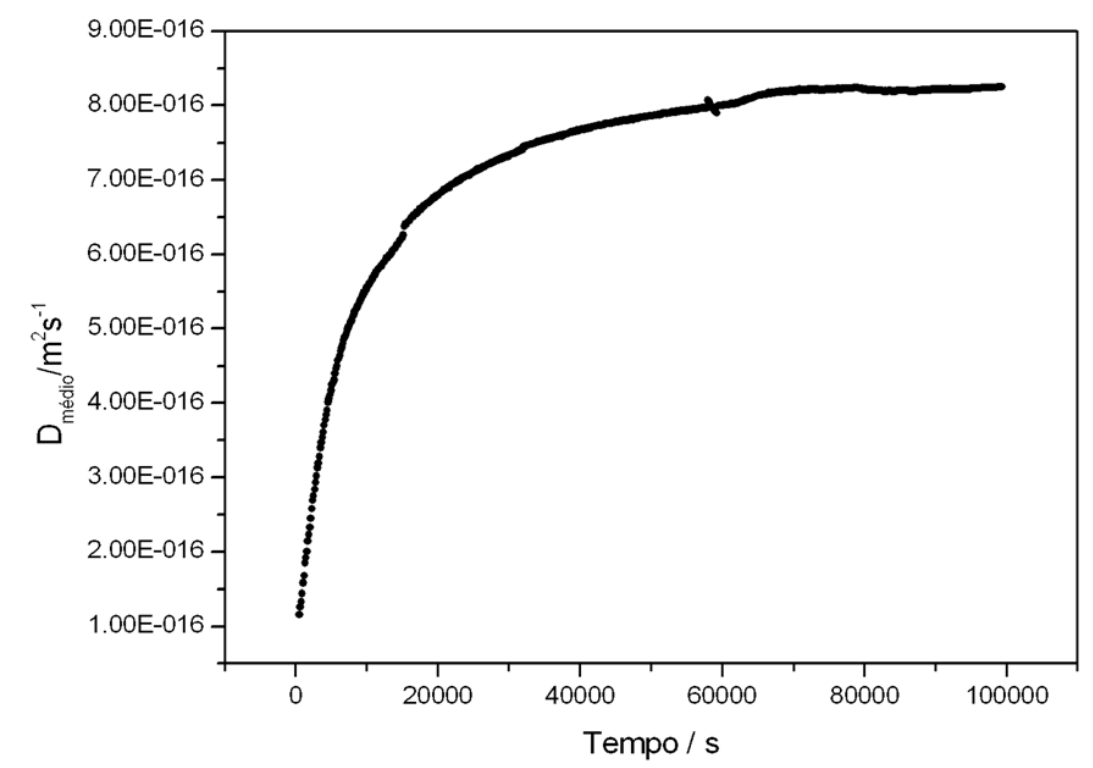

Figura 3. Exemplo de uma curva de aquisição do sistema para a permeação de $\mathrm{HCl}$ por uma membrana polimérica de PVC/pg4 ao longo de 28 horas, mostrando o coeficiente de difusão médio aparente em função do tempo.

Para concluir, podemos dizer que com este aparato de medição conseguimos realizar praticamente qualquer tipo de medida de permeação em líquidos de moléculas ou 
íons por membranas ou meios heterogêneos e coletar dados em tempo real durante períodos prolongados. Os resultados obtidos com este equipamento são extremamente confiáveis e reprodutíveis, e podem ser obtidos com menos de 500 reais ( $R \$ 500,00$ ). Em anexo constam os parâmetros do programa de aquisição de dados de condutometria, a título de exemplo.

\section{ANEXO 1: EXEMPLO DE CONFIGURAÇÃO DE PARÂMETROS DE AQUISIÇÃO DO CONDUTIVÍMETRO}

Cada aparelho envia os dados de uma maneira particular, e isto consta nos manuais de instruções. As conexões para a porta DB9 também devem constar. No caso específico deste aparelho, o tecnopon mod. mCA150, os dados são enviados em sequências de 3 campos, onde constam: temperatura, valor numérico, escala ( $\mathrm{mS}$ ou $\mu \mathrm{S}$ ).

O programa de aquisição de dados utilizado aqui é o Winwedge ${ }^{\circledR}$, quenecessita de um arquivo de configuração para cada aparelho dos quais ele venha a tratar dados. 0 arquivo de configuração aqui é como se fosse um "driver" que vai instruir o computador sobre como deve ser feita a leitura destes sinais e como enviá-las para uma planilha de cálculos como o Excel ${ }^{\circledR}$ ou Open-Office Calc. Estão descritos e explicados a seguir os parâmetros de configuração. Alguns destes parâmetros são fornecidos pelo próprio fabricante do aparelho. Da forma em que está, a rotina registra o horário completo, o valor numérico da leitura, a escala e a temperatura do meio da leitura.

Menu INPUT DATA STRUCTURE

Start Of record event

Any character received \# começa a ler qualquer coisa que o aparelho enviar.

End Of record event

Carriage return or CrLf received \# o registro termina quando o aparelho mandar qualquer um destes sinais.

Menu OVERALL STRUCTURE OF THE DATA STRUCTURE

Each record contains mutliple delimited data fields \# diz que cada registro contém mais de um campo.

Delimiter character: 44, comma \# diz que é uma vírgula que separa os campos dentro do registro.

Maximum nunber of data fields:4 \# quantos campos existem em cada registro

Record preamble keystroke: $\{$ Hour $\}\{:\}$ Minute $\}\{:\}\{$ Second $\}\{$ RIGHT $\}$ \# instrução para que a cada registro na planilha, o programa envie os dados de hora:minuto:segundo e em seguida se desloque o cursor para a direita.

Menu FIELD \# especifica-se aqui o que cada um dos campos é, na ordem em que aparecem.

1

Imput Filter: none \# aceita do jeito que chega 


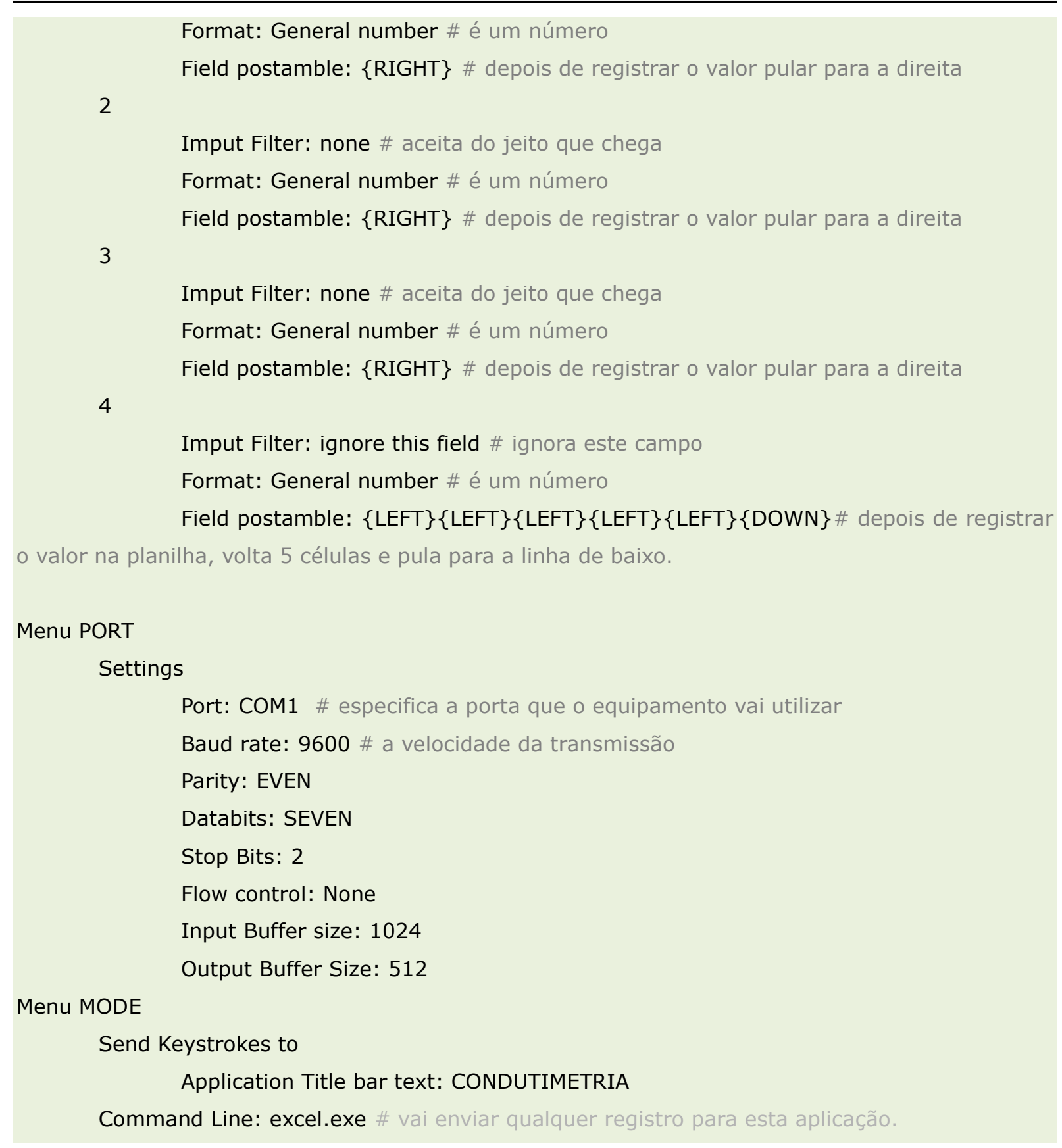

\section{Referências e Notas}

[1] Gokel, G. W.; Carasel, I. A. Chem. Soc. Rev. 2007, 36, 378.

[2] Hilal, N.; Al-Zoubi, H.; Darwish, N. A.; Mohammad, A. W.; Abu Arabi, M. Desalination 2004, 170, 281.

[3] Laciak, B.V.; Langsam, M. In Encyclopedia of Separation Science I.II; Poole, C. F. ; Cooke M.; Adlard E.R., eds; Elsevier Science \& Technology, 2000, 1725.

[4] Zhao, K.; Li, Y. J. Phys. Chem. B 2006, 110, 2755.

[5] Armstrong, R. D.; Nikitas, P. Electrochim. Acta 1985, 30, 1627.

[6] Armstrong, R. D.; Ashassi-Sorkhabi, H. Electrochim. Acta 1987, 32, 135. 
[7] Ryba, O.; Petránek, J. J. Electroanal. Chem. 1976, 67, 321.

[8] Loftsson, T.; Konrádsdóttir, F.; Másson, M. J. Incl. Phenom. Macrocycl. Chem. 2007, $57,613$.

[9] Correia, H. D.; Demets, G. J-F. Electrochem. Commun. 2009, 11, 1928.

[10] Tansel, B.; Sager, J.; Rector, T.; Garland, J.; Strayer, R.F.; Levine L.; Roberts, M.; Hummerick, M.; Bauer, J. Sep. Purif. Technol. 2006, 51, 40.

[11] Baker, R. W. In Membrane Technology and Applications $2^{\mathrm{a}}$ ed., Chichester:John Wiley \& Sons, 2004, cap. 2. 


\section{Índice}

Ácido fórmico, 119

Éter coroa, 78

Óxido de zinco, 103

luminescência, 104

Adutos, 32, 67

Anisotorpia cristalistos, 99

Anti-fraude, 89

Auto-montagem, 24

Azul

deslocamento para o, 99

Azul da Prússia

nanocubos de, 118

Bambus[n]urila, 117

Band Gap, 98

Barreira biológica, 118

Baterias de lítio, 111

Benesi-Hildebrand

Método de, 131

Célula de fluxo lateral, 129

Caviplexação

associativa, 27

dissociativa, 27

Caviplexo, 21

formação, 22

Clatrato, 22

Compostos biomiméticos, 67

Concentração

Gradiente de, 130

Confinamento quântico, 98

Cubion, 117

preparação, 117

Cucurbit[n]urila

Cápsulas, 89 intercalação, 108

Separação, 119

solubilidade de, 119

toxicidade, 78,88

Debye

forças de, 23

Descritores Moleculares, 26

Difusão natural, 117, 130

Diimida Naftálica, 116

Efeito quelato, 67

Efeito SERS, 89

Espalhamento de Mie, 90

Espectroscopia

Reflectância difusa, 131

Estresse estrutural, 111

Estrutural

incremento, 24

Eutrofização, 78

Exciton

banda de, 97

Fertilizantes

lixiviação, 78

NPK, 78

superfosfatos, 78

Filmes finos, 33

Formação

constantes de, 22

Germinação

feijão, 80

outras espécies, 81

Gibbs

energia de, 24

Guest, 22 
Hóspede

molécula, 21

troca de, 27

Halogênios, 119

HBA e HBD, 119

Hemi-cucurbit[n] urila, 116

Hemicucurbiturila, 123

Hidróxidos duplos lamelares, 90 co-precipitação, 104

Hidrofóbico, 24

Hidrogênio

ligação de, 22, 23

Hidropônico, 79

Hospedeira cavidade, 21

Host, 22

Host-Guest, 22

HRTEM, 92

Impedimento estérico, 22

Inclusão

Complexo de, 21

Insulina, 67

Interação

íon-dipolo, 22

eletrostática, 22

solvofóbica, 22

Interação íon-dipolo, 23

Ion $\mathrm{VO}^{2+}$

diedros, 70

oxidação de alcanos, 73

transições eletrônicas, 70

Ionóforo

em membrana, 117

Job

método de, 131

Keesom

forças de, 23
LED, 89

Liberdade

graus de, 21

London

forças de, 23

LSER, 119

Massa efetiva

aproximação da, 99

Matrizes de intercalação, 108

Mecanismo, 21

Meio

hipertônico, 130

hipotônico, 130

Membrana

despolarização de, 117

ultrafina, 118

Nanopartículas, 89

Ag, 90

CdSe-ZnS, 89

moldes para, 89

$\mathrm{PbI}_{2}, 90$

$\mathrm{Pd}, 89$

tamanho, 92

Ouro

Clusteres, 89

Oxygen rebound, 75

Patterson

método de, 109

Pentóxido de vanádio, 90, 110

intercalação de ions lítio, 111

Pilarização, 108

Plasmon

banda de, 91

Pressão osmótica, 117

QSPR, 119

Quântico

confinamento, 89, 97 
ponto, 89

Queimadura, 118

Raio de Bohr

exciton, 98

Reguladores iônicos, 79

Semióforo, 33

Semicondutor

cluster de, 97

Sensor, 89

eletroquímico, 116

piezelétrico, 116

Solvatação

entropia de, 24

esfera de, 23

esfera rígida, 21

Solvente

cavidade, 23

Meio contínuo, 22

Solvofóbica

interação, 24

Terapia Fotodinâmica, 116

Topotática

reação, 21

Valinomicina, 78

Van der Waals

forças de, 23

Vanádio

catálise, 67

complexos de, 67

xerogel, 111

Zeólita, 22

Zincita, 103 